\title{
Regulação do Setor de Telecomunicações em 2015
}

\section{Statutes and Regulations of the Telecommunication Sector}

\author{
Márcio lorio Aranha \\ João Alberto de Oliveira Lima \\ Renata Tonicelli de Mello Quelho
}


Revista de Direito, Estado e Telecomunicações, v. 8, n. 1, p. 209-332 (2015) 


\section{Sumário}

Lista de Abreviaturas e Siglas ................................................ 215

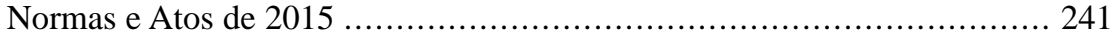

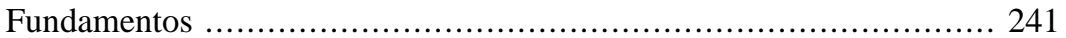

Aspectos Históricos ................................................. 241

Conceitos Fundamentais ................................................ 241

Era da Informação ................................................... 241

Liberdade de Expressão ........................................... 242

Direito à Privacidade ............................................... 242

Infraestrutura e Recursos do Setor de Telecomunicações .................. 242

Infraestrutura de Telecomunicações ........................................... 243

Compartilhamento de Infraestrutura ............................... 243

Bem Público (utilização e restrição) ...................................... 243

Redes de Telecomunicações ................................................... 243

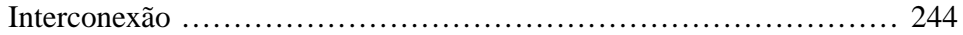

Numeração dos Serviços ............................................... 244

Equipamentos de Telecomunicações ....................................... 244

Antenas .......................................................... 244

Estações de Telecomunicações ......................................... 245

Terminais .......................................................... 246

Espectro de Radiofrequência ............................................ 247

Atribuição, Destinação e Distribuição de Radiofrequência .............. 247

Condições de Uso de Radiofrequência e Canalização (Distribuição de

Canais) ......................................................... 247

Direito de Uso de Radiofrequência ................................... 247

Administração do Setor de Telecomunicações ................................ 248

Fiscalização das Telecomunicações ...................................... 248

Tributação no Setor de Telecomunicações ..................................... 249

Prestação de Serviços ............................................................ 250

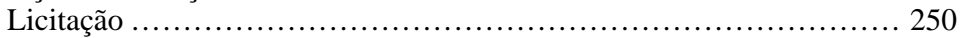

Espécies de Outorga …........................................ 252

Concessão (regras aplicáveis) ..................................... 252

Permissão (regras aplicáveis) …………......................... 253

Autorização (regras aplicáveis) ….................................. 254

Preço Público e Preço Privado ........................................ 254

Processo Administrativo ............................................... 256

Políticas de Telecomunicações ............................................... 256

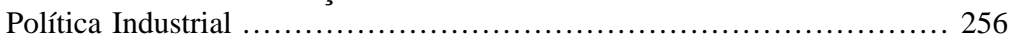

Concorrência no Setor de Telecomunicações ................................. 257

Universalização e Massificação ................................................ 257

Acesso às Telecomunicações ......................................... 258

Portador de Deficiência ............................................. 258

Financiamento da Universalização e Massificação ....................... 258

Metas de Universalização ................................................ 258

Fundos Setoriais de Telecomunicações .................................. 258

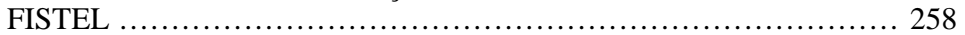

Qualidade do Serviço …............................................. 260

Controle Social, Hierárquico e Interorgânico ….......................... 260

Sigilo em Telecomunicações ............................................... 260

Classificações de Serviços no Setor de Telecomunicações ................. 260 
Quanto ao Regime Jurídico de Prestação ................................ 260

Quanto ao Interesse ................................................. 261

Serviço de Interesse Coletivo ..................................... 261

Serviço de Interesse Restrito ....................................... 261

Quanto ao Gênero .................................................. 261

Serviço Limitado ................................................ 261

Serviço de Valor Adicionado ...................................... 261

Serviço de Radiodifusão ........................................... 262

Serviços no Setor de Telecomunicações .................................. 262

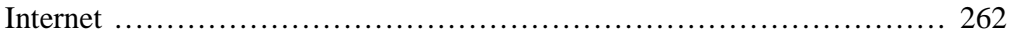

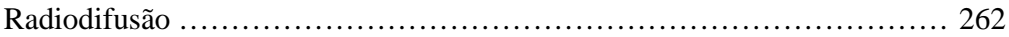

Radiodifusão Comunitária .......................................... 264

Rádio Aberta ................................................... 264

Televisão Aberta ................................................ 264

TV Digital ................................................. 265

Serviço Limitado Especializado (SLE) ............................... 266

Serviço Limitado Móvel Privado ..................................... 266

Serviço Limitado Privado ................................................ 266

Serviço Móvel Especializado ou Trunking ou Trunk ou Sistema

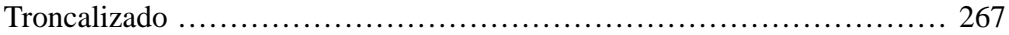

Serviço Móvel Marítimo .................................................. 267

Serviço Móvel Pessoal (SMP) ........................................ 267

Serviço Telefônico Fixo Comutado (STFC) .......................... 268

Serviço de Acesso Condicionado (SeAC) .............................. 270

Serviço de Comunicação Multimída (SCM) ............................. 271

Serviço de Telecomunicações Aeronáuticas .............................. 271

Serviço Móvel Aeronáutico ...................................... 271

Ramos Jurídicos Afins ................................................. 272

Direito da Concorrência ............................................. 272

Direito Urbanístico .................................................. 272

Aplicações de Telecomunicações ...................................... 272

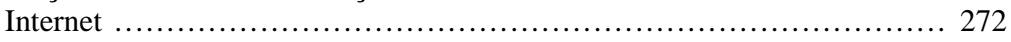

Acessibilidade .................................................. 273

Acesso a Serviços de Interesse Público e Uso de Radiofrequência por tais

Serviços .............................................................. 273

Banda Larga ........................................................ 273

Atores no Setor de Telecomunicações ............................... 273

ANATEL ......................................................... 274

Poder Legislativo ................................................... 276

Tribunal de Contas da União ...................................... 276

Poder Executivo ................................................. 276

Presidência da República ............................................ 277

Ministério das Comunicações ..................................... 277

Ministério da Educação .............................................. 277

Ministério da Cultura ............................................ 278

Poder Judiciário ....................................................... 278

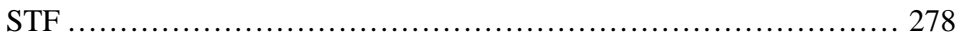

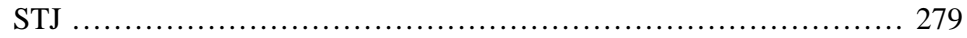

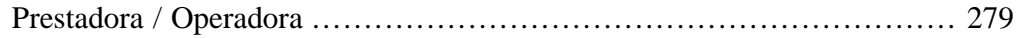

Usuário / Consumidor ................................................ 280

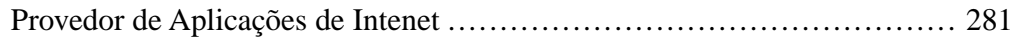

Normas Referenciadas ................................................ 281 


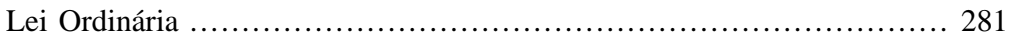

Lei $\mathrm{n}^{\circ} 13.097$, de 19 de janeiro de 2015 .......................... 281

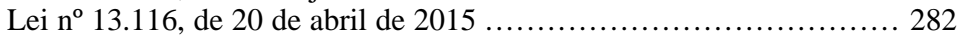

Lei $\mathrm{n}^{\circ} 13.129$, de 26 de maio de 2015 ............................... 283

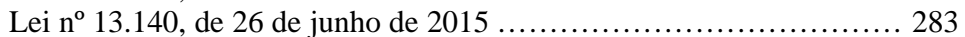

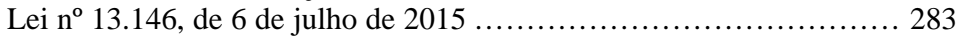

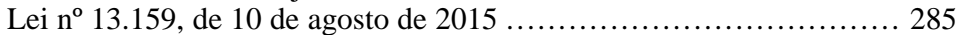

Lei $\mathrm{n}^{\mathrm{o}} 13.188$, de 11 de novembro de 2015 ......................... 285

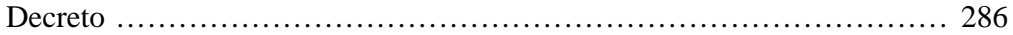

Portaria MC n ${ }^{\circ}$ 6.738, de 21 de dezembro de 2015 .................... 286

Decreto $\mathrm{n}^{\circ} 8.632$, de 30 de dezembro de $2015 \ldots \ldots \ldots \ldots \ldots \ldots \ldots \ldots \ldots \ldots \ldots . \ldots . \ldots . \ldots 286$

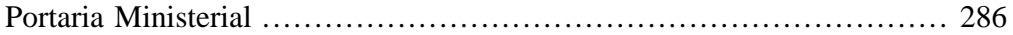

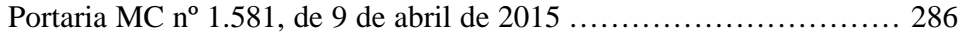

Portaria MC no 320 , de 12 de janeiro de 2015 ...................... 287

Portaria MC n ${ }^{\circ}$ 294, de 30 de janeiro de 2015 ........................ 288

Portaria MC no 4.335, de 17 de setembro de 2015 .................... 288

Portaria $\mathrm{MC} \mathrm{n}^{\mathrm{o}}$ 4.287, de 21 de setembro de $2015 \ldots \ldots \ldots \ldots \ldots \ldots \ldots . \ldots 288$

Portaria MC no 4.699, de 14 de outubro de 2015 ...................... 289

Portaria $\mathrm{MC}^{\mathrm{o}}$ 6.413, de 20 de novembro de $2015 \ldots \ldots \ldots \ldots \ldots \ldots \ldots . \ldots 289$

Portaria MC $n^{\circ} 6.467$, de 24 de novembro de 2015 ...................... 290

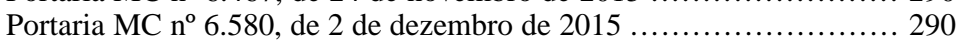

Portaria Interministerial ............................................. 291

Portaria Interministerial no 2.098 , de 14 de maio de 2015 ................. 291

Portaria Interministerial no 4.074, de 26 de Agosto de 2015 .............. 291

Resolução ........................................................... 291

Resolução da ANATEL n ${ }^{\circ}$ 647, de 9 de fevereiro de 2015 ............. 291

Resolução da ANATEL $n^{\circ}$ 648, de 11 de fevereiro de 2015 ............. 292

Resolução da ANATEL n ${ }^{\circ}$ 650, de 16 de março de 2015 ............... 292

Resolução da ANATEL n ${ }^{\circ}$ 651, de 13 de abril de 2015 ................. 293

Resolução da ANATEL n ${ }^{\circ}$ 652, de 27 de maio de 2015 ................ 293

Resolução da ANATEL n ${ }^{\circ}$ 653, de 13 de julho de 2015 ................. 294

Resolução da ANATEL n ${ }^{\circ}$ 654, de 13 de julho de 2015 ................. 294

Resolução da ANATEL n ${ }^{\circ}$ 655, de 5 de Agosto de 2015 ............... 295

Resolução da ANATEL n ${ }^{\circ}$ 656, de 17 de Agosto de 2015 .............. 296

Resolução da ANATEL $n^{\circ}$ 657, de 3 de novembro de 2015 ............ 296

Resolução da ANATEL n ${ }^{\circ}$ 658, de 11 de dezembro de 2015 ............ 296

Resolução da ANATEL $n^{\circ}$ 659, de 28 de dezembro de 2015 ........... 297

Resolução da ANATEL n ${ }^{\circ}$ 660, de 28 de dezembro de 2015 ............ 297

Julgados Referenciados ................................................ 298

Acórdãos ............................................................ 298

Supremo Tribunal Federal (STF) ................................ 298

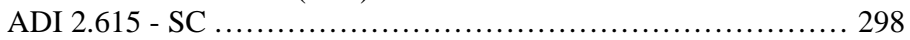

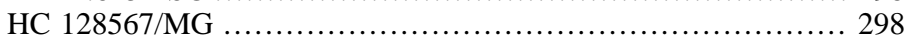

RE 456534 ED/RS .......................................... 299

RE 811620 AgR/MG ....................................... 299

Superior Tribunal de Justiça (STJ) ................................ 300

RESP 1384340 AgRg/DF ................................. 300

Tribunal de Contas da União (TCU) .............................. 300

Acórdão TCU 3311/2015 ...................................... 300

Acórdão TCU 2320/2015 .......................................... 301

Atos Referenciados ................................................... 301

Ato Administrativo .................................................. 301 
Ato 301

Ato do Conselho Diretor da ANATEL n ${ }^{\circ} 448$, de 22 de janeiro de 2015

Decisão .......................................................... 302

Acórdão do Conselho Diretor da ANATEL, de 5 de janeiro de 2015

(Ref. $n^{\circ}$ 6/2015) .......................................... 302

Acórdão do Conselho Diretor da ANATEL, de 24 de fevereiro de 2015 (Ref. no 53/2015) .................................... 302 Acórdão do Conselho Diretor da ANATEL, de 31 de julho de 2015 (Ref. $n^{\circ}$ 305/2015) .............................................. 303 Acórdão do Conselho Diretor da ANATEL, de 5 de novembro de 2015 (Ref. $\left.n^{\circ} 480 / 2015\right)$...................................... 303

Relatório da Ouvidoria da ANATEL ............................... 303

Relatório da Ouvidoria da ANATEL 2015 ........................ 303

Índice Alfabético e Remissivo ............................................ 305 


\section{Lista de Abreviaturas e Siglas}

$1 \mathrm{G}$

$2.5 \mathrm{G}$

$2 \mathrm{G}$

3G

3G HS

3GPP

$4 \mathrm{G}$

$8 \mathrm{~K}$

AACD

ABA

ABAP

ABAR

ABCiber

ABDTIC

ABEMTIC

ABEPEC

ABEPEC

ABEPREST

ABERT

ABETS

ABIFUMO

ABINEE

ABJC

ABNT

ABPI-TV

ABPITV

ABPTA

ABR Telecom

ABRA

ABRACOM

ABRADECEL

ABRAFIC

ABRAFIX

ABRAMULTI

Primeira Geração de Tecnologia de Telefonia Móvel (analógico).

Geração 2.5 de Tecnologia de Telefonia Móvel (GPRS).

Segunda Geração de Tecnologia de Telefonia Móvel (digital para dados, 9.6-14.4Kbps).

Terceira Geração de Tecnologia de Telefonia Móvel (digital para voz e dados, mínimo de 144Kbps).

3G High Speed (Rede celular de Terceira geração de Alto Desempenho). 3rd Generation Partnership Project.

Quarta Geração de Tecnologia de Telefonia Móvel (requisitos da UIT IMT-Advanced).

Tecnologia de Ultra High Definition Television.

Associação de Assistência à Criança Deficiente.

Associação Brasileira de Anunciantes.

Associação Brasileira de Agências de Propaganda.

Associação Brasileira de Agências de Regulação.

Associação Brasileira de Pesquisadores em Cibercultura.

Associação Brasileira de Direito das Tecnologias da Informação e das Comunicações.

Associação Brasileira de Entidades Municipais de Tecnologia da Informação e Comunicação.

Associação Brasileira das Emissoras Públicas Educativas e Culturais.

Associação Brasileira de Ensino e Pesquisa em Comunicação (inativa).

Associação Brasileira de Empresas de Soluções de Telecomunicações e Informática.

Associação Brasileira de Emissoras de Rádio e Televisão.

Associação Brasileira das Empresas de Telecomunicações por Satélite.

Associação Brasileira da Indústria do Fumo.

Associação Brasileira da Indústria Elétrica e Eletrônica.

Associação Brasileira de Jornalismo Científico.

Associação Brasileira de Normas Técnicas.

Associação Brasileira de Produtores Independentes de Televisão.

Associação Brasileira das Empresas Produtoras Independentes de Televisão.

Associação Brasileira dos Programadores de TV por Assinatura.

Associação Brasileira de Recursos de Telecomunicações (Portabilidade Numérica).

Associação Brasileira de Radiodifusores.

Associação Brasileira de Antenas Comunitárias.

Associação Brasileira de Defesa dos Moradores e Usuários Intraquilos com Equipamentos de Telecomunicações Celular.

Associação Brasileira de Film Commissions (Brazilian Association of Film Commissions).

Associação Brasileira de Concessionárias de Serviço Telefônico Fixo Comutado.

Associação Brasileira dos Operadores de Telecomunicações e Provedores de Internet. 
ABRAPPIT

ABRATEL

ABRATER

ABRINT

Abrintel

ABRISAN

ABTA

ABTU

Acel

ACERP

ACLR

AD

ADGI

ADI

ADPF

ADSL

AEB

AET

AFTN

AGVSEL

Ah

AHCIET

AI

AI

$\mathrm{AI} / \mathrm{E}$

AICE

AIE

AIRR

ALAIC

ALCA

ALCAR

AM

AM-DSB-SC

AME

AMMB

AMN

AMNT

AMPS

AN

AN

ANACOM
Associação Brasileira de Pequenos Provedores de Internet e Telecomunicações.

Associação Brasileira de Radiodifusão, Tecnologia e Telecomunicações. Associação Brasileira de Telecomunicações Rurais.

Associação Brasileira de Provedores de Internet e Telecomunicações.

Associação Brasileira de Infraestrutura para Telecomunicações.

Associação Brasileira de Registro de Obras Audiovisuais.

Associação Brasileira de TV por Assinatura.

Associação Brasileira de TVs Universitárias.

Associação Nacional das Operadoras Celulares.

Associação de Comunicação Educativa Roquette Pinto.

Adjacent Channel Leakage Ratio.

Adicional por Chamada (Serviço Móvel Pessoal).

Gerência Geral de Gestão da Informação (ANATEL).

Ação Direta de Inconstitucionalidade (Jurisdição).

Gerência Geral de Planejamento, Orçamento e Finanças (ANATEL).

Asymmetric Digital Subscriber Line.

Agência Espacial Brasileira.

Associação dos Engenheiros de Telecomunicações.

Aeronautical Fixed Telecommunications Network (Rede Internacional Fixa de Telecomunicações Aeronáuticas).

Agravo em Suspensão de Execução de Liminar.

Ampère-hora.

Asociación Iberoamericana de Centros de Investigación y Empresas de Telecomunicaciones.

Acesso Instalado.

Agravo de Instrumento (Jurisdição).

Acesso Instalado da Estação de Comutação.

Acesso Individual Classe Especial.

Acesso Instalado Equivalente.

Agravo de Instrumento em Recurso de Revista (Tribunal Superior do Trabalho).

Asociación Latinoamericana de Investigadores de la Comunicación.

Área de Livre Comércio das Américas.

Associação Brasileira dos Pesquisadores de História da Mídia.

Amplitude Modulation (Modulação em Amplitude).

Amplitude Modulation, Double-Sided Band, Suppressed Carrier (Modulação em Amplitude, em Faixa Lateral Dupla, com Portadora Suprimida).

Valor de Ativo Moderno Equivalente (Separação e Alocação de Contas).

Associação de Marketing Móvel do Brasil.

Artificial Mains Network (Rede Fictícia em V).

Assembléia Mundial de Normalização das Telecomunicações.

Advanced Mobile Phone System (Rede celular 1G).

Área de Numeração.

Área de Numeração (Serviço Telefônico Fixo Comutado).

Autoridade Nacional de Comunicações (de Portugal). 
ANATEL

ANCINE

ANEEL

ANER

ANER

ANJ

ANOp

ANP

ANSI

ANTT

APEX-Brasil

APS

Aptel

AR

AR

AR

AR

ARCTEL

ARIB

ARICEA

ARM

ART

ARTAC

ASTM

AT

AT

ATA

ATB

ATB

ATC

ATS

ATSC

AVADAN

BACEN

BAL

BASIS

BB

$\mathrm{BBC}$

BCB

BDO

BDR
Agência Nacional de Telecomunicações.

Agência Nacional do Cinema.

Agência Nacional de Energia Elétrica.

Associação Nacional das Empresas de Revistas.

Associação Nacional dos Servidores Efetivos das Agências Reguladoras.

Associação Nacional de Jornais.

Auditoria de Natureza Operacional (Tribunal de Contas da União).

Agência Nacional do Petróleo.

American National Standards Institute.

Agência Nacional de Transportes Terrestres.

Agência de Promoção de Exportações do Brasil.

Área de Prestação do Serviço ( Serviço de Acesso Condicionado).

Associação de Empresas Proprietárias de Infra-Estrutura e de Sistemas Privados de Telecomunicações.

Área de Registro.

Área de Registro (Serviço Móvel Especializado).

Área de Registro (Serviço Móvel Pessoal).

Área de Registro (Serviço Telefônico Fixo Comutado).

Associação de Reguladores das Comunicações e Telecomunicações da Comunidade de Países de Língua Portuguesa.

Association of Radio Industries and Businesses (Japão).

Association of Regulators of Information and Communications for Eastern and Southern Africa.

Acordo de Reconhecimento Mútuo (Certificação e Homologação).

Anotação de Responsabilidade Técnica.

Association des régulateurs de telecommunications de l'Afrique central

- Telecommunication Regulators' Association of Central Africa.

American Society for Testing and Materials.

Área de Tarifação (Serviço Móvel Especializado).

Área de Tarifação (Serviço Móvel Pessoal).

Analog Telephone Adaptor.

Área de Tarifa Básica.

Área de Tarifação Básica (Serviço Telefônico Fixo Comutado).

Ativos de Tecnologia Corrente (Separação e Alocação de Contas).

Ativos de Tecnologia Substituída (Separação e Alocação de Contas).

Advanced Television Systems Committee (Padrão de TV Digital - Estados Unidos da América).

Avaliação de Danos - Formulário (Sistema Nacional de Defesa Civil).

Banco Central do Brasil.

Balanceamento Longitudinal.

Business Action to Support the Information Society (Câmara Internacional de Comércio - ICC).

Banda-Base.

British Broadcasting Corporation (Reino Unido).

Banco Central do Brasil.

Base de Dados Operacional (Portabilidade).

Base de Dados de Referência (Portabilidade). 
BDR

BDT

BDTA

BGAN

BIA

BID

BIRD

BIS

$\mathrm{Bn}$

BNDES

BPL

BR

BRASSCOM

BS

BSR

BT

BWA

C-INI

$\mathrm{C} 0,25$

$\mathrm{C} 10$

C120

$\mathrm{CA}$

CAACI

CADE

CADIN

CAMR

CAPDA

CAPT

CARR

CATIS

$\mathrm{CBC}$

$\mathrm{CBC} 1$

CBC 2

CBC 3

CBC 4

CBC 5

Base de Dados Nacional de Referência da Portabilidade.

Bureau de Développement des Télécommunications (Escritório de Desenvolvimento das Telecomunicações da UIT).

Banco de Dados Técnicos e Administrativos (Radiofreqüência).

Broadband Global Area Network (INMARSAT).

Bens e Instalações em Andamento (Separação e Alocação de Contas).

Banco Interamericano de Desenvolvimento.

Banco Internacional para Reconstrução e Desenvolvimento (Banco Mundial).

Bens e Instalações em Serviço (Separação e Alocação de Contas).

Largura da Faixa Necessária (Certificação).

Banco Nacional de Desenvolvimento Econômico e Social.

Broadband over Power Lines (Banda larga por meio de redes de energia elétrica).

Bureau des Radiocommunications (Escritório de Radiocomunicações da UIT).

Associação Brasileira de Empresas de Tecnologia da Informação e Comunicação.

Base Station (Estação Rádio Base).

Bloqueador de Sinais de Radiocomunicações.

Linha de distribuição de Baixa Tensão.

Broadband Wireless Access (4G).

Comitê sobre Infra-estrutura Nacional de Informações.

Capacidade nominal para regime de alta intensidade de descarga $(\mathrm{C} 0,25)$.

Capacidade nominal para regime de média intensidade de descarga (C10).

Capacidade nominal para regime de baixa intensidade de descarga (C120).

Corrente Alternada.

Conferência de Autoridades Audiovisuais e Cinematográficas IberoAmericana.

Conselho Administrativo de Defesa Econômica.

Cadastro Informativo de Créditos não Quitados do Setor Público Federal.

Conferência Administrativa Mundial de Radiocomunicações.

Comitê das Atividades de Pesquisa e Desenvolvimento na Amazônia.

Controle Automático da Potência Transmitida.

Conferência Administrativa Regional de Radiocomunicações.

Centro de Acesso a Tecnologias para a Inclusão Social.

Comissão Brasileira de Comunicações.

Comissão Brasileira de Comunicações $\mathrm{n}^{\circ} 1$ - Redes de Dados e Características de Sistemas Telemáticos (extinta).

Comissão Brasileira de Comunicações $n^{\circ} 2$ - Transmissão de Áudio e Vídeo e Sistemas Multimídia (extinta).

Comissão Brasileira de Comunicações nº 3 - Tarifas e Princípios Contábeis (extinta).

Comissão Brasileira de Comunicações n ${ }^{\circ} 4$ - Definição de Serviços, Planos Estruturais e Gerência de Redes (extinta).

Comissão Brasileira de Comunicações $n^{\circ} 5$ - Sinalização, Comutação, Protocolos, Linguagens e Aspectos Gerais de Redes (extinta).

Revista de Direito, Estado e Telecomunicações, v. 8, n. 1, p. 209-332 (2015) 
CBC 6

CBC 7

CBC 8

CBC 9

CBC 1

CBC 10

CBC 11

CBC 12

CBC 13

CBC 2

CBC 3

CBC 4

CBC Temp.

CBDT

$\mathrm{CBF}$

CBLC

CBR

CBT

CBTTs

$\mathrm{CC}$

CCA

CCC

$\mathrm{CCC}$

CCC

CCIR

CCITT

CCJC

$\mathrm{CCOM}$

CCOMGEX

CCP.I

CCP.II

CCP.III

CCPs-CITEL

CCT
Comissão Brasileira de Comunicações $\mathrm{n}^{\circ} 6$ - Planta Externa e Compatibilidade Eletromagnética (extinta).

Comissão Brasileira de Comunicações $\mathrm{n}^{\circ} 7$ - Desenvolvimento das Telecomunicações (extinta).

Comissão Brasileira de Comunicações $\mathrm{n}^{\circ} 8$ - Serviços Móveis, de Radiodeterminação e de Radioamador (extinta).

Comissão Brasileira de Comunicações n ${ }^{\circ} 9$ - Serviços Fixos e Científicos (extinta).

Comissão Brasileira de Comunicações $\mathrm{n}^{\circ} 1$ - Governança e Regimes Internacionais.

Comissão Brasileira de Comunicações n ${ }^{\circ} 10$ - Administração do Espectro Radioelétrico e Propagação (extinta).

Comissão Brasileira de Comunicações n ${ }^{\circ} 11$ - Radiodifusão (extinta).

Comissão Brasileira de Comunicações n ${ }^{\circ} 12$ - Negociações Internacionais em Telecomunicações (extinta).

Comissão Brasileira de Comunicações $n^{\circ} 13$ - Governança da Internet (extinta).

Comissão Brasileira de Comunicações n 2 - Radiocomunicações.

Comissão Brasileira de Comunicações $\mathrm{n}^{\circ} 3$ - Normalização de Telecomunicações.

Comissão Brasileira de Comunicações $\mathrm{n}^{\circ} 4$ - Desenvolvimento das Telecomunicações.

Comissão Brasileira de Telecomunicações Temporária.

Coleção Brasileira de Direito Regulatório das Telecomunicações.

Confederação Brasileira de Futebol.

Comissão Brasileira de Liquidação e Custódia.

Comissão Brasileira de Radiocomunicações.

Código Brasileiro de Telecomunicações (Lei no 4.117/62).

Comissões Brasileiras de Telecomunicações.

Corrente Contínua.

Base de Custos Correntes.

Central de Comutação e Controle (Serviço Móvel Pessoal).

Central de Comutação e Controle (Sistemas de Acesso sem Fio do STFC).

Central de Controle e Comutação do SMC (Internacional).

Comitê Consultivo Internacional das Radiocomunicações.

Comitê Consultivo Internacional de Telegrafia e Telefonia.

Comissão de Constituição e Justiça e de Cidadania.

Centro de Políticas, Direito, Economia e Tecnologias das Comunicações da UnB.

Centro de Comunicações e Guerra Eletrônica do Exército.

Comitê Consultivo Permanente $n^{\circ} 1$ da Comissão Interamericana de Telecomunicações.

Comitê Consultivo Permanente $\mathrm{n}^{\mathrm{o}} 2$ da Comissão Interamericana de Telecomunicações.

Comitê Consultivo Permanente $n^{\circ} 3$ da Comissão Interamericana de Telecomunicações.

Comitês Consultivos Permanentes da CITEL.

Cargo Comissionado Técnico (Agências Reguladoras). 


\begin{tabular}{|c|c|}
\hline CCT & $\begin{array}{l}\text { Comissão de Ciência, Tecnologia, Inovação, Comunicação e Informática } \\
\text { (Senado Federal). }\end{array}$ \\
\hline CCT & Conselho Nacional de Ciência e Tecnologia. \\
\hline CCTCI & $\begin{array}{l}\text { Comissão de Ciência e Tecnologia, Comunicação e Informática (Câmara } \\
\text { dos Deputados). }\end{array}$ \\
\hline ccTLD & $\begin{array}{l}\text { country code Top Level Domain (Domínio de Primeiro Nível) } \\
\text { (INTERNET). }\end{array}$ \\
\hline CDA & Certidão de Dívida Ativa. \\
\hline $\mathrm{CDC}$ & Código de Defesa do Consumidor. \\
\hline CDEIC & $\begin{array}{l}\text { Comissão de Desenvolvimento Econômico, Indústria e Comércio (Câmara } \\
\text { dos Deputados). }\end{array}$ \\
\hline CDI & Cadastro de Demonstração de Interesse (Radiodifusão Comunitária). \\
\hline CDI & Comutação Digital Integrada. \\
\hline CDMA & Code Division Multiple Access (Múltiplo Acesso por Divisão em Código). \\
\hline CDMA 1xEV-DO & CDMA Evolution Data-Optimized (Rede celular 3G). \\
\hline CDMA 1xEV-DV & CDMA Evolution, Data and Voice (Rede celular 3G). \\
\hline $\mathrm{CDN}$ & Content Delivery Network (Rede de Entrega de Conteúdo). \\
\hline CDUST & Comitê de Defesa dos Usuários de Serviços de Telecomunicações. \\
\hline CEDEC & $\begin{array}{l}\text { Coordenadoria Estadual de Defesa Civil (Sistema Nacional de Defesa } \\
\text { Civil). }\end{array}$ \\
\hline CEFET & Centro Federal de Educação Tecnológica. \\
\hline CEITEC & Centro Nacional de Tecnologia Eletrônica Avançada S.A. \\
\hline CENAD & $\begin{array}{l}\text { Centro Nacional de Gerenciamento de Riscos e Desastres (Sistema } \\
\text { Nacional de Defesa Civil). }\end{array}$ \\
\hline CENELEC & European Commitee for Electrotechnical Standardization. \\
\hline CEPED & $\begin{array}{l}\text { Centro Universitário de Ensino e Pesquisa sobre Desastres (Sistema } \\
\text { Nacional de Defesa Civil). }\end{array}$ \\
\hline CERT.br & $\begin{array}{l}\text { Centro de Estudos, Resposta e Tratamento de Incidentes de Segurança } \\
\text { no Brasil (Comitê Gestor da Internet no Brasil). }\end{array}$ \\
\hline CETIC.br & $\begin{array}{l}\text { Centro de Estudos sobre as Tecnologias da Informação e da Comunicação } \\
\text { (Comitê Gestor da Internet no Brasil). }\end{array}$ \\
\hline CFM & Conselho Federal de Medicina. \\
\hline CFTV & $\begin{array}{l}\text { Serviço Especial de Circuito Fechado de Televisão com Utilização de } \\
\text { Radioenlace. }\end{array}$ \\
\hline CG-CBC & Grupo de Coordenação das Comissões Brasileiras de Comunicações. \\
\hline CG-ProTIC & $\begin{array}{l}\text { Comitê Gestor do Programa de Apoio à Pesquisa, Desenvolvimento e } \\
\text { Inovação em Tecnologias Digitais de Informação e Comunicação. }\end{array}$ \\
\hline CGCOB & Coordenação-Geral de Cobrança e Recuperação de Créditos. \\
\hline CGIbr & Comitê Gestor da Internet no Brasil. \\
\hline CGPD & $\begin{array}{l}\text { Comitê Gestor de Políticas de Inclusão das Pessoas com Deficiência } \\
\text { (Presidência da República). }\end{array}$ \\
\hline CGPID & CGPID. \\
\hline CGRBT & Comitê Gestor de Articulação Institucional da Rede Brasil de Tecnologia. \\
\hline $\mathrm{Cia} \mathrm{C}^{2}$ & Companhia de Comando e Controle (Exército Brasileiro). \\
\hline CIC & Central de Intermediação de Comunicação Telefônica. \\
\hline CIDE & Contribuição de Intervenção no Domínio Econômico. \\
\hline CIP & Câmara Interbancária de Pagamentos. \\
\hline CIPA & Comissão Interna de Prevenção de Acidentes. \\
\hline
\end{tabular}


CISCOMIS

CITEL

CJF

CMDT

CMGLO

CMI

CMPC

CMPRL

CMR

CMSI

$\mathrm{CN}$

CNAL

$\mathrm{CNC}$

CNDI

CNI

$\mathrm{CNPq}$

CNPq-MCT

COE

COE

COER

COFDM

COFINS

COG

COGEF

COL

COMDEC

COMESA

COMPÓS

CONANDA

Conapsi

CONAR

CONARQ

CONCAR

CONDEC

CONDECINE

CONFAZ

CONFECOM

CONTCOP

CONTEL
Comissão de Desenvolvimento do Projeto e da Implantação do Sistema de Comunicações Militares por Satélite.

Comissão Interamericana de Telecomunicações.

Conselho da Justiça Federal.

Conferência Mundial de Desenvolvimento das Telecomunicações.

Gerência de Engenharia, Planejamento e Controle de Licitações e Outorgas.

Cúpula Mundial da Informação.

Custo Médio Ponderado de Capital.

Gerência de Autorização do Uso de Radiofrequências e Licenciamento de Estações (ANATEL).

Conferência Mundial de Radiocomunicações.

Cúpula Mundial sobre a Sociedade da Informação (World Summit on the Information Society - WSIS).

Código Nacional.

Cadastro Nacional de Áreas Locais.

Conselho Nacional de Comunicações.

Conselho Nacional de Desenvolvimento Industrial.

Confederação Nacional da Indústria.

Conselho Nacional de Desenvolvimento Científico e Tecnológico.

Centro Nacional de Pesquisa do Ministério da Ciência e Tecnologia.

Coeficiente de Onda Estacionária.

Coeficiente de Reflexão.

Certificado de Operador de Estação de Radioamador.

Coded Orthogonal Frequency Division Multiplexing.

Contribuição para o Financiamento da Seguridade Social.

Cabo Óptico Geral.

Comissão de Gerência do Espectro de Radiofreqüência de Interesse do Ministério da Defesa.

Copa do Mundo FIFA 2014 - Comitê Organizador Brasileiro Ltda.

Coordenadoria Municipal de Defesa Civil (Sistema Nacional de Defesa Civil).

Common Market for Eastern and Southern Africa.

Associação Nacional das Pós-Graduações em Comunicação.

Conselho Nacional dos Direitos da Criança e do Adolescente.

Conselho Nacional dos Provedores de Serviço de Internet.

Conselho Nacional de Auto-Regulamentação Publicitária.

Conselho Nacional de Arquivos.

Comissão Nacional de Cartografia.

Conselho Nacional de Defesa Civil (Sistema Nacional de Defesa Civil).

Contribuição para o Desenvolvimento da Indústria Cinematográfica Nacional.

Conselho Nacional de Política Fazendária.

Conferência Nacional de Comunicação.

Confederação Nacional dos Trabalhadores em Comunicações e Publicidade (Representação profissional).

Conselho Nacional de Telecomunicações (Extinto em 25/02/1967). 


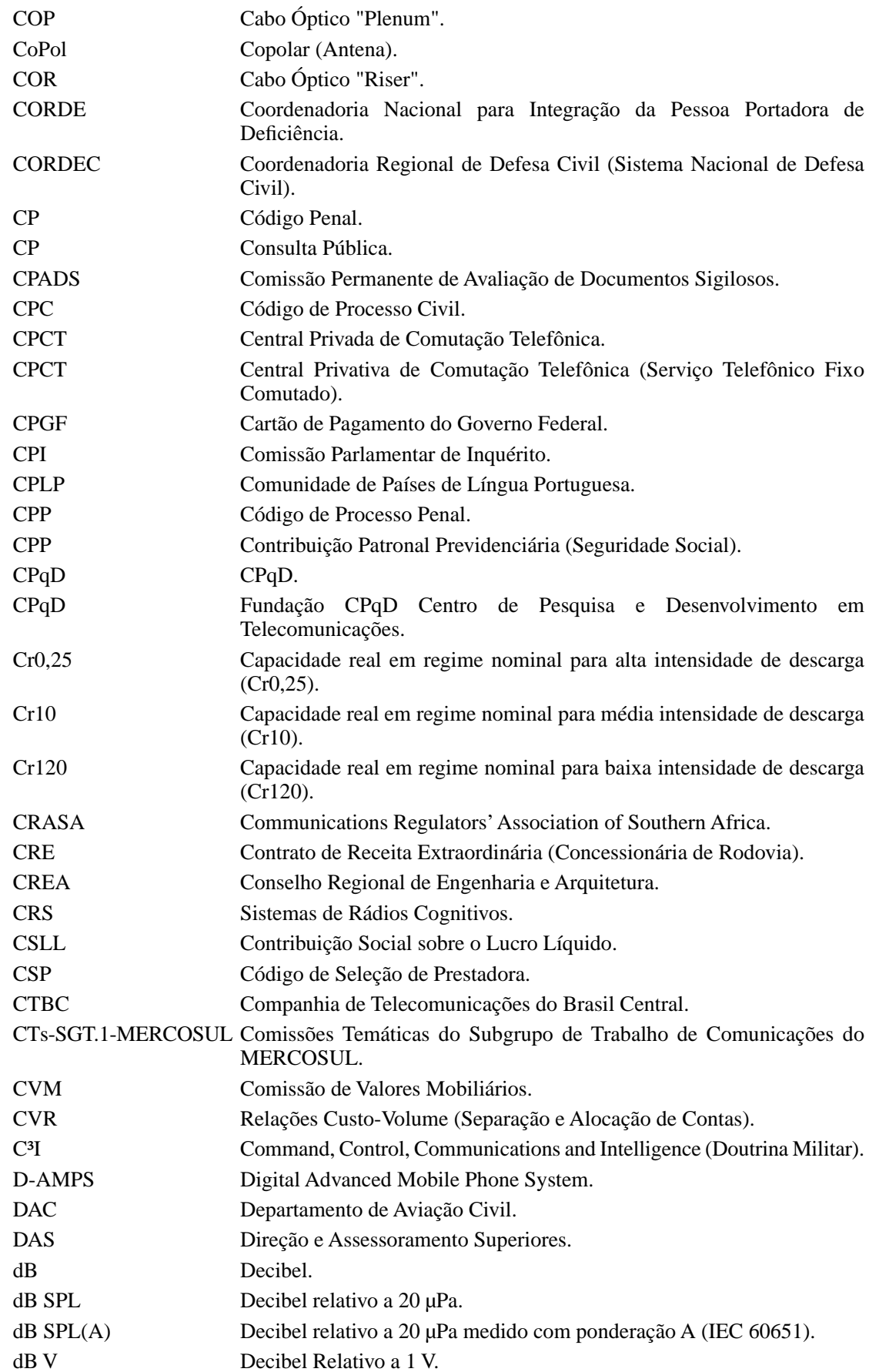




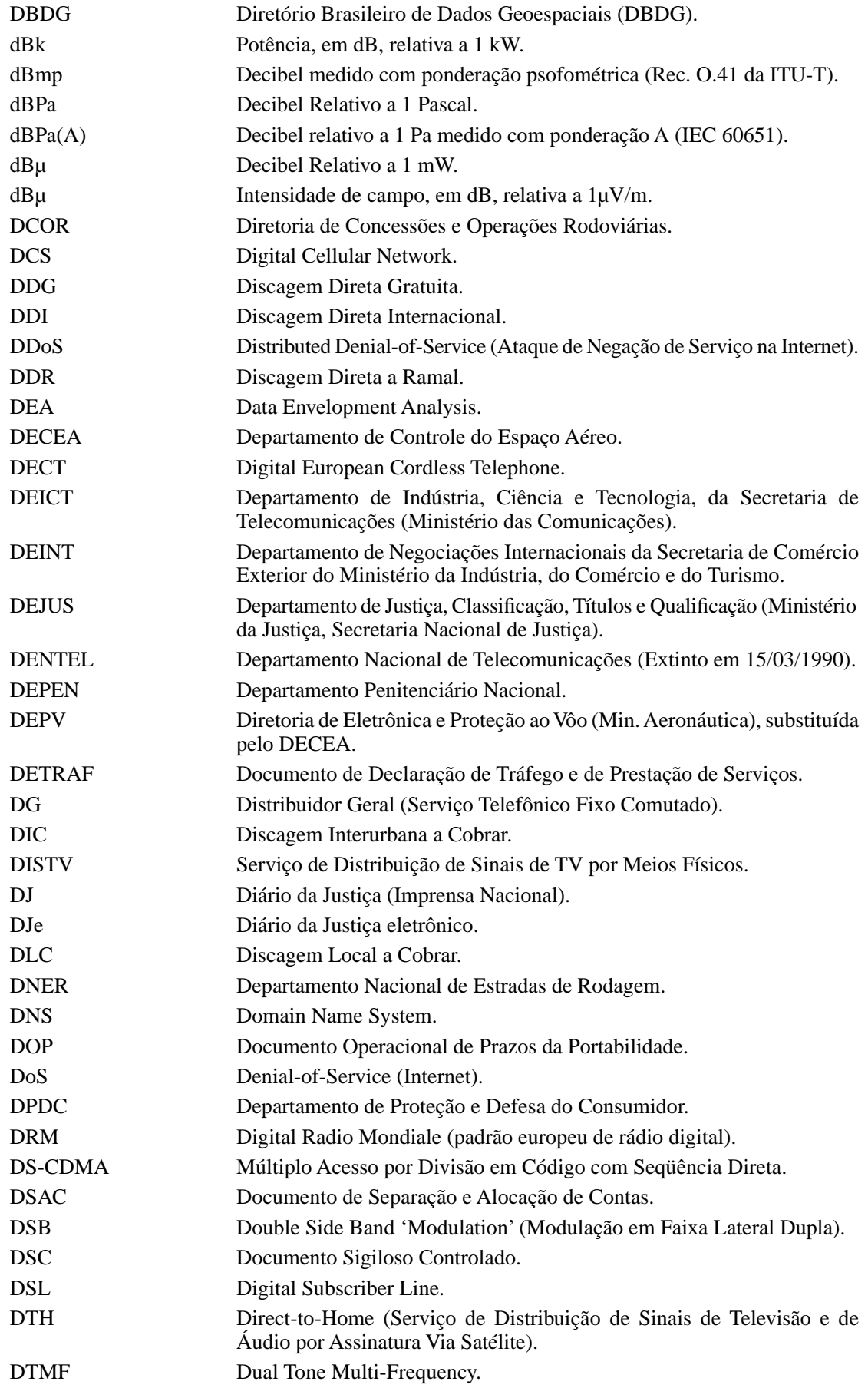




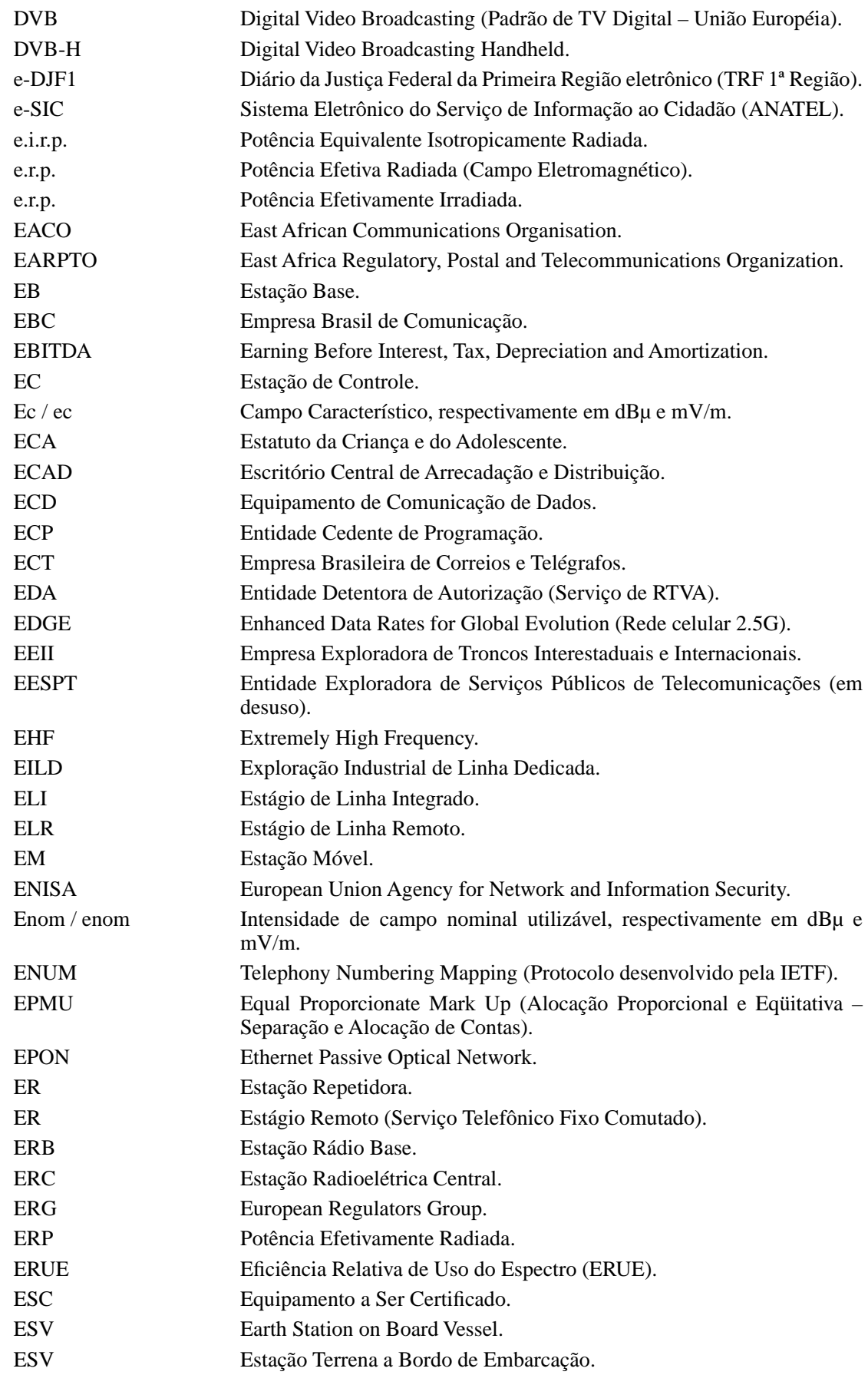


ET

ETA

ETD

ETIR

ETSI

$\mathrm{Eu} / \mathrm{eu}$

EUE

FA

FAC

FCC

FCM

FCPT

FCT

FCT

FDD

FDMA

FEBRAPEL

FEC

FENAJ

FGP

FGTS

FH-CDMA

FI

FIFA

FINEP

FINSOCIAL

FISTEL

FITTEL

FM

FMCA

FME

FNC

FNDCT

FNPJ

FNT

Fonacate

FORCINE

FS

FTTB

FTTC

FTTH

FTTN

FUNCAP
Estação Terminal.

Estação Terminal de Acesso.

Equipamento Terminal de Dados.

Equipe de Tratamento e Resposta a Incidentes de Segurança da Informação (ANATEL).

European Telecommunications Standards Institute.

Intensidade de campo utilizável, respectivamente em $\mathrm{dB} \mu \mathrm{e} \mathrm{mV/m}$.

Eficiência de Uso do Espectro (EUE).

Fator de Amortecimento.

Fully Allocated Costs (Custos Totalmente Alocados).

Federal Communications Commission (United States of America).

Financial Capital Maintenance.

Fórum de Certificação de Produtos para Telecomunicações.

Função Comissionada Técnica.

Funções Comissionadas de Telecomunicações.

Frequency Division Duplexing (Duplexação por Divisão na Frequência).

Frequency Division Multiple Access (Múltiplo Acesso por Divisão em Frequência).

Federação Brasileira de Telecomunicações (Representação empresarial).

Código de Correção de Erro.

Federação Nacional dos Jornalistas.

Fundo Garantidor de Parcerias Público-Privadas.

Fundo de Garantia por Tempo de Serviço.

Múltiplo Acesso por Divisão em Código com Saltos de Frequiência.

Frequência Intermediária.

Fédération Internationale de Football Association.

Financiadora de Estudos e Projetos.

Fundo de Investimento Social.

Fundo de Fiscalização das Telecomunicações.

Federação Interestadual dos Trabalhadores em Telecomunicações.

Frequência Modulada.

Fixed-Mobile Convergence Alliance.

Frequência Modulada com Fins Exclusivamente Educativos.

Fundo Nacional da Cultura.

Fundo Nacional de Desenvolvimento Científico e Tecnológico.

Fórum Nacional de Professores de Jornalismo.

Fundo Nacional de Telecomunicações.

Fórum Nacional Permanente de Carreiras Típicas de Estado.

Fórum Brasileiro de Ensino de Cinema e Audiovisual.

Fornecedora de Sinal.

Fiber to the Building.

Fiber to the Curb.

Fiber to the Home.

Fiber to the Node.

Fundo Especial para Calamidades Públicas (Sistema Nacional de Defesa Civil). 
Fundomic

Funtec

FUNTTEL

FUST

FWA

GCOM

GESAC

GETEL

GGRR

GGSN

GIP

GIP

GIPAQ

GIRED

GMC

GMDSS

GNR

GPON

GPRS

GPS

GSM

GTDS

GTI

GVT

HCA

HCA

HCI

$\mathrm{HF}$

HFBC

HMM

HNMT

HNMT

HSDPA

HSPA

HSUPA

IAF
Fundo de Universalização do Acesso a Serviços de Telecomunicação (Minas Gerais).

Fundo Tecnológico (BNDES).

Fundo para o Desenvolvimento Tecnológico das Telecomunicações.

Fundo de Universalização dos Serviços de Telecomunicações.

Fixed Wireless Access.

Grupo Interdisciplinar de Políticas, Direito, Economia e Tecnologias das Comunicações (UnB).

Governo Eletrônico - Serviço de Atendimento ao Cidadão.

Grupo de Estudos em Direito das Telecomunicações (UnB).

Grupo de Gestão de Riscos e Acompanhamento do Desempenho das Redes de Telecomunicações.

Gateway GPRS Support Node.

Grupo de Implantação da Portabilidade.

Grupo de Implementação da Portabilidade.

Grupo de Implantação de Processos de Aferição da Qualidade.

Grupo de Implantação do Processo de Redistribuição e Digitalização de Canais de TV e RTV - GIRED.

Grupo Mercado Comum.

Sistema Global de Socorro e Segurança Marítima.

Guia Nacional de Recolhimento de Tributos Estaduais.

Gigabit Passive Optical Network.

General Packet Radio Service (Rede celular 2.5G).

Global Positioning System (Sistema de Posicionamento Global).

Global System Mobile -Global System for Mobile Communications (Originariamente Groupe Spécial Mobile).

Grupo de Trabalho de Desburocratização e Simplificação dos Processos de Outorga e Pós-Outorga de Serviços de Radiodifusão (Ministério das Comunicações).

Grupo de Trabalho Interministerial.

GLOBAL VILLAGE TELECOM LTDA.

Base de Custos Históricos ( Separação e Alocação de Contas).

Historical Cost Accounting (Base de Custos Históricos na Separação e Alocação de Contas).

Altura do Centro de Fase do Sistema Irradiante.

High Frequency (Alta Freqüência).

Conferência Administrativa Mundial de Radiocomunicações para o planejamento das faixas de ondas decamétricas atribuídas ao serviço de radiodifusão, realizada em 1987.

Hora de Maior Movimento.

Altura da Antena sobre o Nível Médio do Terreno.

Altura do Sistema Irradiante em Relação ao Nível Médio do Terreno (Radiodifusão).

High Speed Downlink Packet Access (Rede celular 3G).

High-Speed Packet Access (tipo de padrão de telefonia móvel por dados) (Rede celular 3G).

High Speed Uplink Packet Access (Rede celular 3G).

International Accreditation Forum (Certificação e Homologação). 


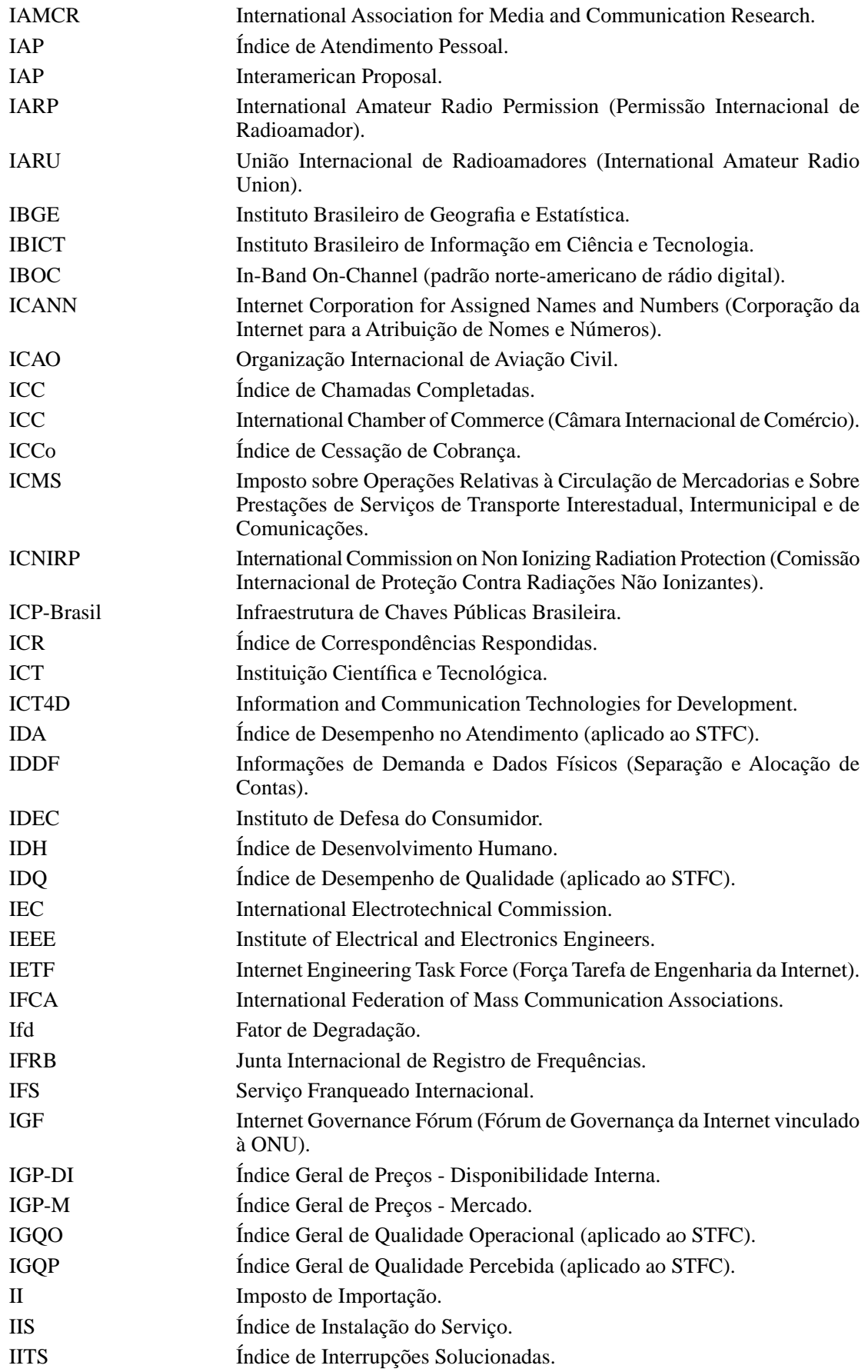




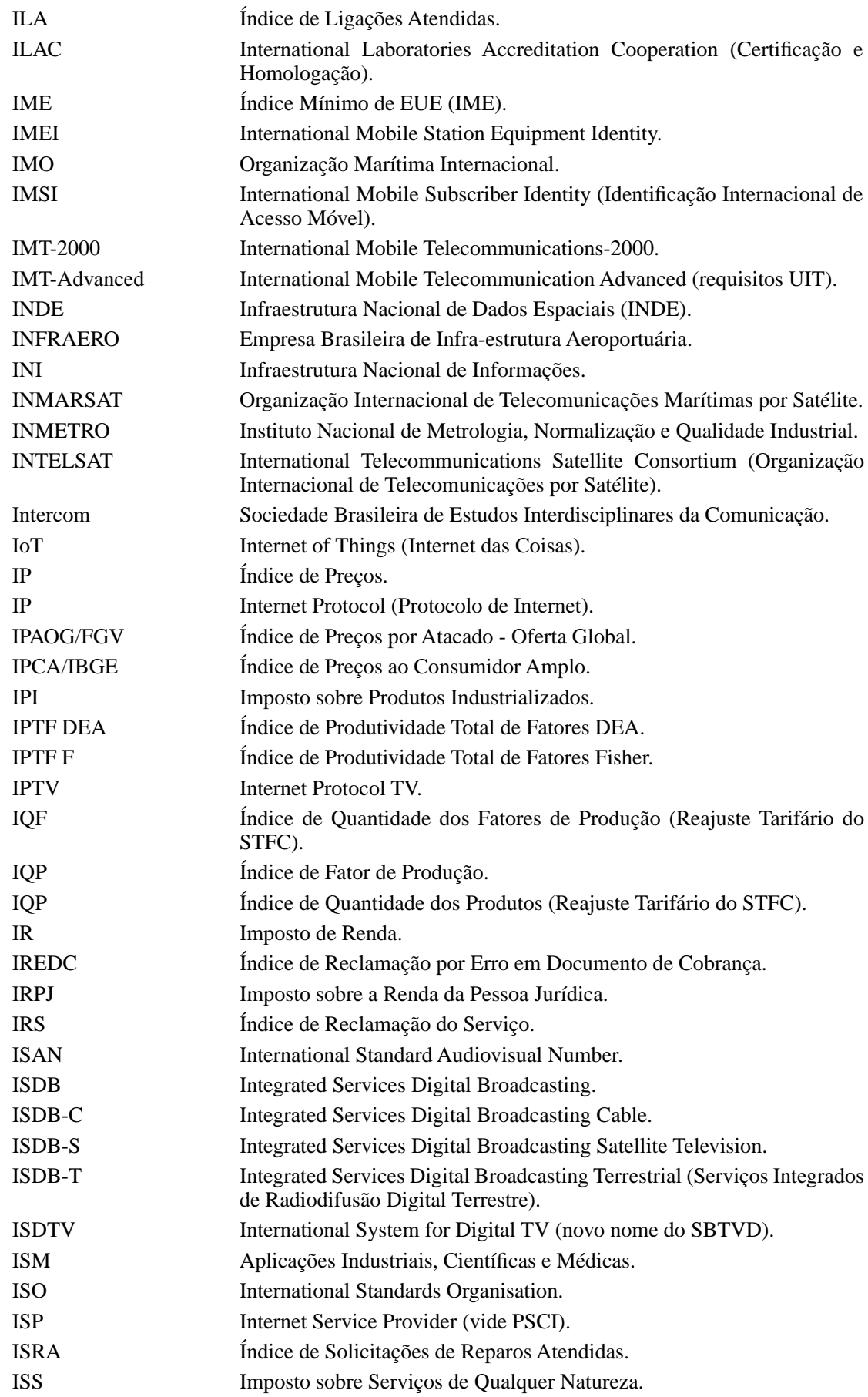


IST

ISYDS

ITE

ITI

ITU

1

LABRE

LAN

LaPCom

LBS

LDI

LDN

LED

LEP

LF

LGT

LIBRAS

LLU

LMDS

LPFM

LRGP

LRIC

LSI

LSZH

LTE

LTOG

LUSOCOM

M2M

MAN

MdE

MDGs

MEF

MERCOSUL

MF

MICS

MIFR

MIN

MINFRA

MMDS

MMS

MMSI

MMSI
Índice de Serviços de Telecomunicações.

Integrated System for Decision Support (vide SIAD).

Índice Temporal de EUE.

Instituto Nacional de Tecnologia da Informação (Autarquia vinculada à Casa Civil da Presidência da República).

International Telecommunication Union (União Internacional de Telecomunicações).

Comprimento de Onda.

Liga de Amadores Brasileiros de Rádio Emissão.

Local Area Network.

Laboratório de Políticas de Comunicação da UnB.

Location Based Services.

Longa Distância Internacional.

Longa Distância Nacional.

Light Emitting Diode (Diodo Emissor de Luz).

Lei de Execuções Penais.

Low Frequency.

Lei Geral de Telecomunicações.

Língua Brasileira de Sinais.

Local Loop Unbundling.

Local Point-Multipoint Distribution Service.

Low-Power FM stations (Rádios Comunitárias).

Loudness Rating Guard-Ring Position.

Long Run Incremental Costs (Custos Incrementais de Longo Prazo) (Serviço Telefônico Fixo Comutado).

Laboratório de Sistemas Integráveis da USP.

"Low Smoke and Zero Halogen".

Long Term Evolution.

Lista Telefônica Obrigatória e Gratuita.

Federação Lusófona de Ciências da Comunicação.

Machine to Machine (comunicação entre máquinas).

Metropolitan Area Network.

Memorando de Entendimento - MdE.

Millenium Development Goals (UN Millenium Summit 2000).

Mobile Entertainment Forum.

Mercado Comum do Sul.

Medium Frequency (Média Freqüência).

Sistemas de Comunicações de Implantes Médicos.

Master International Frequency Register (Registro Mestre da UIT).

Valor do Minuto de Tarifação (Serviço Telefônico Fixo Comutado).

Ministério da Infraestrutura (Extinto pela Lei 8.422, de 13/05/1992).

Multichannel Multipoint Distribution Service (Serviço de Distribuição de Sinais Multiponto Multicanal).

Multimedia Message.

Identidade do Serviço Limitado Móvel Marítimo.

Maritime Mobile Service Identity. 
MNO

MOB

MOB-87

MORAN

MOS

MSCID

MT

MVNO

MVPD

NBM

NC

NCL

NCM

NFC

NFST

NGN

NGT

NMI

NOPRED

NPOESS

NRA

NSR

NUDEC

NWA

NWICO

OCC

OCD

OCDE

OECD

OFDM

OFDMA

OIT

OL

$\mathrm{OM}$

OMC

OPGW

OPI

ORB-85
Mobile Network Operator (Operador de Rede Móvel).

Conferência Administrativa Mundial de Radiocomunicações para os serviços móveis.

Conferência Administrativa Mundial de Radiocomunicações para os Serviços Móveis, realizada em 1987.

Modelo Ran Sharing.

Mean Opinion Score (Pontuação Média de Opinião).

Mobile Switching Center Identification.

Linha de distribuição de Média Tensão.

Mobile Virtual Network Operator (Operador de Rede Virtual Móvel).

Multichannel Video Programming Distributors (Provedores de Programação de Vídeo Multicanal).

Nomenclatura Brasileira de Mercadorias.

Noise Criteria.

Nested Context Language (Interatividade do ISDB-T: linguagem do ambiente Ginga-NCL).

Nomenclatura Comum do Mercosul.

Near Field Communications.

Nota Fiscal de Serviço de Telecomunicações.

Next Generation Network.

Norma Geral de Telecomunicações (Ministério das Comunicações).

NetMundial Initiative.

Notificação Preliminar de Desastres - Formulário (Sistema Nacional de Defesa Civil).

National Polar-Orbiting Environmental Satellite System.

National Regulatory Authorities (União Européia).

Nível do Sinal Recebido.

Núcleo Comunitário de Defesa Civil (Sistema Nacional de Defesa Civil).

Nomadic Wireless Access (Aplicação Nomádica).

New World Information and Communication Order.

Organismo de Certificação Credenciado.

Organismo de Certificação Designado.

Organização para Cooperação e Desenvolvimento Econômico.

Organisation for Economic Co-operation and Development (Organização para Cooperação e Desenvolvimento Econômico).

Orthogonal Frequency Division Multiplexing (Multiplexação Ortogonal por Divisão de Freqüência).

Orthogonal Frequency-Division Multiple Access.

Oxidative Induction Time (Tempo de Indução Oxidativa).

Oscilador Local.

Onda Média.

Organização Mundial do Comércio.

Optical Ground Wire (Cabos Pára-raios com Fibras Ópticas).

Oferta Pública de Interconexão.

Conferência Administrativa Mundial de Radiocomunicações para uso da Órbita de Satélites Geoestacionários e o Planejamento dos Serviços Espaciais que a Utilizam, realizada em 1985.

OSA 


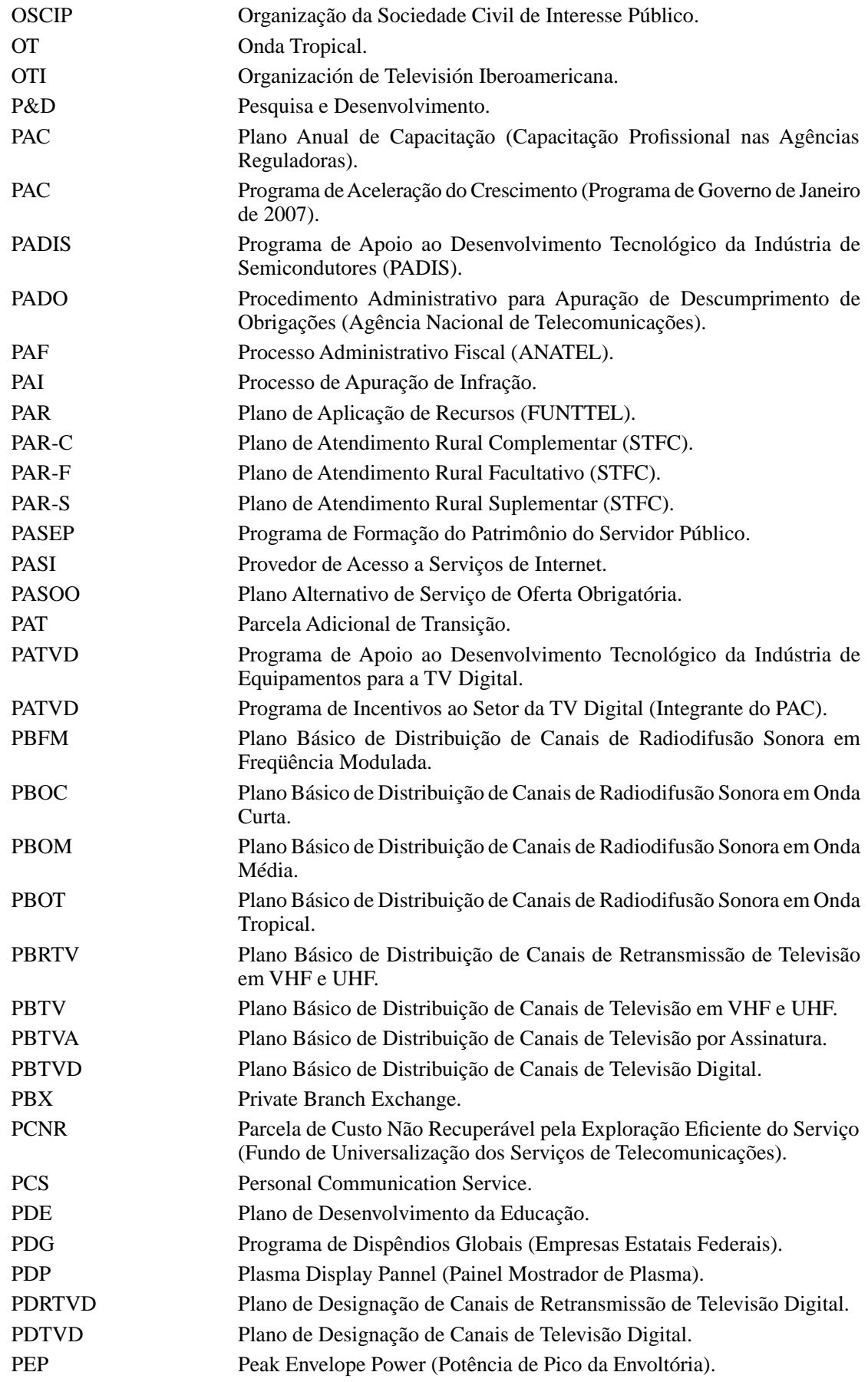


PF

PGA

PGA-SME

PGA-SMP

PGCN

PGMC

PGMQ

PGMQ-2006

PGMQ-SMP

PGMU

PGMU-2006

PGO

PGR

PGRiscos

PICT

PIS

PISP

PLC

PMD

PMM

PMM1

PMM2

PMS

PMT

PNBL

POI

POP

POSIC/Anatel

PP

PPA

PPB

PPDESS

PPDF

PPDUR

ppm

PPP

PR

PRB

PRF

PRO-REG
Procuradoria Federal no Estado.

Plano Geral de Autorizações.

Plano Geral de Autorizações do Serviço Móvel Especializado.

Plano Geral de Autorizações do Serviço Móvel Pessoal.

Plano Geral de Códigos Nacionais.

Plano Geral de Metas de Competição.

Plano Geral de Metas de Qualidade.

Plano Geral de Metas de Qualidade do STFC para a Renovação dos Contratos de Concessão.

Plano Geral de Metas de Qualidade para o Serviço Móvel Pessoal.

Plano Geral de Metas de Universalização.

Plano Geral de Metas para Universalização do STFC no Regime Público para a Renovação dos Contratos de Concessão.

Plano Geral de Outorgas.

Plano Geral de Atualização da Regulamentação das Telecomunicações no Brasil.

Plano de Gestão de Riscos.

Projeto de Proteção da Infraestrutura Crítica de Telecomunicações (Anatel e CPqD).

Programa de Integração Social.

Plano de Indenização por Serviços Prestados (Telebras).

Power Line Communications.

Polarization Mode Dispersion (Modo de Polarização por Dispersão) (Cabo de Fibra Óptica).

Período de Maior Movimento (Televisão por Assinatura (Gênero)).

Período de Maior Movimento diurno, das $9 \mathrm{~h}$ às $11 \mathrm{~h}$ (STFC).

Período de Maior Movimento noturno, das 20h às 22h (STFC).

Poder de Mercado Significativo.

Período de Maior Tráfego (PMT).

Programa Nacional de Banda Larga.

Ponto de Interconexão.

Post Office Protocol (INTERNET).

Política de Segurança da Informação e Comunicações da ANATEL.

Conferência de Plenipotenciários da UIT.

Plano Plurianual.

Processo Produtivo Básico.

Preço Público pelo Direito de Exploração de Serviços de Telecomunicações e pelo Direito de Exploração de Satélite.

Previsão de Demanda e Dados Físicos (Separação e Alocação de Contas).

Preço Público pelo Direito de Uso de Radiofreqüencias.

partes por milhão.

Parceria Público-Privada.

Perda de Retorno.

Ponto de Referência da Boca.

Procuradoria Regional Federal.

Programa de Fortalecimento da Capacidade Institucional para Gestão em Regulação. 


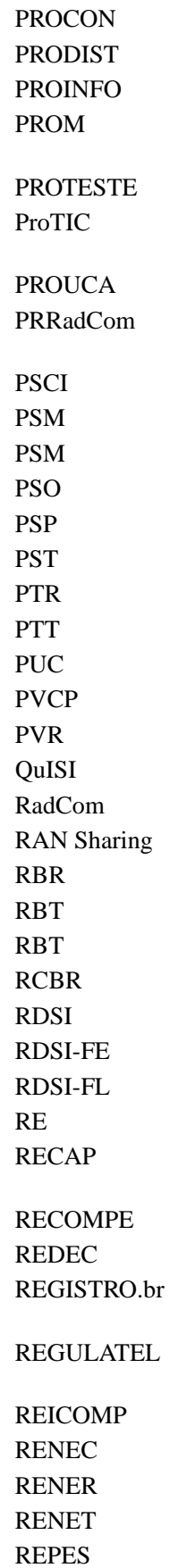

Promotoria de Defesa do Consumidor.

PRODIST - Procedimentos de Distribuição (Energia Elétrica).

Programa Nacional de Informática na Educação.

Plano Regional de Distribuição de Canais de Radiodifusão Sonora em Onda Média ou Plano do Rio de Janeiro (Radiodifusão Sonora).

Associação Brasileira de Defesa do Consumidor.

Programa de Apoio à Pesquisa, Desenvolvimento e Inovação em Tecnologias Digitais de Informação e Comunicação.

Programa Um Computador por Aluno.

Plano de Referência para Distribuição de Canais do Serviço de Radiodifusão Comunitária.

Provedor de Serviço de Conexão à INTERNET.

Posto de Multifacilidades.

Posto de Serviço Multifacilidades.

Procedimento Simplificado de Outorga.

Potência de Saída da Portadora.

Posto de Serviço de Telecomunicações.

Ponto de Terminação de Rede.

Ponto de Troca de Tráfego (Internet).

Prestação, Utilidade ou Comodidade (Serviço Telefônico Fixo Comutado).

Gerência Geral de Comunicações Pessoais Terrestres (ANATEL).

Personal Video Recorder.

Índice Qualcomm da Sociedade da Inovação.

Serviço de Radiodifusão Comunitária.

Radio Access Network Sharing.

Relação de Bens Reversíveis.

Rede Brasil de Tecnologia.

Rede de distribuição de Baixa Tensão.

Regulamento de Controle de Bens Reversíveis.

Rede Digital de Serviços Integrados.

Rede Digital de Serviços Integrados - Faixa Estreita.

Rede Digital de Serviços Integrados - Faixa Larga.

Recurso Extraordinário.

Regime Especial de Aquisição de Bens de Capital para Empresas Exportadoras.

Regime Especial de Aquisição de Computadores para Uso Educacional.

Regional Estadual de Defesa Civil (Sistema Nacional de Defesa Civil).

Registro de Domínios para a Internet no Brasil (Comitê Gestor da Internet no Brasil).

Foro Latino-Americano de Autoridades Reguladoras das Telecomunicações.

Regime Especial de Incentivo a Computadores para Uso Educacional.

Rede Nacional de Estações Costeiras.

Rede Nacional de Emergência de Radioamadores.

Rede Nacional de Emergência de Prestadoras de Telecomunicações.

Regime Especial de Tributação para a Plataforma de Exportação de Serviços de Tecnologia da Informação. 
REPNBL-Redes

REsp

RF

RF

RFID

RGC

RGP

RGQ-SCM

RGQ-SMP

RIQ

RITU

RLL

RMT

RNI

RNP

RNR

ROL

RPF

RpTV

RR

RRD

RRV-SMP

RSAC

RSQ

RTAC

RTFM

RTV

RTVA

RTVC

RTVD

RTVD

RTVE

RTVI

RUE

RUER

RVU-M

SA

SAC
Regime Especial de Tributação do Programa Nacional de Banda Larga para Implantação de Redes de Telecomunicações.

Recurso Especial.

Radiofrequência.

Radiofrequência (Campo Eletromagnético).

Radio Frequency Identification Device (Sistema de Identificação por Radiofreqüência).

Regulamento Geral de Direitos do Consumidor de Serviços de Telecomunicações.

Regulamento Geral de Portabilidade.

Regulamento de Gestão da Qualidade do Serviço de Comunicação Multimídia.

Regulamento de Gestão da Qualidade da Prestação do Serviço Móvel Pessoal.

Regulamento de Indicadores de Qualidade do Serviço Telefônico Fixo Comutado.

Rede de Intercâmbio de Televisão Universitária.

Radio in the Local Loop.

Rede de distribuição de Média Tensão.

Radiação Não Ionizante (Campo Eletromagnético).

Rede Nacional de Pesquisa.

Rede Nacional de Radiovideometria.

Receita Operacional Líquida.

Request for Proposal.

Serviço de Repetição de Televisão.

Regulamento de Radiocomunicações da UIT.

Restricted Radiation Device.

SMP por meio de Rede Virtual.

Regulamento de Separação e Alocação de Contas.

Raiz quadrada da soma dos quadrados.

Regulamento de Celebração e Acompanhamento de Termo de Compromisso de Ajustamento de Conduta.

Regulamento Técnico para Emissoras de Radiodifusão Sonora em Frequência Modulada.

Serviço de Retransmissão de Televisão.

Serviço de Retransmissão de Televisão com utilização de tecnologia analógica.

Serviço de RTV Comercial.

Retransmissão de Televisão com Utilização da Tecnologia Digital.

Serviço de Retransmissão de Televisão com utilização de tecnologia digital.

Serviço de RTV Educativo.

Serviço de RTV Institucional.

Regulamento de Uso do Espectro.

Regulamento de Uso do Espectro de Radiofrequências.

Valor de Referência de VU-M.

Specific Absorption (Absorção Específica).

Serviço de Atendimento ao Consumidor. 
SAC

SACP

SAM

SAMU

SAP

SAPN

SAR

SARC

SART

SATVA

SBC

SBPJOR

SBRD

SBTVD

SBTVD-T

SCI

SCM

SCMa

SCR

SDE

SDK

SDN

SDR

$\mathrm{SeAC}$

SEAE

SECEX

SEDH

SEFID

SEI

SELIC

SER

SERDS

SET

SETA

SFS

SGAL

SGB

SGB

SGDC

SGIQ

SGME

SGT.1
Stand Alone Cost (Custo Total Individual - Separação e Alocação de Contas).

Sistema de Acompanhamento de Consulta Pública.

Serviço Avançado de Mensagens.

Serviço de Atendimento Móvel de Urgência.

Secondary Audio Programming (Programa Secundário de Áudio).

Sistema de Administração dos Recursos de Numeração.

Specific Absorption Rate (Taxa de Absorção Específica).

Serviço Auxiliar de Radiodifusão e Correlatos.

Transponder de busca e salvamento.

Sistema de Acompanhamento das Obrigações das Prestadoras de TV por Assinatura.

Sistema Brasileiro de Certificação.

Sociedade Brasileira de Pesquisadores em Jornalismo.

Sistema Brasileiro de Rádio Digital.

Sistema Brasileiro de Televisão Digital.

Sistema Brasileiro de Televisão Digital Terrestre.

Serviço de Conexão à INTERNET.

Serviço de Comunicação Multimídia.

Serviço de Comunicação de Massa por assinatura.

Serviço de Comunicações de Interesse Restrito.

Secretaria de Direito Econômico (Ministério da Justiça).

Software Development Kit.

Software Defined Networking.

Rádios Definidos por Software.

Serviço de Acesso Condicionado.

Secretaria de Acompanhamento Econômico (Ministério da Fazenda).

Secretaria de Controle Externo (Tribunal de Contas da União).

Secretaria Especial de Direitos Humanos da Presidência da República.

Secretaria de Fiscalização de Desestatização (Tribunal de Contas da União).

Sistema Eletrônico de Informações (Ministério das Comunicações).

Sistema Especial de Liquidação e Custódia.

Serviço Especial de Radiochamada, Regime Regulatório.

Serviço Especial de Radiodeterminação por Satélite.

Sociedade Brasileira de Engenharia de Televisão.

Sindicato Nacional das Empresas Operadoras de Sistemas de Televisão por Assinatura (Representação empresarial).

Serviço Fixo por Satélite.

Sistema de Gerenciamento de Áreas Locais.

Sistema Geodésico Brasileiro.

Sistema Geoestacionário Brasileiro.

Satélite Geoestacionário de Defesa e Comunicações Estratégicas.

Sistema de Gerenciamento de Indicadores de Qualidade.

Sistema de Gestão e Monitoragem do Espectro.

Subgrupo de Trabalho $\mathrm{n}^{\circ} 1$ - Comunicações do Mercosul. 


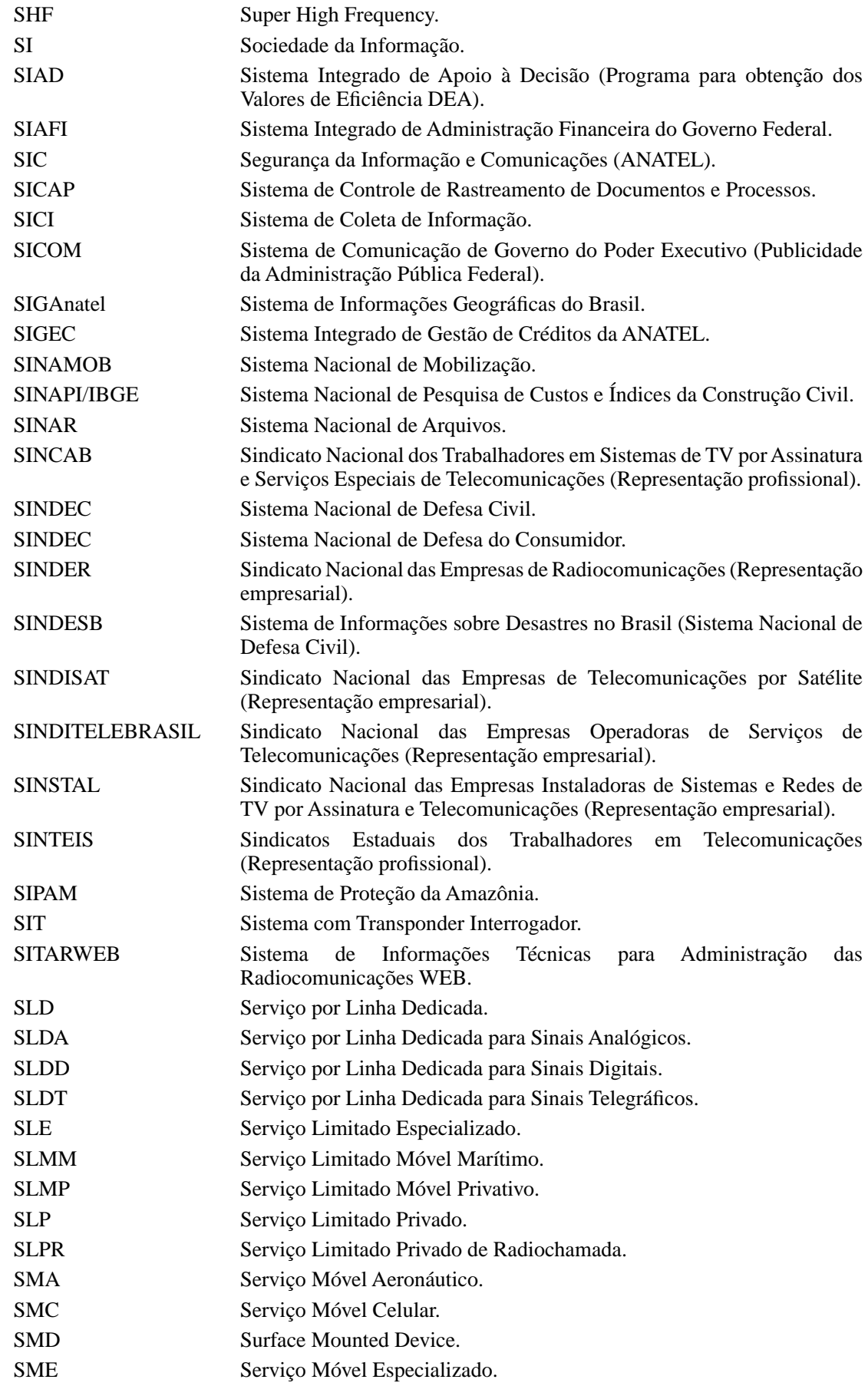


SMGS

SMM

SMP

SMS

SMS

SMT

SNC

SNOA

Socicom

SOCINE

SOR

SORM

SPV

SRA

SRC

SRD

SRD

SRE

SRS

SRT

SRTT

SSB

STE

STEL

STF

STFC

STJ

STM

STP

STS

SUDAM

SUDECO

SUFRAMA

SVA

TAB

TAC

TAC

TAP

TAP

TAP

TBSMC

TCD

TCP
Serviço Móvel Global por Satélite.

Serviço Móvel Marítimo.

Serviço Móvel Pessoal.

Serviço Móvel por Satélite.

Short Message Service.

Surface Mounted Technology.

Secretaria Nacional de Comunicações (MINFRA).

Sistema de Negociação das Ofertas de Atacado (PGMC).

Federação Brasileira das Associações Científicas e Acadêmicas de Comunicação.

Sociedade Brasileira de Estudos de Cinema.

Superintendência de Outorga e Recursos à Prestação (ANATEL).

System of Operative-Investigative Measures (sistema russo de interceptação legal de comunicações eletrônicas).

Superintendência de Serviços Privados.

Serviço de Radiocomunicação Aeronáutica Público-Restrito.

Superintendência de Relações com Consumidores.

Short Range Device.

Sistema de Controle de Radiodifusão.

Serviço de Radiotáxi Especializado, Regime Regulatório.

Serviço de Pesquisa Espacial.

Serviço de Radiotáxi.

Serviço de Rede de Transporte de Telecomunicações.

Single Side Band 'Modulation' (Modulação em Faixa Lateral Simples).

Secretaria de Telecomunicações (Ministério das Comunicações).

Sistema de Serviços de Telecomunicações.

Supremo Tribunal Federal.

Serviço Telefônico Fixo Comutado Destinado ao Uso do Público em Geral.

Superior Tribunal de Justiça.

Superior Tribunal Militar.

Serviço Telefônico Público (em desuso).

Serviço de Transporte de Sinais de Telecomunicações por Satélite.

Superintendencia de Desenvolvimento da Amazônia.

Superintendência de Desenvolvimento do Centro-Oeste.

Superintendência da Zona Franca de Manaus.

Serviço de Valor Adicionado.

Tarifa Aduaneira do Brasil.

Termo de Ajuste de Conduta.

Termo de Compromisso de Ajustamento de Conduta.

Television Association of Programmers (Estados Unidos da América).

Terminal de Acesso Público.

Terminal de Acesso Público (Serviço Telefônico Fixo Comutado).

Tarifa Básica do Serviço Móvel Celular.

Termo de Compromisso de Desempenho.

Transport Control Protocol (INTERNET). 
TCU

TDD

TDMA

TEB

TEC

TelComp

TELEBRAS

TELEBRASIL

TELEX

TFDR

TFEL

TFF

TFI

THD

TIC

TIPI

TISA

TIV

TMC

TME

TMN

TOE

TR

TRASA

TRD

TRF

TRF1

TRI

TRX

TSC

TSC

TSE

TST

TT

TU

TU-COM

TU-M

TU-RIU

TU-RIU1

TU-RIU2

TU-RL

TUP
Tribunal de Contas da União.

Time Division Duplexing (Duplexação por Divisão no Tempo).

Time Division Multiple Access (Múltiplo Acesso por Divisão em Tempo).

Taxa de Erro de Bits.

Tarifa Externa Comum.

Associação Brasileira das Prestadoras de Serviços de Telecomunicações Competitivas.

Telecomunicações Brasileiras S.A..

Associação Brasileira de Telecomunicações.

Comutação Telegráfica.

Taxa de Licenciamento para Uso ou Ocupação das Faixas de Domínio das Rodovias (TFDR).

Thin-Film Electroluminescent (Displays Eletroluminescentes a Filme Fino).

Taxa de Fiscalização do Funcionamento.

Taxa de Fiscalização da Instalação.

Distorção harmônica total.

Information and Communication Technology.

Tabela de Incidência do Imposto sobre Produtos Industrializados.

Traveller Information Services Association.

Tecnologia de Informação Veicular (Rastreamento de Veículos).

Traffic Message Channel (Canal de Mensagem de Trânsito).

Tarifa de Mudança de Endereço (Serviço Telefônico Fixo Comutado).

Telecommunications Management Network.

Taxa de Onda.

Taxa Referencial.

Telecommunications Regulators' Association of Southern Africa.

Taxa Referencial Diária.

Tribunal Regional Federal.

Tribunal Regional Federal da $1^{a}$ Região.

Termo de Responsabilidade de Instalação.

Transceptor.

Terminal Móvel de Acesso a Ser Certificado.

Terminal Portátil a Ser Certificado.

Tribunal Superior Eleitoral.

Tribunal Superior do Trabalho.

Tronco/Canal Telefônico de Entrada.

Tarifa de Uso (Serviço Telefônico Fixo Comutado).

Tarifa de Uso de Comutação (Serviço Telefônico Fixo Comutado).

Tarifa de Uso Móvel.

Tarifa de Uso de Rede Interurbana.

Tarifa de Uso de Rede Interurbana Nível 1 (Serviço Telefônico Fixo Comutado)

Tarifa de Uso de Rede Interurbana Nível 2.

Tarifa de Uso de Rede Local.

Telefone de Uso Público. 
TUP

TVA

TVA

TVC

Tve

TVRO

UAC

UCS

UHDTV

UHF

UIT

UIT-R

UIT-R-SA

ULEPICC

UMB

UMTS

UNE-P

UNICEF

UO

UPS

UR

URA

URA

URA

URD

URV

USG

USSD

UTP

UTRAN

UWB

UWIA

VBI

VC

VC-1

VC-2

VC-3

VC-T

VC-VST-R

$\mathrm{VC} 1$

VCA
Telefone de Uso Público (Serviço Telefônico Fixo Comutado).

Serviço Especial de Televisão por Assinatura.

Televisão por Assinatura (Espécie de Serviço Especial).

TV a Cabo.

Televisão Educativa.

Television Receive Only (TV aberta recebida por satélite, via antena parabólica).

Unidade de Atendimento de Cooperativa.

Unidade de Controle do Sistema (Sistemas de Acesso sem Fio do STFC).

Ultra High Definition Television (Radiodifusão 8K).

Ultra High Frequency (Frequiência Ultra Alta).

União Internacional de Telecomunicações (Union Internationale des Télécommunications / Unión Internacional de Telecommunicaciones).

Setor de Radiocomunicações da União Internacional de Telecomunicações.

Recomendações da UIT sobre Aplicações Espaciais e Meteorologia.

Unión Latina de Economía Política de la Información, la Comunicación y la Cultura.

Ultra Mobile Broadband.

Universal Mobile Telecommunications Service (Rede celular 3G).

Desagregação de Plataforma.

United Nations Children's Fund (Fundo das Nações Unidas para a Infância).

Unidade Operacional.

Uninterruptable Power Supply.

Unidade Retificadora.

Unidade de Resposta Audível (SMP - Gestão da Qualidade).

Unidade de Resposta Automática.

Unidade Remota de Assinante.

Unidade Receptora Decodificadora (Serviço de Acesso Condicionado).

Unidade Real de Valor.

Unidade de Supervisão e Gerência (Sistemas de Acesso sem Fio do STFC).

Unstructured Supplementary Service Data (Redes Móveis).

Unidade de Tarifação para TUP e TAP (Serviço Telefônico Fixo Comutado).

Universal Terrestrial Radio Access Network.

Ultrawideband.

Ubiquitous Wireless Internet Access.

Vertical Blanking Interval (Intervalo de Apagamento Vertical).

Valor de Comunicação (Serviço Telefônico Fixo Comutado).

Valor de Comunicação 1.

Valor de Comunicação 2.

Valor de Comunicação 3.

Valor de Comunicação (Serviço Móvel Especializado).

Valor de Comunicação do Visitante em Roaming.

Valor de Comunicação 1 (Serviço Móvel Pessoal).

Valor de Chamada Atendida (Serviço Telefônico Fixo Comutado). 
VELOX

VHF

VIGP

VLF

VM

VMA

VMA

VPA

Vpe

VR

VSAT

VSAT

VSWR

VTP

VU-M

VU-M

VU-T

WACC

WAN

WAP

WATRA

WCDMA

WDM

WDMA

Wi-Fi

WIMAX

WiMesh

WISP

WLAN

WLL

WMAN

WP5D

WSIS

WTPF-09

WTPF-09

xDSL

XPD

XPOL

$\theta$ ini
Serviço de acesso à internet de banda larga comercializado pela empresa Oi.

Very High Frequency (Frequiência Muito Alta).

Variação do Índice Geral de Preços - Disponibilidade Interna.

Very Low Frequency.

Valor da Multa (Radiodifusão - Regulamento de Sanções Administrativas).

Valor de Uso de Meio Adicional (STFC fora da Área de Tarifa Básica).

Valor de Utilização de Meios Adicionais.

Valor Patrimonial da Ação.

Volt por elemento.

Valor de Referência (Radiodifusão - Regulamento de Sanções Administrativas).

Estação Terrena de Pequeno Porte.

Very Small Aperture Terminal (Certificação).

Relação de Onda Estacionária.

Valor da Unidade de Tarifação para TUP e TAP (Serviço Telefônico Fixo Comutado).

Valor de Remuneração de Uso de Rede do SMP.

Valor de Uso de Rede Móvel.

Valor de Remuneração de Uso de Rede do SME.

Weighted Average Cost of Capital (Custo Médio Ponderado de Capital na Separação e Alocação de Contas).

Wide Area Network.

Wireless Application Protocol.

West Africa Telecommunications Regulators Assembly.

Wideband CDMA (CDMA de banda larga).

Wavelength Division Multiplexing (Multiplexação por Divisão de Comprimento de Onda).

Wavelegth Division Multiple Access (Acesso Múltiplo por Divisão de Comprimento de Onda).

Wireless Fidelity (padrão IEEE 802.11).

Worldwide Interoperability for Microwave Access.

WiMesh - Wireless Mesh.

Wireless Internet Service Provider.

Wireless Local Area Network.

Wireless Local Loop (Rede Local sem Fio).

Wireless Metropolitan Area Network.

Working Party 5D (Grupo de trabalho da UIT-R responsável pelo IMT).

World Summit on the Information Society (Cúpula Mundial sobre a Sociedade da Informação - CMSI).

Fórum Mundial sobre Políticas de Telecomunicações.

World Telecommunication Policy Forum.

$\mathrm{x}$ Digital Subscriber Line.

Cross Polarization Discrimination.

Polarização Cruzada.

Ângulo Teta Inicial. 


\title{
Normas e Atos de 2015
}

\section{Fundamentos}

\section{Aspectos Históricos}

\author{
Atos
}

Relatório da Ouvidoria da ANATEL 2015

\section{Conceitos Fundamentais}

\section{Jurisprudência}

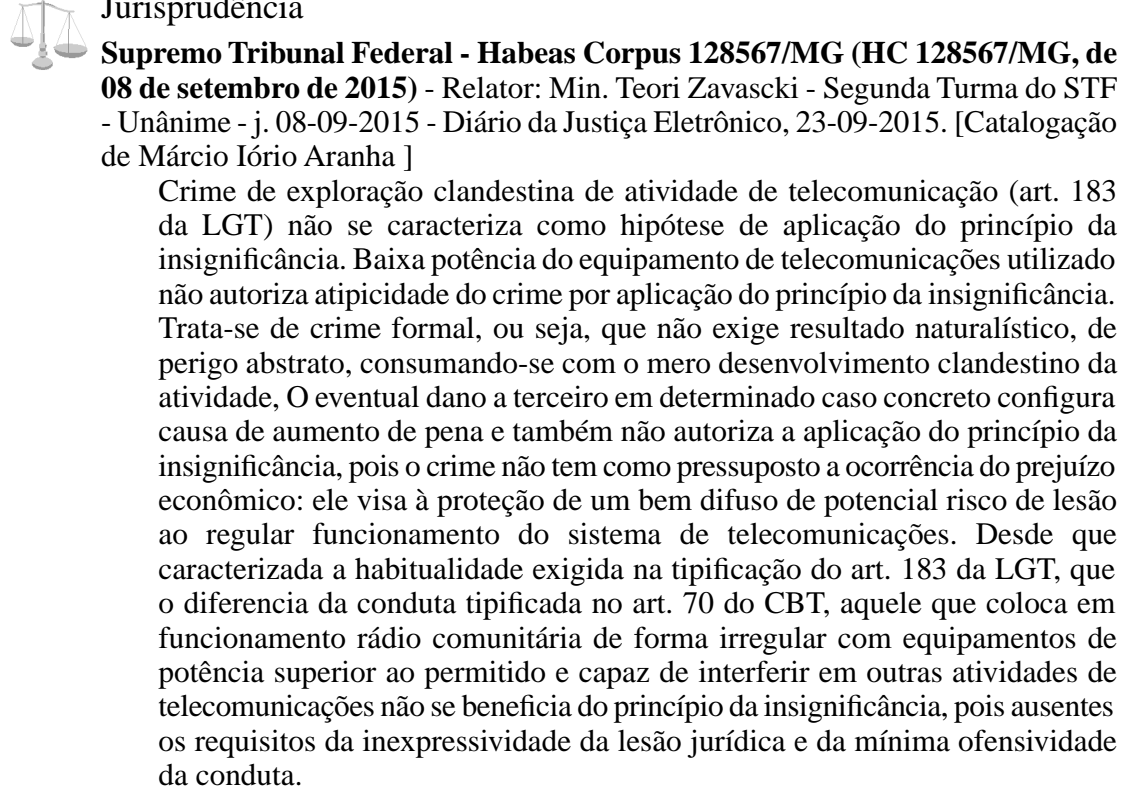

\section{Era da Informação}

\section{Jurisprudência}

Superior Tribunal de Justiça - Agravo Regimental no Recurso Especial $\mathbf{n}^{\mathbf{0}}$ 1384340 (STJ - RESP 1384340 AgRg/DF - Distrito Federal) - Relator: Min. Paulo de Tarso Sanseverino - Terceira Turma do STJ - Unânime - j. 05-05-2015 Diário da Justiça Eletrônico, 12-05-2015. [Catalogação de Márcio Iório Aranha ] O Marco Civil da Internet ( Lei 12.965/2014) não se aplica a fatos pretéritos a sua edição. Comentário ofensivo postado no ORKUT é de responsabilidade do provedor de hospedagem devidamente notificado que não providenciou a identificação do IP do autor da defesa, mesmo que a impossibilidade de identificação do ofensor resulte de caso fortuito ou força maior ocorridos durante o atraso na identificação do IP do autor da ofensa. 


\section{Normatização}

Lei no 13.146, de 6 de julho de 2015 - Institui a Lei Brasileira de Inclusão da Pessoa com Deficiência (Estatuto da Pessoa com Deficiência)

$\checkmark$ Exigência de obrigatória acessibilidade nos sítios da internet mantidos por empresas com sede ou representação comercial no País ou por órgãos de governo, para uso por pessoa com deficiência.

\section{Liberdade de Expressão}

Jurisprudência

Superior Tribunal de Justiça - Agravo Regimental no Recurso Especial $\mathbf{n}^{\circ}$ 1384340 (STJ - RESP 1384340 AgRg/DF - Distrito Federal) - Relator: Min. Paulo de Tarso Sanseverino - Terceira Turma do STJ - Unânime - j. 05-05-2015 Diário da Justiça Eletrônico, 12-05-2015. [Catalogação de Márcio Iório Aranha ] O Marco Civil da Internet ( Lei 12.965/2014) não se aplica a fatos pretéritos a sua edição. Comentário ofensivo postado no ORKUT é de responsabilidade do provedor de hospedagem devidamente notificado que não providenciou a identificação do IP do autor da defesa, mesmo que a impossibilidade de identificação do ofensor resulte de caso fortuito ou força maior ocorridos durante o atraso na identificação do IP do autor da ofensa.

\section{Normatização}

Lei $\mathbf{n}^{\circ}$ 13.188, de 11 de novembro de 2015 - Dispõe sobre o direito de resposta ou retificação do ofendido em matéria divulgada, publicada ou transmitida por veículo de comunicação social

\section{Direito à Privacidade}

Tema Conexo: Políticas de Telecomunicações : Sigilo em Telecomunicações.

\section{Normatização}

Lei no 13.129, de 26 de maio de 2015 - Altera a Lei no 9.307, de 23 de setembro de 1996, e a Lei no 6.404, de 15 de dezembro de 1976, para ampliar o âmbito de aplicação da arbitragem e dispor sobre a escolha dos árbitros quando as partes recorrem a órgão arbitral, a interrupção da prescrição pela instituição da arbitragem, a concessão de tutelas cautelares e de urgência nos casos de arbitragem, a carta arbitral e a sentença arbitral, e revoga dispositivos da Lei no 9.307, de 23 de setembro de 1996.

$\boldsymbol{V}$ A arbitragem que envolva a administração pública respeita o princípio da publicidade.

Lei $\mathbf{n}^{\mathbf{0}}$ 13.188, de 11 de novembro de 2015 - Dispõe sobre o direito de resposta ou retificação do ofendido em matéria divulgada, publicada ou transmitida por veículo de comunicação social

\section{Infraestrutura e Recursos do Setor de Telecomunicações}

\section{Normatização}

Resolução da ANATEL n $^{\circ}$ 655, de 5 de Agosto de 2015 - Aprova o Regulamento do Acompanhamento de Compromissos de Aquisição de Produtos e Sistemas 
Nacionais e estabelece regras específicas para o cumprimento do Compromisso de Aquisição de Produtos de Tecnologia Nacional

$\Rightarrow$ Anexo - Regulamento do Acompanhamento de Compromissos de Aquisição de Produtos e Sistemas Nacionais

\section{Infraestrutura de Telecomunicações}

\section{Normatização}

Lei $\mathbf{n}^{\circ}$ 13.116, de 20 de abril de 2015 - (Lei Geral das Antenas) Estabelece normas gerais para implantação e compartilhamento da infraestrutura de telecomunicações e altera as Leis nos 9.472, de 16 de julho de 1997, 11.934, de 5 de maio de 2009, e 10.257, de 10 de julho de 2001.

$\checkmark$ Exclusiva competência da União sobre a regulamentação e a fiscalização de aspectos técnicos das redes e dos serviços de telecomunicações, inclusive sobre seleção de tecnologia, topologia das redes e qualidade dos serviços prestados.

\section{Compartilhamento de Infraestrutura}

\section{Normatização}

Lei $\mathbf{n}^{\mathbf{0}}$ 13.116, de 20 de abril de 2015 - (Lei Geral das Antenas) Estabelece normas gerais para implantação e compartilhamento da infraestrutura de telecomunicações e altera as Leis nos 9.472, de 16 de julho de 1997, 11.934, de 5 de maio de 2009, e 10.257 , de 10 de julho de 2001 .

$\checkmark$ Obrigatoriedade do compartilhamento de infraestrutura da capacidade excedente da infraestrutura de suporte, exceto justificado motivo técnico e respeitado o patrimônio urbanístico, histórico, cultural, turístico e paisagístico.

\section{Bem Público (utilização e restrição)}

\section{Normatização}

Lei n⿳ 13.116, de 20 de abril de 2015 - (Lei Geral das Antenas) Estabelece normas gerais para implantação e compartilhamento da infraestrutura de telecomunicações e altera as Leis nos 9.472, de 16 de julho de 1997, 11.934, de 5 de maio de 2009, e 10.257, de 10 de julho de 2001.

Resolução da ANATEL $\mathbf{n}^{\circ}$ 660, de 28 de dezembro de 2015 - Altera o Regulamento do Preço Público Relativo à Administração dos Recursos de Numeração, aprovado pela Resolução n ${ }^{\circ} 451$, de 8 de dezembro de 2006

\section{Redes de Telecomunicações}

\section{Normatização}

Lei n⿳ 13.116, de 20 de abril de 2015 - (Lei Geral das Antenas) Estabelece normas gerais para implantação e compartilhamento da infraestrutura de telecomunicações e altera as Leis nos 9.472, de 16 de julho de 1997, 11.934, de 5 de maio de 2009, e 10.257 , de 10 de julho de 2001.

$\checkmark$ Exclusiva competência da União sobre a regulamentação e a fiscalização de aspectos técnicos das redes e dos serviços de telecomunicações, inclusive sobre seleção de tecnologia, topologia das redes e qualidade dos serviços prestados. 


\section{Interconexão}

Atos

Acórdão do Conselho Diretor da ANATEL, de 5 de novembro de 2015 (Ref. $n^{\circ}$ 480/2015) - É ilícito o incentivo à realização de acessos discados à internet em horário de tarifa reduzida sob a promessa de que os usuários de STFC sejam remunerados pelo tempo de conexão ao provedor de acesso à internet, caracterizando a conduta prevista no art. 29 do Regulamento Geral de Interconexão, aprovado pela Resolução $n^{\circ} 410 / 2015$, de uso indevido das rotas de interconexão para cursar tráfego artificialmente gerado além do "estritamente necessário à prestação do serviço" (art. 152 da LGT), bem como é possível a imposição de determinação administrativa de interrupção de tráfego, ou bloqueio de interconexão, para correção da conduta e devolução de valores pagos a mais, independentemente de ampla defesa e contraditório, por se tratar de ato de ofício da ANATEL para coibir conduta ilícita de regulado.

\section{Numeração dos Serviços}

\section{Normatização}

Resolução da ANATEL $\mathbf{n}^{\circ}$ 660, de 28 de dezembro de 2015 - Altera o Regulamento do Preço Público Relativo à Administração dos Recursos de Numeração, aprovado pela Resolução n ${ }^{\circ}$ 451, de 8 de dezembro de 2006

\section{Equipamentos de Telecomunicações}

\section{Antenas}

\section{Normatização}

Lei $n^{0}$ 13.097, de 19 de janeiro de 2015 - Reduz a zero as alíquotas da Contribuição para o PIS/PASEP, da COFINS, da Contribuição para o PIS/Pasep-Importação e da Cofins-Importação incidentes sobre a receita de vendas e na importação de partes utilizadas em aerogeradores; prorroga os benefícios previstos nas Leis nos 9.250, de 26 de dezembro de 1995, 9.440, de 14 de março de 1997, 10.931, de 2 de agosto de 2004, 11.196, de 21 de novembro de 2005, 12.024, de 27 de agosto de 2009, e 12.375, de 30 de dezembro de 2010; altera o art. 46 da Lei no12.715, de 17 de setembro de 2012, que dispõe sobre a devolução ao exterior ou a destruição de mercadoria estrangeira cuja importação não seja autorizada; altera as Leis nos 9.430, de 27 de dezembro de 1996, 12.546, de 14 de dezembro de 2011, 12.973, de 13 de maio de 2014, 9.826, de 23 de agosto de 1999, 10.833, de 29 de dezembro de 2003, 10.865, de 30 de abril de 2004, 11.051, de 29 de dezembro de 2004, 11.774, de 17 de setembro de 2008, 10.637, de 30 de dezembro de 2002, 12.249, de 11 de junho de 2010,10.522, de 19 de julho de 2002, 12.865, de 9 de outubro de 2013, 10.820, de 17 de dezembro de 2003, 6.634, de 2 de maio de 1979, 7.433, de 18 de dezembro de 1985, 11.977, de 7 de julho de 2009, 10.931, de 2 de agosto de 2004, 11.076, de 30 de dezembro de 2004, 9.514, de 20 de novembro de 1997, 9.427, de 26 de dezembro de 1996, 9.074, de 7 de julho de 1995, 12.783, de 11 de janeiro de 2013, 11.943, de 28 de maio de 2009, 10.848, de 15 de março de 2004, 7.565, de 19 de dezembro de 1986, 12.462, de 4 de agosto de 2011, 9.503, de 23 de setembro de 1997, 11.442, de 5 de janeiro de 2007, 8.666, de 21 de junho de 1993, 9.782, de 26 de janeiro de 1999, 6.360, de 23 de setembro de 1976, 5.991, de 17 de dezembro de 1973, 12.850, de 2 de agosto de 2013, 5.070, de 7 de julho 
de $1966,9.472$, de 16 de julho de 1997, 10.480, de 2 de julho de 2002, 8.112, de 11 de dezembro de 1990, 6.530, de 12 de maio de 1978, 5.764, de 16 de dezembro de 1971, 8.080, de 19 de setembro de 1990, 11.079, de 30 de dezembro de 2004, 13.043, de 13 de novembro de 2014, 8.987, de 13 de fevereiro de 1995, 10.925, de 23 de julho de 2004, 12.096, de 24 de novembro de 2009, 11.482, de 31 de maio de 2007, 7.713, de 22 de dezembro de 1988, a Lei Complementar no 123, de 14 de dezembro de 2006, o Decreto-Lei no 745, de 7 de agosto de 1969, e o Decreto no 70.235, de 6 de março de 1972; revoga dispositivos das Leis nos 4.380, de 21 de agosto de 1964, 6.360, de 23 de setembro de 1976, 7.789, de 23 de novembro de $1989,8.666$, de 21 de junho de 1993, 9.782, de 26 de janeiro de 1999, 10.150, de 21 de dezembro de 2000, 9.430, de 27 de dezembro de 1996, 12.973, de 13 de maio de 2014, 8.177, de 1 o de março de 1991, 10.637, de 30 de dezembro de 2002, 10.833, de 29 de dezembro de 2003, 10.865, de 30 de abril de 2004, 11.051, de 29 de dezembro de 2004 e 9.514, de 20 de novembro de 1997, e do Decreto-Lei no 3.365 , de 21 de junho de 1941; e dá outras providências.

$\checkmark$ Isenta do pagamento das Taxas de Fiscalização de Instalação e de Funcionamento de estações de telecomunicações as estações rádio base, e repetidoras, de baixa potência dos serviços de telecomunicações de interesse coletivo cuja potência de pico máxima, medida na saída do transmissor, não seja superior a $5 \mathrm{~W}$ e $10 \mathrm{~W}$ sofrerão a cobrança de $10 \%$ dos valores de taxas de fiscalização de instalação aplicáveis às demais estações rádio base.

Lei n⿳ 13.116, de 20 de abril de 2015 - (Lei Geral das Antenas) Estabelece normas gerais para implantação e compartilhamento da infraestrutura de telecomunicações e altera as Leis nos 9.472, de 16 de julho de 1997, 11.934, de 5 de maio de 2009, e 10.257 , de 10 de julho de 2001 .

\section{Estações de Telecomunicações}

\section{Normatização}

Lei $n^{0}$ 13.097, de 19 de janeiro de 2015 - Reduz a zero as alíquotas da Contribuição para o PIS/PASEP, da COFINS, da Contribuição para o PIS/Pasep-Importação e da Cofins-Importação incidentes sobre a receita de vendas e na importação de partes utilizadas em aerogeradores; prorroga os benefícios previstos nas Leis nos 9.250, de 26 de dezembro de 1995, 9.440, de 14 de março de 1997, 10.931, de 2 de agosto de 2004, 11.196, de 21 de novembro de 2005, 12.024, de 27 de agosto de 2009, e 12.375, de 30 de dezembro de 2010; altera o art. 46 da Lei no12.715, de 17 de setembro de 2012, que dispõe sobre a devolução ao exterior ou a destruição de mercadoria estrangeira cuja importação não seja autorizada; altera as Leis nos 9.430, de 27 de dezembro de 1996, 12.546, de 14 de dezembro de 2011, 12.973, de 13 de maio de 2014, 9.826 , de 23 de agosto de 1999, 10.833, de 29 de dezembro de 2003, 10.865, de 30 de abril de 2004, 11.051, de 29 de dezembro de 2004, 11.774, de 17 de setembro de 2008, 10.637, de 30 de dezembro de 2002, 12.249, de 11 de junho de 2010, 10.522, de 19 de julho de 2002, 12.865, de 9 de outubro de 2013, 10.820, de 17 de dezembro de 2003, 6.634, de 2 de maio de 1979, 7.433, de 18 de dezembro de 1985, 11.977, de 7 de julho de 2009, 10.931, de 2 de agosto de 2004, 11.076, de 30 de dezembro de 2004, 9.514, de 20 de novembro de 1997 , 9.427, de 26 de dezembro de 1996, 9.074, de 7 de julho de 1995, 12.783, de 11 de janeiro de 2013, 11.943, de 28 de maio de 2009, 10.848, de 15 de março de 2004, 7.565 , de 19 de dezembro de 1986, 12.462, de 4 de agosto de 2011, 9.503, de 23 de setembro de $1997,11.442$, de 5 de janeiro de $2007,8.666$, de 21 de junho de 1993, 9.782, de 26 de janeiro de 1999, 6.360, de 23 de setembro de 1976, 5.991, de 17 de dezembro de 1973, 12.850, de 2 de agosto de 2013, 5.070, de 7 de julho 
de 1966, 9.472, de 16 de julho de 1997, 10.480, de 2 de julho de 2002, 8.112, de 11 de dezembro de 1990, 6.530, de 12 de maio de 1978, 5.764, de 16 de dezembro de $1971,8.080$, de 19 de setembro de 1990, 11.079, de 30 de dezembro de 2004, 13.043, de 13 de novembro de 2014, 8.987, de 13 de fevereiro de 1995, 10.925, de 23 de julho de 2004, 12.096, de 24 de novembro de 2009, 11.482, de 31 de maio de 2007, 7.713, de 22 de dezembro de 1988, a Lei Complementar no 123, de 14 de dezembro de 2006, o Decreto-Lei no 745, de 7 de agosto de 1969, e o Decreto no 70.235, de 6 de março de 1972; revoga dispositivos das Leis nos 4.380, de 21 de agosto de 1964, 6.360, de 23 de setembro de 1976, 7.789, de 23 de novembro de $1989,8.666$, de 21 de junho de 1993, 9.782, de 26 de janeiro de 1999, 10.150, de 21 de dezembro de 2000, 9.430, de 27 de dezembro de 1996, 12.973, de 13 de maio de 2014, 8.177, de 1 o de março de 1991, 10.637, de 30 de dezembro de 2002, 10.833 , de 29 de dezembro de 2003, 10.865, de 30 de abril de 2004, 11.051, de 29 de dezembro de 2004 e 9.514, de 20 de novembro de 1997, e do Decreto-Lei no 3.365, de 21 de junho de 1941; e dá outras providências.

$\checkmark$ Isenta do pagamento das Taxas de Fiscalização de Instalação e de Funcionamento de estações de telecomunicações as estações rádio base, e repetidoras, de baixa potência dos serviços de telecomunicações de interesse coletivo cuja potência de pico máxima, medida na saída do transmissor, não seja superior a $5 \mathrm{~W}$ e $10 \mathrm{~W}$ sofrerão a cobrança de $10 \%$ dos valores de taxas de fiscalização de instalação aplicáveis às demais estações rádio base.

Lei n⿳ 13.116, de 20 de abril de 2015 - (Lei Geral das Antenas) Estabelece normas gerais para implantação e compartilhamento da infraestrutura de telecomunicações e altera as Leis nos 9.472, de 16 de julho de 1997, 11.934, de 5 de maio de 2009, e 10.257 , de 10 de julho de 2001 .

\section{Terminais}

\section{Normatização}

Lei $\mathbf{n}^{\mathbf{0}}$ 13.097, de 19 de janeiro de 2015 - Reduz a zero as alíquotas da Contribuição para o PIS/PASEP, da COFINS, da Contribuição para o PIS/Pasep-Importação e da Cofins-Importação incidentes sobre a receita de vendas e na importação de partes utilizadas em aerogeradores; prorroga os benefícios previstos nas Leis nos 9.250, de 26 de dezembro de 1995, 9.440, de 14 de março de 1997, 10.931, de 2 de agosto de 2004, 11.196, de 21 de novembro de 2005, 12.024, de 27 de agosto de 2009, e 12.375, de 30 de dezembro de 2010; altera o art. 46 da Lei no12.715, de 17 de setembro de 2012, que dispõe sobre a devolução ao exterior ou a destruição de mercadoria estrangeira cuja importação não seja autorizada; altera as Leis nos 9.430, de 27 de dezembro de 1996, 12.546, de 14 de dezembro de 2011, 12.973, de 13 de maio de 2014, 9.826 , de 23 de agosto de 1999, 10.833, de 29 de dezembro de 2003, 10.865, de 30 de abril de 2004, 11.051, de 29 de dezembro de 2004, 11.774, de 17 de setembro de 2008, 10.637, de 30 de dezembro de 2002, 12.249, de 11 de junho de 2010,10.522, de 19 de julho de 2002, 12.865 , de 9 de outubro de 2013, 10.820, de 17 de dezembro de 2003, 6.634, de 2 de maio de 1979, 7.433, de 18 de dezembro de 1985, 11.977, de 7 de julho de 2009, 10.931, de 2 de agosto de 2004, 11.076, de 30 de dezembro de 2004, 9.514, de 20 de novembro de 1997, 9.427, de 26 de dezembro de 1996, 9.074, de 7 de julho de 1995, 12.783, de 11 de janeiro de 2013, 11.943, de 28 de maio de 2009, 10.848, de 15 de março de 2004, 7.565 , de 19 de dezembro de 1986, 12.462, de 4 de agosto de 2011, 9.503, de 23 de setembro de $1997,11.442$, de 5 de janeiro de $2007,8.666$, de 21 de junho de 1993, 9.782, de 26 de janeiro de 1999, 6.360, de 23 de setembro de 1976, 5.991, de 17 de dezembro de 1973, 12.850, de 2 de agosto de 2013, 5.070, de 7 de julho 
de $1966,9.472$, de 16 de julho de 1997, 10.480, de 2 de julho de 2002, 8.112, de 11 de dezembro de 1990, 6.530, de 12 de maio de 1978, 5.764, de 16 de dezembro de 1971, 8.080, de 19 de setembro de 1990, 11.079, de 30 de dezembro de 2004, 13.043, de 13 de novembro de 2014, 8.987, de 13 de fevereiro de 1995, 10.925, de 23 de julho de 2004, 12.096, de 24 de novembro de 2009, 11.482, de 31 de maio de 2007, 7.713, de 22 de dezembro de 1988, a Lei Complementar no 123, de 14 de dezembro de 2006, o Decreto-Lei no 745, de 7 de agosto de 1969, e o Decreto no 70.235, de 6 de março de 1972; revoga dispositivos das Leis nos 4.380, de 21 de agosto de 1964, 6.360, de 23 de setembro de 1976, 7.789, de 23 de novembro de $1989,8.666$, de 21 de junho de 1993, 9.782, de 26 de janeiro de 1999, 10.150, de 21 de dezembro de 2000, 9.430, de 27 de dezembro de 1996, 12.973, de 13 de maio de 2014, 8.177, de 1 o de março de 1991, 10.637, de 30 de dezembro de 2002, 10.833, de 29 de dezembro de 2003, 10.865, de 30 de abril de 2004, 11.051, de 29 de dezembro de 2004 e 9.514, de 20 de novembro de 1997, e do Decreto-Lei no 3.365 , de 21 de junho de 1941; e dá outras providências.

$\checkmark$ Isenta do pagamento das Taxas de Fiscalização de Instalação e de Funcionamento de estações de telecomunicações as estações rádio base, e repetidoras, de baixa potência dos serviços de telecomunicações de interesse coletivo cuja potência de pico máxima, medida na saída do transmissor, não seja superior a $5 \mathrm{~W}$ e $10 \mathrm{~W}$ sofrerão a cobrança de $10 \%$ dos valores de taxas de fiscalização de instalação aplicáveis às demais estações rádio base.

Lei $\mathbf{n}^{\mathbf{0}}$ 13.146, de 6 de julho de 2015 - Institui a Lei Brasileira de Inclusão da Pessoa com Deficiência (Estatuto da Pessoa com Deficiência)

$\checkmark \mathrm{O}$ art. 66 da Lei 13.146/2015 estabelece o dever do poder público de incentivar a oferta de aparelhos de telefonia fixa e móvel celular com acessibilidade, entre outras tecnologias assistivas.

\section{Espectro de Radiofrequência}

\section{Atribuição, Destinação e Distribuição de Radiofrequência}

\section{Normatização}

Resolução da ANATEL $\mathbf{n}^{0}$ 648, de 11 de fevereiro de 2015 - Destina faixas de radiofrequências para o Serviço de Acesso Condicionado (SeAC)

\section{Condições de Uso de Radiofrequência e Canalização (Distribuição de Canais)}

\section{Normatização}

Portaria MC n⿳ 1.581, de 9 de abril de 2015 - Regulamenta o uso da faixa de $174 \mathrm{MHz}$ a $216 \mathrm{MHz}$ (VHF alto) para TV Digital

Resolução da ANATEL $\mathbf{n}^{\circ}$ 657, de 3 de novembro de 2015 - Altera o Regulamento sobre Condições de Uso de Radiofrequências nas Faixas de $800 \mathrm{MHz}$, $900 \mathrm{MHz}, 1.800 \mathrm{MHz}, 1.900 \mathrm{MHz}$ e $2.100 \mathrm{MHz}$, aprovado pela Resolução n ${ }^{\circ}$ 454, de 11 de dezembro de 2006

\section{Direito de Uso de Radiofrequência}

\section{Atos}

Acórdão do Conselho Diretor da ANATEL, de 24 de fevereiro de 2015 (Ref. $\mathbf{n}^{\mathbf{0}}$ 53/2015) - A renúncia de outorgas de radiofrequências para cumprimento de 
exigência editalícia em licitação realizada pela ANATEL opera efeitos de extinção das outorgas renunciadas imediatamente após decorrido o prazo fixado no compromisso aposto aos autos do processo e a despeito da comprovação de início de negociações para transferência das outorgas correspondentes, não cabendo à licitante opor ao ato de extinção o fato de que não teria ultimado a transferência das outorgas ou do controle societário das empresas que detivessem outorgas nas subfaixas e áreas de prestação renunciadas pela licitante para pessoa não pertencente a seu grupo econômico. Alcançado o termo final do prazo compromissado sem a transferência de outorgas ou de controle societário das empresas que as detiverem, compete à ANATEL extinguir unilateralmente as outorgas abdicadas como exigência licitatória, independentemente da demora nas negociações privadas, exceto o caso de mora atribuível a ato ou inação da Administração Pública na anuência prévia correspondente.

\section{Administração do Setor de Telecomunicações}

\section{Fiscalização das Telecomunicações}

\section{Jurisprudência}

Tribunal de Contas da União - Acórdão do TCU n 3311, de 09 de dezembro de 2015 - Relator: Min. Benjamin Zymler - Plenário do TCU - Unânime - j. 0912-2015. [Catalogação de Márcio Iório Aranha ]

Determinações à ANATEL sobre o acompanhamento dos bens reversíveis das concessões de Serviço Telefônico Fixo Comutado, bem como exigência de que a ANATEL disponibilize em seu sítio eletrônico, no prazo de 210 dias da ciência do acórdão, todas as relações de bens reversíveis de 2009 a 2014, contendo todos os dados classificados como sendo de caráter público, em formato de arquivo aberto, não-proprietário, estruturado e legível por máquina.

Supremo Tribunal Federal - Habeas Corpus 128567/MG (HC 128567/MG, de 08 de setembro de 2015) - Relator: Min. Teori Zavascki - Segunda Turma do STF - Unânime - j. 08-09-2015 - Diário da Justiça Eletrônico, 23-09-2015. [Catalogação de Márcio Iório Aranha ]

Crime de exploração clandestina de atividade de telecomunicação (art. 183 da LGT) não se caracteriza como hipótese de aplicação do princípio da insignificância. Baixa potência do equipamento de telecomunicações utilizado não autoriza atipicidade do crime por aplicação do princípio da insignificância. Trata-se de crime formal, ou seja, que não exige resultado naturalístico, de perigo abstrato, consumando-se com o mero desenvolvimento clandestino da atividade, $\mathrm{O}$ eventual dano a terceiro em determinado caso concreto configura causa de aumento de pena e também não autoriza a aplicação do princípio da insignificância, pois o crime não tem como pressuposto a ocorrência do prejuízo econômico: ele visa à proteção de um bem difuso de potencial risco de lesão ao regular funcionamento do sistema de telecomunicações. Desde que caracterizada a habitualidade exigida na tipificação do art. 183 da LGT, que o diferencia da conduta tipificada no art. 70 do CBT, aquele que coloca em funcionamento rádio comunitária de forma irregular com equipamentos de potência superior ao permitido e capaz de interferir em outras atividades de telecomunicações não se beneficia do princípio da insignificância, pois ausentes os requisitos da inexpressividade da lesão jurídica e da mínima ofensividade da conduta. 


\section{Normatização}

Lei $\mathbf{n}^{\circ}$ 13.129, de 26 de maio de 2015 - Altera a Lei no 9.307, de 23 de setembro de 1996, e a Lei no 6.404, de 15 de dezembro de 1976, para ampliar o âmbito de aplicação da arbitragem e dispor sobre a escolha dos árbitros quando as partes recorrem a órgão arbitral, a interrupção da prescrição pela instituição da arbitragem, a concessão de tutelas cautelares e de urgência nos casos de arbitragem, a carta arbitral e a sentença arbitral, e revoga dispositivos da Lei no 9.307, de 23 de setembro de 1996.

$\checkmark$ Impossibilidade de submissão de direitos indisponíveis à arbitragem envolvendo a administração pública.

Portaria MC n 294, de 30 de janeiro de 2015 - Estabelece o valor máximo da multa por infração às disposições da Lei 4.117/62 ou demais normas aplicáveis aos serviços de radiodifusão e seus ancilares.

Resolução da ANATEL n 654, de 13 de julho de 2015 - Aprova o Regulamento das Condições de Aferição do Grau de Satisfação e da Qualidade Percebida Junto aos Usuários de Serviços de Telecomunicações

$\rightarrow$ - Regulamento das Condições de Aferição do Grau de Satisfação e da Qualidade Percebida Junto aos Usuários de Serviços de Telecomunicações

\section{Tributação no Setor de Telecomunicações}

\section{Jurisprudência}

Tribunal de Contas da União - Acórdão TCU 2320, de 16 de setembro de 2015 - Relator: Min. Ministro Vital do Rêgo - Plenário do TCU - Unânime - j. 16-092015. [Catalogação de Márcio Iório Aranha ]

Uso indevido de recursos do Fundo de Fiscalização das Telecomunicações (FISTEL) para abertura de créditos adicionais destinados ao custeio de ações estranhas aos serviços de custeio, manutenção e aperfeiçoamento da fiscalização dos serviços de telecomunicações fere a caracterização de tais recursos como fontes vinculadas. É possível, entretanto, a desvinculação de tais recursos mediante transferência de receita excedente ao Tesouro Nacional. A receita excedente deve constar, segundo determinação do TCU À ANATEL, de quadro demonstrativo do planejamento plurianual das receitas e despesas que acompanhe as propostas orçamentárias da autarquia e do FISTEL. Entendimento majoritário de que a afetação de receitas é característica das contribuições e não das taxas, desde que norma específica dê tratamento de uso livre dos saldos e que sejam preservadas continuamente as finalidades inicialmente estabelecidas pela taxa.

\section{Normatização}

Lei no 13.097, de 19 de janeiro de 2015 - Reduz a zero as alíquotas da Contribuição para o PIS/PASEP, da COFINS, da Contribuição para o PIS/Pasep-Importação e da Cofins-Importação incidentes sobre a receita de vendas e na importação de partes utilizadas em aerogeradores; prorroga os benefícios previstos nas Leis nos 9.250, de 26 de dezembro de 1995, 9.440, de 14 de março de 1997, 10.931, de 2 de agosto de 2004, 11.196, de 21 de novembro de 2005, 12.024, de 27 de agosto de 2009, e 12.375, de 30 de dezembro de 2010; altera o art. 46 da Lei no12.715, de 17 de setembro de 2012, que dispõe sobre a devolução ao exterior ou a destruição de mercadoria estrangeira cuja importação não seja autorizada; altera as Leis nos 
9.430, de 27 de dezembro de 1996, 12.546, de 14 de dezembro de 2011, 12.973, de 13 de maio de 2014, 9.826, de 23 de agosto de 1999, 10.833, de 29 de dezembro de 2003, 10.865, de 30 de abril de 2004, 11.051, de 29 de dezembro de 2004, 11.774, de 17 de setembro de 2008, 10.637, de 30 de dezembro de 2002, 12.249, de 11 de junho de 2010,10.522, de 19 de julho de 2002, 12.865, de 9 de outubro de 2013, 10.820, de 17 de dezembro de 2003, 6.634, de 2 de maio de 1979, 7.433, de 18 de dezembro de 1985, 11.977, de 7 de julho de 2009, 10.931, de 2 de agosto de 2004, 11.076, de 30 de dezembro de 2004, 9.514, de 20 de novembro de 1997, 9.427, de 26 de dezembro de 1996, 9.074, de 7 de julho de 1995, 12.783, de 11 de janeiro de 2013, 11.943, de 28 de maio de 2009, 10.848, de 15 de março de 2004, 7.565 , de 19 de dezembro de 1986, 12.462, de 4 de agosto de 2011, 9.503, de 23 de setembro de $1997,11.442$, de 5 de janeiro de $2007,8.666$, de 21 de junho de 1993, 9.782, de 26 de janeiro de 1999, 6.360, de 23 de setembro de 1976, 5.991, de 17 de dezembro de 1973, 12.850, de 2 de agosto de 2013, 5.070, de 7 de julho de 1966, 9.472, de 16 de julho de 1997, 10.480, de 2 de julho de 2002, 8.112, de 11 de dezembro de 1990, 6.530, de 12 de maio de 1978, 5.764, de 16 de dezembro de $1971,8.080$, de 19 de setembro de 1990, 11.079, de 30 de dezembro de 2004, 13.043, de 13 de novembro de 2014, 8.987, de 13 de fevereiro de 1995, 10.925, de 23 de julho de 2004, 12.096, de 24 de novembro de 2009, 11.482, de 31 de maio de 2007, 7.713, de 22 de dezembro de 1988, a Lei Complementar no 123, de 14 de dezembro de 2006, o Decreto-Lei no 745, de 7 de agosto de 1969, e o Decreto no 70.235, de 6 de março de 1972; revoga dispositivos das Leis nos 4.380, de 21 de agosto de 1964, 6.360, de 23 de setembro de 1976, 7.789, de 23 de novembro de $1989,8.666$, de 21 de junho de 1993, 9.782, de 26 de janeiro de 1999, 10.150, de 21 de dezembro de 2000, 9.430, de 27 de dezembro de 1996, 12.973, de 13 de maio de 2014, 8.177, de 1o de março de 1991, 10.637, de 30 de dezembro de 2002, 10.833 , de 29 de dezembro de 2003, 10.865, de 30 de abril de 2004, 11.051, de 29 de dezembro de 2004 e 9.514 , de 20 de novembro de 1997, e do Decreto-Lei no 3.365 , de 21 de junho de 1941; e dá outras providências.

$\checkmark$ Isenta do pagamento das Taxas de Fiscalização de Instalação e de Funcionamento de estações de telecomunicações as estações rádio base, e repetidoras, de baixa potência dos serviços de telecomunicações de interesse coletivo cuja potência de pico máxima, medida na saída do transmissor, não seja superior a $5 \mathrm{~W}$ e $10 \mathrm{~W}$ sofrerão a cobrança de $10 \%$ dos valores de taxas de fiscalização de instalação aplicáveis às demais estações rádio base.

\section{Prestação de Serviços}

\section{Licitação}

\section{Normatização}

Lei n' 13.097, de 19 de janeiro de 2015 - Reduz a zero as alíquotas da Contribuição para o PIS/PASEP, da COFINS, da Contribuição para o PIS/Pasep-Importação e da Cofins-Importação incidentes sobre a receita de vendas e na importação de partes utilizadas em aerogeradores; prorroga os benefícios previstos nas Leis nos 9.250, de 26 de dezembro de 1995, 9.440, de 14 de março de 1997, 10.931, de 2 de agosto de 2004, 11.196, de 21 de novembro de 2005, 12.024, de 27 de agosto de 2009, e 12.375, de 30 de dezembro de 2010; altera o art. 46 da Lei no12.715, de 17 de setembro de 2012, que dispõe sobre a devolução ao exterior ou a destruição de mercadoria estrangeira cuja importação não seja autorizada; altera as Leis nos 9.430, de 27 de dezembro de 1996, 12.546, de 14 de dezembro de 2011, 12.973, de 13 de maio de 2014, 9.826, de 23 de agosto de 1999, 10.833, de 29 de dezembro 
de 2003, 10.865, de 30 de abril de 2004, 11.051, de 29 de dezembro de 2004, 11.774, de 17 de setembro de 2008, 10.637, de 30 de dezembro de 2002, 12.249, de 11 de junho de 2010, 10.522, de 19 de julho de 2002, 12.865, de 9 de outubro de 2013, 10.820, de 17 de dezembro de 2003, 6.634, de 2 de maio de 1979, 7.433, de 18 de dezembro de 1985, 11.977, de 7 de julho de 2009, 10.931, de 2 de agosto de 2004, 11.076, de 30 de dezembro de 2004, 9.514, de 20 de novembro de 1997, 9.427, de 26 de dezembro de 1996, 9.074, de 7 de julho de 1995, 12.783, de 11 de janeiro de 2013, 11.943, de 28 de maio de 2009, 10.848, de 15 de março de 2004, 7.565 , de 19 de dezembro de 1986, 12.462, de 4 de agosto de 2011, 9.503, de 23 de setembro de 1997, 11.442, de 5 de janeiro de 2007, 8.666, de 21 de junho de 1993, 9.782, de 26 de janeiro de 1999, 6.360, de 23 de setembro de 1976, 5.991, de 17 de dezembro de 1973, 12.850, de 2 de agosto de 2013, 5.070, de 7 de julho de 1966, 9.472, de 16 de julho de 1997, 10.480, de 2 de julho de 2002, 8.112, de 11 de dezembro de 1990, 6.530, de 12 de maio de 1978, 5.764, de 16 de dezembro de 1971, 8.080, de 19 de setembro de 1990, 11.079, de 30 de dezembro de 2004, 13.043, de 13 de novembro de 2014, 8.987, de 13 de fevereiro de 1995, 10.925, de 23 de julho de 2004, 12.096, de 24 de novembro de 2009, 11.482, de 31 de maio de 2007, 7.713, de 22 de dezembro de 1988, a Lei Complementar no 123, de 14 de dezembro de 2006, o Decreto-Lei no 745, de 7 de agosto de 1969, e o Decreto no 70.235, de 6 de março de 1972; revoga dispositivos das Leis nos 4.380, de 21 de agosto de 1964, 6.360, de 23 de setembro de 1976, 7.789, de 23 de novembro de 1989, 8.666, de 21 de junho de 1993, 9.782, de 26 de janeiro de 1999, 10.150, de 21 de dezembro de 2000, 9.430, de 27 de dezembro de 1996, 12.973, de 13 de maio de 2014, 8.177, de 1 o de março de 1991, 10.637, de 30 de dezembro de 2002, 10.833, de 29 de dezembro de 2003, 10.865, de 30 de abril de 2004, 11.051, de 29 de dezembro de 2004 e 9.514, de 20 de novembro de 1997, e do Decreto-Lei no 3.365 , de 21 de junho de 1941; e dá outras providências.

$\checkmark$ Autorização legal para parcelamento de preço público devido em razão da outorga de serviços de radiodifusão.

\section{Atos}

Acórdão do Conselho Diretor da ANATEL, de 24 de fevereiro de 2015 (Ref. $\mathbf{n}^{\mathbf{0}} \mathbf{5 3}$ /2015) - A renúncia de outorgas de radiofrequências para cumprimento de exigência editalícia em licitação realizada pela ANATEL opera efeitos de extinção das outorgas renunciadas imediatamente após decorrido o prazo fixado no compromisso aposto aos autos do processo e a despeito da comprovação de início de negociações para transferência das outorgas correspondentes, não cabendo à licitante opor ao ato de extinção o fato de que não teria ultimado a transferência das outorgas ou do controle societário das empresas que detivessem outorgas nas subfaixas e áreas de prestação renunciadas pela licitante para pessoa não pertencente a seu grupo econômico. Alcançado o termo final do prazo compromissado sem a transferência de outorgas ou de controle societário das empresas que as detiverem, compete à ANATEL extinguir unilateralmente as outorgas abdicadas como exigência licitatória, independentemente da demora nas negociações privadas, exceto o caso de mora atribuível a ato ou inação da Administração Pública na anuência prévia correspondente. 


\section{Espécies de Outorga}

\section{Concessão (regras aplicáveis)}

\section{Jurisprudência}

Tribunal de Contas da União - Acórdão do TCU no 3311, de 09 de dezembro de 2015 - Relator: Min. Benjamin Zymler - Plenário do TCU - Unânime - j. 0912-2015. [Catalogação de Márcio Iório Aranha ]

Determinações à ANATEL sobre o acompanhamento dos bens reversíveis das concessões de Serviço Telefônico Fixo Comutado, bem como exigência de que a ANATEL disponibilize em seu sítio eletrônico, no prazo de 210 dias da ciência do acórdão, todas as relações de bens reversíveis de 2009 a 2014 , contendo todos os dados classificados como sendo de caráter público, em formato de arquivo aberto, não-proprietário, estruturado e legível por máquina.

Supremo Tribunal Federal - Agravo Regimental no Recurso Extraordinário 811620 (RE 811620 AgR/MG) - Relator: Min. Edson Fachin - Plenário do STF Unânime - j. 13-10-2015 - Diário da Justiça Eletrônico, 28-10-2015. [Catalogação de Márcio Iório Aranha ]

Inconstitucionalidade de disciplina estadual para cobrança de taxa de uso e ocupação de solo e espaço aéreo de instalações de equipamentos necessários à prestação de serviço público de telecomunicações por invasão de competência legislativa da União.

Supremo Tribunal Federal - Ação Direta de Inconstitucionalidade $\mathbf{n}^{\circ} \mathbf{2 . 6 1 5}$ (ADI 2.615 - Santa Catarina) - Relator: Min. Eros Grau - Plenário do STF Maioria - j. 11-03-2015 - Diário da Justiça Eletrônico, 11-03-2015. [Catalogação de Márcio Iório Aranha ]

Inconstitucionalidade de disciplina estudual sobre as condições de cobrança do valor da assinatura básica por invasão de competência da União. O argumento de que se trata de direito do consumidor não autoriza estado-membro da federação a legislar sobre assinatura básica.

Supremo Tribunal Federal - Embargos de Declaração no Recurso Extraordinário 456534 Embargos de Declaração - (RE 456534/RS) - Relator: Min. Luís Roberto Barroso - Relator para o Acórdão: Min. Aldir Passarinho Primeira Turma do STF - Unânime - j. 23-06-2015 - Diário da Justiça Eletrônico, 06-08-2015. [Catalogação de Márcio Iório Aranha ]

Constitucionalidade de disciplina municipal para cobrança de taxa de licença para instalação e de verificação da permanência das condições técnicas iniciais dos equipamentos destinados à energia elétrica e ao fornecimento de serviços de telecomunicações. A cobrança da taxa em razão do exercício do poder de polícia municipal para fiscalização quanto ao atendimento de regras de posturas municipais, desde que prevista em lei, é constitucional. O exercício de poder de polícia in casu é presumido.

\section{Normatização}

Lei $n^{0}$ 13.140, de 26 de junho de 2015 - Dispõe sobre a mediação entre particulares como meio de solução de controvérsias e sobre a autocomposição de conflitos no âmbito da administração pública; altera a Lei no 9.469, de 10 de julho de 1997, e o Decreto no 70.235, de 6 de março de 1972; e revoga o $§ 20$ do art. 6 o da Lei no 9.469, de 10 de julho de 1997. 
$\mathrm{O}$ art. $32, \S 5^{\circ}$ da Lei $13.140 / 2015$ dispõe que se compreende na competência das câmaras de prevenção e resolução administrativa de conflitos as questões que envolvam equilíbrio econômico-financeiro de contratos celebrados pela administração com particulares.

Portaria MC n 4.335, de 17 de setembro de 2015 - Dispõe sobre os procedimentos de permissão e concessão para execução dos serviços de radiodifusão sonora em frequência modulada e de sons e imagens, com finalidade exclusivamente educativa

$\rightarrow$ Anexo I - Requerimento de Demonstração de Interesse

$\Rightarrow$ Anexo II - Proposta para Pessoa Jurídica de Direito Público Interno

- Anexo III - Proposta para Pessoa Jurídica de Direito Privado

$\rightarrow$ Anexo IV - Documentos Necessários para Habilitação

$\Rightarrow$ Anexo V - Requerimento de Renovação de Outorga - Pessoa Jurídica de Direito Público Interno

$\Rightarrow$ Anexo VI - Requerimento de Renovação de Outorga - Pessoa Jurídica de Direito Privado

$\rightarrow$ Anexo VII - Alteração de Quadro Diretivo

Resolução da ANATEL n 654, de 13 de julho de 2015 - Aprova o Regulamento das Condições de Aferição do Grau de Satisfação e da Qualidade Percebida Junto aos Usuários de Serviços de Telecomunicações

- - Regulamento das Condições de Aferição do Grau de Satisfação e da Qualidade Percebida Junto aos Usuários de Serviços de Telecomunicações

Resolução da ANATEL no 659, de 28 de dezembro de 2015 - Aprova a alteração da Cláusula 3.2 do Contrato de Concessão para a prestação do Serviço Telefônico Fixo Comutado - STFC, nas modalidades de serviço Local, Longa Distância Nacional - LDN e Longa Distância Internacional - LDI, para ampliar prazo para a realização de alterações referentes ao período de 2016 a 2020

$\checkmark$ Altera a data da penúltima revisão quinquenal dos contratos de concessão do STFC de 31 de dezembro de 2015 para 30 de abril de 2016.

\section{Permissão (regras aplicáveis)}

\section{Normatização}

Lei n⿳ 13.140, de 26 de junho de 2015 - Dispõe sobre a mediação entre particulares como meio de solução de controvérsias e sobre a autocomposição de conflitos no âmbito da administração pública; altera a Lei no 9.469, de 10 de julho de 1997, e o Decreto no 70.235, de 6 de março de 1972; e revoga o § 20 do art. 60 da Lei no 9.469, de 10 de julho de 1997 .

$\boldsymbol{V} \mathrm{O}$ art. $32, \S 5^{\circ}$ da Lei 13.140/2015 dispõe que se compreende na competência das câmaras de prevenção e resolução administrativa de conflitos as questões que envolvam equilíbrio econômico-financeiro de contratos celebrados pela administração com particulares.

Portaria MC no 4.335, de 17 de setembro de 2015 - Dispõe sobre os procedimentos de permissão e concessão para execução dos serviços de radiodifusão sonora em frequência modulada e de sons e imagens, com finalidade exclusivamente educativa

$\Rightarrow$ Anexo I - Requerimento de Demonstração de Interesse 
$\Rightarrow$ Anexo II - Proposta para Pessoa Jurídica de Direito Público Interno

$\rightarrow$ Anexo III - Proposta para Pessoa Jurídica de Direito Privado

$\rightarrow$ Anexo IV - Documentos Necessários para Habilitação

$\Rightarrow$ Anexo V - Requerimento de Renovação de Outorga - Pessoa Jurídica de Direito Público Interno

$\rightarrow$ Anexo VI - Requerimento de Renovação de Outorga - Pessoa Jurídica de Direito Privado

$\Rightarrow$ Anexo VII - Alteração de Quadro Diretivo

\section{Autorização (regras aplicáveis)}

Jurisprudência

Supremo Tribunal Federal - Agravo Regimental no Recurso Extraordinário 811620 (RE 811620 AgR/MG) - Relator: Min. Edson Fachin - Plenário do STF Unânime - j. 13-10-2015 - Diário da Justiça Eletrônico, 28-10-2015. [Catalogação de Márcio Iório Aranha ]

Inconstitucionalidade de disciplina estadual para cobrança de taxa de uso e ocupação de solo e espaço aéreo de instalações de equipamentos necessários à prestação de serviço público de telecomunicações por invasão de competência legislativa da União.

Supremo Tribunal Federal - Ação Direta de Inconstitucionalidade $\mathbf{n}^{0} \mathbf{2 . 6 1 5}$ (ADI 2.615 - Santa Catarina) - Relator: Min. Eros Grau - Plenário do STF Maioria - j. 11-03-2015 - Diário da Justiça Eletrônico, 11-03-2015. [Catalogação de Márcio Iório Aranha ]

Inconstitucionalidade de disciplina estudual sobre as condições de cobrança do valor da assinatura básica por invasão de competência da União. O argumento de que se trata de direito do consumidor não autoriza estado-membro da federação a legislar sobre assinatura básica.

Supremo Tribunal Federal - Embargos de Declaração no Recurso Extraordinário 456534 Embargos de Declaração - (RE 456534/RS) - Relator: Min. Luís Roberto Barroso - Relator para o Acórdão: Min. Aldir Passarinho Primeira Turma do STF - Unânime - j. 23-06-2015 - Diário da Justiça Eletrônico, 06-08-2015. [Catalogação de Márcio Iório Aranha ]

Constitucionalidade de disciplina municipal para cobrança de taxa de licença para instalação e de verificação da permanência das condições técnicas iniciais dos equipamentos destinados à energia elétrica e ao fornecimento de serviços de telecomunicações. A cobrança da taxa em razão do exercício do poder de polícia municipal para fiscalização quanto ao atendimento de regras de posturas municipais, desde que prevista em lei, é constitucional. O exercício de poder de polícia in casu é presumido.

\section{Preço Público e Preço Privado}

\section{Normatização}

Lei $n^{\circ}$ 13.097, de 19 de janeiro de 2015 - Reduz a zero as alíquotas da Contribuição para o PIS/PASEP, da COFINS, da Contribuição para o PIS/Pasep-Importação e da Cofins-Importação incidentes sobre a receita de vendas e na importação de partes utilizadas em aerogeradores; prorroga os benefícios previstos nas Leis nos 
9.250, de 26 de dezembro de 1995, 9.440, de 14 de março de 1997, 10.931, de 2 de agosto de 2004, 11.196, de 21 de novembro de 2005, 12.024, de 27 de agosto de 2009, e 12.375, de 30 de dezembro de 2010; altera o art. 46 da Lei no12.715, de 17 de setembro de 2012, que dispõe sobre a devolução ao exterior ou a destruição de mercadoria estrangeira cuja importação não seja autorizada; altera as Leis nos 9.430, de 27 de dezembro de 1996, 12.546, de 14 de dezembro de 2011, 12.973, de 13 de maio de 2014, 9.826 , de 23 de agosto de 1999, 10.833, de 29 de dezembro de 2003, 10.865, de 30 de abril de 2004, 11.051, de 29 de dezembro de 2004, 11.774, de 17 de setembro de 2008, 10.637, de 30 de dezembro de 2002, 12.249, de 11 de junho de 2010,10.522, de 19 de julho de 2002, 12.865 , de 9 de outubro de 2013, 10.820, de 17 de dezembro de 2003, 6.634, de 2 de maio de 1979, 7.433, de 18 de dezembro de 1985, 11.977, de 7 de julho de 2009, 10.931, de 2 de agosto de 2004, 11.076, de 30 de dezembro de 2004, 9.514, de 20 de novembro de 1997, 9.427, de 26 de dezembro de 1996, 9.074, de 7 de julho de 1995, 12.783, de 11 de janeiro de 2013, 11.943, de 28 de maio de 2009, 10.848, de 15 de março de 2004, 7.565 , de 19 de dezembro de 1986, 12.462, de 4 de agosto de 2011, 9.503, de 23 de setembro de $1997,11.442$, de 5 de janeiro de 2007, 8.666, de 21 de junho de 1993, 9.782, de 26 de janeiro de 1999, 6.360, de 23 de setembro de 1976, 5.991, de 17 de dezembro de 1973, 12.850, de 2 de agosto de 2013, 5.070, de 7 de julho de 1966, 9.472, de 16 de julho de 1997, 10.480, de 2 de julho de 2002, 8.112, de 11 de dezembro de 1990, 6.530, de 12 de maio de 1978, 5.764, de 16 de dezembro de 1971, 8.080, de 19 de setembro de 1990, 11.079, de 30 de dezembro de 2004, 13.043, de 13 de novembro de 2014, 8.987, de 13 de fevereiro de 1995, 10.925, de 23 de julho de 2004, 12.096, de 24 de novembro de 2009, 11.482, de 31 de maio de 2007, 7.713, de 22 de dezembro de 1988, a Lei Complementar no 123, de 14 de dezembro de 2006, o Decreto-Lei no 745, de 7 de agosto de 1969, e o Decreto no 70.235, de 6 de março de 1972; revoga dispositivos das Leis nos 4.380, de 21 de agosto de 1964, 6.360, de 23 de setembro de 1976, 7.789, de 23 de novembro de $1989,8.666$, de 21 de junho de 1993, 9.782, de 26 de janeiro de 1999, 10.150, de 21 de dezembro de 2000, 9.430, de 27 de dezembro de 1996, 12.973, de 13 de maio de 2014, 8.177, de 1o de março de 1991, 10.637, de 30 de dezembro de 2002, 10.833, de 29 de dezembro de 2003, 10.865, de 30 de abril de 2004, 11.051, de 29 de dezembro de 2004 e 9.514, de 20 de novembro de 1997, e do Decreto-Lei no 3.365 , de 21 de junho de 1941; e dá outras providências.

$\checkmark$ Autorização legal para parcelamento de preço público devido em razão da outorga de serviços de radiodifusão.

Lei $\mathbf{n}^{\circ}$ 13.129, de 26 de maio de 2015 - Altera a Lei no 9.307, de 23 de setembro de 1996, e a Lei no 6.404, de 15 de dezembro de 1976, para ampliar o âmbito de aplicação da arbitragem e dispor sobre a escolha dos árbitros quando as partes recorrem a órgão arbitral, a interrupção da prescrição pela instituição da arbitragem, a concessão de tutelas cautelares e de urgência nos casos de arbitragem, a carta arbitral e a sentença arbitral, e revoga dispositivos da Lei no 9.307, de 23 de setembro de 1996.

$\checkmark$ Possibilidade de arbitragem envolvendo a administração pública, desde que sobre direitos patrimoniais disponíveis.

Lei n⿳ 13.140, de 26 de junho de 2015 - Dispõe sobre a mediação entre particulares como meio de solução de controvérsias e sobre a autocomposição de conflitos no âmbito da administração pública; altera a Lei no 9.469, de 10 de julho de 1997, e o Decreto no 70.235, de 6 de março de 1972; e revoga o § 2o do art. 60 da Lei no 9.469, de 10 de julho de 1997.

$\boldsymbol{V} \mathrm{O}$ art. $32, \S 5^{\circ}$ da Lei 13.140/2015 dispõe que se compreende na competência das câmaras de prevenção e resolução administrativa de conflitos as questões que 
envolvam equilíbrio econômico-financeiro de contratos celebrados pela administração com particulares.

Resolução da ANATEL $\mathbf{n}^{0}$ 660, de 28 de dezembro de 2015 - Altera o Regulamento do Preço Público Relativo à Administração dos Recursos de Numeração, aprovado pela Resolução n ${ }^{\circ}$ 451, de 8 de dezembro de 2006

\section{Processo Administrativo}

\section{Normatização}

Portaria MC no 4.335, de 17 de setembro de 2015 - Dispõe sobre os procedimentos de permissão e concessão para execução dos serviços de radiodifusão sonora em frequência modulada e de sons e imagens, com finalidade exclusivamente educativa

$\Rightarrow$ Anexo I - Requerimento de Demonstração de Interesse

- Anexo II - Proposta para Pessoa Jurídica de Direito Público Interno

$\rightarrow$ Anexo III - Proposta para Pessoa Jurídica de Direito Privado

$\rightarrow$ Anexo IV - Documentos Necessários para Habilitação

$\rightarrow$ Anexo V - Requerimento de Renovação de Outorga - Pessoa Jurídica de Direito Público Interno

$\Rightarrow$ Anexo VI - Requerimento de Renovação de Outorga - Pessoa Jurídica de Direito Privado

$\rightarrow$ Anexo VII - Alteração de Quadro Diretivo

Atos

Acórdão do Conselho Diretor da ANATEL, de 31 de julho de 2015 (Ref. n $^{\circ}$ 305/2015) - Tempestividade de recurso administrativo deve ser certificada do momento do seu recebimento no protocolo da Agência, não da postagem do documento.

\section{Políticas de Telecomunicações}

\section{Política Industrial}

\section{Normatização}

Resolução da ANATEL n ${ }^{\circ}$ 655, de 5 de Agosto de 2015 - Aprova o Regulamento do Acompanhamento de Compromissos de Aquisição de Produtos e Sistemas Nacionais e estabelece regras específicas para o cumprimento do Compromisso de Aquisição de Produtos de Tecnologia Nacional

$\Rightarrow$ Anexo - Regulamento do Acompanhamento de Compromissos de Aquisição de Produtos e Sistemas Nacionais 


\section{Concorrência no Setor de Telecomunicações}

\section{- Concorrência no Setor de Telecomunicações}

- O Serviço de Comunicação Multimídia apresenta-se como serviço convergente com pretensão de introduzir utilidades concorrentes às fornecidas por serviços tradicionais do setor.

\section{Normatização}

Lei n⿳ 13.116, de 20 de abril de 2015 - (Lei Geral das Antenas) Estabelece normas gerais para implantação e compartilhamento da infraestrutura de telecomunicações e altera as Leis nos 9.472, de 16 de julho de 1997, 11.934, de 5 de maio de 2009, e 10.257 , de 10 de julho de 2001 .

\section{Atos}

Acórdão do Conselho Diretor da ANATEL, de 24 de fevereiro de 2015 (Ref. $\mathbf{n}^{\mathbf{0}} \mathbf{5 3}$ /2015) - A renúncia de outorgas de radiofrequências para cumprimento de exigência editalícia em licitação realizada pela ANATEL opera efeitos de extinção das outorgas renunciadas imediatamente após decorrido o prazo fixado no compromisso aposto aos autos do processo e a despeito da comprovação de início de negociações para transferência das outorgas correspondentes, não cabendo à licitante opor ao ato de extinção o fato de que não teria ultimado a transferência das outorgas ou do controle societário das empresas que detivessem outorgas nas subfaixas e áreas de prestação renunciadas pela licitante para pessoa não pertencente a seu grupo econômico. Alcançado o termo final do prazo compromissado sem a transferência de outorgas ou de controle societário das empresas que as detiverem, compete à ANATEL extinguir unilateralmente as outorgas abdicadas como exigência licitatória, independentemente da demora nas negociações privadas, exceto o caso de mora atribuível a ato ou inação da Administração Pública na anuência prévia correspondente.

Ato do Conselho Diretor da ANATEL $n^{\circ}$ 448, de 22 de janeiro de 2015 Concede anuência prévia à transferência do controle integral da GVT PARTICIPAÇÕES S/A para a TELEFÔNICA BRASIL S/A, mediante condicionamentos de eliminação de sobreposição de outorgas do STFC, de assunção pela adquirente das obrigações de manutenção de cobertura geográfica e continuidade de atendimento do STFC, SCM e SeAC, de manutenção das ofertas de planos de serviços e ofertas conjuntas de STFC, SCM e SeAC então vigentes pelo prazo mínimo de 18 meses, de manutenção dos contratos em vigor com os usuários ao tempo da operação pelo prazo mínimo de 18 meses, de expansão da cobertura da rede e dos princípios serviços de telecomunicações envolvidos na operação, dentre outros.

\section{Universalização e Massificação}

\section{Normatização}

Lei n⿳ 13.116, de 20 de abril de 2015 - (Lei Geral das Antenas) Estabelece normas gerais para implantação e compartilhamento da infraestrutura de telecomunicações e altera as Leis nos 9.472, de 16 de julho de 1997, 11.934, de 5 de maio de 2009, e 10.257 , de 10 de julho de 2001 . 


\title{
Acesso às Telecomunicações
}

\section{Portador de Deficiência}

\author{
Normatização
}

Lei $\mathbf{n}^{\circ}$ 13.146, de 6 de julho de 2015 - Institui a Lei Brasileira de Inclusão da Pessoa com Deficiência (Estatuto da Pessoa com Deficiência)

$\checkmark$ Determina que as empresas prestadoras de serviços de telecomunicações deverão garantir pleno acesso à pessoa com deficiência, conforme regulamentação específica. Também determina que os serviços de radiodifusão de sons e imagens devem permitir o uso dos recursos de subdtitulação por meio de legenda oculta, janela com intérprete de Libras, e autodescrição, bem como torna obrigatória a acessibilidade nos sítios da internet mantidos por empresas com sede ou representação comercial no País ou por órgãos de governo, para uso por pessoa com deficiência.

\section{Financiamento da Universalização e Massificação}

\section{Normatização}

Portaria MC no 4.699, de 14 de outubro de 2015 - Altera a Portaria $n^{\circ} 376$, de 19 de agosto de 2011, referente à instituição do Projeto de Implantação e Manutenção das Cidades Digitais

$\checkmark$ Previsão de que a execução de ações de implantação de infraestrutura de conexão entre órgãos e equipamentos públicos locais e à internet, inclusive por meio de contrução de backhaul, poderão ser executadas por meio de recursos oriundos de emendas parlamentares.

\section{Metas de Universalização}

\section{Normatização}

Resolução da ANATEL $n^{0}$ 659, de 28 de dezembro de 2015 - Aprova a alteração da Cláusula 3.2 do Contrato de Concessão para a prestação do Serviço Telefônico Fixo Comutado - STFC, nas modalidades de serviço Local, Longa Distância Nacional - LDN e Longa Distância Internacional - LDI, para ampliar prazo para a realização de alterações referentes ao período de 2016 a 2020

$\checkmark$ Altera a data da penúltima revisão quinquenal dos contratos de concessão do STFC de 31 de dezembro de 2015 para 30 de abril de 2016.

\section{Fundos Setoriais de Telecomunicações}

\section{FISTEL}

\section{Jurisprudência}

Tribunal de Contas da União - Acórdão TCU 2320, de 16 de setembro de 2015 - Relator: Min. Ministro Vital do Rêgo - Plenário do TCU - Unânime - j. 16-092015. [Catalogação de Márcio Iório Aranha ]

Uso indevido de recursos do Fundo de Fiscalização das Telecomunicações (FISTEL) para abertura de créditos adicionais destinados ao custeio de ações estranhas aos serviços de custeio, manutenção e aperfeiçoamento da fiscalização dos serviços de telecomunicações fere a caracterização de tais 
recursos como fontes vinculadas. É possível, entretanto, a desvinculação de tais recursos mediante transferência de receita excedente ao Tesouro Nacional. A receita excedente deve constar, segundo determinação do TCU À ANATEL, de quadro demonstrativo do planejamento plurianual das receitas e despesas que acompanhe as propostas orçamentárias da autarquia e do FISTEL. Entendimento majoritário de que a afetação de receitas é característica das contribuições e não das taxas, desde que norma específica dê tratamento de uso livre dos saldos e que sejam preservadas continuamente as finalidades inicialmente estabelecidas pela taxa.

\section{Normatização}

Lei no 13.097, de 19 de janeiro de 2015 - Reduz a zero as alíquotas da Contribuição para o PIS/PASEP, da COFINS, da Contribuição para o PIS/Pasep-Importação e da Cofins-Importação incidentes sobre a receita de vendas e na importação de partes utilizadas em aerogeradores; prorroga os benefícios previstos nas Leis nos 9.250, de 26 de dezembro de 1995, 9.440, de 14 de março de 1997, 10.931, de 2 de agosto de 2004, 11.196, de 21 de novembro de 2005, 12.024, de 27 de agosto de 2009, e 12.375, de 30 de dezembro de 2010; altera o art. 46 da Lei no12.715, de 17 de setembro de 2012, que dispõe sobre a devolução ao exterior ou a destruição de mercadoria estrangeira cuja importação não seja autorizada; altera as Leis nos 9.430, de 27 de dezembro de 1996, 12.546, de 14 de dezembro de 2011, 12.973, de 13 de maio de 2014, 9.826, de 23 de agosto de 1999, 10.833, de 29 de dezembro de 2003, 10.865, de 30 de abril de 2004, 11.051, de 29 de dezembro de 2004, 11.774, de 17 de setembro de 2008, 10.637, de 30 de dezembro de 2002, 12.249, de 11 de junho de 2010,10.522, de 19 de julho de 2002, 12.865, de 9 de outubro de 2013, 10.820, de 17 de dezembro de 2003, 6.634, de 2 de maio de 1979, 7.433, de 18 de dezembro de 1985, 11.977, de 7 de julho de 2009, 10.931, de 2 de agosto de 2004, 11.076, de 30 de dezembro de 2004, 9.514, de 20 de novembro de 1997, 9.427, de 26 de dezembro de 1996, 9.074, de 7 de julho de 1995, 12.783, de 11 de janeiro de 2013, 11.943, de 28 de maio de 2009, 10.848, de 15 de março de 2004, 7.565, de 19 de dezembro de 1986, 12.462, de 4 de agosto de 2011, 9.503, de 23 de setembro de 1997, 11.442, de 5 de janeiro de 2007, 8.666, de 21 de junho de 1993, 9.782, de 26 de janeiro de 1999, 6.360, de 23 de setembro de 1976, 5.991, de 17 de dezembro de 1973, 12.850, de 2 de agosto de 2013, 5.070, de 7 de julho de 1966, 9.472, de 16 de julho de 1997, 10.480, de 2 de julho de 2002, 8.112, de 11 de dezembro de 1990, 6.530, de 12 de maio de 1978, 5.764, de 16 de dezembro de 1971, 8.080, de 19 de setembro de 1990, 11.079, de 30 de dezembro de 2004, 13.043, de 13 de novembro de 2014, 8.987, de 13 de fevereiro de 1995, 10.925, de 23 de julho de 2004, 12.096, de 24 de novembro de 2009, 11.482, de 31 de maio de 2007, 7.713, de 22 de dezembro de 1988, a Lei Complementar no 123, de 14 de dezembro de 2006, o Decreto-Lei no 745, de 7 de agosto de 1969, e o Decreto no 70.235, de 6 de março de 1972; revoga dispositivos das Leis nos 4.380, de 21 de agosto de 1964, 6.360, de 23 de setembro de 1976, 7.789, de 23 de novembro de 1989, 8.666, de 21 de junho de 1993, 9.782, de 26 de janeiro de 1999, 10.150, de 21 de dezembro de 2000, 9.430, de 27 de dezembro de 1996, 12.973, de 13 de maio de 2014, 8.177, de 1 o de março de 1991, 10.637, de 30 de dezembro de 2002, 10.833, de 29 de dezembro de 2003, 10.865, de 30 de abril de 2004, 11.051, de 29 de dezembro de 2004 e 9.514, de 20 de novembro de 1997, e do Decreto-Lei no 3.365 , de 21 de junho de 1941; e dá outras providências.

$\checkmark$ Isenta do pagamento das Taxas de Fiscalização de Instalação e de Funcionamento de estações de telecomunicações as estações rádio base, e repetidoras, de baixa 
potência dos serviços de telecomunicações de interesse coletivo cuja potência de pico máxima, medida na saída do transmissor, não seja superior a $5 \mathrm{~W}$ e $10 \mathrm{~W}$ sofrerão a cobrança de $10 \%$ dos valores de taxas de fiscalização de instalação aplicáveis às demais estações rádio base.

\section{Qualidade do Serviço}

\section{Normatização}

Resolução da ANATEL n 654, de 13 de julho de 2015 - Aprova o Regulamento das Condições de Aferição do Grau de Satisfação e da Qualidade Percebida Junto aos Usuários de Serviços de Telecomunicações

- - Regulamento das Condições de Aferição do Grau de Satisfação e da Qualidade Percebida Junto aos Usuários de Serviços de Telecomunicações

\section{Controle Social, Hierárquico e Interorgânico}

\section{Normatização}

Lei no 13.129, de 26 de maio de 2015 - Altera a Lei no 9.307, de 23 de setembro de 1996, e a Lei no 6.404, de 15 de dezembro de 1976, para ampliar o âmbito de aplicação da arbitragem e dispor sobre a escolha dos árbitros quando as partes recorrem a órgão arbitral, a interrupção da prescrição pela instituição da arbitragem, a concessão de tutelas cautelares e de urgência nos casos de arbitragem, a carta arbitral e a sentença arbitral, e revoga dispositivos da Lei no 9.307, de 23 de setembro de 1996.

$\checkmark$ Impossibilidade de submissão de direitos indisponíveis à arbitragem envolvendo a administração pública.

Resolução da ANATEL $\mathbf{n}^{\circ}$ 654, de 13 de julho de 2015 - Aprova o Regulamento das Condições de Aferição do Grau de Satisfação e da Qualidade Percebida Junto aos Usuários de Serviços de Telecomunicações

$\Rightarrow$ - Regulamento das Condições de Aferição do Grau de Satisfação e da Qualidade Percebida Junto aos Usuários de Serviços de Telecomunicações

Atos

Relatório da Ouvidoria da ANATEL 2015

\section{Sigilo em Telecomunicações}

Tema Conexo: Fundamentos : Conceitos Fundamentais : Direito à Privacidade.

\section{Classificações de Serviços no Setor de Telecomunicações}

\section{Quanto ao Regime Jurídico de Prestação}

Jurisprudência

Supremo Tribunal Federal - Agravo Regimental no Recurso Extraordinário 811620 (RE 811620 AgR/MG) - Relator: Min. Edson Fachin - Plenário do STF Unânime - j. 13-10-2015 - Diário da Justiça Eletrônico, 28-10-2015. [Catalogação de Márcio Iório Aranha ] 
Inconstitucionalidade de disciplina estadual para cobrança de taxa de uso e ocupação de solo e espaço aéreo de instalações de equipamentos necessários à prestação de serviço público de telecomunicações por invasão de competência legislativa da União.

\section{Quanto ao Interesse}

\section{Serviço de Interesse Coletivo}

\section{Normatização}

Lei $n^{0}$ 13.146, de 6 de julho de 2015 - Institui a Lei Brasileira de Inclusão da Pessoa com Deficiência (Estatuto da Pessoa com Deficiência)

$\checkmark$ Determina que as empresas prestadoras de serviços de telecomunicações deverão garantir pleno acesso à pessoa com deficiência, conforme regulamentação específica.

Resolução da ANATEL no 654, de 13 de julho de 2015 - Aprova o Regulamento das Condições de Aferição do Grau de Satisfação e da Qualidade Percebida Junto aos Usuários de Serviços de Telecomunicações

$\Rightarrow$ - Regulamento das Condições de Aferição do Grau de Satisfação e da Qualidade Percebida Junto aos Usuários de Serviços de Telecomunicações

\section{Serviço de Interesse Restrito}

Normatização

Resolução da ANATEL no 651, de 13 de abril de 2015 - Aprova o Regulamento do Serviço Limitado Móvel Aeronáutico e do Serviço Limitado Móvel Marítimo

$\Rightarrow$ Anexo - Regulamento do Serviço Limitado Móvel Aeronáutico e do Serviço Limitado Móvel Marítimo

\section{Quanto ao Gênero}

\section{Serviço Limitado}

\section{Normatização}

Resolução da ANATEL no 651, de 13 de abril de 2015 - Aprova o Regulamento do Serviço Limitado Móvel Aeronáutico e do Serviço Limitado Móvel Marítimo

- Anexo - Regulamento do Serviço Limitado Móvel Aeronáutico e do Serviço Limitado Móvel Marítimo

\section{Serviço de Valor Adicionado}

\section{Normatização}

Lei $\mathbf{n}^{0}$ 13.146, de 6 de julho de 2015 - Institui a Lei Brasileira de Inclusão da Pessoa com Deficiência (Estatuto da Pessoa com Deficiência)

$\checkmark$ Exigência de obrigatória acessibilidade nos sítios da internet mantidos por empresas com sede ou representação comercial no País ou por órgãos de governo, para uso por pessoa com deficiência. 


\section{Serviço de Radiodifusão}

Tema Conexo: Serviços no Setor de Telecomunicações : Radiodifusão.

\section{Serviços no Setor de Telecomunicações}

\section{Internet}

\section{Normatização}

Lei no 13.146, de 6 de julho de 2015 - Institui a Lei Brasileira de Inclusão da Pessoa com Deficiência (Estatuto da Pessoa com Deficiência)

$\checkmark$ Exigência de obrigatória acessibilidade nos sítios da internet mantidos por empresas com sede ou representação comercial no País ou por órgãos de governo, para uso por pessoa com deficiência.

Lei $\mathrm{n}^{\circ}$ 13.188, de 11 de novembro de 2015 - Dispõe sobre o direito de resposta ou retificação do ofendido em matéria divulgada, publicada ou transmitida por veículo de comunicação social

Portaria MC no 320, de 12 de janeiro de 2015 - Altera a Portaria ${ }^{\circ}$ 55, de 12 de março de 2013, do Ministério das Comunicações, que regulamenta os procedimentos para submissão, análise, aprovação, acompanhamento e fiscalização dos projetos apresentados ao Ministério das Comunicações referentes ao Regime Especial de Tributação do Programa Nacional de Banda Larga para Implantação de Redes de Telecomunicações - REPNBL-Redes.

$\Rightarrow$ Anexo - Alterações dos percentuais mínimos para equipamentos e componentes de redes produzidos de acordo com o respectivo PPB e desenvolvidos com tecnologia nacional

\section{Radiodifusão}

Temas Conexos: Classificações de Serviços no Setor de Telecomunicações : Quanto ao Gênero : Serviço de Radiodifusão e Atores no Setor de Telecomunicações : Poder Executivo : Ministério das Comunicações.

Competência da Presidência da República para outorgar, por meio de concessão, a exploração dos serviços de radiodifusão de sons e imagens, e do Ministério das Comunicações para outorgar, por meio de concessão, permissão ou autorização, a exploração dos serviços de radiodifusão sonora.

\section{Normatização}

Lei ${ }^{0}$ 13.097, de 19 de janeiro de 2015 - Reduz a zero as alíquotas da Contribuição para o PIS/PASEP, da COFINS, da Contribuição para o PIS/Pasep-Importação e da Cofins-Importação incidentes sobre a receita de vendas e na importação de partes utilizadas em aerogeradores; prorroga os benefícios previstos nas Leis nos 9.250, de 26 de dezembro de 1995, 9.440, de 14 de março de 1997, 10.931, de 2 de agosto de 2004, 11.196, de 21 de novembro de 2005, 12.024, de 27 de agosto de 2009, e 12.375, de 30 de dezembro de 2010; altera o art. 46 da Lei no12.715, de 17 de setembro de 2012, que dispõe sobre a devolução ao exterior ou a destruição de mercadoria estrangeira cuja importação não seja autorizada; altera as Leis nos 9.430, de 27 de dezembro de 1996, 12.546, de 14 de dezembro de 2011, 12.973, de 13 de maio de 2014, 9.826 , de 23 de agosto de 1999, 10.833, de 29 de dezembro de 2003, 10.865, de 30 de abril de 2004, 11.051, de 29 de dezembro de 2004, 
11.774, de 17 de setembro de 2008, 10.637, de 30 de dezembro de 2002, 12.249, de 11 de junho de 2010,10.522, de 19 de julho de 2002, 12.865, de 9 de outubro de 2013, 10.820, de 17 de dezembro de 2003, 6.634, de 2 de maio de 1979, 7.433, de 18 de dezembro de 1985, 11.977, de 7 de julho de 2009, 10.931, de 2 de agosto de 2004, 11.076, de 30 de dezembro de 2004, 9.514, de 20 de novembro de 1997, 9.427, de 26 de dezembro de 1996, 9.074, de 7 de julho de 1995, 12.783, de 11 de janeiro de 2013, 11.943, de 28 de maio de 2009, 10.848, de 15 de março de 2004, 7.565 , de 19 de dezembro de 1986, 12.462, de 4 de agosto de 2011, 9.503, de 23 de setembro de 1997, 11.442, de 5 de janeiro de 2007, 8.666, de 21 de junho de 1993, 9.782, de 26 de janeiro de 1999, 6.360, de 23 de setembro de 1976, 5.991, de 17 de dezembro de 1973, 12.850, de 2 de agosto de 2013, 5.070, de 7 de julho de 1966, 9.472, de 16 de julho de 1997, 10.480, de 2 de julho de 2002, 8.112, de 11 de dezembro de 1990, 6.530, de 12 de maio de 1978, 5.764, de 16 de dezembro de 1971, 8.080, de 19 de setembro de 1990, 11.079, de 30 de dezembro de 2004, 13.043, de 13 de novembro de 2014, 8.987, de 13 de fevereiro de 1995, 10.925, de 23 de julho de 2004, 12.096, de 24 de novembro de 2009, 11.482 , de 31 de maio de 2007, 7.713, de 22 de dezembro de 1988, a Lei Complementar no 123, de 14 de dezembro de 2006, o Decreto-Lei no 745, de 7 de agosto de 1969, e o Decreto no 70.235, de 6 de março de 1972; revoga dispositivos das Leis nos 4.380, de 21 de agosto de 1964, 6.360, de 23 de setembro de 1976, 7.789, de 23 de novembro de 1989, 8.666, de 21 de junho de 1993, 9.782, de 26 de janeiro de 1999, 10.150, de 21 de dezembro de 2000, 9.430, de 27 de dezembro de 1996, 12.973, de 13 de maio de 2014, 8.177, de 1 o de março de 1991, 10.637, de 30 de dezembro de 2002, 10.833, de 29 de dezembro de 2003, 10.865, de 30 de abril de 2004, 11.051, de 29 de dezembro de 2004 e 9.514, de 20 de novembro de 1997, e do Decreto-Lei no 3.365 , de 21 de junho de 1941; e dá outras providências.

$\checkmark$ Autorização legal para parcelamento de preço público devido em razão da outorga de serviços de radiodifusão.

Lei n⿳ 13.140, de 26 de junho de 2015 - Dispõe sobre a mediação entre particulares como meio de solução de controvérsias e sobre a autocomposição de conflitos no âmbito da administração pública; altera a Lei no 9.469, de 10 de julho de 1997, e o Decreto no 70.235, de 6 de março de 1972; e revoga o § 2o do art. 60 da Lei no 9.469, de 10 de julho de 1997 .

$\checkmark \mathrm{O}$ art. $32, \S 5^{\circ}$ da Lei $13.140 / 2015$ dispõe que se compreende na competência das câmaras de prevenção e resolução administrativa de conflitos as questões que envolvam equilíbrio econômico-financeiro de contratos celebrados pela administração com particulares.

Lei $\mathbf{n}^{\circ}$ 13.188, de 11 de novembro de 2015 - Dispõe sobre o direito de resposta ou retificação do ofendido em matéria divulgada, publicada ou transmitida por veículo de comunicação social

Portaria MC no 294, de 30 de janeiro de 2015 - Estabelece o valor máximo da multa por infração às disposições da Lei 4.117/62 ou demais normas aplicáveis aos serviços de radiodifusão e seus ancilares.

Portaria MC $\mathrm{n}^{\mathbf{0}}$ 6.413, de 20 de novembro de 2015 - Altera a Norma Regulamentar do Canal de Cidadania, aprovado pela Portaria $n^{\circ} 489$, de 18 de dezembro de 2012 


\title{
Radiodifusão Comunitária
}

\author{
Jurisprudência
}

Supremo Tribunal Federal - Habeas Corpus 128567/MG (HC 128567/MG, de 08 de setembro de 2015) - Relator: Min. Teori Zavascki - Segunda Turma do STF - Unânime - j. 08-09-2015 - Diário da Justiça Eletrônico, 23-09-2015. [Catalogação de Márcio Iório Aranha ]

Crime de exploração clandestina de atividade de telecomunicação (art. 183 da LGT) não se caracteriza como hipótese de aplicação do princípio da insignificância. Baixa potência do equipamento de telecomunicações utilizado não autoriza atipicidade do crime por aplicação do princípio da insignificância. Trata-se de crime formal, ou seja, que não exige resultado naturalístico, de perigo abstrato, consumando-se com o mero desenvolvimento clandestino da atividade, $\mathrm{O}$ eventual dano a terceiro em determinado caso concreto configura causa de aumento de pena e também não autoriza a aplicação do princípio da insignificância, pois o crime não tem como pressuposto a ocorrência do prejuízo econômico: ele visa à proteção de um bem difuso de potencial risco de lesão ao regular funcionamento do sistema de telecomunicações. Desde que caracterizada a habitualidade exigida na tipificação do art. 183 da LGT, que o diferencia da conduta tipificada no art. 70 do CBT, aquele que coloca em funcionamento rádio comunitária de forma irregular com equipamentos de potência superior ao permitido e capaz de interferir em outras atividades de telecomunicações não se beneficia do princípio da insignificância, pois ausentes os requisitos da inexpressividade da lesão jurídica e da mínima ofensividade da conduta.

\section{Rádio Aberta}

\section{Normatização}

Portaria MC no 4.335, de 17 de setembro de 2015 - Dispõe sobre os procedimentos de permissão e concessão para execução dos serviços de radiodifusão sonora em frequência modulada e de sons e imagens, com finalidade exclusivamente educativa

$\rightarrow$ Anexo I - Requerimento de Demonstração de Interesse

$\rightarrow$ Anexo II - Proposta para Pessoa Jurídica de Direito Público Interno

- Anexo III - Proposta para Pessoa Jurídica de Direito Privado

$\rightarrow$ Anexo IV - Documentos Necessários para Habilitação

$\rightarrow$ Anexo V - Requerimento de Renovação de Outorga - Pessoa Jurídica de Direito Público Interno

$\rightarrow$ Anexo VI - Requerimento de Renovação de Outorga - Pessoa Jurídica de Direito Privado

$\rightarrow$ Anexo VII - Alteração de Quadro Diretivo

\section{Televisão Aberta}

\section{Normatização}

Lei $\mathbf{n}^{\circ}$ 13.146, de 6 de julho de 2015 - Institui a Lei Brasileira de Inclusão da Pessoa com Deficiência (Estatuto da Pessoa com Deficiência) 
O art. 67 da Lei 13.146/2015 determina que os serviços de radiodifusão de sons e imagens devem permitir o uso dos recursos de subdtitulação por meio de legenda oculta, janela com intérprete de Libras, e autodescrição.

\section{TV Digital}

\section{Normatização}

Lei $\mathbf{n}^{\circ} \mathbf{1 3 . 1 5 9}$, de 10 de agosto de 2015 - Altera a Lei no 11.484 , de 31 de maio de 2007, que dispõe sobre os incentivos às indústrias de equipamentos para TV Digital e de componentes eletrônicos semicondutores e sobre a proteção à propriedade intelectual das topografias de circuitos integrados, instituindo o Programa de Apoio ao Desenvolvimento Tecnológico da Indústria de Semicondutores - PADIS e o Programa de Apoio ao Desenvolvimento Tecnológico da Indústria de Equipamentos para a TV Digital - PATVD.

Portaria MC no 6.738, de 21 de dezembro de 2015 - Dispõe sobre os procedimentos de autorização para a execução do Serviço de Retransmissão de Televisão, em caráter secundário, com utilização de tecnologia digital e dá outras providências

$\rightarrow$ Anexo I - Manifestação Formal de Interesse

$\Rightarrow$ Anexo II - Documentos Necessários para Habilitação de Pessoas de Direito Público Interno (Estados, Distrito Federal e Municípios)

$\Rightarrow$ Anexo III - Documentos Necessários para Habilitação de Pessoas Jurídicas integrantes da Administração Indireta Federal, Estadual, Distrital e Municipal

$\Rightarrow$ Anexo IV - Documentos Necessários para Habilitação de Concessionárias do Serviço de Radiodifusão de Sons e Imagens interessadas na Execução do Serviço de RTV para Retransmitir seus próprios sinais

$\rightarrow$ Anexo V - Documentos Necessários para Habilitação de Demais Pessoas Jurídicas

- Anexo VI - Declaração de Concordância

Portaria MC n' 1.581, de 9 de abril de 2015 - Regulamenta o uso da faixa de $174 \mathrm{MHz}$ a $216 \mathrm{MHz}$ (VHF alto) para TV Digital

Portaria MC $\mathbf{n}^{0}$ 4.287, de 21 de setembro de 2015 - Dispõe sobre os procedimentos de seleção pública e de autorização para a execução do Serviço de Retransmissão de Televisão, com utilização de tecnologia digital, ancilar ao Serviço de Radiodifusão de Sons e Imagens, durante a transição do sistema de transmissão analógica para o sistema de transmissão digital e dá outras providências

$\Rightarrow$ Anexo I - Continuidade do Serviço de RTV em Tecnologia Digital

- Anexo II - Alteração de Características Técnicas para o Serviço de RTVD

$\rightarrow$ Anexo III - Proposta para Aprovação de Locais e Equipamentos - RTVD

$\Rightarrow$ Anexo IV - Continuidade do Serviço de RTV em Tecnologia Digital

Portaria MC $\mathrm{n}^{0}$ 6.580, de 2 de dezembro de 2015 - Requer relatório consubstanciado sobre a evolução do processo de transição para a TV Digital do Grupo de Implantação do Processo de Redistribuição e Digitalização de Canais de TV e RTV (GIRED), bem como altera a Portaria MC n ${ }^{\circ} 4.287$, de 22 de setembro de 2015 e a Portaria $\mathrm{MC} \mathrm{n}^{\circ}$ 925, de 22 de agosto de 2014 para, dentre outras coisas, autorizar o desligamento antecipado do sinal analógico nos casos que especifica 
Portaria Interministerial $\mathbf{n}^{\mathbf{0}} \mathbf{2 . 0 9 8}$, de 14 de maio de 2015 - Estabelece as diretrizes para operacionalização do Canal da Educação no âmbito do Sistema Brasileiro de Televisão Digital Terrestre - SBTVD-T

Portaria Interministerial $n^{0}$ 4.074, de 26 de Agosto de 2015 - Estabelece as diretrizes para operacionalização do Canal da Cultura no Sistema Brasileiro de Televisão Digital Terrestre

\section{Serviço Limitado Especializado (SLE)}

\section{Normatização}

Resolução da ANATEL $n^{\circ}$ 647, de 9 de fevereiro de 2015 - Aprova a Norma de adaptação dos instrumentos de permissão e de autorização do Serviço Móvel Especializado (SME) para o Serviço Móvel Pessoal (SMP), Serviço Limitado Privado (SLP) ou Serviço Limitado Especializado (SLE), na forma do Anexo a esta Resolução, altera a Resolução $n^{\circ}$ 454/2006 e seus anexo, e dá outras disposições.

$\rightarrow$ Anexo - Norma de adaptação dos instrumentos de permissão e de autorização do Serviço Móvel Especializado (SME) para o Serviço Móvel Pessoal (SMP), Serviço Limitado Privado (SLP) ou Serviço Limitado Especializado (SLE)

\section{Serviço Limitado Móvel Privado}

\section{Normatização}

Resolução da ANATEL $n^{0}$ 647, de 9 de fevereiro de 2015 - Aprova a Norma de adaptação dos instrumentos de permissão e de autorização do Serviço Móvel Especializado (SME) para o Serviço Móvel Pessoal (SMP), Serviço Limitado Privado (SLP) ou Serviço Limitado Especializado (SLE), na forma do Anexo a esta Resolução, altera a Resolução n ${ }^{\circ}$ 454/2006 e seus anexo, e dá outras disposições.

$\Rightarrow$ Anexo - Norma de adaptação dos instrumentos de permissão e de autorização do Serviço Móvel Especializado (SME) para o Serviço Móvel Pessoal (SMP), Serviço Limitado Privado (SLP) ou Serviço Limitado Especializado (SLE)

$\checkmark$ Determina que não sejam expedidas novas autorizações de uso de radiofrequencias, prorrogado o prazo de autorizações em vigor, licenciada nova estação ou consignada nova radiofrequencia nos canais de 1 a 500 na faixa de 806 a $821 \mathrm{MHz}$ e 851 a $866 \mathrm{MHz}$ para o SLMP.

\section{Serviço Limitado Privado}

\section{Normatização}

Resolução da ANATEL no 647, de 9 de fevereiro de 2015 - Aprova a Norma de adaptação dos instrumentos de permissão e de autorização do Serviço Móvel Especializado (SME) para o Serviço Móvel Pessoal (SMP), Serviço Limitado Privado (SLP) ou Serviço Limitado Especializado (SLE), na forma do Anexo a esta Resolução, altera a Resolução ${ }^{\circ}$ 454/2006 e seus anexo, e dá outras disposições.

$\rightarrow$ Anexo - Norma de adaptação dos instrumentos de permissão e de autorização do Serviço Móvel Especializado (SME) para o Serviço Móvel Pessoal (SMP), Serviço Limitado Privado (SLP) ou Serviço Limitado Especializado (SLE) 


\section{Serviço Móvel Especializado ou Trunking ou Trunk ou Sistema Troncalizado}

\section{Normatização}

Resolução da ANATEL no 647, de 9 de fevereiro de 2015 - Aprova a Norma de adaptação dos instrumentos de permissão e de autorização do Serviço Móvel Especializado (SME) para o Serviço Móvel Pessoal (SMP), Serviço Limitado Privado (SLP) ou Serviço Limitado Especializado (SLE), na forma do Anexo a esta Resolução, altera a Resolução n ${ }^{\circ}$ 454/2006 e seus anexo, e dá outras disposições.

$\Rightarrow$ Anexo - Norma de adaptação dos instrumentos de permissão e de autorização do Serviço Móvel Especializado (SME) para o Serviço Móvel Pessoal (SMP), Serviço Limitado Privado (SLP) ou Serviço Limitado Especializado (SLE)

\section{Serviço Móvel Marítimo}

\section{Normatização}

Resolução da ANATEL no 651, de 13 de abril de 2015 - Aprova o Regulamento do Serviço Limitado Móvel Aeronáutico e do Serviço Limitado Móvel Marítimo

$\rightarrow$ Anexo - Regulamento do Serviço Limitado Móvel Aeronáutico e do Serviço Limitado Móvel Marítimo

\section{Serviço Móvel Pessoal (SMP)}

\section{Normatização}

Lei n⿳ 13.116, de 20 de abril de 2015 - (Lei Geral das Antenas) Estabelece normas gerais para implantação e compartilhamento da infraestrutura de telecomunicações e altera as Leis nos 9.472, de 16 de julho de 1997, 11.934, de 5 de maio de 2009, e 10.257 , de 10 de julho de 2001.

Lei $\mathbf{n}^{\circ}$ 13.146, de 6 de julho de 2015 - Institui a Lei Brasileira de Inclusão da Pessoa com Deficiência (Estatuto da Pessoa com Deficiência)

$\checkmark$ Determina que as empresas prestadoras de serviços de telecomunicações deverão garantir pleno acesso à pessoa com deficiência, conforme regulamentação específica.

Resolução da ANATEL no 647, de 9 de fevereiro de 2015 - Aprova a Norma de adaptação dos instrumentos de permissão e de autorização do Serviço Móvel Especializado (SME) para o Serviço Móvel Pessoal (SMP), Serviço Limitado Privado (SLP) ou Serviço Limitado Especializado (SLE), na forma do Anexo a esta Resolução, altera a Resolução n ${ }^{\circ}$ 454/2006 e seus anexo, e dá outras disposições.

- Anexo - Norma de adaptação dos instrumentos de permissão e de autorização do Serviço Móvel Especializado (SME) para o Serviço Móvel Pessoal (SMP), Serviço Limitado Privado (SLP) ou Serviço Limitado Especializado (SLE)

$\boldsymbol{V}$ Destinação das subfaixas de 806 a $821 \mathrm{MHz}$ e 851 a $866 \mathrm{MHz}$ ao SMP sem prejuízo de destinação ao Serviço Móvel Especializado - SME.

Resolução da ANATEL no 654, de 13 de julho de 2015 - Aprova o Regulamento das Condições de Aferição do Grau de Satisfação e da Qualidade Percebida Junto aos Usuários de Serviços de Telecomunicações

$\Rightarrow$ - Regulamento das Condições de Aferição do Grau de Satisfação e da Qualidade Percebida Junto aos Usuários de Serviços de Telecomunicações 
Resolução da ANATEL n 656, de 17 de Agosto de 2015 - Aprova o Regulamento sobre Gestão de Risco das Redes de Telecomunicações e Uso de Serviços de Telecomunicações em Desastres, Situações de Emergência e Estado de Calamidade Pública

$\Rightarrow$ Anexo - Regulamento sobre Gestão de Risco das Redes de Telecomunicações e Uso de Serviços de Telecomunicações em Desastres, Situações de Emergência e Estado de Calamidade Pública

\section{Serviço Telefônico Fixo Comutado (STFC)}

\section{Jurisprudência}

Tribunal de Contas da União - Acórdão do TCU no 3311, de 09 de dezembro de 2015 - Relator: Min. Benjamin Zymler - Plenário do TCU - Unânime - j. 0912-2015. [Catalogação de Márcio Iório Aranha ]

Determinações à ANATEL sobre o acompanhamento dos bens reversíveis das concessões de Serviço Telefônico Fixo Comutado, bem como exigência de que a ANATEL disponibilize em seu sítio eletrônico, no prazo de 210 dias da ciência do acórdão, todas as relações de bens reversíveis de 2009 a 2014 , contendo todos os dados classificados como sendo de caráter público, em formato de arquivo aberto, não-proprietário, estruturado e legível por máquina.

Supremo Tribunal Federal - Agravo Regimental no Recurso Extraordinário 811620 (RE 811620 AgR/MG) - Relator: Min. Edson Fachin - Plenário do STF Unânime - j. 13-10-2015 - Diário da Justiça Eletrônico, 28-10-2015. [Catalogação de Márcio Iório Aranha ]

Inconstitucionalidade de disciplina estadual para cobrança de taxa de uso e ocupação de solo e espaço aéreo de instalações de equipamentos necessários à prestação de serviço público de telecomunicações por invasão de competência legislativa da União.

Supremo Tribunal Federal - Ação Direta de Inconstitucionalidade no 2.615 (ADI 2.615 - Santa Catarina) - Relator: Min. Eros Grau - Plenário do STF Maioria - j. 11-03-2015 - Diário da Justiça Eletrônico, 11-03-2015. [Catalogação de Márcio Iório Aranha ]

Inconstitucionalidade de disciplina estudual sobre as condições de cobrança do valor da assinatura básica por invasão de competência da União. O argumento de que se trata de direito do consumidor não autoriza estado-membro da federação a legislar sobre assinatura básica.

\section{Normatização}

Lei $\mathbf{n}^{\mathbf{0}}$ 13.116, de 20 de abril de 2015 - (Lei Geral das Antenas) Estabelece normas gerais para implantação e compartilhamento da infraestrutura de telecomunicações e altera as Leis nos 9.472, de 16 de julho de 1997, 11.934, de 5 de maio de 2009, e 10.257 , de 10 de julho de 2001.

Lei $n^{0}$ 13.140, de 26 de junho de 2015 - Dispõe sobre a mediação entre particulares como meio de solução de controvérsias e sobre a autocomposição de conflitos no âmbito da administração pública; altera a Lei no 9.469, de 10 de julho de 1997, e o Decreto no 70.235, de 6 de março de 1972; e revoga o § 2o do art. 6o da Lei no 9.469, de 10 de julho de 1997.

$\boldsymbol{\sim} \mathrm{O}$ art. $32, \S 5^{\circ}$ da Lei 13.140/2015 dispõe que se compreende na competência das câmaras de prevenção e resolução administrativa de conflitos as questões que 
envolvam equilíbrio econômico-financeiro de contratos celebrados pela administração com particulares.

Lei no 13.146, de 6 de julho de 2015 - Institui a Lei Brasileira de Inclusão da Pessoa com Deficiência (Estatuto da Pessoa com Deficiência)

$\checkmark$ Determina que as empresas prestadoras de serviços de telecomunicações deverão garantir pleno acesso à pessoa com deficiência, conforme regulamentação específica.

Resolução da ANATEL no 652, de 27 de maio de 2015 - Altera os Anexos I e II do Regulamento sobre Áreas Locais para o Serviço Telefônico Fixo Comutado Destinado ao Uso do Público em Geral - STFC

Resolução da ANATEL n $^{\circ}$ 653, de 13 de julho de 2015 - Aprova alteração do Anexo I ao Regulamento de Tarifação do Serviço Telefônico Fixo Comutado Destinado ao Uso do Público em Geral - STFC Prestado no Regime Público, aprovado pela Resolução $\mathrm{n}^{\circ}$ 424, de 6 de dezembro de 2005, e do Plano Geral de Códigos Nacionais - PGCN, Anexo II à Resolução nº 263, de 8 de junho de 2001, para inserir: a) o município de Paraíso das Águas, no estado do Mato Grosso do Sul, na Área de Tarifação 672K (Costa Rica) e atribuir-lhe o Código Nacional 67; b) o município de Mojuí dos Campos, no estado do Pará, na Área de Tarifação 915 (Santarém) e atribuir-lhe o Código Nacional 93; c) o município de Pinto Bandeira, no estado do Rio Grande do Sul, na Área de Tarifação 542C (Bento Gonçalves) e atribuir-lhe o Código Nacional 54; d) o município de Pescaria Brava, no estado de Santa Catarina, na Ârea de Tarifação 486 (Tubarão) e atribuir-lhe o Código Nacional 48; e, e) o município de Balneário Rincão, no estado de Santa Catarina, na Área de Tarifação 484 (Criciúma) e atribuir-lhe o Código Nacional 48

$\rightarrow$ Anexo I - Alterações do Anexo I ao Regulamento de Tarifação do Serviço Telefônico Fixo Comutado Destinado ao Uso do Público em Geral - STFC Prestado no Regime Público

$\Rightarrow$ Anexo II - Alterações do Anexo II do Plano Geral de Códigos Nacionais - PGCN

Resolução da ANATEL no 654, de 13 de julho de 2015 - Aprova o Regulamento das Condições de Aferição do Grau de Satisfação e da Qualidade Percebida Junto aos Usuários de Serviços de Telecomunicações

$\Rightarrow$ - Regulamento das Condições de Aferição do Grau de Satisfação e da Qualidade Percebida Junto aos Usuários de Serviços de Telecomunicações

Resolução da ANATEL $n^{\circ}$ 659, de 28 de dezembro de 2015 - Aprova a alteração da Cláusula 3.2 do Contrato de Concessão para a prestação do Serviço Telefônico Fixo Comutado - STFC, nas modalidades de serviço Local, Longa Distância Nacional - LDN e Longa Distância Internacional - LDI, para ampliar prazo para a realização de alterações referentes ao período de 2016 a 2020

$\checkmark$ Altera a data da penúltima revisão quinquenal dos contratos de concessão do STFC de 31 de dezembro de 2015 para 30 de abril de 2016.

\section{Atos}

Acórdão do Conselho Diretor da ANATEL, de 5 de janeiro de 2015 (Ref. $\mathbf{n}^{\circ}$ 6/2015) - Possibilidade de celebração de TAC sobre infração de natureza grave relativa a indícios de prestação não outorgada de STFC, mesmo que a conduta já tenha sido regularizada. A celebração de TAC submete-se ao juízo da autoridade sobre a conveniência e oportunidade do acordo negocial como solução alternativa ao tradicional rito do procedimento sancionador para regularização de condutas infrativas 
Ato do Conselho Diretor da ANATEL no 448, de 22 de janeiro de 2015 Concede anuência prévia à transferência do controle integral da GVT PARTICIPAÇÕES S/A para a TELEFÔNICA BRASIL S/A, mediante condicionamentos de eliminação de sobreposição de outorgas do STFC, de assunção pela adquirente das obrigações de manutenção de cobertura geográfica e continuidade de atendimento do STFC, SCM e SeAC, de manutenção das ofertas de planos de serviços e ofertas conjuntas de STFC, SCM e SeAC então vigentes pelo prazo mínimo de 18 meses, de manutenção dos contratos em vigor com os usuários ao tempo da operação pelo prazo mínimo de 18 meses, de expansão da cobertura da rede e dos princípios serviços de telecomunicações envolvidos na operação, dentre outros.

\section{Serviço de Acesso Condicionado (SeAC)}

\section{Jurisprudência}

Supremo Tribunal Federal - Embargos de Declaração no Recurso Extraordinário 456534 Embargos de Declaração - (RE 456534/RS) - Relator: Min. Luís Roberto Barroso - Relator para o Acórdão: Min. Aldir Passarinho Primeira Turma do STF - Unânime - j. 23-06-2015 - Diário da Justiça Eletrônico, 06-08-2015. [Catalogação de Márcio Iório Aranha ]

Constitucionalidade de disciplina municipal para cobrança de taxa de licença para instalação e de verificação da permanência das condições técnicas iniciais dos equipamentos destinados à energia elétrica e ao fornecimento de serviços de telecomunicações. A cobrança da taxa em razão do exercício do poder de polícia municipal para fiscalização quanto ao atendimento de regras de posturas municipais, desde que prevista em lei, é constitucional. O exercício de poder de polícia in casu é presumido.

\section{Normatização}

Lei $\mathbf{n}^{\circ}$ 13.146, de 6 de julho de 2015 - Institui a Lei Brasileira de Inclusão da Pessoa com Deficiência (Estatuto da Pessoa com Deficiência)

$\checkmark$ Determina que as empresas prestadoras de serviços de telecomunicações deverão garantir pleno acesso à pessoa com deficiência, conforme regulamentação específica.

Lei $\mathbf{n}^{\mathbf{0}}$ 13.188, de 11 de novembro de 2015 - Dispõe sobre o direito de resposta ou retificação do ofendido em matéria divulgada, publicada ou transmitida por veículo de comunicação social

Resolução da ANATEL $n^{\circ}$ 648, de 11 de fevereiro de 2015 - Destina faixas de radiofrequências para o Serviço de Acesso Condicionado (SeAC)

Resolução da ANATEL no 654, de 13 de julho de 2015 - Aprova o Regulamento das Condições de Aferição do Grau de Satisfação e da Qualidade Percebida Junto aos Usuários de Serviços de Telecomunicações

$\Rightarrow$ - Regulamento das Condições de Aferição do Grau de Satisfação e da Qualidade Percebida Junto aos Usuários de Serviços de Telecomunicações

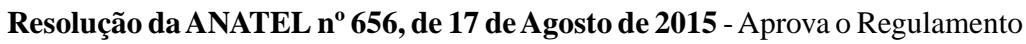
sobre Gestão de Risco das Redes de Telecomunicações e Uso de Serviços de Telecomunicações em Desastres, Situações de Emergência e Estado de Calamidade Pública

- Anexo - Regulamento sobre Gestão de Risco das Redes de Telecomunicações e Uso de Serviços de Telecomunicações em Desastres, Situações de Emergência e Estado de Calamidade Pública 


\section{Atos}

Ato do Conselho Diretor da ANATEL $n^{0}$ 448, de 22 de janeiro de 2015 Concede anuência prévia à transferência do controle integral da GVT PARTICIPAÇÕES S/A para a TELEFÔNICA BRASIL S/A, mediante condicionamentos de eliminação de sobreposição de outorgas do STFC, de assunção pela adquirente das obrigações de manutenção de cobertura geográfica e continuidade de atendimento do STFC, SCM e SeAC, de manutenção das ofertas de planos de serviços e ofertas conjuntas de STFC, SCM e SeAC então vigentes pelo prazo mínimo de 18 meses, de manutenção dos contratos em vigor com os usuários ao tempo da operação pelo prazo mínimo de 18 meses, de expansão da cobertura da rede e dos princípios serviços de telecomunicações envolvidos na operação, dentre outros.

\section{Serviço de Comunicação Multimída (SCM)}

\section{Normatização}

Resolução da ANATEL no 654, de 13 de julho de 2015 - Aprova o Regulamento das Condições de Aferição do Grau de Satisfação e da Qualidade Percebida Junto aos Usuários de Serviços de Telecomunicações

$\Rightarrow$ - Regulamento das Condições de Aferição do Grau de Satisfação e da Qualidade Percebida Junto aos Usuários de Serviços de Telecomunicações

\section{Atos}

Ato do Conselho Diretor da ANATEL no 448, de 22 de janeiro de 2015 Concede anuência prévia à transferência do controle integral da GVT PARTICIPAÇÕES S/A para a TELEFÔNICA BRASIL S/A, mediante condicionamentos de eliminação de sobreposição de outorgas do STFC, de assunção pela adquirente das obrigações de manutenção de cobertura geográfica e continuidade de atendimento do STFC, SCM e SeAC, de manutenção das ofertas de planos de serviços e ofertas conjuntas de STFC, SCM e SeAC então vigentes pelo prazo mínimo de 18 meses, de manutenção dos contratos em vigor com os usuários ao tempo da operação pelo prazo mínimo de 18 meses, de expansão da cobertura da rede e dos princípios serviços de telecomunicações envolvidos na operação, dentre outros.

\section{Serviço de Telecomunicações Aeronáuticas}

\section{Serviço Móvel Aeronáutico}

\section{Normatização}

Resolução da ANATEL no 651, de 13 de abril de 2015 - Aprova o Regulamento do Serviço Limitado Móvel Aeronáutico e do Serviço Limitado Móvel Marítimo

$\rightarrow$ Anexo - Regulamento do Serviço Limitado Móvel Aeronáutico e do Serviço Limitado Móvel Marítimo 


\section{Ramos Jurídicos Afins}

\section{Direito da Concorrência}

Atos

Ato do Conselho Diretor da ANATEL no 448, de 22 de janeiro de 2015 Concede anuência prévia à transferência do controle integral da GVT PARTICIPAÇÕES S/A para a TELEFÔNICA BRASIL S/A, mediante condicionamentos de eliminação de sobreposição de outorgas do STFC, de assunção pela adquirente das obrigações de manutenção de cobertura geográfica e continuidade de atendimento do STFC, SCM e SeAC, de manutenção das ofertas de planos de serviços e ofertas conjuntas de STFC, SCM e SeAC então vigentes pelo prazo mínimo de 18 meses, de manutenção dos contratos em vigor com os usuários ao tempo da operação pelo prazo mínimo de 18 meses, de expansão da cobertura da rede e dos princípios serviços de telecomunicações envolvidos na operação, dentre outros.

\section{Direito Urbanístico}

\section{Normatização}

Lei n⿳ 13.116, de 20 de abril de 2015 - (Lei Geral das Antenas) Estabelece normas gerais para implantação e compartilhamento da infraestrutura de telecomunicações e altera as Leis nos 9.472, de 16 de julho de 1997, 11.934, de 5 de maio de 2009, e 10.257 , de 10 de julho de 2001 .

\section{Aplicações de Telecomunicações}

\section{Internet}

\section{Jurisprudência}

Superior Tribunal de Justiça - Agravo Regimental no Recurso Especial $\mathbf{n}^{\circ}$ 1384340 (STJ - RESP 1384340 AgRg/DF - Distrito Federal) - Relator: Min. Paulo de Tarso Sanseverino - Terceira Turma do STJ - Unânime - j. 05-05-2015 Diário da Justiça Eletrônico, 12-05-2015. [Catalogação de Márcio Iório Aranha ]

O Marco Civil da Internet ( Lei 12.965/2014) não se aplica a fatos pretéritos a sua edição. Comentário ofensivo postado no ORKUT é de responsabilidade do provedor de hospedagem devidamente notificado que não providenciou a identificação do IP do autor da defesa, mesmo que a impossibilidade de identificação do ofensor resulte de caso fortuito ou força maior ocorridos durante o atraso na identificação do IP do autor da ofensa.

\section{Normatização}

Lei $\mathbf{n}^{\circ}$ 13.146, de 6 de julho de 2015 - Institui a Lei Brasileira de Inclusão da Pessoa com Deficiência (Estatuto da Pessoa com Deficiência)

$\boldsymbol{V}$ Exigência de obrigatória acessibilidade nos sítios da internet mantidos por empresas com sede ou representação comercial no País ou por órgãos de governo, para uso por pessoa com deficiência. 
Lei $\mathbf{n}^{0}$ 13.188, de 11 de novembro de 2015 - Dispõe sobre o direito de resposta ou retificação do ofendido em matéria divulgada, publicada ou transmitida por veículo de comunicação social

\section{Acessibilidade}

\section{Normatização}

Lei no 13.146, de 6 de julho de 2015 - Institui a Lei Brasileira de Inclusão da Pessoa com Deficiência (Estatuto da Pessoa com Deficiência)

\section{Acesso a Serviços de Interesse Público e Uso de Radiofrequência por tais Serviços}

\section{Normatização}

Resolução da ANATEL n ${ }^{\circ}$ 656, de 17 de Agosto de 2015 - Aprova o Regulamento sobre Gestão de Risco das Redes de Telecomunicações e Uso de Serviços de Telecomunicações em Desastres, Situações de Emergência e Estado de Calamidade Pública

$\rightarrow$ Anexo - Regulamento sobre Gestão de Risco das Redes de Telecomunicações e Uso de Serviços de Telecomunicações em Desastres, Situações de Emergência e Estado de Calamidade Pública

\section{Banda Larga}

\section{Normatização}

Portaria MC no 320, de 12 de janeiro de 2015 - Altera a Portaria ${ }^{\circ}$ 55, de 12 de março de 2013, do Ministério das Comunicações, que regulamenta os procedimentos para submissão, análise, aprovação, acompanhamento e fiscalização dos projetos apresentados ao Ministério das Comunicações referentes ao Regime Especial de Tributação do Programa Nacional de Banda Larga para Implantação de Redes de Telecomunicações - REPNBL-Redes.

$\rightarrow$ Anexo - Alterações dos percentuais mínimos para equipamentos e componentes de redes produzidos de acordo com o respectivo PPB e desenvolvidos com tecnologia nacional

Resolução da ANATEL no 655, de 5 de Agosto de 2015 - Aprova o Regulamento do Acompanhamento de Compromissos de Aquisição de Produtos e Sistemas Nacionais e estabelece regras específicas para o cumprimento do Compromisso de Aquisição de Produtos de Tecnologia Nacional

$\Rightarrow$ Anexo - Regulamento do Acompanhamento de Compromissos de Aquisição de Produtos e Sistemas Nacionais

\section{Atores no Setor de Telecomunicações}

\section{Jurisprudência}

Tribunal de Contas da União - Acórdão TCU 2320, de 16 de setembro de 2015 - Relator: Min. Ministro Vital do Rêgo - Plenário do TCU - Unânime - j. 16-092015. [Catalogação de Márcio Iório Aranha ] 
Uso indevido de recursos do Fundo de Fiscalização das Telecomunicações (FISTEL) para abertura de créditos adicionais destinados ao custeio de ações estranhas aos serviços de custeio, manutenção e aperfeiçoamento da fiscalização dos serviços de telecomunicações fere a caracterização de tais recursos como fontes vinculadas. É possível, entretanto, a desvinculação de tais recursos mediante transferência de receita excedente ao Tesouro Nacional. A receita excedente deve constar, segundo determinação do TCU À ANATEL, de quadro demonstrativo do planejamento plurianual das receitas e despesas que acompanhe as propostas orçamentárias da autarquia e do FISTEL. Entendimento majoritário de que a afetação de receitas é característica das contribuições e não das taxas, desde que norma específica dê tratamento de uso livre dos saldos e que sejam preservadas continuamente as finalidades inicialmente estabelecidas pela taxa.

Supremo Tribunal Federal - Agravo Regimental no Recurso Extraordinário 811620 (RE 811620 AgR/MG) - Relator: Min. Edson Fachin - Plenário do STF Unânime - j. 13-10-2015 - Diário da Justiça Eletrônico, 28-10-2015. [Catalogação de Márcio Iório Aranha ]

Inconstitucionalidade de disciplina estadual para cobrança de taxa de uso e ocupação de solo e espaço aéreo de instalações de equipamentos necessários à prestação de serviço público de telecomunicações por invasão de competência legislativa da União.

Supremo Tribunal Federal - Ação Direta de Inconstitucionalidade no 2.615 (ADI 2.615 - Santa Catarina) - Relator: Min. Eros Grau - Plenário do STF Maioria - j. 11-03-2015 - Diário da Justiça Eletrônico, 11-03-2015. [Catalogação de Márcio Iório Aranha ]

Inconstitucionalidade de disciplina estudual sobre as condições de cobrança do valor da assinatura básica por invasão de competência da União. O argumento de que se trata de direito do consumidor não autoriza estado-membro da federação a legislar sobre assinatura básica.

Supremo Tribunal Federal - Embargos de Declaração no Recurso Extraordinário 456534 Embargos de Declaração - (RE 456534/RS) - Relator: Min. Luís Roberto Barroso - Relator para o Acórdão: Min. Aldir Passarinho Primeira Turma do STF - Unânime - j. 23-06-2015 - Diário da Justiça Eletrônico, 06-08-2015. [Catalogação de Márcio Iório Aranha ]

Constitucionalidade de disciplina municipal para cobrança de taxa de licença para instalação e de verificação da permanência das condições técnicas iniciais dos equipamentos destinados à energia elétrica e ao fornecimento de serviços de telecomunicações. A cobrança da taxa em razão do exercício do poder de polícia municipal para fiscalização quanto ao atendimento de regras de posturas municipais, desde que prevista em lei, é constitucional. O exercício de poder de polícia in casu é presumido.

\section{ANATEL}

\section{Normatização}

Lei $\mathbf{n}^{\circ}$ 13.129, de 26 de maio de 2015 - Altera a Lei no 9.307, de 23 de setembro de 1996, e a Lei no 6.404, de 15 de dezembro de 1976, para ampliar o âmbito de aplicação da arbitragem e dispor sobre a escolha dos árbitros quando as partes recorrem a órgão arbitral, a interrupção da prescrição pela instituição da arbitragem, a concessão de tutelas cautelares e de urgência nos casos de arbitragem, a carta 
arbitral e a sentença arbitral, e revoga dispositivos da Lei no 9.307, de 23 de setembro de 1996.

$\checkmark$ Possibilidade de arbitragem envolvendo a administração pública, desde que sobre direitos patrimoniais disponíveis e respeite os princípios da legalidade e da publicidade.

Lei $\mathbf{n}^{0}$ 13.140, de 26 de junho de 2015 - Dispõe sobre a mediação entre particulares como meio de solução de controvérsias e sobre a autocomposição de conflitos no âmbito da administração pública; altera a Lei no 9.469, de 10 de julho de 1997, e o Decreto no 70.235, de 6 de março de 1972; e revoga o $§ 20$ do art. 6o da Lei no 9.469, de 10 de julho de 1997.

$\checkmark \mathrm{O}$ art. $32, \S 5^{\circ}$ da Lei $13.140 / 2015$ dispõe que se compreende na competência das câmaras de prevenção e resolução administrativa de conflitos as questões que envolvam equilíbrio econômico-financeiro de contratos celebrados pela administração com particulares.

Resolução da ANATEL no 650, de 16 de março de 2015 - Aprova o Regimento Interno do Comitê de Defesa dos Usuários de Serviços de Telecomunicações CDUST

- Anexo - Regimento Interno do Comitê de Defesa dos Usuários de Serviços de Telecomunicações (CDUST)

Resolução da ANATEL no 658, de 11 de dezembro de 2015 - Revoga o Plano Geral de Atualização da Regulamentação das Telecomunicações no Brasil (PGR)

\section{Atos}

Acórdão do Conselho Diretor da ANATEL, de 24 de fevereiro de 2015 (Ref. $\mathbf{n}^{\mathbf{0}}$ 53/2015) - A renúncia de outorgas de radiofrequências para cumprimento de exigência editalícia em licitação realizada pela ANATEL opera efeitos de extinção das outorgas renunciadas imediatamente após decorrido o prazo fixado no compromisso aposto aos autos do processo e a despeito da comprovação de início de negociações para transferência das outorgas correspondentes, não cabendo à licitante opor ao ato de extinção o fato de que não teria ultimado a transferência das outorgas ou do controle societário das empresas que detivessem outorgas nas subfaixas e áreas de prestação renunciadas pela licitante para pessoa não pertencente a seu grupo econômico. Alcançado o termo final do prazo compromissado sem a transferência de outorgas ou de controle societário das empresas que as detiverem, compete à ANATEL extinguir unilateralmente as outorgas abdicadas como exigência licitatória, independentemente da demora nas negociações privadas, exceto o caso de mora atribuível a ato ou inação da Administração Pública na anuência prévia correspondente.

Acórdão do Conselho Diretor da ANATEL, de 31 de julho de 2015 (Ref. $\mathbf{n}^{\circ}$ 305/2015) - Tempestividade de recurso administrativo deve ser certificada do momento do seu recebimento no protocolo da Agência, não da postagem do documento.

Acórdão do Conselho Diretor da ANATEL, de 5 de janeiro de 2015 (Ref. no 6/2015) - Possibilidade de celebração de TAC sobre infração de natureza grave relativa a indícios de prestação não outorgada de STFC, mesmo que a conduta já tenha sido regularizada. A celebração de TAC submete-se ao juízo da autoridade sobre a conveniência e oportunidade do acordo negocial como solução alternativa ao tradicional rito do procedimento sancionador para regularização de condutas infrativas 
Acórdão do Conselho Diretor da ANATEL, de 5 de novembro de 2015 (Ref. $n^{\circ}$ 480/2015) - É ilícito o incentivo à realização de acessos discados à internet em horário de tarifa reduzida sob a promessa de que os usuários de STFC sejam remunerados pelo tempo de conexão ao provedor de acesso à internet, caracterizando a conduta prevista no art. 29 do Regulamento Geral de Interconexão, aprovado pela Resolução $n^{\circ} 410 / 2015$, de uso indevido das rotas de interconexão para cursar tráfego artificialmente gerado além do "estritamente necessário à prestação do serviço" (art. 152 da LGT), bem como é possível a imposição de determinação administrativa de interrupção de tráfego, ou bloqueio de interconexão, para correção da conduta e devolução de valores pagos a mais, independentemente de ampla defesa e contraditório, por se tratar de ato de ofício da ANATEL para coibir conduta ilícita de regulado.

Relatório da Ouvidoria da ANATEL 2015

\section{Poder Legislativo}

\section{Tribunal de Contas da União}

\section{Jurisprudência}

\section{Tribunal de Contas da União - Acórdão TCU 2320, de 16 de setembro de 2015} - Relator: Min. Ministro Vital do Rêgo - Plenário do TCU - Unânime - j. 16-092015. [Catalogação de Márcio Iório Aranha ]

Uso indevido de recursos do Fundo de Fiscalização das Telecomunicações (FISTEL) para abertura de créditos adicionais destinados ao custeio de ações estranhas aos serviços de custeio, manutenção e aperfeiçoamento da fiscalização dos serviços de telecomunicações fere a caracterização de tais recursos como fontes vinculadas. É possível, entretanto, a desvinculação de tais recursos mediante transferência de receita excedente ao Tesouro Nacional. A receita excedente deve constar, segundo determinação do TCU À ANATEL, de quadro demonstrativo do planejamento plurianual das receitas e despesas que acompanhe as propostas orçamentárias da autarquia e do FISTEL. Entendimento majoritário de que a afetação de receitas é característica das contribuições e não das taxas, desde que norma específica dê tratamento de uso livre dos saldos e que sejam preservadas continuamente as finalidades inicialmente estabelecidas pela taxa.

Tribunal de Contas da União - Acórdão do TCU n 3311, de 09 de dezembro de 2015 - Relator: Min. Benjamin Zymler - Plenário do TCU - Unânime - j. 0912-2015. [Catalogação de Márcio Iório Aranha ]

Determinações à ANATEL sobre o acompanhamento dos bens reversíveis das concessões de Serviço Telefônico Fixo Comutado, bem como exigência de que a ANATEL disponibilize em seu sítio eletrônico, no prazo de 210 dias da ciência do acórdão, todas as relações de bens reversíveis de 2009 a 2014, contendo todos os dados classificados como sendo de caráter público, em formato de arquivo aberto, não-proprietário, estruturado e legível por máquina.

\section{Poder Executivo}

\section{Normatização}

Lei $\mathbf{n}^{\mathbf{0}}$ 13.129, de 26 de maio de $\mathbf{2 0 1 5}$ - Altera a Lei no 9.307, de 23 de setembro de 1996, e a Lei no 6.404, de 15 de dezembro de 1976, para ampliar o âmbito de 
aplicação da arbitragem e dispor sobre a escolha dos árbitros quando as partes recorrem a órgão arbitral, a interrupção da prescrição pela instituição da arbitragem, a concessão de tutelas cautelares e de urgência nos casos de arbitragem, a carta arbitral e a sentença arbitral, e revoga dispositivos da Lei no 9.307, de 23 de setembro de 1996.

$\checkmark$ Possibilidade de arbitragem envolvendo a administração pública, desde que sobre direitos patrimoniais disponíveis e respeite os princípios da legalidade e da publicidade.

\section{Presidência da República}

\section{Normatização}

Lei $\mathbf{n}^{\circ}$ 13.159, de 10 de agosto de 2015 - Altera a Lei no 11.484, de 31 de maio de 2007, que dispõe sobre os incentivos às indústrias de equipamentos para TV Digital e de componentes eletrônicos semicondutores e sobre a proteção à propriedade intelectual das topografias de circuitos integrados, instituindo o Programa de Apoio ao Desenvolvimento Tecnológico da Indústria de Semicondutores - PADIS e o Programa de Apoio ao Desenvolvimento Tecnológico da Indústria de Equipamentos para a TV Digital - PATVD.

\section{Ministério das Comunicações}

Tema Conexo: Serviços no Setor de Telecomunicações : Radiodifusão.

\section{Normatização}

Portaria MC no 4.335, de 17 de setembro de 2015 - Dispõe sobre os procedimentos de permissão e concessão para execução dos serviços de radiodifusão sonora em frequência modulada e de sons e imagens, com finalidade exclusivamente educativa

- Anexo I - Requerimento de Demonstração de Interesse

$\Rightarrow$ Anexo II - Proposta para Pessoa Jurídica de Direito Público Interno

$\rightarrow$ Anexo III - Proposta para Pessoa Jurídica de Direito Privado

- Anexo IV - Documentos Necessários para Habilitação

$\rightarrow$ Anexo V - Requerimento de Renovação de Outorga - Pessoa Jurídica de Direito Público Interno

$\Rightarrow$ Anexo VI - Requerimento de Renovação de Outorga - Pessoa Jurídica de Direito Privado

$\rightarrow$ Anexo VII - Alteração de Quadro Diretivo

\section{Ministério da Educação}

\section{Normatização}

Portaria Interministerial $\mathbf{n}^{\mathbf{0}} \mathbf{2 . 0 9 8}$, de 14 de maio de 2015 - Estabelece as diretrizes para operacionalização do Canal da Educação no âmbito do Sistema Brasileiro de Televisão Digital Terrestre - SBTVD-T 


\section{Ministério da Cultura}

Normatização

Portaria Interministerial no 4.074, de 26 de Agosto de 2015 - Estabelece as diretrizes para operacionalização do Canal da Cultura no Sistema Brasileiro de Televisão Digital Terrestre

\section{Poder Judiciário}

\section{STF}

\section{Jurisprudência}

Supremo Tribunal Federal - Agravo Regimental no Recurso Extraordinário 811620 (RE 811620 AgR/MG) - Relator: Min. Edson Fachin - Plenário do STF Unânime - j. 13-10-2015 - Diário da Justiça Eletrônico, 28-10-2015. [Catalogação de Márcio Iório Aranha ]

Inconstitucionalidade de disciplina estadual para cobrança de taxa de uso e ocupação de solo e espaço aéreo de instalações de equipamentos necessários à prestação de serviço público de telecomunicações por invasão de competência legislativa da União.

Supremo Tribunal Federal - Ação Direta de Inconstitucionalidade $\mathbf{n}^{\circ} \mathbf{2 . 6 1 5}$ (ADI 2.615 - Santa Catarina) - Relator: Min. Eros Grau - Plenário do STF Maioria - j. 11-03-2015 - Diário da Justiça Eletrônico, 11-03-2015. [Catalogação de Márcio Iório Aranha ]

Inconstitucionalidade de disciplina estudual sobre as condições de cobrança do valor da assinatura básica por invasão de competência da União. O argumento de que se trata de direito do consumidor não autoriza estado-membro da federação a legislar sobre assinatura básica.

Supremo Tribunal Federal - Embargos de Declaração no Recurso Extraordinário 456534 Embargos de Declaração - (RE 456534/RS) - Relator: Min. Luís Roberto Barroso - Relator para o Acórdão: Min. Aldir Passarinho Primeira Turma do STF - Unânime - j. 23-06-2015 - Diário da Justiça Eletrônico, 06-08-2015. [Catalogação de Márcio Iório Aranha ]

Constitucionalidade de disciplina municipal para cobrança de taxa de licença para instalação e de verificação da permanência das condições técnicas iniciais dos equipamentos destinados à energia elétrica e ao fornecimento de serviços de telecomunicações. A cobrança da taxa em razão do exercício do poder de polícia municipal para fiscalização quanto ao atendimento de regras de posturas municipais, desde que prevista em lei, é constitucional. O exercício de poder de polícia in casu é presumido.

Supremo Tribunal Federal - Habeas Corpus 128567/MG (HC 128567/MG, de 08 de setembro de 2015) - Relator: Min. Teori Zavascki - Segunda Turma do STF - Unânime - j. 08-09-2015 - Diário da Justiça Eletrônico, 23-09-2015. [Catalogação de Márcio Iório Aranha ]

Crime de exploração clandestina de atividade de telecomunicação (art. 183 da LGT) não se caracteriza como hipótese de aplicação do princípio da insignificância. Baixa potência do equipamento de telecomunicações utilizado não autoriza atipicidade do crime por aplicação do princípio da insignificância. Trata-se de crime formal, ou seja, que não exige resultado naturalístico, de perigo abstrato, consumando-se com o mero desenvolvimento clandestino da 
atividade, $\mathrm{O}$ eventual dano a terceiro em determinado caso concreto configura causa de aumento de pena e também não autoriza a aplicação do princípio da insignificância, pois o crime não tem como pressuposto a ocorrência do prejuízo econômico: ele visa à proteção de um bem difuso de potencial risco de lesão ao regular funcionamento do sistema de telecomunicações. Desde que caracterizada a habitualidade exigida na tipificação do art. 183 da LGT, que o diferencia da conduta tipificada no art. 70 do CBT, aquele que coloca em funcionamento rádio comunitária de forma irregular com equipamentos de potência superior ao permitido e capaz de interferir em outras atividades de telecomunicações não se beneficia do princípio da insignificância, pois ausentes os requisitos da inexpressividade da lesão jurídica e da mínima ofensividade da conduta.

\section{STJ}

\section{Jurisprudência}

Superior Tribunal de Justiça - Agravo Regimental no Recurso Especial $\mathbf{n}^{\circ}$ 1384340 (STJ - RESP 1384340 AgRg/DF - Distrito Federal) - Relator: Min. Paulo de Tarso Sanseverino - Terceira Turma do STJ - Unânime - j. 05-05-2015 Diário da Justiça Eletrônico, 12-05-2015. [Catalogação de Márcio Iório Aranha ]

O Marco Civil da Internet ( Lei 12.965/2014) não se aplica a fatos pretéritos a sua edição. Comentário ofensivo postado no ORKUT é de responsabilidade do provedor de hospedagem devidamente notificado que não providenciou a identificação do IP do autor da defesa, mesmo que a impossibilidade de identificação do ofensor resulte de caso fortuito ou força maior ocorridos durante o atraso na identificação do IP do autor da ofensa.

\section{Prestadora / Operadora}

\section{Normatização}

Lei n⿳ 13.116, de 20 de abril de 2015 - (Lei Geral das Antenas) Estabelece normas gerais para implantação e compartilhamento da infraestrutura de telecomunicações e altera as Leis nos 9.472, de 16 de julho de 1997, 11.934, de 5 de maio de 2009, e 10.257 , de 10 de julho de 2001 .

Lei $\mathbf{n}^{\mathbf{0}}$ 13.129, de 26 de maio de 2015 - Altera a Lei no 9.307, de 23 de setembro de 1996, e a Lei no 6.404, de 15 de dezembro de 1976, para ampliar o âmbito de aplicação da arbitragem e dispor sobre a escolha dos árbitros quando as partes recorrem a órgão arbitral, a interrupção da prescrição pela instituição da arbitragem, a concessão de tutelas cautelares e de urgência nos casos de arbitragem, a carta arbitral e a sentença arbitral, e revoga dispositivos da Lei no 9.307, de 23 de setembro de 1996.

$\checkmark$ Possibilidade de arbitragem envolvendo a administração pública, desde que sobre direitos patrimoniais disponíveis e respeite os princípios da legalidade e da publicidade.

Lei $n^{0}$ 13.140, de 26 de junho de 2015 - Dispõe sobre a mediação entre particulares como meio de solução de controvérsias e sobre a autocomposição de conflitos no âmbito da administração pública; altera a Lei no 9.469, de 10 de julho de 1997, e o Decreto no 70.235, de 6 de março de 1972; e revoga o $\S 2$ o do art. 6o da Lei no 9.469, de 10 de julho de 1997. 
O art. 32, §5 $5^{\circ}$ da Lei 13.140/2015 dispõe que se compreende na competência das câmaras de prevenção e resolução administrativa de conflitos as questões que envolvam equilíbrio econômico-financeiro de contratos celebrados pela administração com particulares.

Atos

Acórdão do Conselho Diretor da ANATEL, de 5 de janeiro de 2015 (Ref. $\mathbf{n}^{\circ}$ 6/2015) - Possibilidade de celebração de TAC sobre infração de natureza grave relativa a indícios de prestação não outorgada de STFC, mesmo que a conduta já tenha sido regularizada. A celebração de TAC submete-se ao juízo da autoridade sobre a conveniência e oportunidade do acordo negocial como solução alternativa ao tradicional rito do procedimento sancionador para regularização de condutas infrativas

Ato do Conselho Diretor da ANATEL no 448, de 22 de janeiro de 2015 Concede anuência prévia à transferência do controle integral da GVT PARTICIPAÇÕES S/A para a TELEFÔNICA BRASIL S/A, mediante condicionamentos de eliminação de sobreposição de outorgas do STFC, de assunção pela adquirente das obrigações de manutenção de cobertura geográfica e continuidade de atendimento do STFC, SCM e SeAC, de manutenção das ofertas de planos de serviços e ofertas conjuntas de STFC, SCM e SeAC então vigentes pelo prazo mínimo de 18 meses, de manutenção dos contratos em vigor com os usuários ao tempo da operação pelo prazo mínimo de 18 meses, de expansão da cobertura da rede e dos princípios serviços de telecomunicações envolvidos na operação, dentre outros.

\section{Usuário / Consumidor}

\section{Jurisprudência}

Superior Tribunal de Justiça - Agravo Regimental no Recurso Especial $\mathbf{n}^{\circ}$ 1384340 (STJ - RESP 1384340 AgRg/DF - Distrito Federal) - Relator: Min. Paulo de Tarso Sanseverino - Terceira Turma do STJ - Unânime - j. 05-05-2015 Diário da Justiça Eletrônico, 12-05-2015. [Catalogação de Márcio Iório Aranha ]

O Marco Civil da Internet ( Lei 12.965/2014) não se aplica a fatos pretéritos a sua edição. Comentário ofensivo postado no ORKUT é de responsabilidade do provedor de hospedagem devidamente notificado que não providenciou a identificação do IP do autor da defesa, mesmo que a impossibilidade de identificação do ofensor resulte de caso fortuito ou força maior ocorridos durante o atraso na identificação do IP do autor da ofensa.

\section{Normatização}

Resolução da ANATEL no 650, de 16 de março de 2015 - Aprova o Regimento Interno do Comitê de Defesa dos Usuários de Serviços de Telecomunicações CDUST

$\Rightarrow$ Anexo - Regimento Interno do Comitê de Defesa dos Usuários de Serviços de Telecomunicações (CDUST) 


\title{
Provedor de Aplicações de Intenet
}

\author{
Jurisprudência
}

Superior Tribunal de Justiça - Agravo Regimental no Recurso Especial $\mathbf{n}^{\circ}$ 1384340 (STJ - RESP 1384340 AgRg/DF - Distrito Federal) - Relator: Min. Paulo de Tarso Sanseverino - Terceira Turma do STJ - Unânime - j. 05-05-2015 Diário da Justiça Eletrônico, 12-05-2015. [Catalogação de Márcio Iório Aranha ] O Marco Civil da Internet ( Lei 12.965/2014) não se aplica a fatos pretéritos a sua edição. Comentário ofensivo postado no ORKUT é de responsabilidade do provedor de hospedagem devidamente notificado que não providenciou a identificação do IP do autor da defesa, mesmo que a impossibilidade de identificação do ofensor resulte de caso fortuito ou força maior ocorridos durante o atraso na identificação do IP do autor da ofensa.

\section{Normas Referenciadas}

\section{Lei Ordinária}

\begin{tabular}{|c|c|}
\hline \multicolumn{2}{|r|}{$\begin{array}{l}\text {, de } 26 \text { de dezembro de } 1995,9.440 \text {, de } 14 \\
21 \text { de novembro de } 2005,12.024 \text {, de } 27 \text { de a } \\
\text { art. } 46 \text { da Lei no } 12.715 \text {, de } 17 \text { de setembro } \\
\text { iição de mercadoria estrangeira cuja import } \\
\text { zembro de } 1996,12.546 \text {, de } 14 \text { de dezembr } \\
\text { sto de } 1999,10.833 \text {, de } 29 \text { de dezembro de } 2 \\
\text { o de } 2004,11.774 \text {, de } 17 \text { de setembro de } 2 \\
\text { nho de } 2010,10.522 \text {, de } 19 \text { de julho de } 2002 \\
\text { de } 2003,6.634 \text {, de } 2 \text { de maio de } 1979,7.4 \\
10.931 \text {, de } 2 \text { de agosto de } 2004,11.076 \text {, de }\end{array}$} \\
\hline Nota Vigência & Data de publicação no DOU \\
\hline Dispositivos & $\begin{array}{l}\text { CF, Art. 21, inciso XII, alínea a (em 15/08/1995); CF, Art. 223, caput; LGT, Art. 211, } \\
\text { caput. }\end{array}$ \\
\hline Altera & $\begin{array}{l}\text { Lei } n^{\circ} 5.070 / 1966 \text { - Cria o Fundo de Fiscalização das Telecomunicações e dá outras } \\
\text { providências. Alterada pela Lei no } 9.472 / 97 \text { (LGT). }\end{array}$ \\
\hline Correlata & 14 \\
\hline
\end{tabular}




\begin{tabular}{|l|l|}
\hline Publicação & Diário Oficial da União, Seção 1,20/01/2015, pág. p.1 \\
\hline Temas & Temas : Administração do Setor de Telecomunicações : Outorgas : Licitação \\
& Temas : Administração do Setor de Telecomunicações : Outorgas : Preço Público e Preço \\
& Privado \\
& Temas : Administração do Setor de Telecomunicações : Tributação no Setor de \\
& Telecomunicações \\
& Temas : Infraestrutura e Recursos do Setor de Telecomunicações : Equipamentos de \\
& Telecomunicações : Antenas \\
& Temas : Infraestrutura e Recursos do Setor de Telecomunicações : Equipamentos de \\
& Telecomunicações : Estações de Telecomunicações \\
& Temas : Infraestrutura e Recursos do Setor de Telecomunicações : Equipamentos de \\
& Telecomunicações : Terminais \\
& Temas : Políticas de Telecomunicações : Fundos Setoriais de Telecomunicações : FISTEL \\
& Temas : Serviços no Setor de Telecomunicações : Radiodifusão \\
\hline
\end{tabular}

Lei n⿳ 13.116, de 20 de abril de 2015 - (Lei Geral das Antenas) Estabelece normas gerais para implantação e compartilhamento da infraestrutura de telecomunicações e altera as Leis nos 9.472 , de 16 de julho de 1997, 11.934, de 5 de maio de 2009, e 10.257, de 10 de julho de 2001.

\begin{tabular}{|c|c|}
\hline Nota Vigência & Data de publicação no DOU \\
\hline Dispositivos & $\begin{array}{l}\text { CF, Art. 21, inciso XI (em 15/08/1995); CF, Art. 21, inciso XII, alínea a (em 15/08/1995); } \\
\text { LGT, Art. } 74 \text { (em 20/04/2015); LGT, Art. 173, caput. }\end{array}$ \\
\hline Altera & $\begin{array}{l}\text { Lei } n^{\circ} 9.472 / 1997 \text { - Dispõe sobre a organização dos serviços de telecomunicações, a } \\
\text { criação e funcionamento de um órgão regulador e outros aspectos institucionais, nos } \\
\text { termos da Emenda Constitucional } n^{\circ} 8 \text {, de } 1995 \text {. } \\
\text { Lei } 10.257 \text {, de } 10 \text { de julho de } 2001 \\
\text { Lei } n^{\circ} 11.934 / 2009 \text { - Dispõe sobre limites à exposição humana a campos elétricos, } \\
\text { magnéticos e eletromagnéticos; altera a Lei no } 4.771 \text {, de } 15 \text { de setembro de } 1965 \text {; e dá } \\
\text { outras providências. }\end{array}$ \\
\hline Correlata & $\begin{array}{l}\text { Resolução ANATEL-ANEEL } n^{\circ} 4 \text {, de } 16 \text { de dezembro de } 2014 \text { - Aprova o preço de } \\
\text { referência para o compartilhamento de postes entre distribuidoras de energia elétrica e } \\
\text { prestadoras de serviços de telecomunicações, a ser utilizado nos processos de resolução } \\
\text { de conflitos, e estabelece regras para uso e ocupação dos Pontos de Fixação }\end{array}$ \\
\hline Publicação & Diário Oficial da União, Seção 1, 22-04-2015, pág. p. 10 \\
\hline Temas & $\begin{array}{l}\text { Temas : Atores no Setor de Telecomunicações : Prestadora / Operadora } \\
\text { Temas : Infra-estrutura e Recursos do Setor de Telecomunicações : Infraestrutura de } \\
\text { Telecomunicações : Bem Público (utilização e restrição) } \\
\text { Temas : Infraestrutura e Recursos do Setor de Telecomunicações : Equipamentos de } \\
\text { Telecomunicações : Antenas } \\
\text { Temas : Infraestrutura e Recursos do Setor de Telecomunicações : Equipamentos de } \\
\text { Telecomunicações : Estações de Telecomunicações } \\
\text { Temas : Infraestrutura e Recursos do Setor de Telecomunicações : Infra-estrutura de } \\
\text { Telecomunicações : Compartilhamento de Infraestrutura } \\
\text { Temas : Infraestrutura e Recursos do Setor de Telecomunicações : Infraestrutura de } \\
\text { Telecomunicações } \\
\text { Temas : Infraestrutura e Recursos do Setor de Telecomunicações : Redes de } \\
\text { Telecomunicações } \\
\text { Temas : Políticas de Telecomunicações : Concorrência no Setor de Telecomunicações } \\
\text { Temas : Políticas de Telecomunicações : Universalização e Massificação } \\
\text { Temas : Ramos Jurídicos Afins : Direito Urbanístico } \\
\text { Temas : Serviços no Setor de Telecomunicações : Serviço Móvel Pessoal (SMP) }\end{array}$ \\
\hline
\end{tabular}


Temas : Serviços no Setor de Telecomunicações : Serviço Telefônico Fixo Comutado (STFC)

Lei $\mathbf{n}^{0}$ 13.129, de 26 de maio de 2015 - Altera a Lei no 9.307, de 23 de setembro de 1996, e a Lei no 6.404, de 15 de dezembro de 1976, para ampliar o âmbito de aplicação da arbitragem e dispor sobre a escolha dos árbitros quando as partes recorrem a órgão arbitral, a interrupção da prescrição pela instituição da arbitragem, a concessão de tutelas cautelares e de urgência nos casos de arbitragem, a carta arbitral e a sentença arbitral, e revoga dispositivos da Lei no 9.307, de 23 de setembro de 1996.

\begin{tabular}{|l|l|}
\hline Nota Vigência & Após 60 dias da data de publicação. \\
\hline Dispositivos & $\begin{array}{l}\text { CF, Art. 21, inciso XI; CF, Art. 21, inciso XII, alínea a (em 15/08/1995); LGT, Art. 1 } \\
\text { Parágrafo Único; LGT, Art. 19, inciso XVII; LGT, Art. 83, Parágrafo Unico; LGT, Art. } \\
\text { 93, inciso XV; LGT, Art. 103, caput; LGT, Art. 127, caput. }\end{array}$ \\
\hline Altera & $\begin{array}{l}\text { Lei no 6.404/1976 } \\
\text { Lei da Arbitragem - Dispõe sobre a arbitragem. }\end{array}$ \\
\hline Publicação & Diário Oficial da União, Seção 1, 27-05-2015, pág. p.1 \\
\hline Temas & $\begin{array}{l}\text { Temas : Administração do Setor de Telecomunicações : Fiscalização das Telecomunicações } \\
\text { Temas : Administração do Setor de Telecomunicações : Outorgas : Preço Público e Preço } \\
\text { Privado } \\
\text { Temas : Atores no Setor de Telecomunicações : ANATEL } \\
\text { Temas : Atores no Setor de Telecomunicações : Poder Executivo } \\
\text { Temas : Atores no Setor de Telecomunicações : Prestadora / Operadora } \\
\text { Temas : Fundamentos : Conceitos Fundamentais : Direito à Privacidade } \\
\text { Temas : Políticas de Telecomunicações : Controle Social, Hierárquico e Interorgânico }\end{array}$ \\
\hline
\end{tabular}

Lei $n^{0}$ 13.140, de 26 de junho de 2015 - Dispõe sobre a mediação entre particulares como meio de solução de controvérsias e sobre a autocomposição de conflitos no âmbito da administração pública; altera a Lei no 9.469, de 10 de julho de 1997, e o Decreto no 70.235, de 6 de março de 1972; e revoga o § 2o do art. 6o da Lei no 9.469, de 10 de julho de 1997.

\begin{tabular}{|l|l|}
\hline Nota Vigência & 180 dias após sua publicação no DOU \\
\hline Dispositivos & $\begin{array}{l}\text { CF, Art. 21, inciso XI (em 15/08/1995); CF, Art. 21, inciso XII, alínea a (em 15/08/1995); } \\
\text { LGT, Art. 1', Parágrafo Unico; LGT, Art. 19, inciso XVII; LGT, Art. 83, Parágrafo Unico; } \\
\text { LGT, Art. 93, inciso XV; LGT, Art. 110, inciso III. }\end{array}$ \\
\hline Altera & $\begin{array}{l}\text { Lei no 9.469/ 1997 } \\
\text { Decreto }{ }^{\circ} \text { 70.235, de } 6 \text { de março de 1972 }\end{array}$ \\
\hline Publicação & Diário Oficial da União, Seção 1, 29-06-2015, pág. p.4 \\
& $\begin{array}{l}\text { Temas : Administração do Setor de Telecomunicações : Outorgas : Concessão (regras } \\
\text { aplicáveis) } \\
\text { Temas : Administração do Setor de Telecomunicações : Outorgas : Permissão (regras } \\
\text { aplicáveis) } \\
\text { Temas : Administração do Setor de Telecomunicações : Outorgas : Preço Público e Preço } \\
\text { Privado } \\
\text { Temas : Atores no Setor de Telecomunicações : ANATEL } \\
\text { Temas : Atores no Setor de Telecomunicações : Prestadora / Operadora } \\
\text { Temas : Serviços no Setor de Telecomunicações : Radiodifusão } \\
\text { Temas : Serviços no Setor de Telecomunicações : Serviço Telefônico Fixo Comutado } \\
\text { (STFC) }\end{array}$ \\
\hline
\end{tabular}

Lei $\mathbf{n}^{0}$ 13.146, de 6 de julho de 2015 - Institui a Lei Brasileira de Inclusão da Pessoa com Deficiência (Estatuto da Pessoa com Deficiência)

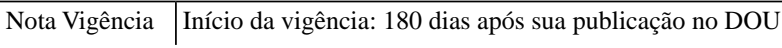




\begin{tabular}{|c|c|}
\hline & $\begin{array}{l}\text { Prorrogação até } 31 \text { de dezembro de } 2021 \text { da vigência da Lei 8989, de } 24 \text { de fevereiro de } \\
995 .\end{array}$ \\
\hline Dispositivos & $\begin{array}{l}\text { F, Art. 21, inciso XI (em 15/08/1995); CF, Art. 21, inciso XII, alínea a (em 15/08/1995); } \\
\text { GT, Art. } 79, \S 1^{\circ} \text {; LGT, Art. } 156, \S 1^{\circ} \text {. }\end{array}$ \\
\hline $\mathrm{Al}$ & 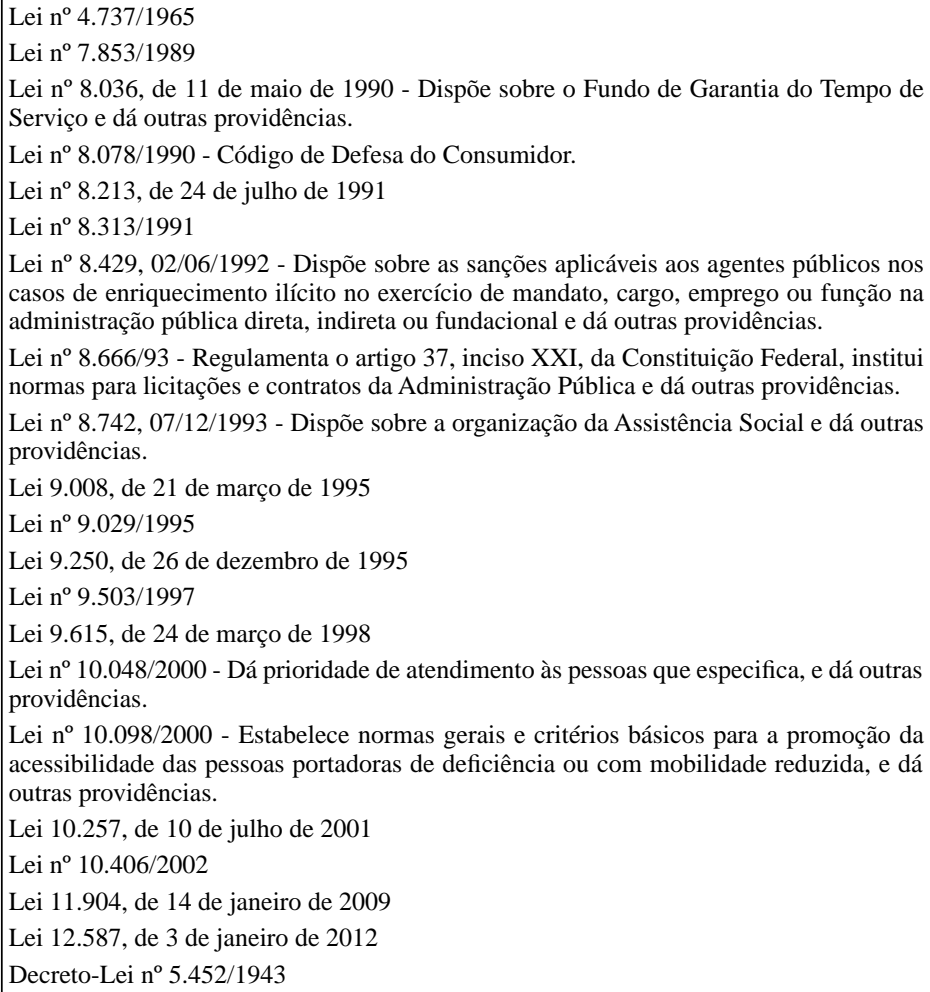 \\
\hline Cor & $\begin{array}{l}\text { Lei n }{ }^{\circ} 8.313 / 1991 \\
\text { Lei no } 8.429,02 / 06 / 1992 \text { - Dispõe sobre as sanções aplicáveis aos agentes públicos nos } \\
\text { casos de enriquecimento ilícito no exercício de mandato, cargo, emprego ou função na } \\
\text { administração pública direta, indireta ou fundacional e dá outras providências. } \\
\text { Lei no 9.472/1997 - Dispõe sobre a organização dos serviços de telecomunicações, a } \\
\text { criação e funcionamento de um órgão regulador e outros aspectos institucionais, nos } \\
\text { termos da Emenda Constitucional no } 8 \text {, de } 1995 \text {. } \\
\text { Decreto Legislativo no } 186 \text {, de } 9 \text { de julho de } 2008 \\
\text { Decreto } 6.949 \text {, de } 25 \text { de agosto de } 2009\end{array}$ \\
\hline Publicação & Diário Oficial da União, Seção 1, 07-07-2015, pág. p.2 \\
\hline Temas & $\begin{array}{l}\text { Temas : Aplicações de Telecomunicações : Acessibilidade } \\
\text { Temas : Aplicações de Telecomunicações : Internet } \\
\text { Temas : Classificações de Serviços no Setor de Telecomunicações : Quanto ao Gênero : } \\
\text { Serviço de Valor Adicionado } \\
\text { Temas : Classificações de Serviços no Setor de Telecomunicações : Quanto ao Interesse } \\
\text { : Serviço de Interesse Coletivo } \\
\text { Temas : Fundamentos : Conceitos Fundamentais : Era da Informação } \\
\text { Temas : Infraestrutura e Recursos do Setor de Telecomunicações : Equipamentos de } \\
\text { Telecomunicações : Terminais }\end{array}$ \\
\hline
\end{tabular}




\begin{tabular}{|l|l|}
\hline Temas : Políticas de Telecomunicações : Universalização : Acesso à Telecomunicações \\
: Portador de Deficiência \\
Temas : Serviços no Setor de Telecomunicações : Internet \\
Temas : Serviços no Setor de Telecomunicações : Radiodifusão : Televisão Aberta \\
Temas : Serviços no Setor de Telecomunicações : Serviço Móvel Pessoal (SMP) \\
Temas : Serviços no Setor de Telecomunicações : Serviço Telefônico Fixo Comutado \\
(STFC) \\
Temas : Serviços no Setor de Telecomunicações : Serviço de Acesso Condicionado \\
(SeAC)
\end{tabular}

Lei n⿳ 13.159, de 10 de agosto de 2015 - Altera a Lei no 11.484, de 31 de maio de 2007, que dispõe sobre os incentivos às indústrias de equipamentos para TV Digital e de componentes eletrônicos semicondutores e sobre a proteção à propriedade intelectual das topografias de circuitos integrados, instituindo o Programa de Apoio ao Desenvolvimento Tecnológico da Indústria de Semicondutores - PADIS e o Programa de Apoio ao Desenvolvimento Tecnológico da Indústria de Equipamentos para a TV Digital - PATVD.

\begin{tabular}{|l|l|}
\hline Nota Vigência & Data de publicação no DOU \\
\hline Dispositivos & LGT, Art. $2^{\circ}$, inciso VI; LGT, Art. 211, caput. \\
\hline Altera & $\begin{array}{l}\text { Lei n }{ }^{\circ} 11.484 / 2007 \text { - Dispõe sobre os incentivos às indústrias de equipamentos para TV } \\
\text { Digital e de componentes eletrônicos semicondutores e sobre a proteção à propriedade } \\
\text { intelectual das topografias de circuitos integrados, instituindo o Programa de Apoio ao } \\
\text { Desenvolvimento Tecnológico da Indústria de Semicondutores - PADIS e o Programa } \\
\text { de Apoio ao Desenvolvimento Tecnológico da Indústria de Equipamentos para a TV } \\
\text { Digital - PATVD; altera a Lei no 8.666, de 21 de junho de 1993; e revoga o art. 26 da } \\
\text { Lei no 11.196, de 21 de novembro de 2005. }\end{array}$ \\
\hline Publicação & $\begin{array}{l}\text { Diário Oficial da União, Edição Extra, 11-08-2015, pág. p.1 } \\
\text { Temas : Atores no Setor de Telecomunicações : Poder Executivo : Presidência da } \\
\text { República } \\
\text { Temas : Serviços no Setor de Telecomunicações : Radiodifusão : Televisão Aberta : TV } \\
\text { Digital }\end{array}$ \\
\hline
\end{tabular}

\begin{tabular}{|c|c|}
\hline e & $\begin{array}{l}\text { oro de } 2015 \text { - Dispõe sobre o dir } \\
\text { a ou transmitida por veículo de }\end{array}$ \\
\hline Nota Vigência & Data de publicação no DOU \\
\hline Dis 1 & $\begin{array}{l}\text { CF, Art. } 5^{\circ} \text {, inciso V; CF, Art. } 220, \S 1^{\circ} \text {; CF, Art. 221, inciso IV; CF, Art. 222, } \S 3^{\circ} \text {; LGT, } \\
\text { Art. } 3^{\circ} \text {, inciso V; LGT, Art. } 3^{\circ} \text {, inciso XII; LGT, Art. 211, caput. }\end{array}$ \\
\hline Altera & Código Penal \\
\hline Correlata & $\begin{array}{l}\text { Lei }{ }^{\circ} 5.250 / 1967 \text { - Regula a liberdade de manifestação do pensamento e de informação. } \\
\text { Lei } n^{\circ} 12.965 / 2014 \text { - Estabelece princípios, garantias, direitos e deveres para o uso da } \\
\text { Internet no Brasil. }\end{array}$ \\
\hline Regulamenta & Constituição da República Federativa do Brasil de 1988 \\
\hline Publicação & Diário Oficial da União, Seção 1, 12-11-2015, págs. p. 1-2 \\
\hline Temas & $\begin{array}{l}\text { Temas : Aplicações de Telecomunicações : Internet } \\
\text { Temas : Fundamentos : Conceitos Fundamentais : Direito à Privacidade } \\
\text { Temas : Fundamentos : Conceitos Fundamentais : Liberdade de Expressão } \\
\text { Temas : Serviços no Setor de Telecomunicações : Internet } \\
\text { Temas : Serviços no Setor de Telecomunicações : Radiodifusão } \\
\text { Temas : Serviços no Setor de Telecomunicações : Serviço de Acesso Condicionado } \\
\text { (SeAC) }\end{array}$ \\
\hline
\end{tabular}




\section{Decreto}

\begin{tabular}{|c|c|}
\hline \multicolumn{2}{|c|}{$\begin{array}{l}\text { Portaria MC no 6.738, de } 21 \text { de dezembro de } 2015 \text { - Dispõe sobre os procedimentos de autorização para } \\
\text { a execução do Serviço de Retransmissão de Televisão, em caráter secundário, com utilização de tecnologia } \\
\text { digital e dá outras providências }\end{array}$} \\
\hline Nota Vigência & Data de publicação no DOU \\
\hline & $\begin{array}{l}\text { Anexo I - Manifestação Formal de Interesse } \\
\text { Anexo II - Documentos Necessários para Habilitação de Pessoas de Direito Público } \\
\text { Interno (Estados, Distrito Federal e Municípios) } \\
\text { Anexo III - Documentos Necessários para Habilitação de Pessoas Jurídicas integrantes } \\
\text { da Administração Indireta Federal, Estadual, Distrital e Municipal } \\
\text { Anexo IV - Documentos Necessários para Habilitação de Concessionárias do Serviço de } \\
\text { Radiodifusão de Sons e Imagens interessadas na Execução do Serviço de RTV para } \\
\text { Retransmitir seus próprios sinais } \\
\text { Anexo V - Documentos Necessários para Habilitação de Demais Pessoas Jurídicas } \\
\text { Anexo VI - Declaração de Concordância }\end{array}$ \\
\hline Disp & $\begin{array}{l}\text { Art. 21, inciso XII, alínea a (em 15/08/1995); CF, Art. 223, caput; LGT, Art. 211, } \\
\text { put. }\end{array}$ \\
\hline Altera & $\begin{array}{l}\text { Portaria MC no } 366 \text {, de } 14 \text { de agosto de } 2012 \text { - Dispõe sobre os procedimentos de } \\
\text { autorização para a execução dos serviços de retransmissão e repetição de televisão. }\end{array}$ \\
\hline Corr & $\begin{array}{l}\text { Portaria MC n } \text { n }^{\circ} 77 \text {, de } 20 \text { de junho de } 2014 \text { - Estabelece o cronograma de transição da } \\
\text { transmissão analógica dos serviços de radiodifusão de sons e imagens e de retransmissão } \\
\text { de televisão para o SBTVD-T. } \\
\text { Portaria } \mathrm{n}^{\circ} 481 / 2014 \text { - Disciplina as condições de cobertura para desligamento da } \\
\text { transmissão analógica dos serviços de radiodifusão de sons e imagens e de retransmissão } \\
\text { de televisão e o papel da Anatel no processo de desligamento. }\end{array}$ \\
\hline Regul & $\begin{array}{l}\text { Decreto }{ }^{\circ} 5.371 / 2005 \text { - Aprova o Regulamento do Serviço de Retransmissão de Televisão } \\
\text { e do Serviço de Repetição de Televisão, ancilares ao Serviço de Radiodifusão de Sons e } \\
\text { Imagens. }\end{array}$ \\
\hline Publicação & Diárıo Oticıal da Unıăo, Seçăo 1, 23-12-2015, págs. p. 109-111 \\
\hline remas & caçoes : Kađic \\
\hline
\end{tabular}

Decreto $n^{0}$ 8.632, de 30 de dezembro de 2015 - Aprova o Programa de Dispêndios Globais - PDG para 2016 das empresas estatais federais, e dá outras providências

\begin{tabular}{|l|l|}
\hline Nota Vigência & Data de publicação no DOU \\
\hline Anexos & $\begin{array}{l}\text { Anexo I - Programa de Dispêndios Globais - PDG para 2016 das empresas estatais federais } \\
\text { Anexo II - Resultado Primário das Empresas Estatais Federais: Metas para o Exercício } \\
\text { de } 2016\end{array}$ \\
\hline Dispositivos & LGT, Art. 186, caput. \\
\hline Publicação & Diário Oficial da União, Seção 1, 31-12-2015, págs. p. 41-68 \\
\hline
\end{tabular}

\section{Portaria Ministerial}

\begin{tabular}{|l|l|}
\hline $\begin{array}{l}\text { Portaria MC no 1.581, de } 9 \text { de abril de } 2015 \text { - Regulamenta o uso da faixa de } 174 \text { MHz a } 216 \mathrm{MHz} \text { (VHF } \\
\text { alto) para TV Digital }\end{array}$ \\
\hline Órgão Emissor & Ministério das Comunicações - Gabinete do Ministro. \\
\hline Nota Vigência & Data de publicação no DOU. \\
\hline Dispositivos & $\begin{array}{l}\text { CF, Art. 21, inciso XII, alínea a (em 15/08/1995); CF, Art. 223, caput; LGT, Art. 19, } \\
\text { inciso VIII; LGT, Art. 158, } § 1^{\circ} \text {, inciso III; LGT, Art. 211, caput. }\end{array}$ \\
\hline
\end{tabular}




\begin{tabular}{|l|l|}
\hline Correlata & $\begin{array}{l}\text { Decreto }{ }^{\circ} \text { 5.820/2006 - Dispõe sobre a implantação do SBTVD-T, estabelece diretrizes } \\
\text { para a transição do sistema de transmissão analógica para o sistema de transmissão digital } \\
\text { do serviço de radiodifusão de sons e imagens e do serviço de retransmissão de televisão, } \\
\text { e dá outras providências. } \\
\text { Portaria } n^{\circ} 481 / 2014 \text { - Disciplina as condições de cobertura para desligamento da } \\
\text { transmissão analógica dos serviços de radiodifusão de sons e imagens e de retransmissão } \\
\text { de televisão e o papel da Anatel no processo de desligamento. }\end{array}$ \\
\hline Publicação & Diário Oficial da União, Seção 1, 13-04-2015, pág. p. 57 \\
\hline Temas & $\begin{array}{l}\text { Temas : Infraestrutura e Recursos do Setor de Telecomunicações : Espectro de } \\
\text { Radiofrequência : Condições de Uso de Radiofrequência e Canalização (Distribuição de } \\
\text { Canais) } \\
\text { Temas : Serviços no Setor de Telecomunicações : Radiodifusão : Televisão Aberta : TV } \\
\text { Digital }\end{array}$ \\
\hline
\end{tabular}

Portaria MC no 320, de 12 de janeiro de 2015 - Altera a Portaria n n $^{\mathbf{0}}$, de 12 de março de 2013, do Ministério das Comunicações, que regulamenta os procedimentos para submissão, análise, aprovação, acompanhamento e fiscalização dos projetos apresentados ao Ministério das Comunicações referentes ao Regime Especial de Tributação do Programa Nacional de Banda Larga para Implantação de Redes de Telecomunicações - REPNBL-Redes.

\begin{tabular}{|c|c|}
\hline Órgão Emissor & Ministério das Comunicações - Gabinete do Ministro. \\
\hline Nota Vigência & Data de publicação no DOU. \\
\hline Anexos & $\begin{array}{l}\text { Anexo - Alterações dos percentuais mínimos para equipamentos e componentes de redes } \\
\text { produzidos de acordo com o respectivo PPB e desenvolvidos com tecnologia nacional }\end{array}$ \\
\hline Dispositivos & LGT, Art. $2^{\circ}$, inciso I; LGT, Art. $2^{\circ}$, inciso V; LGT, Art. $3^{\circ}$, inciso I. \\
\hline Altera & $\begin{array}{l}\text { Portaria MC no 55, de } 12 \text { de março de } 2013 \text { - Regulamenta os procedimentos para } \\
\text { submissão, análise, aprovação, acompanhamento e fiscalização dos projetos apresentados } \\
\text { ao Ministério das Comunicações referentes ao Regime Especial de Tributação do Programa } \\
\text { Nacional de Banda Larga para Implantação de Redes de Telecomunicações - REPNBL- } \\
\text { Redes, de que trata a Lei n } \mathrm{n}^{\circ} 12.715 \text {, de } 17 \text { de setembro de } 2012 \text { e o Decreto } \mathrm{n}^{\circ} 7.921 \text {, de } \\
15 \text { de fevereiro de } 2013 \text {. } \\
\text { Anexo } 2 \text { - Percentuais mínimos para equipamentos e componentes de redes produzidos } \\
\text { de acordo com o respectivo PPB e desenvolvidos com tecnologia nacional - Percentuais } \\
\text { mínimos para equipamentos e componentes de redes produzidos de acordo com o } \\
\text { respectivo PPB e desenvolvidos com tecnologia nacional. }\end{array}$ \\
\hline Regulamenta & 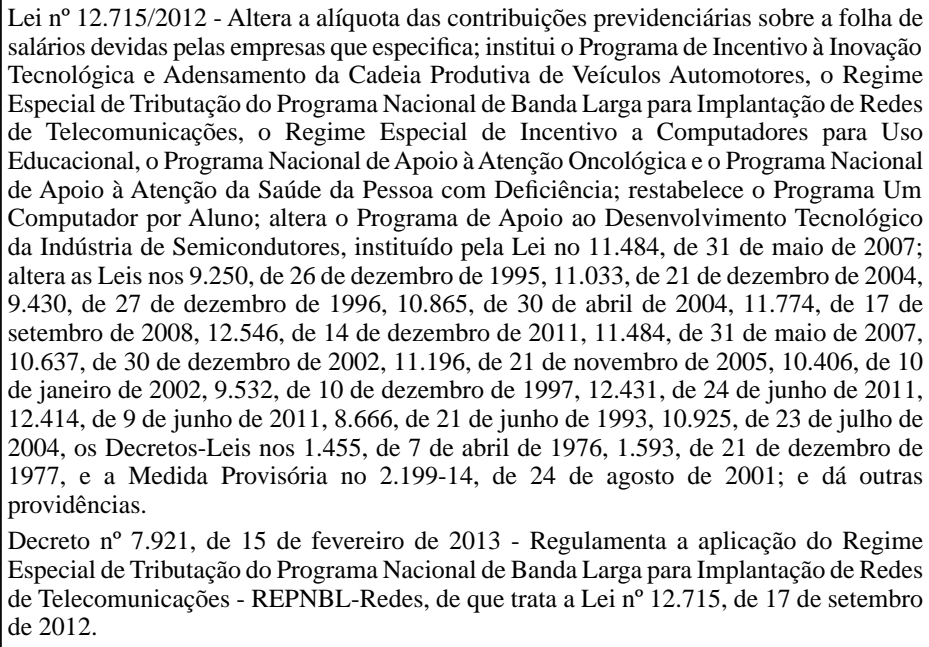 \\
\hline
\end{tabular}




\begin{tabular}{|l|l|}
\hline Publicação & $\begin{array}{l}\text { Diário Oficial da União, Seção 1, 14-01-2015, págs. p. 45-46 } \\
\text { Diário Oficial da União, Seção 1, 16-01-2015, pág. p. 45 [ Retificação ] }\end{array}$ \\
\hline Temas & $\begin{array}{l}\text { Temas : Aplicações de Telecomunicações : Banda Larga } \\
\text { Temas : Serviços no Setor de Telecomunicações : Internet }\end{array}$ \\
\hline
\end{tabular}

Portaria MC no 294, de 30 de janeiro de 2015 - Estabelece o valor máximo da multa por infração às disposições da Lei 4.117/62 ou demais normas aplicáveis aos serviços de radiodifusão e seus ancilares.

\begin{tabular}{|l|l|}
\hline Órgão Emissor & Ministério das Comunicações - Gabinete do Ministro. \\
\hline Nota Vigência & Data de publicação no DOU. \\
\hline Dispositivos & LGT, Art. 211, caput. \\
\hline Regulamenta & Lei no 4.117/1962 - Institui o Código Brasileiro de Telecomunicações. \\
\hline Publicação & Diário Oficial da União, Seção 1, 04-02-2015, pág. p. 28 \\
\hline Temas & $\begin{array}{l}\text { Temas : Administração do Setor de Telecomunicações : Fiscalização das Telecomunicações } \\
\text { Temas : Serviços no Setor de Telecomunicações : Radiodifusão }\end{array}$ \\
\hline
\end{tabular}

Portaria MC no 4.335, de 17 de setembro de 2015 - Dispõe sobre os procedimentos de permissão e concessão para execução dos serviços de radiodifusão sonora em frequência modulada e de sons e imagens, com finalidade exclusivamente educativa

\begin{tabular}{|c|c|}
\hline Órgão Emissor & Comunicações - Gabinete do Ministro. \\
\hline Nota Vigência & Data de publicação no DOU \\
\hline Anexos & $\begin{array}{l}\text { Anexo I - Requerimento de Demonstração de Interesse } \\
\text { Anexo II - Proposta para Pessoa Jurídica de Direito Público Interno } \\
\text { Anexo III - Proposta para Pessoa Jurídica de Direito Privado } \\
\text { Anexo IV - Documentos Necessários para Habilitação } \\
\text { Anexo V - Requerimento de Renovação de Outorga - Pessoa Jurídica de Direito Público } \\
\text { Interno } \\
\text { Anexo VI - Requerimento de Renovação de Outorga - Pessoa Jurídica de Direito Privado } \\
\text { Anexo VII - Alteração de Quadro Diretivo }\end{array}$ \\
\hline Dispositivos & CF, Art. 221, inciso I; CF, Art. 223, caput; LGT, Art. 211, caput. \\
\hline Correlata & $\begin{array}{l}\text { Decreto-Lei n }{ }^{\circ} \text { 236/1967 - Complementa e modifica a Lei número } 4.117 \text { de } 27 \text { de agôsto } \\
\text { de } 1962 . \\
\text { Decreto } \text { n }^{\text {o }} 52.795 / 1963 \text { - Aprova o Regulamento dos Serviços de Radiodifusão. }\end{array}$ \\
\hline Publicação & $\begin{array}{l}\text { Diário Oficial da União, Seção 1, 21-09-2015, págs. 80-83 } \\
\text { Diário Oficial da União, Seção 1, 22-09-2015, pág. p. } 57 \text { [ Retificação ] }\end{array}$ \\
\hline Temas & $\begin{array}{l}\text { Temas : Administração do Setor de Telecomunicações : Outorgas : Concessão (regras } \\
\text { aplicáveis) } \\
\text { Temas : Administração do Setor de Telecomunicações : Outorgas : Permissão (regras } \\
\text { aplicáveis) } \\
\text { Temas : Administração do Setor de Telecomunicações : Processo Administrativo } \\
\text { Temas : Atores no Setor de Telecomunicações : Poder Executivo : Ministério das } \\
\text { Comunicações } \\
\text { Temas : Serviços no Setor de Telecomunicações : Radiodifusão : Rádio Aberta }\end{array}$ \\
\hline
\end{tabular}

Portaria MC n 4.287, de 21 de setembro de 2015 - Dispõe sobre os procedimentos de seleção pública e de autorização para a execução do Serviço de Retransmissão de Televisão, com utilização de tecnologia digital, ancilar ao Serviço de Radiodifusão de Sons e Imagens, durante a transição do sistema de transmissão analógica para o sistema de transmissão digital e dá outras providências

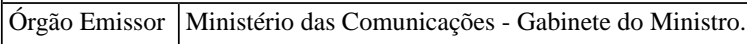




\begin{tabular}{|c|c|}
\hline Nota Vigência & Data de publicação no DOU \\
\hline Anexos & $\begin{array}{l}\text { Anexo I - Continuidade do Serviço de RTV em Tecnologia Digital } \\
\text { Anexo II - Alteração de Características Técnicas para o Serviço de RTVD } \\
\text { Anexo III - Proposta para Aprovação de Locais e Equipamentos - RTVD } \\
\text { Anexo IV - Continuidade do Serviço de RTV em Tecnologia Digital }\end{array}$ \\
\hline Dispositivos & $\begin{array}{l}\text { CF, Art. 21, inciso XII, alínea a (em 15/08/1995); CF, Art. 221, inciso I; CF, Art. 223, } \\
\text { caput; LGT, Art. 211, caput. }\end{array}$ \\
\hline Altera & $\begin{array}{l}\text { Portaria } \mathrm{MC} \mathrm{n}^{\circ} 652 / 2006 \text { - Estabelece critérios, procedimentos e prazos para a consignação } \\
\text { de canais de radiofreqüência destinados à transmissão digital do serviço de radiodifusão } \\
\text { de sons e imagens do serviço de retransmissão de televisão, no âmbito do Sistema } \\
\text { Brasileiro de Televisão Digital Terrestre - SBTVD-T. } \\
\text { Portaria MC n }{ }^{\circ} 925 \text {, de } 22 \text { de agosto de } 2014 \text { - Regulamenta os Requisitos Técnicos dos } \\
\text { Serviços abrangidos pelo Sistema Brasileiro de TV Digital Terrestre. } \\
\text { Portaria MC n }{ }^{\circ} 932 \text {, de } 22 \text { de Agosto de } 2014 \text { - Dispõe sobre Normas Complementares } \\
\text { dos Serviços de RTV e de RpTV. }\end{array}$ \\
\hline Revoga & $\begin{array}{l}\text { Anexo I à Portaria no } 329 \text {, de } 04 \text { de julho de } 2012 \text { - Documentos Necessários à Instrução } \\
\text { dos Processos de Renovação de Outorgas de Concessões, Permissões e Autorizações para } \\
\text { a Execução de Serviços de Radiodifusão, deferidas a Pessoas Jurídicas de Direito Público } \\
\text { Interno, em original ou cópia autenticada. } \\
\text { Anexo III à Portaria n } 329 \text {, de } 04 \text { de julho de } 2012 \text { - Documentos Necessários à Instrução } \\
\text { dos Processos de Renovação de Outorgas de Concessões e Permissões para a Execução } \\
\text { de Serviços de Radiodifusão Exclusivamente Educativos, deferidas a Pessoas Jurídicas } \\
\text { de Natureza Privada, em original ou cópia autenticada. } \\
\text { Portaria MC no } 355 \text {, de } 12 \text { de julho de } 2012 \text { - Dispõe sobre procedimentos para outorga } \\
\text { dos serviços de radiodifusão sonora e de sons e imagens com fins exclusivamente } \\
\text { educativos. }\end{array}$ \\
\hline Correlata & $\begin{array}{l}\text { Decreto } \mathrm{n}^{\circ} 5.820 / 2006 \text { - Dispõe sobre a implantação do SBTVD-T, estabelece diretrizes } \\
\text { para a transição do sistema de transmissão analógica para o sistema de transmissão digital } \\
\text { do serviço de radiodifusão de sons e imagens e do serviço de retransmissão de televisão, } \\
\text { e dá outras providências. } \\
\text { Portaria MC no } 486 \text {, de } 18 \text { de dezembro de } 2012 \text { - Altera a Norma } n^{\circ} 01 / 2010 \text { - Norma } \\
\text { Técnica para Execução dos Serviços de Radiodifusão de Sons e Imagens e de } \\
\text { Retransmissão de Televisão com utilização de tecnologia digital, aprovada pela Portaria } \\
M^{\circ} n^{\circ} 276 \text {, de } 26 \text { de março de } 2010 \text {. }\end{array}$ \\
\hline Publicação & Diário Oficial da União, Seção 1, 22-09-2015, págs. p. 55-56 \\
\hline Temas & $\begin{array}{l}\text { Temas : Serviços no Setor de Telecomunicações : Radiodifusão : Televisão Aberta : TV } \\
\text { Digital }\end{array}$ \\
\hline
\end{tabular}

Portaria MC no 4.699, de 14 de outubro de 2015 - Altera a Portaria n 376, de 19 de agosto de 2011, referente à instituição do Projeto de Implantação e Manutenção das Cidades Digitais

\begin{tabular}{|l|l|}
\hline Órgão Emissor & Ministério das Comunicações - Gabinete do Ministro. \\
\hline Nota Vigência & Data de publicação no DOU \\
\hline Dispositivos & LGT, Art. 2o inciso I; LGT, Art. 187, inciso I. \\
\hline Altera & $\begin{array}{l}\text { Portaria MC n 376/2011 - Institui o Projeto de Implantação e Manutenção das Cidades } \\
\text { Digitais. }\end{array}$ \\
\hline Publicação & Diário Oficial da União, Seção 1, 16-10-2015, pág. p. 52 \\
\hline Temas & $\begin{array}{l}\text { Temas : Atores no Setor de Telecomunicações : Telebras } \\
\text { Temas : Políticas de Telecomunicações : Universalização : Financiamento da } \\
\text { Universalização }\end{array}$ \\
\hline
\end{tabular}

Portaria MC n 6.413, de 20 de novembro de 2015 - Altera a Norma Regulamentar do Canal de Cidadania, aprovado pela Portaria $\mathrm{n}^{\circ} 489$, de 18 de dezembro de 2012 


\begin{tabular}{|l|l|}
\hline Órgão Emissor & Ministério das Comunicações - Gabinete do Ministro. \\
\hline Nota Vigência & Data de publicação no DOU \\
\hline Dispositivos & CF, Art. 223, caput; LGT, Art. 211, caput. \\
\hline Regulamenta & $\begin{array}{l}\text { Decreto no 5.820/2006 - Dispõe sobre a implantação do SBTVD-T, estabelece diretrizes } \\
\text { para a transição do sistema de transmissão analógica para o sistema de transmissão digital } \\
\text { do serviço de radiodifusão de sons e imagens e do serviço de retransmissão de televisão, } \\
\text { e dá outras providências. }\end{array}$ \\
\hline Publicação & Diário Oficial da União, Seção 1, 02.12.2015, pág. p. 43 \\
\hline Temas & Temas : Serviços no Setor de Telecomunicações : Radiodifusão \\
\hline
\end{tabular}

Portaria MC n⿳ 6.467, de 24 de novembro de 2015 - Alterar a Portaria n 127, de 12 de março de 2014, publicada no Diário Oficial da União de 13 de março de 2014, que dispõe sobre os procedimentos adaptação de outorga de radiodifusão sonora em ondas médias para o serviço de radiodifusão sonora em frequência modulada, e dá outras providências

\begin{tabular}{|c|c|}
\hline Órgão Emissor & Ministério das Comunicações - Gabinete do Ministro. \\
\hline Nota Vigência & 21 de dezembro de 2015 \\
\hline Anexos & $\begin{array}{l}\text { Anexo } 1 \text { - Anexo III da Portaria n }{ }^{\circ} \text { 127, de } 2014 \\
\text { Anexo II - Anexo IV da Portaria n 127, de } 2014 \\
\text { Anexo III - Anexo V da Portaria no 127, de } 2014 \\
\text { Anexo IV - Anexo VI da Portaria no } 127 \text {, de } 2014\end{array}$ \\
\hline Dispositivos & CF, Art. 21, inciso XII, alínea a (em 15/08/1995); LGT, Art. 211, caput. \\
\hline Altera & $\begin{array}{l}\text { Portaria } n^{\circ} 127 / 2014 \text { - Disciplina o procedimento a ser adotado para as solicitações de } \\
\text { adaptação de outorga do serviço de radiodifusão sonora em ondas médias para o serviço } \\
\text { de radiodifusão sonora em frequência modulada, nos termos do Decreto } n^{\circ} 8.139 \text {, de } 7 \\
\text { de novembro de } 2013 \text {. }\end{array}$ \\
\hline Correlata & Decreto n 52.795/1963 - Aprova o Regulamento dos Serviços de Radiodifusão. \\
\hline Regulamenta & $\begin{array}{l}\text { Decreto n }{ }^{\circ} 8139 / 2013 \text { - Dispõe sobre as condições para extinção do serviço de radiodifusão } \\
\text { sonora em ondas médias de caráter local, sobre a adaptação das outorgas vigentes para } \\
\text { execução deste serviço e dá outras providências. }\end{array}$ \\
\hline Publicação & Diário Oficial da União, Seção 1, 25-11-2015, págs. p. 36-45 \\
\hline
\end{tabular}

Portaria MC n⿳ 6.580, de 2 de dezembro de 2015 - Requer relatório consubstanciado sobre a evolução do processo de transição para a TV Digital do Grupo de Implantação do Processo de Redistribuição e Digitalização de Canais de TV e RTV (GIRED), bem como altera a Portaria MC ñ 4.287, de 22 de setembro de 2015 e a Portaria MC n 925, de 22 de agosto de 2014 para, dentre outras coisas, autorizar o desligamento antecipado do sinal analógico nos casos que especifica

\begin{tabular}{|c|c|}
\hline Órgão Emissor & Ministério das Comunicações - Gabinete do Ministro. \\
\hline Nota Vigência & Data de publicação no DOU \\
\hline Dispositivos & CF, Art. 21, inciso XII; LGT, Art. 211, caput. \\
\hline Regulamenta & $\begin{array}{l}\text { Decreto } \mathrm{n}^{\circ} 5.820 / 2006 \text { - Dispõe sobre a implantação do SBTVD-T, estabelece diretrizes } \\
\text { para a transição do sistema de transmissão analógica para o sistema de transmissão digital } \\
\text { do serviço de radiodifusão de sons e imagens e do serviço de retransmissão de televisão, } \\
\text { e dá outras providências. } \\
\text { Decreto }{ }^{\circ} 8.061 \text {, de } 29 \text { de julho de } 2013 \text { - Altera o Decreto } \text { n }^{\circ} 5.820 \text {, de } 29 \text { de junho de } \\
\text { 2006, o Regulamento dos Serviços de Radiodifusão, aprovado pelo Decreto no } 52.795 \text {, } \\
\text { de } 31 \text { de outubro de } 1963 \text {, e dá outras providências. }\end{array}$ \\
\hline Publicação & Diário Oficial da União, Seção 1, 04-12-2015, pág. p. 50 \\
\hline Temas & $\begin{array}{l}\text { Temas : Serviços no Setor de Telecomunicações : Radiodifusão : Televisão Aberta : TV } \\
\text { Digital }\end{array}$ \\
\hline
\end{tabular}




\section{Portaria Interministerial}

\begin{tabular}{|l|l|}
\hline $\begin{array}{l}\text { Portaria Interministerial no 2.098, de } 14 \text { de maio de 2015 - Estabelece as diretrizes para operacionalização } \\
\text { do Canal da Educação no âmbito do Sistema Brasileiro de Televisão Digital Terrestre - SBTVD-T }\end{array}$ \\
\hline Órgão Emissor & $\begin{array}{l}\text { Ministério das Comunicações - Gabinete do Ministro; Ministério da Educação e do } \\
\text { Desporto - Gabinete do Ministro. }\end{array}$ \\
\hline Dispositivos & CF, Art. 221, inciso I; CF, Art. 223, caput; LGT, Art. 211, caput. \\
\hline Regulamenta & $\begin{array}{l}\text { Decreto no 5.820/2006 - Dispõe sobre a implantação do SBTVD-T, estabelece diretrizes } \\
\text { para a transição do sistema de transmissão analógica para o sistema de transmissão digital } \\
\text { do serviço de radiodifusão de sons e imagens e do serviço de retransmissão de televisão, } \\
\text { e dá outras providências. }\end{array}$ \\
\hline Publicação & Diário Oficial da União, Seção 1, 15-05-2015, pág. p. 40 \\
\hline Temas & $\begin{array}{l}\text { Temas : Atores no Setor de Telecomunicações : Poder Executivo : Ministério da Educação } \\
\text { Temas : Serviços no Setor de Telecomunicações : Radiodifusão : Televisão Aberta : TV } \\
\text { Digital }\end{array}$ \\
\hline
\end{tabular}

\begin{tabular}{|l|l|}
\hline $\begin{array}{l}\text { Portaria Interministerial } \mathbf{n}^{\mathbf{0}} \text { 4.074, de } 26 \text { de Agosto de } 2015 \text { - Estabelece as diretrizes para } \\
\text { operacionalização do Canal da Cultura no Sistema Brasileiro de Televisão Digital Terrestre }\end{array}$ \\
\hline Órgão Emissor & Ministério das Comunicações - Gabinete do Ministro. \\
\hline Nota Vigência & Data de publicação no DOU \\
\hline Dispositivos & CF, Art. 221, inciso I; CF, Art. 223, caput; LGT, Art. 211, caput. \\
\hline Altera & $\begin{array}{l}\text { Decreto no 5.820/2006 - Dispõe sobre a implantação do SBTVD-T, estabelece diretrizes } \\
\text { para a transição do sistema de transmissão analógica para o sistema de transmissão digital } \\
\text { do serviço de radiodifusão de sons e imagens e do serviço de retransmissão de televisão, } \\
\text { e dá outras providências. }\end{array}$ \\
\hline Publicação & Diário Oficial da União, Seção 1, 27-08-2015, pág. p. 56 \\
\hline Temas & $\begin{array}{l}\text { Temas : Atores no Setor de Telecomunicações : Poder Executivo : Ministério da Cultura } \\
\text { Temas : Serviços no Setor de Telecomunicações : Radiodifusão : Televisão Aberta : TV } \\
\text { Digital }\end{array}$ \\
\hline
\end{tabular}

\section{Resolução}

\begin{tabular}{|c|c|}
\hline \multicolumn{2}{|c|}{$\begin{array}{l}\text { Resolução da ANATEL } \mathbf{n}^{\mathbf{0}} \text { 647, de } 9 \text { de fevereiro de } 2015 \text { - Aprova a Norma de adaptação dos } \\
\text { instrumentos de permissão e de autorização do Serviço Móvel Especializado (SME) para o Serviço Móvel } \\
\text { Pessoal (SMP), Serviço Limitado Privado (SLP) ou Serviço Limitado Especializado (SLE), na forma do } \\
\text { Anexo a esta Resolução, altera a Resolução n⿳0 } 454 / 2006 \text { e seus anexo, e dá outras disposições. }\end{array}$} \\
\hline Órg & $\mathrm{N}$ \\
\hline Nota & Data de publicação no DOU \\
\hline Anex & $\begin{array}{l}\text { Anexo - Norma de adaptação dos instrumentos de permissão e de autorização do Serviço } \\
\text { Móvel Especializado (SME) para o Serviço Móvel Pessoal (SMP), Serviço Limitado } \\
\text { Privado (SLP) ou Serviço Limitado Especializado (SLE) }\end{array}$ \\
\hline Dispositivos & LGT, Art. 130-A, Páragrafo Único. \\
\hline Altera & $\begin{array}{l}\text { Resolução da ANATEL no 454/2006 - Aprova o Regulamento sobre Condições de Uso } \\
\text { de Radiofreqüências nas Faixas de } 800 \mathrm{MHz}, 900 \mathrm{MHz}, 1.800 \mathrm{MHz}, 1.900 \mathrm{MHz} \text { e } 2.100 \\
\text { MHz. }\end{array}$ \\
\hline Correlata & $\begin{array}{l}\text { Resolução da ANATEL no 477/2007 - Aprova o Regulamento do Serviço Móvel Pessoal } \\
\text { - SMP. } \\
\text { Resolução da ANATEL no 516/2008 - Aprova o Plano Geral de Atualização da } \\
\text { Regulamentação das Telecomunicações no Brasil (PGR). }\end{array}$ \\
\hline
\end{tabular}




\begin{tabular}{|l|l|}
\hline & $\begin{array}{l}\text { Resolução da ANATEL no 518/2008 - Aprova alteração no Regulamento do Serviço } \\
\text { Móvel Especializado -SME. - Anexo - Alteração do Regulamento do Serviço Móvel } \\
\text { Especializado -SME. }\end{array}$ \\
\hline Regulamenta & $\begin{array}{l}\text { Lei no 9.472/1997 - Dispõe sobre a organização dos serviços de telecomunicações, a } \\
\text { criação e funcionamento de um órgão regulador e outros aspectos institucionais, nos } \\
\text { termos da Emenda Constitucional no 8, de 1995. }\end{array}$ \\
\hline Publicação & Diário Oficial da União, Seção 1, 11-02-2015, págs. p. 49-50 \\
\hline Temas & $\begin{array}{l}\text { Temas : Serviços no Setor de Telecomunicações : Serviço Limitado Especializado (SLE) } \\
\text { Temas : Serviços no Setor de Telecomunicações : Serviço Limitado Móvel Privado } \\
\text { Temas : Serviços no Setor de Telecomunicações : Serviço Limitado Privado } \\
\text { Temas : Serviços no Setor de Telecomunicações : Serviço Móvel Especializado ou } \\
\text { Trunking ou Trunk ou Sistema Troncalizado } \\
\text { Temas : Serviços no Setor de Telecomunicações : Serviço Móvel Pessoal (SMP) }\end{array}$ \\
\hline
\end{tabular}

Resolução da ANATEL $\mathbf{n}^{\circ}$ 648, de 11 de fevereiro de 2015 - Destina faixas de radiofrequências para o Serviço de Acesso Condicionado (SeAC)

\begin{tabular}{|c|c|}
\hline Órgão Emissor & ANATEL - Conselho Diretor. \\
\hline Nota Vigência & Data de publicação no DOU \\
\hline Dispositivos & $\begin{array}{l}\text { LGT, Art. 19, inciso VIII; LGT, Art. 127, inciso VII; LGT, Art. 157, caput; LGT, Art. } \\
\text { 159, caput; LGT, Art. 160, Parágrafo Único. }\end{array}$ \\
\hline Correlata & 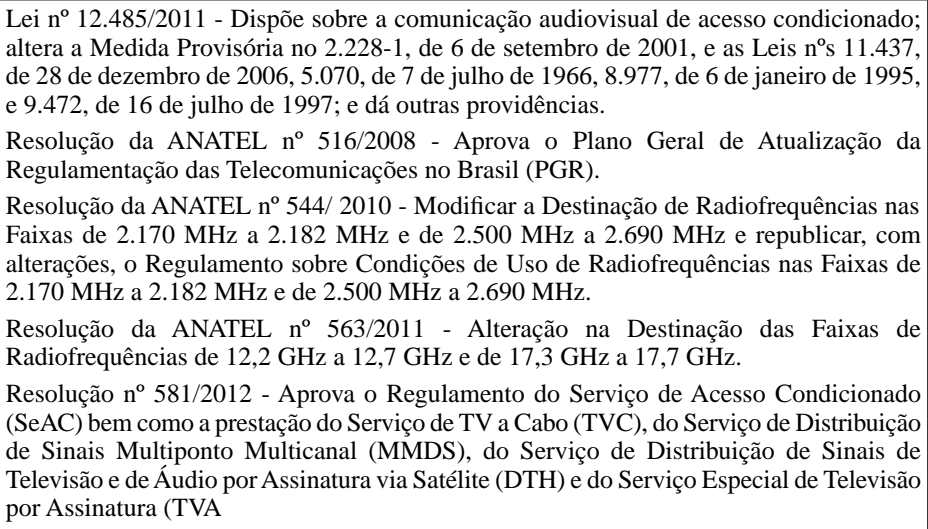 \\
\hline Regulamenta & $\begin{array}{l}\text { Lei } \mathrm{n}^{\circ} \text { 9.472/1997 - Dispõe sobre a organização dos serviços de telecomunicações, a } \\
\text { criação e funcionamento de um órgão regulador e outros aspectos institucionais, nos } \\
\text { termos da Emenda Constitucional } \mathrm{n}^{\circ} 8 \text {, de } 1995 \text {. }\end{array}$ \\
\hline Publicação & Diário Oficial da União, Seção 1, 12-02-2015, pág. p. 91 \\
\hline Temas & $\begin{array}{l}\text { Temas : Infra-estrutura e Recursos do Setor de Telecomunicações : Espectro de } \\
\text { Radiofrequência : Atribuição, Destinação e Distribuição de Radiofrequência } \\
\text { Temas : Serviços no Setor de Telecomunicações : Serviço de Acesso Condicionado } \\
\text { (SeAC) }\end{array}$ \\
\hline
\end{tabular}

\begin{tabular}{|l|l|}
\hline $\begin{array}{l}\text { Resolução da ANATEL no 650, de } 16 \text { de março de } 2015 \text { - Aprova o Regimento Interno do Comitê de } \\
\text { Defesa dos Usuários de Serviços de Telecomunicações - CDUST }\end{array}$ \\
\hline Órgão Emissor & ANATEL - Conselho Diretor. \\
\hline Nota Vigência & Data de publicação no DOU \\
\hline Anexos & $\begin{array}{l}\text { Anexo - Regimento Interno do Comitê de Defesa dos Usuários de Serviços de } \\
\text { Telecomunicações (CDUST) }\end{array}$ \\
\hline
\end{tabular}




\begin{tabular}{|l|l|}
\hline Dispositivos & $\begin{array}{l}\text { LGT, Art. } 2^{\circ} \text {, inciso III; LGT, Art. 3º caput; LGT, Art. 5º caput; LGT, Art. 19, inciso } \\
\text { XVIII. }\end{array}$ \\
\hline Regulamenta & $\begin{array}{l}\text { Lei }{ }^{\circ} \text { 9.472/1997 - Dispõe sobre a organização dos serviços de telecomunicações, a } \\
\text { criação e funcionamento de um órgão regulador e outros aspectos institucionais, nos } \\
\text { termos da Emenda Constitucional no 8, de 1995. }\end{array}$ \\
\hline Publicação & Diário Oficial da União, Seção 1, 17-03-2015, págs. p. 83-85 \\
\hline Temas & $\begin{array}{l}\text { Temas : Atores no Setor de Telecomunicações : ANATEL } \\
\text { Temas : Atores no Setor de Telecomunicações : Usuário / Consumidor }\end{array}$ \\
\hline
\end{tabular}

\begin{tabular}{|l|l|}
\hline \multicolumn{2}{|l|}{$\begin{array}{l}\text { Resolução da ANATEL no 651, de 13 de abril de 2015 - Aprova o Regulamento do Serviço Limitado } \\
\text { Móvel Aeronáutico e do Serviço Limitado Móvel Marítimo }\end{array}$} \\
\hline Órgão Emissor & ANATEL - Conselho Diretor. \\
\hline Nota Vigência & 180 dias após a data de publicação no DOU \\
\hline Anexos & $\begin{array}{l}\text { Anexo - Regulamento do Serviço Limitado Móvel Aeronáutico e do Serviço Limitado } \\
\text { Móvel Marítimo }\end{array}$ \\
\hline Dispositivos & LGT, Art. 1 ${ }^{\circ}$, Parágrafo Único; LGT, Art. 19, inciso X; LGT, Art. 62, Parágrafo Único. \\
\hline Altera & $\begin{array}{l}\text { Anexo à Resolução da ANATEL no 386, de 3 de novembro de 2004 - Regulamento de } \\
\text { Cobrança de Preço Público pelo Direito de Exploração de Serviços de Telecomunicações } \\
\text { e pelo Direito de Exploração de Satélite. }\end{array}$ \\
\hline Revoga & $\begin{array}{l}\text { Portaria no 968, de 19 de agosto de 1976 - Procedimento para Vistoria e Licenciamento } \\
\text { das Estações-rádio Instaladas em Navios e Embarcações } \\
\text { Portaria n } 1786 / 81, \text { de 11 de junho de 1981 - Aprova Formulário DNT-034 Licença de } \\
\text { Estação de Navio }\end{array}$ \\
\hline Regulamenta & $\begin{array}{l}\text { Lei no 9.472/1997 - Dispõe sobre a organização dos serviços de telecomunicações, a } \\
\text { criação e funcionamento de um órgão regulador e outros aspectos institucionais, nos } \\
\text { termos da Emenda Constitucional no 8, de 1995. }\end{array}$ \\
\hline Publicação & $\begin{array}{l}\text { Diário Oficial da União, Seção 1, 14-04-2015, págs. p. 45-47 } \\
\text { Temas : Serviços no Setor de Telecomunicações : Serviço de Telecomunicações } \\
\text { Aeronáuticas : Serviço Móvel Aeronáutico } \\
\text { Temas : Classificações de Serviços no Setor de Telecomunicações : Quanto ao Gênero : } \\
\text { Temas : Classificações de Serviços no Setor de Telecomunicações : Quanto ao Interesse } \\
\text { Terviço de Interesse Restrito }\end{array}$ \\
\hline
\end{tabular}

\begin{tabular}{|l|l|}
\hline \multicolumn{2}{|l|}{$\begin{array}{l}\text { Resolução da ANATEL no 652, de } 27 \text { de maio de } 2015 \text { - Altera os Anexos I e II do Regulamento sobre } \\
\text { Áreas Locais para o Serviço Telefônico Fixo Comutado Destinado ao Uso do Público em Geral - STFC }\end{array}$} \\
\hline Órgão Emissor & ANATEL - Conselho Diretor. \\
\hline Nota Vigência & Data de publicação no DOU \\
\hline Dispositivos & LGT, Art. 64, Parágrafo Único. \\
\hline Revoga & $\begin{array}{l}\text { Anexo à Resolução da ANATEL n 560, de 21 de janeiro de 2011 - Regulamento sobre } \\
\text { Áreas Locais para o Serviço Telefônico Fixo Comutado Destinado ao Uso do Público em } \\
\text { Geral - STFC. }\end{array}$ \\
\hline Regulamenta & $\begin{array}{l}\text { Lei no 9.472/1997 - Dispõe sobre a organização dos serviços de telecomunicações, a } \\
\text { criação e funcionamento de um órgão regulador e outros aspectos institucionais, nos } \\
\text { termos da Emenda Constitucional no 8, de 1995. }\end{array}$ \\
\hline Publicação & Diário Oficial da União, Seção 1, 29-05-2015, págs. p. 94-95 \\
\hline
\end{tabular}


\begin{tabular}{|l|l|}
\hline Temas & $\begin{array}{l}\text { Temas : Serviços no Setor de Telecomunicações : Serviço Telefônico Fixo Comutado } \\
\text { (STFC) }\end{array}$ \\
\hline
\end{tabular}

Resolução da ANATEL no 653, de 13 de julho de 2015 - Aprova alteração do Anexo I ao Regulamento de Tarifação do Serviço Telefônico Fixo Comutado Destinado ao Uso do Público em Geral - STFC Prestado no Regime Público, aprovado pela Resolução $n^{\circ} 424$, de 6 de dezembro de 2005, e do Plano Geral de Códigos Nacionais - PGCN, Anexo II à Resolução nº 263, de 8 de junho de 2001, para inserir: a) o município de Paraíso das Águas, no estado do Mato Grosso do Sul, na Área de Tarifação 672K (Costa Rica) e atribuirlhe o Código Nacional 67; b) o município de Mojuí dos Campos, no estado do Pará, na Área de Tarifação 915 (Santarém) e atribuir-lhe o Código Nacional 93; c) o município de Pinto Bandeira, no estado do Rio Grande do Sul, na Área de Tarifação 542C (Bento Gonçalves) e atribuir-lhe o Código Nacional 54; d) o município de Pescaria Brava, no estado de Santa Catarina, na Área de Tarifação 486 (Tubarão) e atribuirlhe o Código Nacional 48; e, e) o município de Balneário Rincão, no estado de Santa Catarina, na Área de Tarifação 484 (Criciúma) e atribuir-lhe o Código Nacional 48

\begin{tabular}{|c|c|}
\hline Órgão Emissor & ANATEL - Conselho Diretor. \\
\hline Nota Vigência & 180 dias após a publicação \\
\hline Anexos & $\begin{array}{l}\text { Anexo I - Alterações do Anexo I ao Regulamento de Tarifação do Serviço Telefônico } \\
\text { Fixo Comutado Destinado ao Uso do Público em Geral - STFC Prestado no Regime } \\
\text { Público } \\
\text { Anexo II - Alterações do Anexo II do Plano Geral de Códigos Nacionais - PGCN }\end{array}$ \\
\hline Dispositivos & LGT, Art. 64, Parágrafo Único. \\
\hline Altera & $\begin{array}{l}\text { Anexo à Resolução da ANATEL n }{ }^{\circ} 263 \text {, de } 8 \text { de junho de } 2001 \text { - Plano Geral de Códigos } \\
\text { Nacionais - PGCN. } \\
\text { Anexo à Resolução da ANATEL no 424, de } 6 \text { de dezembro de } 2005 \text { - Regulamento de } \\
\text { Tarifação do Serviço Telefônico Fixo Comutado Destinado ou Uso do Público em Geral } \\
\text { - STFC Prestado no Regime Público. }\end{array}$ \\
\hline Regulamenta & $\begin{array}{l}\text { Lei } \mathrm{n}^{\circ} 9.472 / 1997 \text { - Dispõe sobre a organização dos serviços de telecomunicações, a } \\
\text { criação e funcionamento de um órgão regulador e outros aspectos institucionais, nos } \\
\text { termos da Emenda Constitucional n }{ }^{\circ} 8 \text {, de } 1995 \text {. }\end{array}$ \\
\hline Publicação & Diário Oficial da União, Seção 1, 14-07-2015, págs. p. 51-52 \\
\hline Temas & $\begin{array}{l}\text { Temas : Serviços no Setor de Telecomunicações : Serviço Telefônico Fixo Comutado } \\
\text { (STFC) }\end{array}$ \\
\hline
\end{tabular}

Resolução da ANATEL n⿳0 654, de 13 de julho de 2015 - Aprova o Regulamento das Condições de Aferição do Grau de Satisfação e da Qualidade Percebida Junto aos Usuários de Serviços de Telecomunicações

\begin{tabular}{|l|l|}
\hline Órgão Emissor & ANATEL - Conselho Diretor. \\
\hline Nota Vigência & Data de publicação no DOU \\
\hline Anexos & $\begin{array}{l}\text { - Regulamento das Condições de Aferição do Grau de Satisfação e da Qualidade Percebida } \\
\text { Junto aos Usuários de Serviços de Telecomunicações }\end{array}$ \\
\hline Dispositivos & $\begin{array}{l}\text { CF, Art. 175, § único, inciso II; LGT, Art. 2 }{ }^{\circ} \text {, inciso III; LGT, Art. 30 } \text {, inciso I; LGT, Art. } \\
\text { 19, inciso XVIII; LGT, Art. 62, Parágrafo Unico; LGT, Art. 64, Parágrafo Unico; LGT, } \\
\text { Art. 93, inciso III; LGT, Art. 120, inciso X; LGT, Art. 127, inciso I; LGT, Art. 127, inciso } \\
\text { III; LGT, Art. 127, inciso V. }\end{array}$ \\
\hline $\begin{array}{l}\text { Altera } \\
\text { Segulamento de Gestão da Qualidade do Serviço de Comunicação Multimídia (RGQ- } \\
\text { (RGQ-SCM). } \\
\text { Regulamento de Gestão da Qualidade da Prestação do Serviço Móvel Pessoal - RGQ- } \\
\text { SMP - Regulamento de Gestão da Qualidade da Prestação do Serviço Móvel Pessoal - } \\
\text { RGQ-SMP. } \\
\text { Anexo - Regulamento de Gestão de Qualidade da Prestação do Serviço Telefônico Fixo } \\
\text { Comutado - RGQ-STFC - Regulamento de Gestão de Qualidade da Prestação do Serviço } \\
\text { Telefônico Fixo Comutado - RGQ-STFC. }\end{array}$ \\
\hline
\end{tabular}




\begin{tabular}{|c|c|}
\hline Revoga & $\begin{array}{l}\text { Resolução da ANATEL n }{ }^{\circ} \text { 296/2002 - Aprova o Regulamento das Condições de Aferição } \\
\text { do Grau de Satisfação dos Usuários dos Serviços de Telecomuniçacoes. - Anexo - } \\
\text { Regulamento das Condições de Aferição do Grau de Satisfação dos Usuários dos Serviços } \\
\text { de Telecomunicações. } \\
\text { Resolução da ANATEL n }{ }^{\circ} \text { 443/2006 - Aprova a Norma do Processo de Aferição do Grau } \\
\text { de Satisfação da Sociedade com Relação ao Serviço Telefônico Fixo Comutado (STFC), } \\
\text { ao Serviço Móvel Pessoal (SMP) e aos serviços de televisão por assinatura. - Anexo - } \\
\text { Norma do Processo de Aferição do Grau de Satisfação da Sociedade com Relação ao } \\
\text { Serviço Telefônico Fixo Comutado (STFC), ao Serviço Móvel Pessoal (SMP) e aos } \\
\text { serviços de televisão por assinatura. }\end{array}$ \\
\hline Correlata & | Kesoruçao n \\
\hline Regulamenta & $\begin{array}{l}\text { Lei no 9.472/1997 - Dispõe sobre a organização dos serviços de telecomunicações, a } \\
\text { criação e funcionamento de um órgão regulador e outros aspectos institucionais, nos } \\
\text { termos da Emenda Constitucional no } 8 \text {, de } 1995 \text {. }\end{array}$ \\
\hline Publicação & Diário Oficial da União, Seção 1, 14-07-2015, págs. p. 52-53 \\
\hline Temas & $\begin{array}{l}\text { Temas : Administração do Setor de Telecomunicações : Fiscalização das Telecomunicações } \\
\text { Temas : Administração do Setor de Telecomunicações : Outorgas : Concessão (regras } \\
\text { aplicáveis) } \\
\text { Temas : Classificações de Serviços no Setor de Telecomunicações : Quanto ao Interesse } \\
\text { : Serviço de Interesse Coletivo } \\
\text { Temas : Políticas de Telecomunicações : Controle Social, Hierárquico e Interorgânico } \\
\text { Temas : Políticas de Telecomunicações : Qualidade do Serviço } \\
\text { Temas : Serviços no Setor de Telecomunicações : Serviço Móvel Pessoal (SMP) } \\
\text { Temas : Serviços no Setor de Telecomunicações : Serviço Telefônico Fixo Comutado } \\
\text { (STFC) } \\
\text { Temas : Serviços no Setor de Telecomunicações : Serviço de Acesso Condicionado } \\
\text { (SeAC) } \\
\text { Temas : Serviços no Setor de Telecomunicações : Serviço de Comunicação Multimídia } \\
\text { (SCM) }\end{array}$ \\
\hline
\end{tabular}

Resolução da ANATEL no 655, de 5 de Agosto de 2015 - Aprova o Regulamento do Acompanhamento de Compromissos de Aquisição de Produtos e Sistemas Nacionais e estabelece regras específicas para o cumprimento do Compromisso de Aquisição de Produtos de Tecnologia Nacional

\begin{tabular}{|c|c|}
\hline Órgão Emissor & ANATEL - Conselho Diretor. \\
\hline Nota Vigência & Data de publicação no DOU \\
\hline Anexos & $\begin{array}{l}\text { Anexo - Regulamento do Acompanhamento de Compromissos de Aquisição de Produtos } \\
\text { e Sistemas Nacionais }\end{array}$ \\
\hline Dispositivos & LGT, Art. $2^{\circ}$, inciso V; LGT, Art. 78, caput; LGT, Art. 127, inciso IX. \\
\hline Correlata & $\begin{array}{l}\text { Lei no } 8.248 / 1991 \text { - Dispõe sobre a capacitação e competitividade do setor de informática } \\
\text { e automação, e dá outras providências. } \\
\text { Lei no } 8.387 / 1991 \\
\text { Lei no } 9.609 \text {, de } 19 \text { de fevereiro de } 1998 \\
\text { Decreto no } 5.906 / 2006 \\
\text { Resolução da ANATEL no } 516 / 2008 \text { - Aprova o Plano Geral de Atualização da } \\
\text { Regulamentação das Telecomunicações no Brasil (PGR). }\end{array}$ \\
\hline Regulamenta & $\begin{array}{l}\text { Lei } \mathrm{n}^{\circ} 9.472 / 1997 \text { - Dispõe sobre a organização dos serviços de telecomunicações, a } \\
\text { criação e funcionamento de um órgão regulador e outros aspectos institucionais, nos } \\
\text { termos da Emenda Constitucional } n^{\circ} 8 \text {, de } 1995 \text {. }\end{array}$ \\
\hline Publicação & Diário Oficial da União, Seção 1, 06-08-2015, págs. p. 45-47 \\
\hline Temas & $\begin{array}{l}\text { Temas : Aplicações de Telecomunicações : Banda Larga } \\
\text { Temas : Infraestrutura e Recursos do Setor de Telecomunicações }\end{array}$ \\
\hline
\end{tabular}


Temas : Políticas de Telecomunicações : Política Industrial

\begin{tabular}{|c|c|}
\hline \multicolumn{2}{|c|}{$\begin{array}{l}\text { Resolução da ANATEL no 656, de } 17 \text { de Agosto de } 2015 \text { - Aprova o Regulamento sobre Gestão de Risco } \\
\text { das Redes de Telecomunicações e Uso de Serviços de Telecomunicações em Desastres, Situações de } \\
\text { Emergência e Estado de Calamidade Pública }\end{array}$} \\
\hline \multicolumn{2}{|c|}{\begin{tabular}{|l|l|} 
Órgão Emissor & ANATEL - Conselho Diretor. \\
\end{tabular}} \\
\hline \multicolumn{2}{|c|}{\begin{tabular}{|l|l|} 
Órgão Emissor & ANATEL - Conselho Diretor. \\
Nota Vigência & Data de publicação no DOU
\end{tabular}} \\
\hline Anexos & \\
\hline Dispositivos & LGT, Art. 109, inciso II; LGT, Art. $158, \S 1^{\circ}$, inciso IV. \\
\hline Regulamenta & $\begin{array}{l}\text { Lei } \mathrm{n}^{\circ} \text { 9.472/1997 - Dispõe sobre a organização dos serviços de telecomunicações, a } \\
\text { criação e funcionamento de um órgão regulador e outros aspectos institucionais, nos } \\
\text { termos da Emenda Constitucional } n^{\circ} 8 \text {, de } 1995 \text {. }\end{array}$ \\
\hline Publicação & Diário Oficial da União, Seção 1, 19-08-2015, págs. p. 55-56 \\
\hline Temas & $\begin{array}{l}\text { Temas : Aplicações de Telecomunicações : Acesso a Serviços de Interesse Público e Uso } \\
\text { de Radiofrequência por tais Serviços } \\
\text { Temas : Serviços no Setor de Telecomunicações : Serviço Móvel Pessoal (SMP) } \\
\text { Temas : Serviços no Setor de Telecomunicações : Serviço de Acesso Condicionado } \\
\text { (SeAC) }\end{array}$ \\
\hline
\end{tabular}

\begin{tabular}{|c|c|}
\hline \multicolumn{2}{|c|}{$\begin{array}{l}\text { Resolução da ANATEL no } \mathbf{6 5 7} \text {, de } 3 \text { de novembro de } 2015 \text { - Altera o Regulamento sobre Condições de } \\
\text { Uso de Radiofrequências nas Faixas de } 800 \mathrm{MHz}, 900 \mathrm{MHz}, 1.800 \mathrm{MHz}, 1.900 \mathrm{MHz} \text { e } 2.100 \mathrm{MHz} \text {, } \\
\text { aprovado pela Resolução no } 454 \text {, de } 11 \text { de dezembro de } 2006\end{array}$} \\
\hline Órgão Emissor & ANATEL - Conselho Diretor. \\
\hline Nota Vigência & Data de publicação no DOU \\
\hline Disposit & LGT, Art. 19, inciso VIII; LGT, Art. 159, caput; LGT, Art. 161, caput. \\
\hline Altera & $\begin{array}{l}\text { Anexo à Resolução da ANATEL n }{ }^{\circ} 454 \text {, de } 11 \text { de dezembro de } 2006 \text { - Regulamento sobre } \\
\text { Condições de Uso de Radiofreqüências nas Faixas de } 800 \mathrm{MHz}, 900 \mathrm{MHz}, 1.800 \mathrm{MHz}, \\
1.900 \mathrm{MHz} \text { e } 2.100 \mathrm{MHz} \text {. }\end{array}$ \\
\hline Regu & $\begin{array}{l}\text { Lei } \mathrm{n}^{\circ} \text { 9.472/1997 - Dispõe sobre a organização dos serviços de telecomunicações, a } \\
\text { criação e funcionamento de um órgão regulador e outros aspectos institucionais, nos } \\
\text { termos da Emenda Constitucional } n^{\circ} 8 \text {, de } 1995 \text {. }\end{array}$ \\
\hline Publicação & Diário Oficial da União, Seção 1, 04-11-2015, pág. p. 56 \\
\hline emas & $\begin{array}{l}\text { Temas : Infraestrutura e Recursos do Setor de Telecomunicações : Espectro de } \\
\text { Radiofrequência : Condições de Uso de Radiofrequência e Canalização (Distribuição de } \\
\text { Canais) }\end{array}$ \\
\hline
\end{tabular}

\begin{tabular}{|l|l|}
\hline $\begin{array}{l}\text { Resolução da ANATEL no 658, de 11 de dezembro de } 2015 \text { - Revoga o Plano Geral de Atualização da } \\
\text { Regulamentação das Telecomunicações no Brasil (PGR) }\end{array}$ \\
\hline Órgão Emissor & ANATEL - Conselho Diretor. \\
\hline Nota Vigência & Data de publicação no DOU \\
\hline Dispositivos & LGT, Art. 19, caput. \\
\hline Revoga & $\begin{array}{l}\text { Anexo à Resolução da ANATEL no } 516, \text { de } 30 \text { de outubro de } 2008 \text { - Plano Geral de } \\
\text { Atualização da Regulamentação das Telecomunicações no Brasil (PGR). }\end{array}$ \\
\hline Correlata & Portaria ANATEL no 174, de 11 de fevereiro de 2015 \\
\hline Regulamenta & $\begin{array}{l}\text { Lei no 9.472/1997 - Dispõe sobre a organização dos serviços de telecomunicações, a } \\
\text { criação e funcionamento de um órgão regulador e outros aspectos institucionais, nos } \\
\text { termos da Emenda Constitucional no 8, de 1995. }\end{array}$ \\
\hline
\end{tabular}




\begin{tabular}{|l|l|}
\hline Publicação & Diário Oficial da União, Seção 1, 15-12-2015, pág. p. 90 \\
\hline Temas & Temas : Atores no Setor de Telecomunicações : ANATEL \\
\hline
\end{tabular}

\begin{tabular}{|c|c|}
\hline \multicolumn{2}{|c|}{$\begin{array}{l}\text { Resolução da ANATEL no } \mathbf{6 5 9} \text {, de } 28 \text { de dezembro de } 2015 \text { - Aprova a alteração da Cláusula } 3.2 \text { do } \\
\text { Contrato de Concessão para a prestação do Serviço Telefônico Fixo Comutado - STFC, nas modalidades } \\
\text { de serviço Local, Longa Distância Nacional - LDN e Longa Distância Internacional - LDI, para ampliar } \\
\text { prazo para a realização de alterações referentes ao período de } 2016 \text { a } 2020\end{array}$} \\
\hline Órgão Emissor & ANATEL - Conselho Diretor. \\
\hline Nota Vigência & Data de publicação no DOU \\
\hline Dis & $\begin{array}{l}\text { LGT, Art. 19, inciso IV; LGT, Art. 19, inciso VI; LGT, Art. 64, Parágrafo Único; LGT, } \\
\text { Art. 86, § Único, Inciso III; LGT, Art. 93, caput; LGT, Art. 95, caput. }\end{array}$ \\
\hline Altera & $\begin{array}{l}\text { Anexo } 1 \text { - Modelo de Contrato de Concessão para a Prestação de Serviço Telefônico Fixo } \\
\text { Comutado na Modalidade Local - } 2011 \text { - Anexo } 1 \text { - Modelo de Contrato de Concessão } \\
\text { para a Prestação de Serviço Telefônico Fixo Comutado na Modalidade Local - } 2011 . \\
\text { Anexo } 2 \text { - Modelo de Contrato de Concessão para a Prestação de Serviço Telefônico Fixo } \\
\text { Comutado na Modalidade Longa Distância Nacional (Regiões I, II e III) - } 2011 \text { - Modelo } \\
\text { de Contrato de Concessão para a Prestação de Serviço Telefônico Fixo Comutado na } \\
\text { Modalidade Longa Distância Nacional (Regiões I, II e III) - } 2011 . \\
\text { Anexo } 3 \text { - Modelo de Contrato de Concessão para a Prestação de Serviço Telefônico Fixo } \\
\text { Comutado na Modalidade Longa Distância Nacional (Regiaõ IV) - } 2011 \text { - Modelo de } \\
\text { Contrato de Concessão para a Prestação de Serviço Telefônico Fixo Comutado na } \\
\text { Modalidade Longa Distância Nacional (Regiaõ IV) - 2011. } \\
\text { Anexo } 4 \text { - Modelo de Contrato de Concessão para a Prestação de Serviço Telefônico Fixo } \\
\text { Comutado na Modalidade Longa Distância Internacional - } 2011 \text { - Modelo de Contrato } \\
\text { de Concessão para a Prestação de Serviço Telefônico Fixo Comutado na Modalidade } \\
\text { Longa Distância Internacional - 2011. }\end{array}$ \\
\hline Regu & $\begin{array}{l}\text { i n }{ }^{\circ} 9.472 / 1997 \text { - Dispõe sobre a organização dos serviços de telecom } \\
\text { ação e funcionamento de um órgão regulador e outros aspectos institu } \\
\text { mos da Emenda Constitucional } n^{\circ} 8 \text {, de } 1995 \text {. }\end{array}$ \\
\hline Publicação & Diário Oficial da União, Seção 1, 29-12-2015, pág. p. 44 \\
\hline Temas & $\begin{array}{l}\text { Temas : Administração do Setor de Telecomunicações : Outorgas : Concessão (regras } \\
\text { aplicáveis) } \\
\text { Temas : Políticas de Telecomunicações : Universalização : Metas de Universalização } \\
\text { Temas : Serviços no Setor de Telecomunicações : Serviço Telefônico Fixo Comutado } \\
\text { (STFC) }\end{array}$ \\
\hline
\end{tabular}

Resolução da ANATEL no 660, de 28 de dezembro de 2015 - Altera o Regulamento do Preço Público Relativo à Administração dos Recursos de Numeração, aprovado pela Resolução $\mathrm{n}^{\circ} 451$, de 8 de dezembro de 2006

\begin{tabular}{|c|c|}
\hline Órgão Emissor & ANATEL - Conselho Diretor. \\
\hline Nota Vigência & $1^{\circ}$ de janeiro de 2016 \\
\hline Dispositivos & LGT, Art. 151 , caput. \\
\hline Altera & $\begin{array}{l}\text { Anexo à Resolução da ANATEL no 451, de } 8 \text { de dezembro de } 2006 \text { - Regulamento do } \\
\text { Preço Público Relativo à Administração dos Recursos de Numeração. }\end{array}$ \\
\hline Regulamenta & $\begin{array}{l}\text { Lei } \mathrm{n}^{\circ} \text { 9.472/1997 - Dispõe sobre a organização dos serviços de telecomunicações, a } \\
\text { criação e funcionamento de um órgão regulador e outros aspectos institucionais, nos } \\
\text { termos da Emenda Constitucional } n^{\circ} 8 \text {, de } 1995 \text {. }\end{array}$ \\
\hline Publicação & Diário Oficial da União, Seção 1, 30-12-2015, pág. p. 147 \\
\hline Temas & $\begin{array}{l}\text { Temas : Administração do Setor de Telecomunicações : Outorgas : Preço Público e Preço } \\
\text { Privado } \\
\text { Temas : Infra-estrutura e Recursos do Setor de Telecomunicações : Infraestrutura de } \\
\text { Telecomunicações : Bem Público (utilização e restrição) }\end{array}$ \\
\hline
\end{tabular}


Temas : Infraestrutura e Recursos do Setor de Telecomunicações : Redes de Telecomunicações : Numeração dos Serviços

\section{Julgados Referenciados}

\section{Acórdãos}

\section{Supremo Tribunal Federal (STF)}

\begin{tabular}{|l|l|}
\hline \multicolumn{2}{|l|}{ Ação Direta de Inconstitucionalidade no 2.615 (ADI 2.615 - Santa Catarina) } \\
\hline Relator & Min. Eros Grau \\
\hline Órgão Julgador & Plenário do STF \\
\hline Votação & Maioria \\
\hline Julgamento & 11-03-2015 \\
\hline Dispositivos & CF, Art. 21, inciso XI (em 15/08/1995); CF, Art. 22, inciso IV. \\
\hline Publicação & Diário da Justiça Eletrônico, 11-03-2015 \\
\hline $\begin{array}{l}\text { Descrição do Caso } \\
\text { Inconstitucionalidade de disciplina estudual sobre as condições de cobrança do valor da assinatura básica } \\
\text { por invasão de competência da União. O argumento de que se trata de direito do consumidor não autoriza } \\
\text { estado-membro da federação a legislar sobre assinatura básica. }\end{array}$ \\
\hline Temas & $\begin{array}{l}\text { Temas : Administração do Setor de Telecomunicações : Outorgas : Autorização (regras } \\
\text { aplicáveis) } \\
\text { Temas : Administração do Setor de Telecomunicações : Outorgas : Concessão (regras } \\
\text { aplicáveis) } \\
\text { Temas : Atores no Setor de Telecomunicações } \\
\text { Temas : Atores no Setor de Telecomunicações : Poder Judiciário : STF } \\
\text { Temas : Serviços no Setor de Telecomunicações : Serviço Telefônico Fixo Comutado } \\
\text { (STFC) }\end{array}$ \\
\hline Catalogador & \begin{tabular}{l} 
Márcio Iório Aranha \\
\hline
\end{tabular} \\
\hline
\end{tabular}

Habeas Corpus 128567/MG (HC 128567/MG, de 08 de setembro de 2015)

\begin{tabular}{|l|l|}
\hline Relator & Min. Teori Zavascki \\
\hline Órgão Julgador & Segunda Turma do STF \\
\hline Votação & Unânime \\
\hline Julgamento & 08-09-2015 \\
\hline Dispositivos & LGT, Art. 183, caput. \\
\hline Ref. Leg. & Lei n $^{\circ}$ 9.472, de 16 de julho de 1997 \\
\hline Publicação & Diário da Justiça Eletrônico, 23-09-2015 \\
\hline
\end{tabular}

Descrição do Caso

Crime de exploração clandestina de atividade de telecomunicação (art. 183 da LGT) não se caracteriza como hipótese de aplicação do princípio da insignificância. Baixa potência do equipamento de telecomunicações utilizado não autoriza atipicidade do crime por aplicação do princípio da insignificância. Trata-se de crime formal, ou seja, que não exige resultado naturalístico, de perigo abstrato, consumandose com o mero desenvolvimento clandestino da atividade, $\mathrm{O}$ eventual dano a terceiro em determinado caso concreto configura causa de aumento de pena e também não autoriza a aplicação do princípio da insignificância, pois o crime não tem como pressuposto a ocorrência do prejuízo econômico: ele visa à proteção de um bem difuso de potencial risco de lesão ao regular funcionamento do sistema de telecomunicações. Desde que caracterizada a habitualidade exigida na tipificação do art. 183 da LGT, que o diferencia da conduta tipificada no art. 70 do CBT, aquele que coloca em funcionamento rádio comunitária 


\begin{tabular}{|l|l|}
\hline $\begin{array}{l}\text { de forma irregular com equipamentos de potência superior ao permitido e capaz de interferir em outras } \\
\text { atividades de telecomunicações não se beneficia do princípio da insignificância, pois ausentes os requisitos } \\
\text { da inexpressividade da lesão jurídica e da mínima ofensividade da conduta. }\end{array}$ \\
\hline Temas & $\begin{array}{l}\text { Temas : Administração do Setor de Telecomunicações : Fiscalização das Telecomunicações } \\
\text { Temas : Atores no Setor de Telecomunicações : Poder Judiciário : STF } \\
\text { Temas : Fundamentos : Conceitos Fundamentais } \\
\text { Temas : Serviços no Setor de Telecomunicações : Radiodifusão : Radiodifusão Comunitária }\end{array}$ \\
\hline Catalogador & Márcio Iório Aranha \\
\hline
\end{tabular}

\begin{tabular}{|l|l|}
\hline $\begin{array}{l}\text { Embargos de } \\
\text { 456534/RS) }\end{array}$ & Declaração no Recurso Extraordinário 456534 Embargos de Declaração - (RE \\
\hline Relator & Min. Luís Roberto Barroso \\
\hline $\begin{array}{l}\text { R e 1 d o } \\
\text { Acórdão }\end{array}$ & Min. Aldir Passarinho \\
\hline Órgão Julgador & Primeira Turma do STF \\
\hline Votação & Unânime \\
\hline Julgamento & 23-06-2015 \\
\hline Dispositivos & CF, Art. 21, inciso XI (em 15/08/1995); CF, Art. 22, inciso IV. \\
\hline Publicação & Diário da Justiça Eletrônico, 06-08-2015 \\
\hline $\begin{array}{l}\text { Descrição do Caso } \\
\text { Constitucionalidade de disciplina municipal para cobrança de taxa de licença para instalação e de verificação } \\
\text { da permanência das condições técnicas iniciais dos equipamentos destinados à energia elétrica e ao } \\
\text { fornecimento de serviços de telecomunicações. A cobrança da taxa em razão do exercício do poder de } \\
\text { polícia municipal para fiscalização quanto ao atendimento de regras de posturas municipais, desde que } \\
\text { prevista em lei, é constitucional. O exercício de poder de polícia in casu é presumido. }\end{array}$ \\
\hline $\begin{array}{l}\text { Temas } \\
\text { Temas : Administração do Setor de Telecomunicações : Outorgas : Autorização (regras } \\
\text { aplicáveis) } \\
\text { Temas : Administração do Setor de Telecomunicações : Outorgas : Concessão (regras } \\
\text { aplicáveis) } \\
\text { Temas : Atores no Setor de Telecomunicações } \\
\text { Temas : Atores no Setor de Telecomunicações : Poder Judiciário : STF } \\
\text { Temas : Serviços no Setor de Telecomunicações : Serviço de Acesso Condicionado } \\
\text { (SeAC) }\end{array}$ \\
\hline $\begin{array}{l}\text { Catalogador } \\
\text { Márcio Iório Aranha }\end{array}$ \\
\hline
\end{tabular}

\begin{tabular}{|l|l|}
\hline \multicolumn{2}{|l|}{ Agravo Regimental no Recurso Extraordinário 811620 (RE 811620 AgR/MG) } \\
\hline Relator & Min. Edson Fachin \\
\hline Órgão Julgador & Plenário do STF \\
\hline Votação & Unânime \\
\hline Julgamento & $13-10-2015$ \\
\hline Dispositivos & CF, Art. 21, inciso XI (em 15/08/1995); CF, Art. 22, inciso IV. \\
\hline Correlata & Recurso Extraordinário - RG 581.947 \\
\hline Publicação & Diário da Justiça Eletrônico, 28-10-2015 \\
\hline $\begin{array}{l}\text { Descrição do Caso } \\
\text { Inconstitucionalidade de disciplina estadual para cobrança de taxa de uso e ocupação de solo e espaço } \\
\text { aéreo de instalações de equipamentos necessários à prestaça de serviço público de telecomunicações por } \\
\text { invasão de competência legislativa da União. }\end{array}$ \\
\hline
\end{tabular}




\begin{tabular}{|l|l|}
\hline Temas & Temas : Administração do Setor de Telecomunicações : Outorgas : Autorização (regras \\
& aplicáveis) \\
& Temas : Administração do Setor de Telecomunicações : Outorgas : Concessão (regras \\
& aplicáveis) \\
& Temas : Atores no Setor de Telecomunicações \\
& Temas : Atores no Setor de Telecomunicações : Poder Judiciário : STF \\
& Temas : Classificações de Serviços no Setor de Telecomunicações : Quanto ao Regime \\
& Jurídico de Prestação \\
& Temas : Serviços no Setor de Telecomunicações : Serviço Telefônico Fixo Comutado \\
& (STFC) \\
\hline Catalogador & Márcio Iório Aranha \\
\hline
\end{tabular}

\section{Superior Tribunal de Justiça (STJ)}

\begin{tabular}{|c|c|}
\hline \multicolumn{2}{|c|}{$\begin{array}{l}\text { Agravo Regimental no Recurso Especial no } 1384340 \text { (STJ - RESP } 1384340 \text { AgRg/DF - Distrito } \\
\text { Federal) }\end{array}$} \\
\hline Relator & Min. Paulo de Tarso Sanseverino \\
\hline Órgão Julgador & Terceira Turma do STJ \\
\hline Votação & Unânime \\
\hline Julgamento & $05-05-2015$ \\
\hline Dispositivos & $\mathrm{CF}$, Art $5^{\circ}$, inciso $\mathrm{X}$. \\
\hline Publicação & Diário da Justiça Eletrônico, 12-05-2015 \\
\hline \multicolumn{2}{|c|}{ Descrição do Caso } \\
\hline \multicolumn{2}{|c|}{$\begin{array}{l}\text { O Marco Civil da Internet ( Lei } 12.965 / 2014 \text { ) não se aplica a fatos pretéritos a sua edição. Comentário } \\
\text { ofensivo postado no ORKUT é de responsabilidade do provedor de hospedagem devidamente notificado } \\
\text { que não providenciou a identificação do IP do autor da defesa, mesmo que a impossibilidade de identificação } \\
\text { do ofensor resulte de caso fortuito ou força maior ocorridos durante o atraso na identificação do IP do } \\
\text { autor da ofensa. }\end{array}$} \\
\hline Temas & $\begin{array}{l}\text { Temas : Aplicações de Telecomunicações : Internet } \\
\text { Temas : Atores no Setor de Telecomunicações : Poder Judiciário : STJ } \\
\text { Temas : Atores no Setor de Telecomunicações : Provedor de Aplicações de Intenet } \\
\text { Temas : Atores no Setor de Telecomunicações : Usuário / Consumidor } \\
\text { Temas : Fundamentos : Conceitos Fundamentais : Era da Informação } \\
\text { Temas : Fundamentos : Conceitos Fundamentais : Liberdade de Expressão }\end{array}$ \\
\hline Catalogador & Márcio Iório Aranha \\
\hline
\end{tabular}

\section{Tribunal de Contas da União (TCU)}

\begin{tabular}{|l|l|}
\hline \multicolumn{2}{|l|}{ Acórdão do TCU $\mathbf{n}^{\mathbf{0}} \mathbf{3 3 1 1}$, de 09 de dezembro de 2015} \\
\hline Relator & Min. Benjamin Zymler \\
\hline Órgão Julgador & Plenário do TCU \\
\hline Votação & Unânime \\
\hline Julgamento & 09-12-2015 \\
\hline Dispositivos & $\begin{array}{l}\text { LGT, Art. 39, Parágrafo Único; LGT, Art. 86, § Único, Inciso III; LGT, Art. 93, inciso } \\
\text { XI; LGT, Art. 101, caput; LGT, Art. 173, caput. }\end{array}$ \\
\hline Ref. Leg. & $\begin{array}{l}\text { Lei }{ }^{\circ} \text { 9.472, de 16 de julho de 1997 } \\
\text { Lei }{ }^{\circ} \text { 12.527, de 18 de novembro de 2011 }\end{array}$ \\
\hline Descrição do Caso
\end{tabular}




\begin{tabular}{|c|c|}
\hline \multicolumn{2}{|c|}{$\begin{array}{l}\text { Determinações à ANATEL sobre o acompanhamento dos bens reversíveis das concessões de Serviço } \\
\text { Telefônico Fixo Comutado, bem como exigência de que a ANATEL disponibilize em seu sítio eletrônico, } \\
\text { no prazo de } 210 \text { dias da ciência do acórdão, todas as relações de bens reversíveis de } 2009 \text { a } 2014 \text {, contendo } \\
\text { todos os dados classificados como sendo de caráter público, em formato de arquivo aberto, não-proprietário, } \\
\text { estruturado e legível por máquina. }\end{array}$} \\
\hline Temas & $\begin{array}{l}\text { Temas : Administração do Setor de Telecomunicações : Fiscalização das Telecomunicações } \\
\text { Temas : Administração do Setor de Telecomunicações : Outorgas : Concessão (regras } \\
\text { aplicáveis) } \\
\text { Temas : Atores no Setor de Telecomunicações : Poder Legislativo : Tribunal de Contas } \\
\text { da União } \\
\text { Temas : Serviços no Setor de Telecomunicações : Serviço Telefônico Fixo Comutado } \\
\text { (STFC) }\end{array}$ \\
\hline Catalogador & Márcio Iório Aranha \\
\hline
\end{tabular}

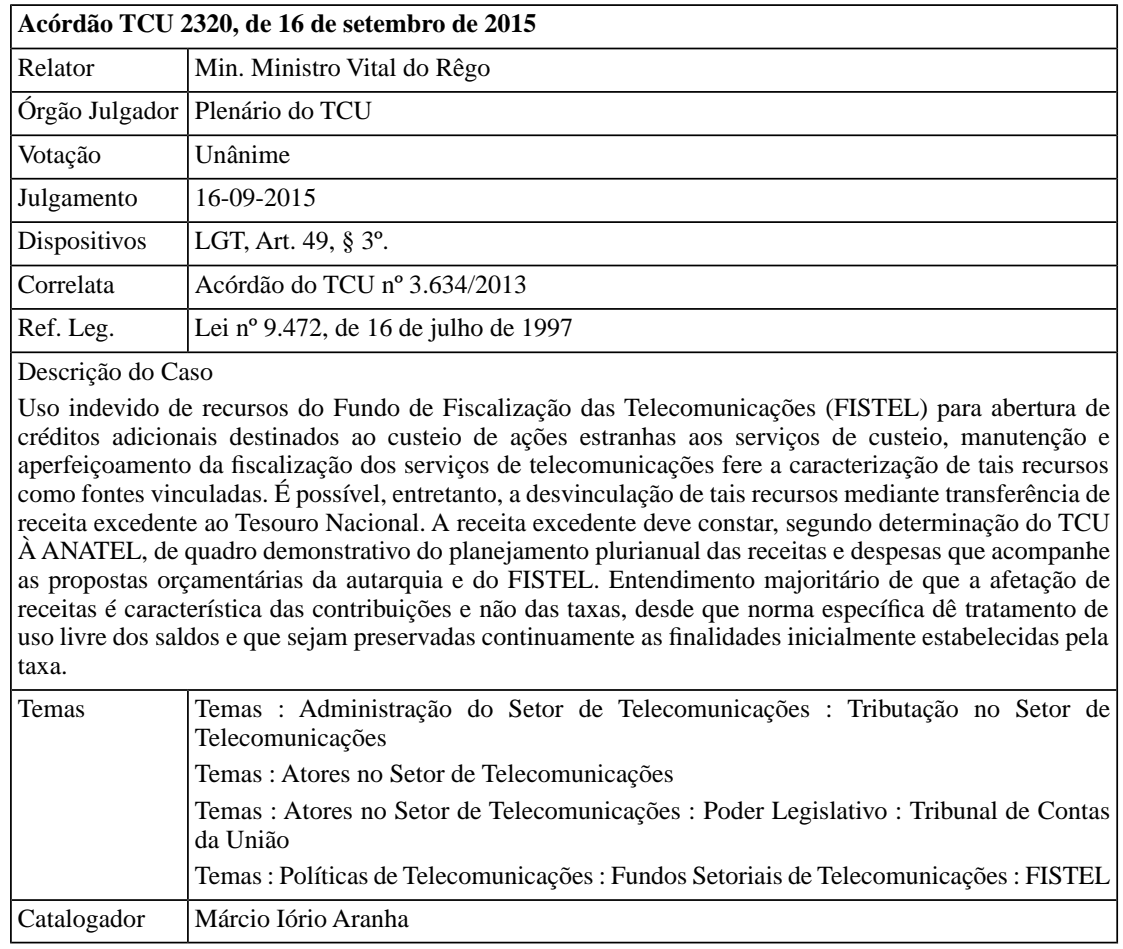

\section{Atos Referenciados}

\section{Ato Administrativo}

\section{Ato}

\section{Ato do Conselho Diretor da ANATEL no 448, de 22 de janeiro de 2015}

\begin{tabular}{l|l} 
Ementa & Concede anuência prévia à transferência do controle integral da GVT PARTICIPAÇÕES
\end{tabular} S/A para a TELEFÔNICA BRASIL S/A, mediante condicionamentos de eliminação de sobreposição de outorgas do STFC, de assunção pela adquirente das obrigações de 


\begin{tabular}{|l|l|}
\hline & $\begin{array}{l}\text { manutenção de cobertura geográfica e continuidade de atendimento do STFC, SCM e } \\
\text { SeAC, de manutenção das ofertas de planos de serviços e ofertas conjuntas de STFC, } \\
\text { SCM e SeAC então vigentes pelo prazo mínimo de 18 meses, de manutenção dos contratos } \\
\text { em vigor com os usuários ao tempo da operação pelo prazo mínimo de } 18 \text { meses, de } \\
\text { expansão da cobertura da rede e dos princípios serviços de telecomunicações envolvidos } \\
\text { na operação, dentre outros. }\end{array}$ \\
\hline Órgão Emissor & ANATEL - Conselho Diretor. \\
\hline Nota Vigência & Data de publicação no DOU \\
\hline Nota Eficácia & Anuência válida por 180 dias, prorrogáveis por mais 180 dias a pedido \\
\hline Dispositivos & $\begin{array}{l}\text { LGT, Art. } 7^{\circ}, \S 1^{\circ} \text {; LGT, Art. 19, inciso XIX; LGT, Art. 71, caput; LGT, Art. 97, Parágrafo } \\
\text { Unico. }\end{array}$ \\
\hline Regulamenta & $\begin{array}{l}\text { Lei no 9.472/1997 - Dispõe sobre a organização dos serviços de telecomunicações, a } \\
\text { criação e funcionamento de um órgão regulador e outros aspectos institucionais, nos } \\
\text { termos da Emenda Constitucional no 8, de 1995. }\end{array}$ \\
\hline Publicação & $\begin{array}{l}\text { Diário Oficial da União, Seção 1, 26-01-2015, pág. 50 } \\
\text { Temas : Atores no Setor de Telecomunicações : Prestadora / Operadora } \\
\text { Temas : Políticas de Telecomunicações : Concorrência no Setor de Telecomunicações } \\
\text { Temas : Ramos Jurídicos Afins : Direito da Concorrência } \\
\text { Temas : Serviços no Setor de Telecomunicações : Serviço Telefônico Fixo Comutado } \\
\text { (STFC) } \\
\text { Temas : Serviços no Setor de Telecomunicações : Serviço de Acesso Condicionado } \\
\text { (SeAC) } \\
\text { Temas : Serviços no Setor de Telecomunicações : Serviço de Comunicação Multimídia } \\
\text { (SCM) }\end{array}$ \\
\hline
\end{tabular}

\section{Decisão}

\begin{tabular}{|l|l|}
\hline \multicolumn{2}{|l|}{ Acórdão do Conselho Diretor da ANATEL, de 5 de janeiro de 2015 (Ref. no 6/2015) } \\
\hline Ementa & $\begin{array}{l}\text { Possibilidade de celebração de TAC sobre infração de natureza grave relativa a indícios } \\
\text { de prestação não outorgada de STFC, mesmo que a conduta já tenha sido regularizada. } \\
\text { A celebração de TAC submete-se ao juízo da autoridade sobre a conveniência e } \\
\text { oportunidade do acordo negocial como solução alternativa ao tradicional rito do } \\
\text { procedimento sancionador para regularização de condutas infrativas }\end{array}$ \\
\hline Órgão Emissor & ANATEL - Conselho Diretor. \\
\hline Dispositivos & $\begin{array}{l}\text { LGT, Art. 19, inciso XXV; LGT, Art. 20, Parágrafo Único; LGT, Art. 64, Parágrafo } \\
\text { Único; LGT, Art. 82, caput. }\end{array}$ \\
\hline Publicação & Diário Oficial da União, Seção 1, 14-01-2015, pág. p. 46 \\
\hline Temas & $\begin{array}{l}\text { Temas : Atores no Setor de Telecomunicações : ANATEL } \\
\text { Temas : Atores no Setor de Telecomunicações : Prestadora / Operadora } \\
\text { Temas : Serviços no Setor de Telecomunicações : Serviço Telefônico Fixo Comutado } \\
\text { (STFC) }\end{array}$ \\
\hline
\end{tabular}

\begin{tabular}{|l|l|}
\hline Acórdão do Conselho Diretor da ANATEL, de 24 de fevereiro de 2015 (Ref. $\mathbf{n}^{\mathbf{0}} \mathbf{5 3 / 2 0 1 5}$ ) \\
\hline Ementa & $\begin{array}{l}\text { A renúncia de outorgas de radiofrequências para cumprimento de exigência editalícia em } \\
\text { licitação realizada pela ANATEL opera efeitos de extinção das outorgas renunciadas } \\
\text { imediatamente após decorrido o prazo fixado no compromisso aposto aos autos do processo } \\
\text { e a despeito da comprovação de início de negociações para transferência das outorgas } \\
\text { correspondentes, não cabendo à licitante opor ao ato de extinção o fato de que não teria } \\
\text { ultimado a transferência das outorgas ou do controle societário das empresas que } \\
\text { detivessem outorgas nas subfaixas e áreas de prestação renunciadas pela licitante para } \\
\text { pessoa não pertencente a seu grupo econômico. Alcançado o termo final do prazo } \\
\text { compromissado sem a transferência de outorgas ou de controle societário das empresas }\end{array}$
\end{tabular}




\begin{tabular}{|l|l|}
\hline & $\begin{array}{l}\text { que as detiverem, compete à ANATEL extinguir unilateralmente as outorgas abdicadas } \\
\text { como exigência licitatória, independentemente da demora nas negociações privadas, } \\
\text { exceto o caso de mora atribuível a ato ou inação da Administração Pública na anuência } \\
\text { prévia correspondente. }\end{array}$ \\
\hline Órgão Emissor & ANATEL - Conselho Diretor. \\
\hline Dispositivos & $\begin{array}{l}\text { LGT, Art. 19, inciso XXV; LGT, Art. 20, Parágrafo Único; LGT, Art. 135, Parágrafo } \\
\text { Unico; LGT, Art. 142, Parágrafo Único. }\end{array}$ \\
\hline Publicação & Diário Oficial da União, Seção 1, 10-03-2015, pág. 14 \\
\hline Temas & $\begin{array}{l}\text { Temas : Administração do Setor de Telecomunicações : Outorgas : Licitação } \\
\text { Temas : Atores no Setor de Telecomunicações : ANATEL } \\
\text { Temas : Infraestrutura e Recursos do Setor de Telecomunicações : Espectro de } \\
\text { Radiofrequência : Direito de Uso de Radiofrequência } \\
\text { Temas : Políticas de Telecomunicações : Concorrência no Setor de Telecomunicações }\end{array}$ \\
\hline
\end{tabular}

\begin{tabular}{|l|l|}
\hline Acórdão do Conselho Diretor da ANATEL, de 31 de julho de 2015 (Ref. $\left.\mathbf{n}^{\mathbf{0} 305 / 2015}\right)$ \\
\hline Ementa & $\begin{array}{l}\text { Tempestividade de recurso administrativo deve ser certificada do momento do seu } \\
\text { recebimento no protocolo da Agência, não da postagem do documento. }\end{array}$ \\
\hline Órgão Emissor & ANATEL - Conselho Diretor. \\
\hline Dispositivos & $\begin{array}{l}\text { CF, Art. } 5^{\circ}, \text { inciso LIV; CF, Art.5 }{ }^{\circ} \text { inciso LV; LGT, Art. 19, inciso XXV; LGT, Art. 20, } \\
\text { Parágrafo Único; LGT, Art. 38, caput; LGT, Art. 175, caput. }\end{array}$ \\
\hline Publicação & Diário Oficial da União, Seção 1, 02-09-2015, pág. p. 68 \\
\hline Temas & $\begin{array}{l}\text { Temas : Administração do Setor de Telecomunicações : Processo Administrativo } \\
\text { Temas : Atores no Setor de Telecomunicações : ANATEL }\end{array}$ \\
\hline
\end{tabular}

\begin{tabular}{|l|l|}
\hline Acórdão do Conselho Diretor da ANATEL, de 5 de novembro de 2015 (Ref. no 480/2015) \\
\hline Ementa & $\begin{array}{l}\text { É ilícito o incentivo à realização de acessos discados à internet em horário de tarifa } \\
\text { reduzida sob a promessa de que os usuários de STFC sejam remunerados pelo tempo de } \\
\text { conexão ao provedor de acesso à internet, caracterizando a conduta prevista no art. 29 do } \\
\text { Regulamento Geral de Interconexão, aprovado pela Resolução no 410/2015, de uso } \\
\text { indevido das rotas de interconexão para cursar tráfego artificialmente gerado além do } \\
\text { "estritamente necessário à prestação do serviço" (art. 152 da LGT), bem como é possível } \\
\text { a imposição de determinação administrativa de interrupção de tráfego, ou bloqueio de } \\
\text { interconexão, para correção da conduta e devolução de valores pagos a mais, } \\
\text { independentemente de ampla defesa e contraditório, por se tratar de ato de ofício da } \\
\text { ANATEL para coibir conduta ilícita de regulado. }\end{array}$ \\
\hline Órgão Emissor & ANATEL - Conselho Diretor. \\
\hline Dispositivos & LGT, Art. 19, inciso XXV; LGT, Art. 20, Parágrafo Único; LGT, Art. 152, caput. \\
\hline Publicação & Diário Oficial da União, Seção 1, 23-11-2015, pág. p. 111 \\
\hline Temas & $\begin{array}{l}\text { Temas : Atores no Setor de Telecomunicações : ANATEL } \\
\text { Temas : Infra-estrutura e Recursos do Setor de Telecomunicações : Redes de } \\
\text { Telecomunicações : Interconexão }\end{array}$ \\
\hline
\end{tabular}

\section{Relatório da Ouvidoria da ANATEL}

\begin{tabular}{|l|l|}
\hline \multicolumn{2}{|l|}{ Relatório da Ouvidoria da ANATEL 2015} \\
\hline Órgão Emissor & ANATEL - Ouvidoria. \\
\hline Dispositivos & LGT, Art. 45, Parágrafo Único. \\
\hline Publicação & Diário Oficial da União, Seção 1, 01-10-2015, pág. p. 111 \\
\hline Temas & Temas : Atores no Setor de Telecomunicações : ANATEL
\end{tabular}


Temas : Fundamentos : Aspectos Históricos

Temas : Políticas de Telecomunicações : Controle Social, Hierárquico e Interorgânico 


\section{Índice Alfabético e Remissivo}

\section{Símbolos}

$174 \mathrm{MHz}$ a $216 \mathrm{MHZ}$

VHF Alto

sua utilização para execução de serviço de radiodifusão de sons e imagens em tecnologia digital, 286

[Portaria MC n ${ }^{\circ} 1.581$, de 9 de abril de 2015]

2.500 MHz a 2.690 MHz

Regulamento do Acompanhamento de Compromissos de Aquisição de Produtos e Sistemas Nacionais aprovação do, 295

[Resolução da ANATEL nº 655, de 5 de Agosto de 2015]

4G

(ver Quarta Geração de Tecnologia de Telefonia Móvel (requisitos da UIT IMT-Advanced))

\section{$700 \mathrm{MHz}$}

Regulamento do Acompanhamento de Compromissos de Aquisição de Produtos e Sistemas Nacionais aprovação do, 295

[Resolução da ANATEL n ${ }^{\circ}$ 655, de 5 de Agosto de 2015]

800 MHz, 900 MHz, 1.800 MHz, 1.900 MHz e 2.100 MHz, 296

[Resolução da ANATEL no 657, de 3 de novembro de 2015]

A

Ação Direta de Inconstitucionalidade ( ver Ação Direta de Inconstitucionalidade (Jurisdição))

Ação Direta de Inconstitucionalidade (Jurisdição)

ADI 2615/SC

inconstitucionalidade de disciplina estadual das condições de cobrança do valor da assinatura básica por invasão de competência federativa, 298
[ADI 2.615 - SC]

Acessibilidade, 273

Acessibilidade, 283

[Lei $\mathrm{n}^{\circ}$ 13.146, de 6 de julho de 2015]

Radiodifusão

exigência de que os serviços de radiodifusão de sons e imagens permitam o uso de recursos de substitulação por meio de legenda oculta, janela com intérprete da Libras, e audiodescrição, $\mathbf{2 8 3}$

[Lei $\mathrm{n}^{\circ} 13.146$, de 6 de julho de 2015]

Serviço de Telecomunicações

exigência de que as empresas prestadoras de serviços de telecomunicações devam garantiar pleno acesso à pessoa com deficiência, 283

[Lei ${ }^{\circ} 13.146$, de 6 de julho de 2015]

Serviço Móvel Pessoal

dever do poder público de incentivar a oferta de aparelhos de telefonia fixa e móvel celular com acessibilidade, entre outras tecnologias assistivas, $\mathbf{2 8 3}$

[Lei ${ }^{\circ} 13.146$, de 6 de julho de 2015]

Serviço Telefônico Fixo Comutado

dever do poder público de incentivar a oferta de aparelhos de telefonia fixa e móvel celular com acessibilidade, entre outras tecnologias assistivas, $\mathbf{2 8 3}$

[Lei ${ }^{\circ} 13.146$, de 6 de julho de 2015]

Acesso a Informação

Acórdão TCU 3311/2015

exigência do TCU à ANATEL para que disponibilize em seu sítio eletrônico, no prazo de 210 dias da ciência do acórdão, todas as relações de bens reversíveis de 2009 a 2014, contendo todos os dados classificados como sendo de caráter público, em formato de arquivo aberto, não-proprietário, estruturado e legível por máquina, 300

[Acórdão TCU 3311/2015] 
Acesso a Serviços de Interesse Público e Uso de Radiofrequência por tais Serviços, 273

Acesso às Telecomunicações, 258

Adaptação

Rádio AM para FM

procedimentos de adaptação da, 290

[Portaria MC $\mathrm{n}^{\circ}$ 6.467, de 24 de novembro de 2015]

ADI
$\left(\begin{array}{llll}v e r & \text { Ação } & \text { Direta de }\end{array}\right.$ Inconstitucionalidade (Jurisdição))

Administração do Setor de

Telecomunicações, 248

Administração Pública Federal

Arbitragem

exigência de sua submissão ao princípio da publicidade quando se tratar de arbitragem que envolva a administração pública, 283

[Lei ${ }^{\circ} 13.129$, de 26 de maio de 2015]

Aeroporto, 282

[Lei $\mathrm{n}^{\circ}$ 13.116, de 20 de abril de 2015]

\section{Afetação de Receita}

Fundo de Fiscalização das

Telecomunicações

possibilidade de uso de receita excedente em fins diversos dos de custeio, manutenção e aperfeiçoamento da fiscalização dos serviços de telecomunicações caso tenham sido desvinculadas mediante transferência de receita excedente ao Tesouro Nacional, 301

[Acórdão TCU 2320/2015]

Agência Nacional de Telecomunicações, 283

[Lei no 13.129, de 26 de maio de 2015]

Resolução de Disputas

alteração da Lei de Arbitragem para incluir expressa possibilidade da administração pública direta $\mathrm{e}$ indireta utilizar da arbitragem para dirimir conflitos relativos a direitos patrimoniais disponíveis, $\mathbf{2 8 3}$

[Lei ${ }^{\circ} 13.129$, de 26 de maio de 2015] previsão de competência das câmaras de prevenção e resolução administrativa de conflitos sobre questões que envolvam equilíbrio econômico-financeiro de contratos celebrados pela administração com particulares, 283

[Lei ${ }^{\circ} 13.140$, de 26 de junho de 2015]

Ampla Defesa

(ver também Direito a Ampla Defesa e Contraditório)

Processo Administrativo

tempestividade de recurso é computada do momento do protocolo na Agência e não de postagem da peça recursal, 303

[Acórdão do Conselho Diretor da ANATEL, de 31 de julho de 2015 (Ref. $\left.n^{\circ} 305 / 2015\right)$ ]

ANATEL, 274

(ver Agência Nacional de Telecomunicações)

\section{Antenas, 244}

Anuência Prévia

à transferência do controle integral da GVT para a TELEFÔNICA, 301

[Ato do Conselho Diretor da ANATEL $\mathrm{n}^{\circ} 448$, de 22 de janeiro de 2015]

Aplicações de Telecomunicações, 272

\section{Arbitragem}

(ver também Resolução de Disputas)

aplicabilidade da Lei de Arbitragem a questões envolvendo a ANATEL e as concessionárias de STFC, 283

[Lei ${ }^{\circ} 13.129$, de 26 de maio de 2015]

Direito Patrimonial Disponível

alteração da Lei de Arbitragem para incluir expressa possibilidade da administração pública direta e indireta utilizar da arbitragem para dirimir conflitos relativos a direitos patrimoniais disponíveis, $\mathbf{2 8 3}$

[Lei ${ }^{\circ} 13.129$, de 26 de maio de 2015]

exigência de que a arbitragem se submete ao direito posto quando envolva a administração pública, 283

[Lei ${ }^{\circ} 13.129$, de 26 de maio de 2015]

Lei de Arbitragem

sua alteração para incluir expressa possibilidade da administração pública direta e indireta utilizar da arbitragem para dirimir conflitos relativos a direitos patrimoniais disponíveis, $\mathbf{2 8 3}$

[Lei ${ }^{\circ} 13.129$, de 26 de maio de 2015]

\section{Artificial}

Tráfego Artificial 
conduta ilítica de uso indevido das rotas de interconexão para cursar tráfego artificialmente gerado, $\mathbf{3 0 3}$ [Acórdão do Conselho Diretor da ANATEL, de 5 de novembro de 2015 (Ref. $n^{\circ}$ 480/2015)]

Aspectos Históricos, 241

\section{Assinatura Básica}

argumento de que se trata de direito consumidor não autoriza estadomembro da federação a legislar sobre, 298

[ADI 2.615 - SC]

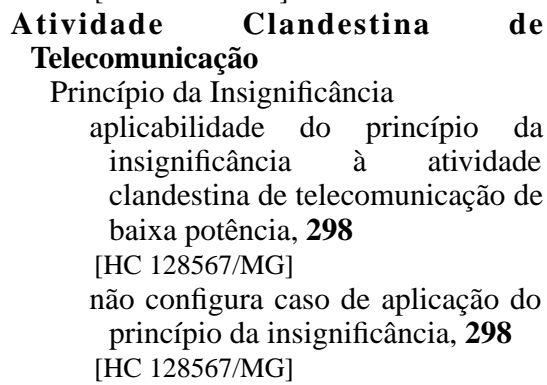

Atores no Setor de Telecomunicações, 273

Atribuição, Destinação e Distribuição de Radiofrequência, 247

Autorização (regras aplicáveis), 254

B

\section{Backhaul, 289}

(ver também Banda Larga)

[Portaria MC no 4.699, de 14 de outubro de 2015]

possibilidade de emendas parlamentares para financiamento de ações de implantação de infraestrutura de conexão entre órgãos e equipamentos públicos locais e à internet, inclusive por meio de construção de, $\mathbf{2 8 9}$

[Portaria MC n ${ }^{\circ} 4.699$, de 14 de outubro de 2015]

Telecomunicações Brasileiras S.A.

executora de ações de implantação de infraestrutura de conexão entre órgãos e equipamentos públicos locais e à internet, inclusive por meio de construção de backhaul, 289
[Portaria MC $\mathrm{n}^{\circ} 4.699$, de 14 de outubro de 2015]

\section{Baixa Potência}

Estação Rádio Base

sua definição como o equipamento definido no art. 156-A da Lei 9.472, de 1997, quando esta não continha tal dispositivo, 281

[Lei no 13.097, de 19 de janeiro de 2015]

Banda Larga, 273

Banda Larga

(ver também Backhaul)

(ver também Programa Nacional de

Banda Larga)

Regime Especial de Tributação do

Programa Nacional de Banda Larga para Implantação de Redes de Telecomunicações regulamentação do, $\mathbf{2 8 7}$

[Portaria $\mathrm{MC} \mathrm{n}^{\circ} 320$, de 12 de janeiro de 2015]

Regulamento do Acompanhamento de Compromissos de Aquisição de

Produtos e Sistemas Nacionais aprovação do, 295

[Resolução da ANATEL n ${ }^{\circ}$ 655, de 5 de Agosto de 2015]

Banda Larga Móvel de Quarta Geração (ver Quarta Geração de Tecnologia de Telefonia Móvel (requisitos da UIT IMT-Advanced))

Bem Público (utilização e restrição), 243

Bem Reversível

(ver também Reversão)

Acórdão TCU 3311/2015

determinações à ANATEL sobre o acompanhamento dos bens reversíveis das concessões de Serviço Telefônico Fixo Comutado, 300

[Acórdão TCU 3311/2015]

Bombeiro, 296

(ver também Corpo de Bombeiros)

[Resolução da ANATEL nº 656, de 17 de Agosto de 2015]

\section{C}

\section{Calamidade Pública, 296}

[Resolução da ANATEL n ${ }^{\circ}$ 656, de 17 de Agosto de 2015] 
Regulamento sobre Gestão de Risco das Redes de Telecomunicações e Uso de Serviços de Telecomunicações em Desastres, Situações de Emergência e Estado de Calamidade Pública aprovação do, 296

[Resolução da ANATEL n 656, de 17 de Agosto de 2015]

\section{Canal da cidadania}

Norma Regulamentar do Canal da

Cidadania

alteração da, 289

[Portaria MC $\mathrm{n}^{\circ}$ 6.413, de 20 de novembro de 2015]

\section{Canal de Cidadania}

sua preferência no uso da faixa de VHF

Alto (174 MHz a $216 \mathrm{MHz}), 286$

[Portaria MC $\mathrm{n}^{\circ} 1.581$, de 9 de abril de 2015]

Canal de Cultura

\section{(ver também Cultura)}

diretrizes para sua operacionalização, 291

[Portaria Interministerial $\mathrm{n}^{\mathrm{o}} 4.074$, de 26 de Agosto de 2015]

sua preferência no uso da faixa de VHF

Alto (174 MHz a $216 \mathrm{MHz}), \mathbf{2 8 6}$

[Portaria MC n ${ }^{\circ} 1.581$, de 9 de abril de 2015]

\section{Canal de Educação}

diretrizes para operacionalização do, 291

[Portaria Interministerial $\mathrm{n}^{\circ} 2.098$, de 14 de maio de 2015]

sua preferência no uso da faixa de VHF

Alto (174 MHz a $216 \mathrm{MHz}), 286$

[Portaria $\mathrm{MC} \mathrm{n}^{\circ} 1.581$, de 9 de abril de 2015]

Canal do Poder Executivo

sua preferência no uso da faixa de VHF

Alto (174 MHz a $216 \mathrm{MHz}), 286$

[Portaria MC no 1.581, de 9 de abril de 2015]

\section{Catástrofe}

Regulamento sobre Gestão de Risco das Redes de Telecomunicações e Uso de Serviços de Telecomunicações em Desastres, Situações de Emergência e Estado de Calamidade Pública aprovação do, 296

[Resolução da ANATEL nº 656, de 17 CDUST (ver Comitê de Defesa dos Usuários de Serviços de Telecomunicações)

\section{Cidades Digitais}

Backhaul

possibilidade de emendas parlamentares para financiamento de ações de implantação de infraestrutura de conexão entre órgãos e equipamentos públicos locais e à internet, inclusive por meio de construção de, 289

[Portaria MC n ${ }^{\circ} 4.699$, de 14 de outubro de 2015]

Telecomunicações Brasileiras S.A.

executora de ações de implantação de infraestrutura de conexão entre órgãos e equipamentos públicos locais e à internet, inclusive por meio de construção de backhaul, 289

[Portaria MC n ${ }^{\circ} 4.699$, de 14 de outubro de 2015]

\section{Clandestino}

(ver Atividade Clandestina de Telecomunicação)

Classificações de Serviços no Setor de

Telecomunicações, 260

Comentário de Usuário da Internet

sua não inclusão no conceito de matéria objeto de regulamentação do direito de resposta ou retificação do ofendido da Lei 13.188/2015, 285

[Lei $\mathrm{n}^{\circ} 13.188$, de 11 de novembro de 2015]

Comitê de Defesa dos Usuários de Serviços de Telecomunicações

regimento interno do, $\mathbf{2 9 2}$

[Resolução da ANATEL nº 650, de 16 de março de 2015]

Compartilhamento de Infraestrutura, 243

\section{Competência}

Assinatura Básica

inconstitucionalidade de disciplina estadual das condições de cobrança do valor da assinatura básica por invasão de competência federativa, 298

[ADI 2.615 - SC]

Faixa de Domínio

insconstitucionalidade de disciplina estadual de cobrança de taxa de uso 
e ocupação de solo e espaço aéreo sobre instalação de equipamentos necessários à prestação de serviço público de telecomunicações, 299 [RE $811620 \mathrm{AgR} / \mathrm{MG}]$

Taxa Municipal de Licença e Fiscalização para Localização, Instalação e Funcionamento

constitucionalidade de disciplina municipal para cobrança de taxa de licença para instalação e de verificação da permanência das condições técnicas iniciais dos equipamentos destinados à energia elétrica e ao fornecimento de serviços de telecomunicações, 299 [RE $456534 \mathrm{ED} / \mathrm{RS}$ ]

\section{Comportamento Fraudulento}

Interconexão

conduta ilítica de uso indevido das rotas de interconexão para cursar tráfego artificialmente gerado, $\mathbf{3 0 3}$ [Acórdão do Conselho Diretor da ANATEL, de 5 de novembro de 2015 (Ref. ${ }^{\circ}$ 480/2015)]

Compromisso de Aquisição de Produtos e Sistemas com Tecnologia Desenvolvida no País

Regulamento do Acompanhamento de Compromissos de Aquisição de Produtos e Sistemas Nacionais aprovação do, 295

[Resolução da ANATEL n ${ }^{\circ} 655$, de 5 de Agosto de 2015]

Compromisso de Renúncia a Outorgas extinção de outorga como decorrência de compromisso de renúncia de outorga em licitação independentemente de início de negociações privadas de transferência da outorga ou de controle acionário das empresas que a detenha, $\mathbf{3 0 2}$

[Acórdão do Conselho Diretor da ANATEL, de 24 de fevereiro de 2015 (Ref. $n^{\circ}$ 53/2015)]

\section{Comunicação Social}

Direito de Resposta

sua disciplina e do direito de retificação do ofendido em matéria divulgada ou transmitida por veículo de comunicação social, inclusive a internet, $\mathbf{2 8 5}$
[Lei $\mathrm{n}^{\circ} 13.188$, de 11 de novembro de 2015]

Conceitos Fundamentais, 241

Concessão (regras aplicáveis), 252

Concessão

Equilíbrio Econômico-Financeiro

previsão de competência das câmaras de prevenção e resolução administrativa de conflitos sobre questões que envolvam equilíbrio econômico-financeiro de contratos celebrados pela administração com particulares, 283

[Lei $\mathrm{n}^{\circ} 13.140$, de 26 de junho de 2015] prorrogação da data da penúltima revisão quinquenal (2015) dos contratos de concessão de STFC pós renovação, 297

[Resolução da ANATEL nº 659, de 28 de dezembro de 2015]

Resolução de Disputas

previsão de competência das câmaras de prevenção e resolução administrativa de conflitos sobre questões que envolvam equilíbrio econômico-financeiro de contratos celebrados pela administração com particulares, 283

[Lei ${ }^{\circ} 13.140$, de 26 de junho de 2015]

Concorrência no Setor de

Telecomunicações, 257

Condições de Uso de Radiofrequência e Canalização (Distribuição de Canais), 247

Conflito entre Operadoras

(ver Resolução de Disputas)

Conflito Federativo

Assinatura Básica

argumento de que se trata de direito consumidor não autoriza estadomembro da federação a legislar sobre, 298

[ADI 2.615 - SC]

Faixa de Domínio

insconstitucionalidade de disciplina estadual de cobrança de taxa de uso e ocupação de solo e espaço aéreo sobre instalação de equipamentos necessários à prestação de serviço público de telecomunicações, 299 [RE $811620 \mathrm{AgR} / \mathrm{MG}]$ 
Taxa Municipal de Licença e Fiscalização para Localização, Instalação e Funcionamento constitucionalidade de disciplina municipal para cobrança de taxa de licença para instalação e de verificação da permanência das condições técnicas iniciais dos equipamentos destinados à energia elétrica e ao fornecimento de serviços de telecomunicações, 299

\section{Consumidor, 294} [RE $456534 \mathrm{ED} / \mathrm{RS}$ ]

\section{(ver também Usuário)}

[Resolução da ANATEL n 654, de 13 de julho de 2015]

\section{Contraditório}

\section{(ver também Direito a Ampla Defesa e}

Contraditório)

Processo Administrativo

tempestividade de recurso é computada do momento do protocolo na Agência e não de postagem da peça recursal, $\mathbf{3 0 3}$

[Acórdão do Conselho Diretor da ANATEL, de 31 de julho de 2015 (Ref. $\left.n^{\circ} 305 / 2015\right)$ ]

\section{Contrato de Concessão}

\section{(ver também Outorga)}

prorrogação da data da penúltima revisão quinquenal (2015) dos contratos de concessão de STFC pós renovação, 297

[Resolução da ANATEL n ${ }^{\circ}$ 659, de 28 de dezembro de 2015]

\section{Controle Social, Hierárquico e Interorgânico, 260 \\ Convenção de Arbitragem}

autoridade competente para celebração da, 283

[Lei ${ }^{\circ} 13.129$, de 26 de maio de 2015]

\section{Convenção de Tampere}

Regulamento sobre Gestão de Risco das Redes de Telecomunicações e Uso de Serviços de Telecomunicações em Desastres, Situações de Emergência e Estado de Calamidade Pública aprovação do, 296

[Resolução da ANATEL nº 656, de 17 de Agosto de 2015]

Conveniência e Oportunidade

Termo de Ajuste de Conduta inexistência de vinculação entre o interesse público na celebração de TAC e a natureza da matéria tratada em processo sancionador, $\mathbf{3 0 2}$

[Acórdão do Conselho Diretor da ANATEL, de 5 de janeiro de 2015 (Ref. $\left.\left.n^{\circ} 6 / 2015\right)\right]$

\section{Conversão}

Bem Reversível determinações à ANATEL sobre o acompanhamento dos bens reversíveis das concessões de Serviço Telefônico Fixo Comutado, 300

[Acórdão TCU 3311/2015]

\section{Corpo de Bombeiros}

(ver Bombeiro)

Corpo de Bombeiros

(ver também Bombeiro)

Regulamento sobre Gestão de Risco das

Redes de Telecomunicações e Uso de

Serviços de Telecomunicações em

Desastres, Situações de Emergência e

Estado de Calamidade Pública aprovação do, 296

[Resolução da ANATEL n 656 , de 17 de Agosto de 2015]

Crime

Atividade Clandestina de

Telecomunicação

aplicabilidade do princípio da insignificância à atividade clandestina de telecomunicação de baixa potência, 298

[HC 128567/MG]

não configura caso de aplicação do princípio da insignificância, 298

[HC 128567/MG]

Crime de Menor Potencial Ofensivo

(ver Princípio da Insignificância)

\section{Cultura, 291}

\section{(ver também Canal de Cultura)}

[Portaria Interministerial $\mathrm{n}^{\circ} 4.074$, de 26 de Agosto de 2015]

D

\section{Dano Moral}

Direito de Resposta retratação ou retificação espontânea não impedem o exercício do direito 
de resposta nem prejudicam a ação de reparação por dano moral, $\mathbf{2 8 5}$

[Lei ${ }^{\circ} 13.188$, de 11 de novembro de 2015]

Defesa

Radar

sua não submissão à disciplina da Lei 13.116, sobre os processo de licenciamento, instalação e compartilhamento de infraestrutura de telecomunicações em área urbana, 282

Defesa Civil

[Lei ${ }^{\circ} 13.116$, de 20 de abril de 2015]

Regulamento sobre Gestão de Risco das

Redes de Telecomunicações e Uso de

Serviços de Telecomunicações em

Desastres, Situações de Emergência e

Estado de Calamidade Pública aprovação do, 296

[Resolução da ANATEL n ${ }^{\circ}$ 656, de 17 de Agosto de 2015]

Defesa do consumidor

(ver Consumidor)

Defesa do Usuário

(ver Usuário)

Deficiência Auditiva, 283

[Lei ${ }^{\circ} 13.146$, de 6 de julho de 2015]

Deficiência Física, 283

[Lei no 13.146, de 6 de julho de 2015]

Desastre

Regulamento sobre Gestão de Risco das

Redes de Telecomunicações e Uso de

Serviços de Telecomunicações em

Desastres, Situações de Emergência e

Estado de Calamidade Pública

aprovação do, 296

[Resolução da ANATEL n 656, de 17 de Agosto de 2015]

\section{Desligamento da TV Analógica}

desligamento antecipado do sinal analógico, 290

[Portaria $\mathrm{MC} \mathrm{n}^{\circ} 6.580$, de 2 de dezembro de 2015]

Digitalização, 286

(ver também TV Digital)

[Portaria $\mathrm{MC} \mathrm{n}^{\circ}$ 1.581, de 9 de abril de 2015]

Direito a Ampla Defesa e Contraditório

(ver também Ampla Defesa)

(ver também Contraditório)

Processo Administrativo tempestividade de recurso é computada do momento do protocolo na Agência e não de postagem da peça recursal, $\mathbf{3 0 3}$

[Acórdão do Conselho Diretor da ANATEL, de 31 de julho de 2015 (Ref. $\left.\left.n^{\circ} 305 / 2015\right)\right]$

\section{Direito à Imagem}

Direito de Resposta

sua disciplina e do direito de retificação do ofendido em matéria divulgada ou transmitida por veículo de comunicação social, inclusive a internet, $\mathbf{2 8 5}$

[Lei $\mathrm{n}^{\circ} 13.188$, de 11 de novembro de 2015]

\section{Direito à Informação}

Deficiente Físico

exigência de que os serviços de radiodifusão de sons e imagens permitam o uso de recursos de substitulação por meio de legenda oculta, janela com intérprete da Libras, e audiodescrição, 283

[Lei ${ }^{\circ}$ 13.146, de 6 de julho de 2015]

Direito de Resposta

sua disciplina e do direito de retificação do ofendido em matéria divulgada ou transmitida por veículo de comunicação social, inclusive a internet, $\mathbf{2 8 5}$

[Lei $\mathrm{n}^{\circ} 13.188$, de 11 de novembro de 2015]

\section{Direito à Intimidade}

Direito de Resposta

sua disciplina e do direito de retificação do ofendido em matéria divulgada ou transmitida por veículo de comunicação social, inclusive a internet, $\mathbf{2 8 5}$

[Lei $\mathrm{n}^{\circ} 13.188$, de 11 de novembro de 2015]

Direito à intimidade, 285

[Lei $\mathrm{n}^{\circ} 13.188$, de 11 de novembro de 2015]

Direito à livre manifestação do pensamento

Direito de Resposta

sua disciplina e do direito de retificação do ofendido em matéria divulgada ou transmitida por veículo de comunicação social, inclusive a internet, $\mathbf{2 8 5}$ 
[Lei $\mathrm{n}^{\circ} 13.188$, de 11 de novembro de 2015]

Direito à Privacidade, 242

Direito à Privacidade

Direito de Resposta

sua disciplina e do direito de retificação do ofendido em matéria divulgada ou transmitida por veículo de comunicação social, inclusive a internet, $\mathbf{2 8 5}$

[Lei ${ }^{\circ} 13.188$, de 11 de novembro de 2015]

Direito da Concorrência, 272

Direito de Acesso

Radiodifusão

exigência de que os serviços de radiodifusão de sons e imagens permitam o uso de recursos de substitulação por meio de legenda oculta, janela com intérprete da Libras, e audiodescrição, 283

[Lei $n^{\circ}$ 13.146, de 6 de julho de 2015]

Serviço de Telecomunicações

exigência de que as empresas prestadoras de serviços de telecomunicações devam garantiar pleno acesso à pessoa com deficiência, 283

[Lei $\mathrm{n}^{\circ}$ 13.146, de 6 de julho de 2015]

\section{Direito de Resposta}

retratação ou retificação espontânea não impedem o exercício do direito de resposta nem prejudicam a ação de reparação por dano moral, $\mathbf{2 8 5}$

[Lei $\mathrm{n}^{\circ} 13.188$, de 11 de novembro de 2015]

Direito de Retificação

sua disciplina e do direito de resposta em matéria divulgada ou transmitida por veículo de comunicação social, inclusive a internet, $\mathbf{2 8 5}$

[Lei $\mathrm{n}^{\circ} 13.188$, de 11 de novembro de 2015]

Direito de Uso de Radiofrequência, 247

Direito do Consumidor

(ver Consumidor)

Direito do Consumidor

Assinatura Básica

argumento de que se trata de direito consumidor não autoriza estadomembro da federação a legislar sobre, 298
[ADI 2.615 - SC]

\section{Direito Patrimonial Disponível}

alteração da Lei de Arbitragem para incluir expressa possibilidade da administração pública direta e indireta utilizar da arbitragem para dirimir conflitos relativos a direitos patrimoniais disponíveis, $\mathbf{2 8 3}$

[Lei ${ }^{\circ} 13.129$, de 26 de maio de 2015]

Direito Urbanístico, 272

E

Emenda Parlamentar

Backhaul

possibilidade de emendas parlamentares para financiamento de ações de implantação de infraestrutura de conexão entre órgãos e equipamentos públicos locais e à internet, inclusive por meio de construção de, $\mathbf{2 8 9}$

[Portaria $\mathrm{MC} \mathrm{n}^{\circ} 4.699$, de 14 de outubro de 2015]

Emergência

(ver Situação de Emergência)

Enchente

Regulamento sobre Gestão de Risco das

Redes de Telecomunicações e Uso de

Serviços de Telecomunicações em

Desastres, Situações de Emergência e

Estado de Calamidade Pública aprovação do, 296

[Resolução da ANATEL n ${ }^{\circ}$ 656, de 17 de Agosto de 2015]

\section{Equilíbrio Econômico-Financeiro}

Resolução de Disputas

previsão de competência das câmaras de prevenção e resolução administrativa de conflitos sobre questões que envolvam equilíbrio econômico-financeiro de contratos celebrados pela administração com particulares, 283

[Lei $\mathrm{n}^{\circ} 13.140$, de 26 de junho de 2015]

Equipamentos de Telecomunicações, 244

Era da Informação, 241

ERB 
(ver Estação Rádio Base)

Espaço Aéreo

Taxa de Licenciamento para Uso ou

Ocupação das Faixas de Domínio das

Rodovias (TFDR)

insconstitucionalidade de disciplina estadual de cobrança de taxa de uso e ocupação de solo e espaço aéreo sobre instalação de equipamentos necessários à prestação de serviço público de telecomunicações, 299 [RE $811620 \mathrm{AgR} / \mathrm{MG}$ ]

Taxa Municipal de Licença e Fiscalização para Localização, Instalação e Funcionamento constitucionalidade de disciplina municipal para cobrança de taxa de licença para instalação e de verificação da permanência das condições técnicas iniciais dos equipamentos destinados à energia elétrica e ao fornecimento de serviços de telecomunicações, 299 [RE $456534 \mathrm{ED} / \mathrm{RS}$ ]

Espécies de Outorga, 252

Espectro de Radiofrequência, 247

Estação Rádio Base

Baixa Potência

sua definição como o equipamento definido no art. 156-A da Lei 9.472, de 1997, quando esta não continha tal dispositivo, 281

[Lei n ${ }^{\circ}$ 13.097, de 19 de janeiro de 2015]

Estações de Telecomunicações, 245

Estrada Vicinal

(ver Backhaul)

$\mathbf{F}$

Faixa de $700 \mathrm{MHz}$

(ver $700 \mathrm{MHz})$

Faixa de Domínio

Taxa de Licenciamento para Uso ou Ocupação das Faixas de Domínio das Rodovias (TFDR)

insconstitucionalidade de disciplina estadual de cobrança de taxa de uso e ocupação de solo e espaço aéreo sobre instalação de equipamentos necessários à prestação de serviço público de telecomunicações, 299 [RE $811620 \mathrm{AgR} / \mathrm{MG}]$
Federalismo

Infraestrutura

seu incentivo mediante lei destinada a sincronizar a disciplina regulatória da União sobre infraestrutura de telecomunicações, em especial as antenas, e o poder municipal de posturas urbanas, $\mathbf{2 8 2}$

[Lei ${ }^{\circ} 13.116$, de 20 de abril de 2015]

Financiamento da Universalização e Massificação, 258

Fiscalização

(ver também Taxa de Fiscalização da Instalação)

(ver também Taxa de Fiscalização do Funcionamento)

exclusividade da competência da União sobre a regulamentação e a fiscalização de aspectos técnicos das redes e dos serviços de telecomunicações, inclusive sobre seleção de tecnologia, topologia das redes e qualidade dos serviços prestados, $\mathbf{2 8 2}$

[Lei ${ }^{\circ}$ 13.116, de 20 de abril de 2015]

Radiodifusão

fixação de valor máximo de multa de $\mathrm{R} \$ 89.053,71$ por infração às disposições da legislação e regulamentações aplicáveis à, $\mathbf{2 8 8}$

[Portaria MC n 294, de 30 de janeiro de 2015]

Fiscalização das Telecomunicações, 248 FISTEL, 258

(ver Fundo de Fiscalização das

FM

Telecomunicações)

(ver Frequência Modulada)

Franquia

(ver Assinatura Básica)

Fraude

Tráfego Artificial

conduta ilítica de uso indevido das rotas de interconexão para cursar tráfego artificialmente gerado, $\mathbf{3 0 3}$

[Acórdão do Conselho Diretor da ANATEL, de 5 de novembro de 2015 (Ref. $n^{\circ}$ 480/2015)]

Frequência Modulada, 288

[Portaria $\mathrm{MC} \mathrm{n}^{\circ} 4.335$, de 17 de setembro de 2015]

Rádio AM 
disciplina da extinção do serviço de radiodifusão sonora em ondas médias e sua possível adaptação de instrumentos de outorgas para os de execução do serviço de radiodifusão sonoram em frequência modulada, 290

[Portaria MC $\mathrm{n}^{\circ}$ 6.467, de 24 de novembro de 2015]

Rádio FM

disciplina da extinção do serviço de radiodifusão sonora em ondas médias e sua possível adaptação de instrumentos de outorgas para os de execução do serviço de radiodifusão sonoram em frequência modulada, 290

[Portaria MC $\mathrm{n}^{\circ}$ 6.467, de 24 de novembro de 2015]

procedimentos de permissão e concessão para execução de modalidade exclusivamente educativa dos serviços de, $\mathbf{2 8 8}$

[Portaria $\mathrm{MC} \mathrm{n}^{\circ} 4.335$, de 17 de setembro de 2015]

Fundamentos, 241

Fundo de Fiscalização das Telecomunicações

(ver também Taxa de Fiscalização do Funcionamento)

possibilidade de uso de receita excedente em fins diversos dos de custeio, manutenção e aperfeiçoamento da fiscalização dos serviços de telecomunicações caso tenham sido desvinculadas mediante transferência de receita excedente ao Tesouro Nacional, 301

[Acórdão TCU 2320/2015]

Fundos Setoriais de Telecomunicações, 258

G

\section{Geração de Tráfego Artificial}

Interconexão

conduta ilítica de uso indevido das rotas de interconexão para cursar tráfego artificialmente gerado, $\mathbf{3 0 3}$

[Acórdão do Conselho Diretor da ANATEL, de 5 de novembro de 2015 (Ref. $n^{\circ}$ 480/2015)]

\section{Gestão de Riscos}

Regulamento sobre Gestão de Risco das Redes de Telecomunicações e Uso de Serviços de Telecomunicações em Desastres, Situações de Emergência e Estado de Calamidade Pública aprovação do, 296

[Resolução da ANATEL n ${ }^{\circ}$ 656, de 17 de Agosto de 2015]

\section{GIRED}

(ver Grupo de Implantação do Processo de Redistribuição e Digitalização de Canais de TV e RTV - GIRED)

GLOBAL VILLAGE TELECOM LTDA, 301

[Ato do Conselho Diretor da ANATEL ${ }^{\circ}$ 448, de 22 de janeiro de 2015]

Anuência Prévia

à transferência do controle integral da GVT para a TELEFÔNICA, 301

[Ato do Conselho Diretor da ANATEL $n^{\circ} 448$, de 22 de janeiro de 2015]

\section{Governo Municipal}

(ver Município)

Grupo de Implantação do Processo de Redistribuição e Digitalização de Canais de TV e RTV - GIRED

requerimento de relatório consubstanciado sobre a evolução do processo de transição para a TV Digital pelo Ministério das Comunicações ao, 290

[Portaria $\mathrm{MC} \mathrm{n}^{\circ} 6.580$, de 2 de dezembro de 2015]

\section{Grupo TELEMAR, 302}

[Acórdão do Conselho Diretor da ANATEL, de 5 de janeiro de 2015 (Ref. $n^{\circ}$ 6/2015)]

\section{Grupo TELESP, 302}

[Acórdão do Conselho Diretor da ANATEL, de 5 de janeiro de 2015 (Ref. $n^{\circ}$ 6/2015)]

\section{GVT}

(ver GLOBAL VILLAGE TELECOM LTDA)

H

\section{Habeas Corpus}

HC128567/MG crime de atividade clandestina de telecomunicações do art. 183 da LGT não configura caso de 
aplicação do princípio da insignificância, 298

[HC 128567/MG]

\section{I}

\section{Incentivo Fiscal}

Equipamentos de Telecomunicações incentivos às indústrias de equipamentos para a TV Digital, 285

[Lei $\mathrm{n}^{\circ} 13.159$, de 10 de agosto de 2015]

\section{Infraestrutura}

Lei Geral das Antenas aprovação da, 282

[Lei no 13.116, de 20 de abril de 2015] seu incentivo mediante lei destinada a sincronizar a disciplina regulatória da União sobre infraestrutura de telecomunicações, em especial as antenas, e o poder municipal de posturas urbanas, $\mathbf{2 8 2}$

[Lei ${ }^{\circ} 13.116$, de 20 de abril de 2015]

Infraestrutura de Telecomunicações, 243

Infraestrutura e Recursos do Setor de

Telecomunicações, 242

Insignficância, 298

[HC 128567/MG]

Insignificância

(ver Princípio da Insignificância)

Interconexão, 244

Interconexão

Fraude

conduta ilítica de uso indevido das rotas de interconexão para cursar tráfego artificialmente gerado, $\mathbf{3 0 3}$ [Acórdão do Conselho Diretor da ANATEL, de 5 de novembro de 2015 (Ref. $n^{\circ}$ 480/2015)]

Regulamento Geral de Interconexão conduta ilítica de uso indevido das rotas de interconexão para cursar tráfego artificialmente gerado, $\mathbf{3 0 3}$ [Acórdão do Conselho Diretor da ANATEL, de 5 de novembro de 2015 (Ref. $n^{\circ}$ 480/2015)]

Tráfego Artificial

conduta ilítica de uso indevido das rotas de interconexão para cursar tráfego artificialmente gerado, $\mathbf{3 0 3}$
[Acórdão do Conselho Diretor da ANATEL, de 5 de novembro de 2015 (Ref. $n^{\circ} 480 / 2015$ )]

\section{Internauta}

Comentário de Usuário da Internet sua não inclusão no conceito de matéria objeto de regulamentação do direito de resposta ou retificação do ofendido da Lei 13.188/2015, 285

[Lei $\mathrm{n}^{\circ} 13.188$, de 11 de novembro de 2015]

Internet, 262, 272

INTERNET

Comentário de Usuário da Internet sua não inclusão no conceito de matéria objeto de regulamentação do direito de resposta ou retificação do ofendido da Lei 13.188/2015, 285

[Lei $\mathrm{n}^{\circ} 13.188$, de 11 de novembro de 2015]

Direito de Resposta

sua disciplina e do direito de retificação do ofendido em matéria divulgada ou transmitida por veículo de comunicação social, inclusive a internet, $\mathbf{2 8 5}$

[Lei $\mathrm{n}^{\circ} 13.188$, de 11 de novembro de 2015]

ORKUT

inaplicabilidade do Marco Civil da Internet a fatos pretéritos a sua edição para o caso de ofensa veiculada no, $\mathbf{3 0 0}$

ISDB-TB [RESP $1384340 \mathrm{AgRg} / \mathrm{DF}]$

(ver Sistema Brasileiro de Televisão Digital Terrestre)

\section{$\mathbf{L}$}

\section{Legalidade, 283}

[Lei no 13.129, de 26 de maio de 2015]

Lei Geral das Antenas aprovação da, $\mathbf{2 8 2}$

[Lei ${ }^{\circ} 13.116$, de 20 de abril de 2015]

\section{Liberdade de Expressão, 242}

\section{LIBRAS}


(ver Língua Brasileira de Sinais)

Licitação, 250

Licitação

Compromisso de Renúncia a Outorgas

extinção de outorga como decorrência de compromisso de renúncia de outorga em licitação independentemente de início de negociações privadas de transferência da outorga ou de controle acionário das empresas que a detenha, $\mathbf{3 0 2}$

[Acórdão do Conselho Diretor da ANATEL, de 24 de fevereiro de 2015 (Ref. n 53/2015)]

Radiodifusão

limite ao valor da outorga para a fixação de penalidades decorrentes de descumprimento do edital de licitação para concessão e permissão de serviços de radiodifusão, $\mathbf{2 8 1}$

[Lei ${ }^{\circ}$ 13.097, de 19 de janeiro de 2015]

Língua Brasileira de Sinais, 283

[Lei no 13.146, de 6 de julho de 2015]

Radiodifusão

exigência de que os serviços de radiodifusão de sons e imagens permitam o uso de recursos de substitulação por meio de legenda oculta, janela com intérprete da Libras, e audiodescrição, 283

[Lei ${ }^{\circ}$ 13.146, de 6 de julho de 2015]

M

Marca

Direito de Resposta

sua disciplina e do direito de retificação do ofendido em matéria divulgada ou transmitida por veículo de comunicação social, inclusive a internet, $\mathbf{2 8 5}$

[Lei ${ }^{\circ} 13.188$, de 11 de novembro de 2015]

\section{Marco Civil da Internet}

Direito de Resposta

sua disciplina e do direito de retificação do ofendido em matéria divulgada ou transmitida por veículo de comunicação social, inclusive a internet, $\mathbf{2 8 5}$
[Lei $\mathrm{n}^{\circ} 13.188$, de 11 de novembro de 2015]

inaplicabilidade do Marco Civil da Internet a fatos pretéritos a sua edição para o caso de ofensa veiculada no ORKUT, 300

[RESP $1384340 \mathrm{AgRg} / \mathrm{DF}$ ]

\section{Matéria Jornalística}

Direito de Resposta

sua disciplina e do direito de retificação do ofendido em matéria divulgada ou transmitida por veículo de comunicação social, inclusive a internet, $\mathbf{2 8 5}$

[Lei $\mathrm{n}^{\circ} 13.188$, de 11 de novembro de 2015]

Metas de Universalização, 258

Militar

Radar

sua não submissão à disciplina da Lei 13.116 , sobre os processo de licenciamento, instalação e compartilhamento de infraestrutura de telecomunicações em área urbana, 282

[Lei $\mathrm{n}^{\circ}$ 13.116, de 20 de abril de 2015]

Ministério da Cultura, 278

Ministério da Educação, 277

Ministério das Comunicações, 277

Ministério das Comunicações

Grupo de Implantação do Processo de Redistribuição e Digitalização de Canais de TV e RTV - GIRED

requerimento de relatório consubstanciado sobre a evolução do processo de transição para a TV Digital pelo Ministério das Comunicações ao, 290

[Portaria $\mathrm{MC} \mathrm{n}^{\circ} 6.580$, de 2 de dezembro de 2015]

\section{Ministro das Comunicações}

(ver Ministério das Comunicações)

\section{Mitigação de Desastre}

Regulamento sobre Gestão de Risco das

Redes de Telecomunicações e Uso de

Serviços de Telecomunicações em

Desastres, Situações de Emergência e

Estado de Calamidade Pública aprovação do, 296

[Resolução da ANATEL n ${ }^{\circ}$ 656, de 17 de Agosto de 2015]

Multa 
(ver Multa (Sanção Administrativa))

Multa (Sanção Administrativa)

Radiodifusão

fixação de valor máximo de multa de $\mathrm{R} \$ 89.053,71$ por infração às disposições da legislação e regulamentações aplicáveis à, $\mathbf{2 8 8}$

[Portaria MC n' 294, de 30 de janeiro de 2015]

Multa

Radiodifusão

limite ao valor da outorga para a fixação de penalidades decorrentes de descumprimento do edital de licitação para concessão e permissão de serviços de radiodifusão, $\mathbf{2 8 1}$

[Lei n 13.097, de 19 de janeiro de 2015]

\section{Município}

Taxa Municipal de Licença e Fiscalização para Localização, Instalação e Funcionamento

constitucionalidade de disciplina municipal para cobrança de taxa de licença para instalação e de verificação da permanência das condições técnicas iniciais dos equipamentos destinados à energia elétrica e ao fornecimento de serviços de telecomunicações, 299 [RE 456534 ED/RS]

\section{$\mathbf{N}$}

Norma de adaptação dos instrumentos de permissão e de autorização do Serviço Móvel Especializado (SME) para o Serviço Móvel Pessoal (SMP), Serviço Limitado Privado (SLP) ou Serviço Limitado Especializado (SLE) aprovação da, 291

[Resolução da ANATEL n ${ }^{\circ}$ 647, de 9 de fevereiro de 2015]

Norma Regulamentar do Canal da Cidadania alteração da, $\mathbf{2 8 9}$

[Portaria MC $\mathrm{n}^{\circ}$ 6.413, de 20 de novembro de 2015]

\section{Numeração}

Regulamento do Preço Público Relativo à Administração dos Recursos de Numeração alteração do, 297

[Resolução da ANATEL n ${ }^{\circ}$ 660, de 28 de dezembro de 2015]

Numeração dos Serviços, 244

\section{O}

Ocupação do uso da faixa de domínio (ver Faixa de Domínio)

Off-shore, 282

[Lei n ${ }^{\circ} 13.116$, de 20 de abril de 2015]

\section{ORKUT}

inaplicabilidade do Marco Civil da Internet a fatos pretéritos a sua edição para o caso de ofensa veiculada no, $\mathbf{3 0 0}$ [RESP $1384340 \mathrm{AgRg} / \mathrm{DF}$ ]

\section{Outorga, 302}

(ver também Contrato de Concessão) (ver também Renúncia)

[Acórdão do Conselho Diretor da ANATEL, de 24 de fevereiro de 2015 (Ref. $n^{\circ}$ 53/2015)] extinção de outorga como decorrência de compromisso de renúncia de outorga em licitação independentemente de início de negociações privadas de transferência da outorga ou de controle acionário das empresas que a detenha, $\mathbf{3 0 2}$

[Acórdão do Conselho Diretor da ANATEL, de 24 de fevereiro de 2015 (Ref. n ${ }^{\circ} 53 / 2015$ )]

\section{$\mathbf{P}$}

\section{PADO}

(ver Procedimento Administrativo para Apuração de Descumprimento de Obrigações (Agência Nacional de Telecomunicações))

\section{Parlamentar}

Emenda Parlamentar

possibilidade de emendas parlamentares para financiamento de ações de implantação de infraestrutura de conexão entre órgãos e equipamentos públicos locais e à internet, inclusive por meio de construção de backhaul, 289

[Portaria MC n ${ }^{\circ} 4.699$, de 14 de outubro PDG de 2015] 
(ver Programa de Dispêndios Globais (Empresas Estatais Federais))

Percepção do Usuário

Regulamento das Condições de Aferição do Grau de Satisfação e da Qualidade Percebida junto aos Usuários de Serviços de Telecomunicações aprovação do, 294

[Resolução da ANATEL n 654, de 13 de julho de 2015]

Permissão

(ver Permissão (Radiodifusão))

Permissão (Radiodifusão)

Resolução de Disputas

previsão de competência das câmaras de prevenção e resolução administrativa de conflitos sobre questões que envolvam equilíbrio econômico-financeiro de contratos celebrados pela administração com particulares, 283

[Lei no 13.140, de 26 de junho de 2015]

Permissão (regras aplicáveis), 253

Pesquisa de Satisfação

Regulamento das Condições de Aferição do Grau de Satisfação e da Qualidade Percebida junto aos Usuários de Serviços de Telecomunicações aprovação do, 294

[Resolução da ANATEL nº 654, de 13 de julho de 2015]

Serviço de Interesse Coletivo

aprovação do regulamento das condições de aferição do grau de satisfação e da qualidade percebida junto aos usuários de serviços de telecomunicações de interesse coletivo, 294

[Resolução da ANATEL no 654, de 13 de julho de 2015]

Petróleo

Plataforma off-shore

sua não submissão à disciplina da Lei 13.116, sobre os processo de licenciamento, instalação e compartilhamento de infraestrutura de telecomunicações em área urbana, 282

[Lei $\mathrm{n}^{\circ}$ 13.116, de 20 de abril de 2015]

PGCN

(ver Plano Geral de Códigos Nacionais)

PGR (ver Plano Geral de Atualização da

Regulamentação das

Telecomunicações no Brasil)

Plano Estratégico 2015-2024

(ver também Plano Geral de Atualização

da Regulamentação das

Telecomunicações no Brasil)

Plano Geral de Atualização da

Regulamentação da s

Telecomunicações no Brasil

sua revogação após aprovação do Plano Estratégico 2015-2024, 296

[Resolução da ANATEL n ${ }^{\circ}$ 658, de 11 de dezembro de 2015]

Plano Geral de Atualização da Regulamentação das Telecomunicações no Brasil, 296

(ver também Plano Estratégico 20152024)

[Resolução da ANATEL n ${ }^{\circ}$ 658, de 11 de dezembro de 2015]

revogação do, 296

[Resolução da ANATEL n ${ }^{\circ}$ 658, de 11 de dezembro de 2015]

Plano Geral de Códigos Nacionais

alteração do, 294

[Resolução da ANATEL n ${ }^{\circ}$ 653, de 13 de julho de 2015]

Plataforma off-shore

(ver Off-shore)

Plataforma off-shore

sua não submissão à disciplina da Lei 13.116, sobre os processo de licenciamento, instalação e compartilhamento de infraestrutura de telecomunicações em área urbana, 282

[Lei no 13.116, de 20 de abril de 2015]

PNBL

(ver Programa Nacional de Banda Larga)

Poder Executivo, 276

Poder Judiciário, 278

Poder Legislativo, 276

Política de Gestão de Riscos

Regulamento sobre Gestão de Risco das Redes de Telecomunicações e Uso de Serviços de Telecomunicações em Desastres, Situações de Emergência e Estado de Calamidade Pública aprovação do, 296 [Resolução da ANATEL n ${ }^{\circ}$ 656, de 17 de Agosto de 2015] 
Política Industrial, 256

Políticas de Telecomunicações, 256

Portador de Deficiência, 258

Postura Urbana

Taxa Municipal de Licença e Fiscalização para Localização, Instalação e Funcionamento constitucionalidade de disciplina municipal para cobrança de taxa de licença para instalação e de verificação da permanência das condições técnicas iniciais dos equipamentos destinados à energia elétrica e ao fornecimento de serviços de telecomunicações, 299 [RE $456534 \mathrm{ED} / \mathrm{RS}$ ]

Preço Público

Regulamento do Preço Público Relativo

à Administração dos Recursos de

Numeração

alteração do, 297

[Resolução da ANATEL n 660 , de 28 de dezembro de 2015]

Preço Público e Preço Privado, 254

Presidência da República, 277

Prestação de Serviços, 250

Prestadora / Operadora, 279

Princípio da Insignificância

(ver Insignficância)

Princípio da Insignificância

Atividade Clandestina de

Telecomunicação

não configura caso de aplicação do princípio da insignificância, 298 [HC 128567/MG]

Princípio da Legalidade

(ver Legalidade)

Princípio da Legalidade

Arbitragem

exigência de que a arbitragem se submete ao direito posto quando envolva a administração pública, 283

[Lei no 13.129, de 26 de maio de 2015]

Princípio da Publicidade

(ver também Publicidade)

Arbitragem

exigência de sua submissão ao princípio da publicidade quando se tratar de arbitragem que envolva a administração pública, $\mathbf{2 8 3}$

[Lei nº 13.129, de 26 de maio de 2015]
Privacidade

(ver Direito à Privacidade)

Procedimento Administrativo para Apuração de Descumprimento de Obrigações

(ver Procedimento Administrativo para Apuração de Descumprimento de Obrigações (Agência Nacional de Telecomunicações))

Procedimento Administrativo para Apuração de Descumprimento de Obrigações (Agência Nacional de Telecomunicações), 302

[Acórdão do Conselho Diretor da ANATEL, de 5 de janeiro de 2015 (Ref. no 6/2015)]

inexistência de vinculação entre o interesse público na celebração de TAC e a natureza da matéria tratada em processo sancionador, $\mathbf{3 0 2}$

[Acórdão do Conselho Diretor da ANATEL, de 5 de janeiro de 2015 (Ref. $\left.n^{\circ} 6 / 2015\right)$ ]

Processo Administrativo, 256

Processo Administrativo

(ver também Recurso)

Rádio FM

procedimentos de permissão e concessão para execução de modalidade exclusivamente educativa dos serviços de, $\mathbf{2 8 8}$

[Portaria $\mathrm{MC} \mathrm{n}^{\circ} 4.335$, de 17 de setembro de 2015]

Recurso

sua tempestividade é computada do momento do protocolo na Agência e não de postagem da peça recursal, 303

[Acórdão do Conselho Diretor da ANATEL, de 31 de julho de 2015 (Ref. $\left.n^{\circ} 305 / 2015\right)$ ]

Programa de Dispêndios Globais (Empresas Estatais Federais)

PDG para 2016, 286

[Decreto $n^{\circ} 8.632 / 2015$ ]

Programa Educativo-Cultural

princípios e objetivos do, $\mathbf{2 8 8}$

[Portaria $\mathrm{MC} \mathrm{n}^{\circ} 4.335$, de 17 de setembro de 2015]

Programa Nacional de Banda Larga

(ver também Banda Larga)

Regime Especial de Tributação do Programa Nacional de Banda Larga 
para Implantação de Redes de

Telecomunicações

regulamentação do, $\mathbf{2 8 7}$

[Portaria $\mathrm{MC} \mathrm{n}^{\circ} 320$, de 12 de janeiro de 2015]

Projeto de Segurança de Infraestruturas

Críticas de Telecomunicações

Regulamento sobre Gestão de Risco das

Redes de Telecomunicações e Uso de

Serviços de Telecomunicações em

Desastres, Situações de Emergência e

Estado de Calamidade Pública

aprovação do, 296

[Resolução da ANATEL n 656, de 17 de Agosto de 2015]

\section{Projeto Setor}

Regulamento sobre Gestão de Risco das

Redes de Telecomunicações e Uso de

Serviços de Telecomunicações em

Desastres, Situações de Emergência e

Estado de Calamidade Pública

aprovação do, 296

[Resolução da ANATEL n ${ }^{\circ}$ 656, de 17 de Agosto de 2015]

Propaganda

(ver Publicidade)

Propriedade Industrial

Direito de Resposta

sua disciplina e do direito de retificação do ofendido em matéria divulgada ou transmitida por veículo de comunicação social, inclusive a internet, $\mathbf{2 8 5}$

[Lei $\mathrm{n}^{\mathrm{o}} 13.188$, de 11 de novembro de 2015]

Propriedade Intelectual

Direito de Resposta

sua disciplina e do direito de retificação do ofendido em matéria divulgada ou transmitida por veículo de comunicação social, inclusive a internet, $\mathbf{2 8 5}$

[Lei ${ }^{\circ} 13.188$, de 11 de novembro de 2015]

Proteção do Consumidor

(ver Consumidor)

Proteção do Usuário

(ver Usuário)

Provedor de Aplicações de Intenet, 281

Publicidade, 283

(ver também Princípio da Publicidade)

[Lei ${ }^{\circ}$ 13.129, de 26 de maio de 2015]
Qualidade do Serviço, 260

Quanto ao Gênero, 261

Quanto ao Interesse, 261

Quanto ao Regime Jurídico de Prestação, 260

Quarta Geração de Tecnologia de Telefonia Móvel (requisitos da UIT IMT-Advanced)

Regulamento do Acompanhamento de Compromissos de Aquisição de

Produtos e Sistemas Nacionais aprovação do, 295

[Resolução da ANATEL n ${ }^{\circ} 655$, de 5 de Agosto de 2015]

\section{$\mathbf{R}$}

Radar

sua não submissão à disciplina da Lei 13.116, sobre os processo de licenciamento, instalação e compartilhamento de infraestrutura de telecomunicações em área urbana, 282

[Lei ${ }^{\circ} 13.116$, de 20 de abril de 2015]

Rádio Aberta, 264

Rádio AM

disciplina da extinção do serviço de radiodifusão sonora em ondas médias e sua possível adaptação de instrumentos de outorgas para os de execução do serviço de radiodifusão sonoram em frequência modulada, 290

[Portaria MC $\mathrm{n}^{\circ}$ 6.467, de 24 de novembro de 2015]

\section{Rádio AM para FM}

procedimentos de adaptação da, 290

[Portaria MC $\mathrm{n}^{\circ}$ 6.467, de 24 de novembro de 2015]

\section{Rádio FM}

disciplina da extinção do serviço de radiodifusão sonora em ondas médias e sua possível adaptação de instrumentos de outorgas para os de execução do serviço de radiodifusão sonoram em frequência modulada, 290

[Portaria MC $\mathrm{n}^{\circ}$ 6.467, de 24 de novembro de 2015]

procedimentos de permissão e concessão para execução de modalidade exclusivamente educativa dos serviços de, 288 
[Portaria $\mathrm{MC} \mathrm{n}^{\circ} 4.335$, de 17 de setembro de 2015]

\section{Radiodifusão, 262 \\ Radiodifusão \\ (ver também Radiodifusão Educativa) (ver também Sistema Brasileiro de Televisão Digital Terrestre) \\ Concessão}

parcelamento de débitos de concessionárias de serviços de radiodifusão decorrentes do inadimplemento do preço público devido em razão da outorga do serviço, 281

[Lei n 13.097 , de 19 de janeiro de 2015]

Cronograma de Implantação da TV Digital

desligamento antecipado do sinal analógico, 290

[Portaria $\mathrm{MC} \mathrm{n}^{\circ} 6.580$, de 2 de dezembro de 2015]

Deficiência Auditiva

exigência de que os serviços de radiodifusão de sons e imagens permitam o uso de recursos de substitulação por meio de legenda oculta, janela com intérprete da Libras, e audiodescrição, $\mathbf{2 8 3}$

[Lei no 13.146, de 6 de julho de 2015]

Deficiência Visual

exigência de que os serviços de radiodifusão de sons e imagens permitam o uso de recursos de substitulação por meio de legenda oculta, janela com intérprete da Libras, e audiodescrição, 283

[Lei n ${ }^{\circ} 13.146$, de 6 de julho de 2015]

Deficiente Físico

exigência de que os serviços de radiodifusão de sons e imagens permitam o uso de recursos de substitulação por meio de legenda oculta, janela com intérprete da Libras, e audiodescrição, 283

[Lei n ${ }^{\circ} 13.146$, de 6 de julho de 2015]

Multa

limite ao valor da outorga para a fixação de penalidades decorrentes de descumprimento do edital de licitação para concessão e permissão de serviços de radiodifusão, 281
[Lei n ${ }^{\circ} 13.097$, de 19 de janeiro de 2015]

Multa (Sanção Administrativa)

fixação de valor máximo de multa de $\mathrm{R} \$ 89.053,71$ por infração às disposições da legislação e regulamentações aplicáveis à radiodifusão, $\mathbf{2 8 8}$

[Portaria MC n 294, de 30 de janeiro de 2015]

Permissão

parcelamento de débitos de permissionárias de serviços de radiodifusão decorrentes do inadimplemento do preço público devido em razão da outorga do serviço, 281

[Lei n ${ }^{\circ} 13.097$, de 19 de janeiro de 2015]

Radiodifusão Comunitária, 264

Radiodifusão Educativa

(ver também Radiodifusão)

Programa Educativo-Cultural princípios e objetivos do, $\mathbf{2 8 8}$

[Portaria $\mathrm{MC} \mathrm{n}^{\circ} 4.335$, de 17 de setembro de 2015]

Rádio FM

procedimentos de permissão e concessão para execução de modalidade exclusivamente educativa dos serviços de, $\mathbf{2 8 8}$

[Portaria $\mathrm{MC} \mathrm{n}^{\circ} 4.335$, de 17 de setembro de 2015]

Radionavegação Aeronáutica

sua não submissão à disciplina da Lei 13.116, sobre os processo de licenciamento, instalação e compartilhamento de infraestrutura de telecomunicações em área urbana, 282 [Lei no 13.116, de 20 de abril de 2015]

\section{Ramos Jurídicos Afins, 272}

RE

\section{(ver Recurso Extraordinário)}

\section{Recurso}

(ver também Processo Administrativo)

Processo Administrativo tempestividade de recurso é computada do momento do protocolo na Agência e não de postagem da peça recursal, $\mathbf{3 0 3}$

[Acórdão do Conselho Diretor da ANATEL, de 31 de julho de 2015 (Ref. $\left.n^{\circ} 305 / 2015\right)$ ] 


\section{Recurso Especial}

RESP 1384340 AgRg/DF

inaplicabilidade do Marco Civil da Internet a fatos pretéritos a sua edição para o caso de ofensa veiculada no ORKUT, 300

[RESP $1384340 \mathrm{AgRg} / \mathrm{DF}$ ]

\section{Recurso Extraordinário}

RE 456534ED/RS

constitucionalidade de disciplina municipal para cobrança de taxa de licença para instalação e de verificação da permanência das condições técnicas iniciais dos equipamentos destinados à energia elétrica e ao fornecimento de serviços de telecomunicações, 299 [RE $456534 \mathrm{ED} / \mathrm{RS}$ ]

RE811620AgR/MG

inconstitucionalidade de disciplina estadual de cobrança de taxa de uso e ocupação de solo e espaço aéreo sobre instalação de equipamentos necessários à prestação de serviço público de telecomunicações, 299

[RE $811620 \mathrm{AgR} / \mathrm{MG}]$

Recursos de Numeração

Regulamento do Preço Público Relativo

à Administração dos Recursos de Numeração

alteração do, 297

[Resolução da ANATEL n 660, de 28 de dezembro de 2015]

Redes de Telecomunicações, 243

Regime Especial de Tributação do Programa Nacional de Banda Larga para Implantação de Redes de Telecomunicações

regulamentação do, $\mathbf{2 8 7}$

[Portaria $\mathrm{MC} \mathrm{n}^{\circ} 320$, de 12 de janeiro de 2015]

\section{Regulação}

exclusividade da competência da União sobre a regulamentação e a fiscalização de aspectos técnicos das redes e dos serviços de telecomunicações, inclusive sobre seleção de tecnologia, topologia das redes e qualidade dos serviços prestados, $\mathbf{2 8 2}$

[Lei $\mathrm{n}^{\circ}$ 13.116, de 20 de abril de 2015]

\section{Regulamentação}

exclusividade da competência da União sobre a regulamentação e a fiscalização de aspectos técnicos das redes e dos serviços de telecomunicações, inclusive sobre seleção de tecnologia, topologia das redes e qualidade dos serviços prestados, $\mathbf{2 8 2}$

[Lei no 13.116, de 20 de abril de 2015]

Regulamento das Condições de Aferição do Grau de Satisfação dos Usuários dos Serviços de Telecomunicações

revogação do, 294

[Resolução da ANATEL n ${ }^{\circ}$ 654, de 13 de julho de 2015]

Regulamento de Gestão da Qualidade do Serviço Móvel Pessoal revogação do, 294

[Resolução da ANATEL n ${ }^{\circ}$ 654, de 13 de julho de 2015]

Regulamento de Gestão de Qualidade da Prestação do Serviço Telefônico Fixo Comutado revogação do, 294

[Resolução da ANATEL n ${ }^{\circ}$ 654, de 13 de julho de 2015]

Regulamento de Gestão de Qualidade do Serviço de Comunicação Multimídia revogação do, 294

[Resolução da ANATEL n 654, de 13 de julho de 2015]

Regulamento de Tarifação do STFC alteração do, 294

[Resolução da ANATEL n ${ }^{\circ}$ 653, de 13 de julho de 2015]

Regulamento do Acompanhamento de Compromissos de Aquisição de Produtos e Sistemas Nacionais aprovação do, 295

[Resolução da ANATEL n ${ }^{\circ}$ 655, de 5 de Agosto de 2015]

Regulamento do Preço Público Relativo à Administração dos Recursos de Numeração

alteração do, 297

[Resolução da ANATEL n 660, de 28 de dezembro de 2015]

Regulamento do Serviço Limitado Móvel Aeronáutico (SLMÁ) e do Serviço Limitado Móvel Marítimo (SLMM) aprovação do, 293 
[Resolução da ANATEL nº 651, de 13 de abril de 2015]

Regulamento Geral de Interconexão

conduta ilítica de uso indevido das rotas de interconexão para cursar tráfego artificialmente gerado, $\mathbf{3 0 3}$

[Acórdão do Conselho Diretor da ANATEL, de 5 de novembro de 2015 (Ref. $\left.\left.n^{\circ} 480 / 2015\right)\right]$

Regulamento sobre Áreas Locais para o STFC

alteração do, 293

[Resolução da ANATEL nº 652, de 27 de maio de 2015]

Regulamento sobre Condições de Uso de Radiofreqüências nas Faixas de 800 MHz, 900 MHz, 1.800 MHz, 1.900 MHz e $2.100 \mathrm{MHz}$ (ver $800 \mathrm{MHz}, 900 \mathrm{MHz}, 1.800 \mathrm{MHz}$, 1.900 MHz e 2.100 MHz)

Regulamento sobre Condições de Uso de Radiofreqüências nas Faixas de 800 MHz, 900 MHz, 1.800 MHz, 1.900 MHz e $2.100 \mathrm{MHz}$ alteração do, 296

[Resolução da ANATEL n ${ }^{\circ}$ 657, de 3 de novembro de 2015]

Regulamento sobre Gestão de Risco das Redes de Telecomunicações e Uso de Serviços de Telecomunicações em Desastres, Situações de Emergência e Estado de Calamidade Pública aprovação do, 296

[Resolução da ANATEL nº 656, de 17 de Agosto de 2015]

Relatório da Ouvidoria

Relatório da Ouvidoria 2015, 303

[Relatório da Ouvidoria da ANATEL 2015]

\section{Renúncia}

(ver também Outorga)

Outorga

sua extinção como decorrência de compromisso de renúncia de outorga em licitação independentemente de início de negociações privadas de transferência da outorga ou de controle acionário das empresas que a detenha, $\mathbf{3 0 2}$
[Acórdão do Conselho Diretor da ANATEL, de 24 de fevereiro de 2015 (Ref. n ${ }^{\circ}$ 53/2015)]

\section{REPNBL-Redes}

(ver Regime Especial de Tributação do Programa Nacional de Banda Larga para Implantação de Redes de Telecomunicações)

\section{Reputação}

Direito de Resposta

sua disciplina e do direito de retificação do ofendido em matéria divulgada ou transmitida por veículo de comunicação social, inclusive a internet, $\mathbf{2 8 5}$

[Lei $\mathrm{n}^{\circ} 13.188$, de 11 de novembro de 2015]

Resolução Administrativa de Conflitos, 283

(ver também Resolução de Disputas)

[Lei n ${ }^{\circ} 13.140$, de 26 de junho de 2015]

\section{Resolução de Disputas}

(ver Solução de Conflitos)

Resolução de Disputas

(ver também Arbitragem)

(ver também Resolução Administrativa de Conflitos)

alteração da Lei de Arbitragem para incluir expressa possibilidade da administração pública direta e indireta utilizar da arbitragem para dirimir conflitos relativos a direitos patrimoniais disponíveis, $\mathbf{2 8 3}$

[Lei n 13.129, de 26 de maio de 2015]

Mediação

previsão de competência das câmaras de prevenção e resolução administrativa de conflitos sobre questões que envolvam equilíbrio econômico-financeiro de contratos celebrados pela administração com particulares, $\mathbf{2 8 3}$

REsp

[Lei n ${ }^{\circ} 13.140$, de 26 de junho de 2015]

(ver Recurso Especial)

Responsabilidade Fiscal

Fundo de Fiscalização das Telecomunicações

possibilidade de uso de receita excedente em fins diversos dos de custeio, manutenção e aperfeiçoamento da fiscalização dos 
serviços de telecomunicações caso tenham sido desvinculadas mediante transferência de receita excedente ao Tesouro Nacional, 301

[Acórdão TCU 2320/2015]

Retransmissão de Televisão com Utilização da Tecnologia Digital, 288

[Portaria $\mathrm{MC} \mathrm{n}^{\circ} 4.287$, de 21 de setembro de 2015]

procedimentos de seleção pública e de autorização para a execução do, $\mathbf{2 8 8}$

[Portaria $\mathrm{MC} \mathrm{n}^{\circ} 4.287$, de 21 de setembro de 2015]

Retransmissão de Televisão com Utilização da Tecnologia Digital, Caráter Secundário

procedimentos de seleção pública e de autorização para a execução do Serviço de RTV em, 286

[Portaria $\mathrm{MC} \mathrm{n}^{\circ} 6.738$, de 21 de dezembro de 2015]

Retransmissão de TV

(ver Serviço de Retransmissão de Televisão)

Reversão, 300

(ver também Bem Reversível)

[Acórdão TCU 3311/2015]

Revisão Quinquenal

Concessão

prorrogação da data da penúltima revisão quinquenal (2015) dos contratos de concessão de STFC pós renovação, 297

[Resolução da ANATEL n ${ }^{\circ} 659$, de 28 de dezembro de 2015]

Contrato de Concessão

prorrogação da data da penúltima revisão quinquenal (2015) dos contratos de concessão de STFC pós renovação, 297

[Resolução da ANATEL n 659 , de 28 de dezembro de 2015]

\section{RGQ-STFC}

(ver Regulamento de Gestão de

Qualidade da Prestação do Serviço

Telefônico Fixo Comutado)

\section{Rodovia}

Faixa de Domínio

insconstitucionalidade de disciplina estadual de cobrança de taxa de uso e ocupação de solo e espaço aéreo sobre instalação de equipamentos necessários à prestação de serviço público de telecomunicações, 299

RTV [RE 811620 AgR/MG]

(ver Serviço de Retransmissão de Televisão)

RTVD

(ver Retransmissão de Televisão com Utilização da Tecnologia Digital)

$\mathbf{S}$

Sanção

Termo de Ajuste de Conduta

sua celebração submete-se ao juízo da autoridade sobre a conveniência e oportunidade do acordo negocial como solução alternativa ao tradicional rito do procedimento sancionador para regularização de condutas infrativas, $\mathbf{3 0 2}$

[Acórdão do Conselho Diretor da ANATEL, de 5 de janeiro de 2015 (Ref. $n^{\circ}$ 6/2015)]

Satisfação do Usuário

Regulamento das Condições de Aferição do Grau de Satisfação dos Usuários dos Serviços de Telecomunicações revogação do, 294

[Resolução da ANATEL n ${ }^{\circ}$ 654, de 13 de julho de 2015]

Regulamento das Condições de Aferição do Grau de Satisfação e da Qualidade Percebida junto aos Usuários de Serviços de Telecomunicações aprovação do, 294

[Resolução da ANATEL n ${ }^{\circ}$ 654, de 13

\section{SBTVD} de julho de 2015]

(ver Sistema Brasileiro de Televisão Digital)

SBTVD-T

(ver Sistema Brasileiro de Televisão Digital Terrestre)

Serviço de Acesso Condicionado (SeAC), 270

Serviço de Acesso Condicionado

destinação de faixas de radiofrequências para 0,292

[Resolução da ANATEL n ${ }^{\circ}$ 648, de 11 de fevereiro de 2015] 


\section{Serviço de Comunicação Multimída (SCM), 271}

Serviço de Interesse Coletivo, 261

Serviço de Interesse Restrito, 261

Serviço de Radiocomunicação Aeronáutica Público-Restrito

sua não submissão à disciplina da Lei 13.116, sobre os processo de licenciamento, instalação e compartilhamento de infraestrutura de telecomunicações em área urbana, 282

[Lei no 13.116, de 20 de abril de 2015]

Serviço de Radiodifusão, 262

Serviço de Radiodifusão de Sons e Imagens

(ver Radiodifusão)

Serviço de Radiodifusão Sonora

(ver Radiodifusão)

Serviço de Retransmissão de Televisão procedimentos de seleção pública e de autorização para a execução do RTVD, 288

[Portaria $\mathrm{MC} \mathrm{n}^{\circ} 4.287$, de 21 de setembro de 2015]

Serviço de Retransmissão de Televisão em Caráter Secundário

procedimentos de seleção pública e de autorização para a execução do Serviço de RTV em, 286

[Portaria $\mathrm{MC} \mathrm{n}^{\circ} 6.738$, de 21 de dezembro de 2015]

Serviço de Telecomunicações Aeronáuticas, 271

Serviço de Valor Adicionado, 261

Serviço Limitado, 261

Serviço Limitado Especializado (SLE), 266

Serviço Limitado Especializado

Norma de adaptação dos instrumentos de permissão e de autorização do Serviço Móvel Especializado (SME) para o Serviço Móvel Pessoal (SMP), Serviço Limitado Privado (SLP) ou Serviço Limitado Especializado (SLE) aprovação da, 291

[Resolução da ANATEL n ${ }^{\circ}$ 647, de 9 de fevereiro de 2015]

Serviço Limitado Móvel Marítimo

Regulamento do Serviço Limitado Móvel Aeronáutico (SLMA) e do Serviço Limitado Móvel Marítimo (SLMM) aprovação do, 293

[Resolução da ANATEL n ${ }^{\circ}$ 651, de 13 de abril de 2015]

Serviço Limitado Móvel Privado, 266

Serviço Limitado Móvel Privativo

vedação de novas autorizações de uso de radiofrequências, prorrogação do prazo das autorizações em vigor, licença de nova estação ou consignação de nova radiofrequência nos canais de 1 a 500 na faixa de 806 a $821 \mathrm{MHz}$ e 851 a $866 \mathrm{MHz}$ para o, 291

[Resolução da ANATEL n ${ }^{\circ}$ 647, de 9 de fevereiro de 2015]

Serviço Limitado Privado, 266

Serviço Limitado Privado

Norma de adaptação dos instrumentos de permissão e de autorização do Serviço Móvel Especializado (SME) para o Serviço Móvel Pessoal (SMP), Serviço Limitado Privado (SLP) ou Serviço Limitado Especializado (SLE) aprovação da, 291

[Resolução da ANATEL n ${ }^{\circ}$ 647, de 9 de fevereiro de 2015]

Serviço Móvel Aeronáutico, 271

Serviço Móvel Aeronáutico, 293

[Resolução da ANATEL nº 651, de 13 de abril de 2015]

Regulamento do Serviço Limitado Móvel Aeronáutico (SLMA) e do Serviço Limitado Móvel Marítimo (SLMM) aprovação do, 293

[Resolução da ANATEL n ${ }^{\circ}$ 651, de 13 de abril de 2015]

Serviço Móvel Especializado

Norma de adaptação dos instrumentos de permissão e de autorização do Serviço Móvel Especializado (SME) para o Serviço Móvel Pessoal (SMP), Serviço Limitado Privado (SLP) ou Serviço Limitado Especializado (SLE) aprovação da, 291

[Resolução da ANATEL n ${ }^{\circ}$ 647, de 9 de fevereiro de 2015]

Serviço Móvel Especializado ou Trunking ou Trunk ou Sistema Troncalizado, 267 Serviço Móvel Marítimo, 267 
(ver Serviço Limitado Móvel Marítimo)

Serviço Móvel Marítimo, 293

[Resolução da ANATEL n ${ }^{\circ}$ 651, de 13 de abril de 2015]

Serviço Móvel Pessoal (SMP), 267

Serviço Móvel Pessoal

Norma de adaptação dos instrumentos de permissão e de autorização do Serviço Móvel Especializado (SME) para o Serviço Móvel Pessoal (SMP), Serviço Limitado Privado (SLP) ou Serviço Limitado Especializado (SLE) aprovação da, 291

[Resolução da ANATEL n ${ }^{\circ}$ 647, de 9 de fevereiro de 2015]

Regulamento sobre Condições de Uso de Radiofrequiências nas Faixas de 800 $\mathrm{MHz}, 900 \mathrm{MHz}, 1.800 \mathrm{MHz}, 1.900$ $\mathrm{MHz}$ e $2.100 \mathrm{MHz}$

alteração do, 296

[Resolução da ANATEL nº 657, de 3 de novembro de 2015]

Tecnologia Assistiva

dever do poder público de incentivar a oferta de aparelhos de telefonia fixa e móvel celular com acessibilidade, entre outras tecnologias assistivas, $\mathbf{2 8 3}$

[Lei $\mathrm{n}^{\circ}$ 13.146, de 6 de julho de 2015]

\section{Serviço Telefônico Fixo Comutado}

(STFC), 268

Serviço Telefônico Fixo Comutado, 268, 294

[Resolução da ANATEL n ${ }^{\circ}$ 653, de 13 de julho de 2015]

Bem Reversível

determinações à ANATEL sobre o acompanhamento dos bens reversíveis das concessões de Serviço Telefônico Fixo Comutado, 300

[Acórdão TCU 3311/2015]

Concessão

prorrogação da data da penúltima revisão quinquenal (2015) dos contratos de concessão de STFC pós renovação, 297

[Resolução da ANATEL n ${ }^{\circ}$ 659, de 28 de dezembro de 2015]

Revisão Quinquenal prorrogação da data da penúltima revisão quinquenal (2015) dos contratos de concessão de STFC pós renovação, 297

[Resolução da ANATEL n 659, de 28 de dezembro de 2015]

Tecnologia Assistiva

dever do poder público de incentivar a oferta de aparelhos de telefonia fixa e móvel celular com acessibilidade, entre outras tecnologias assistivas, $\mathbf{2 8 3}$

[Lei ${ }^{\circ} 13.146$, de 6 de julho de 2015]

Serviços no Setor de Telecomunicações, 262

Sigilo em Telecomunicações, 260

Sistema Brasileiro de Televisão Digital

Canal de Cultura diretrizes para sua operacionalização, 291

[Portaria Interministerial $\mathrm{n}^{\circ} 4.074$, de 26 de Agosto de 2015]

Sistema Brasileiro de Televisão Digital Terrestre

(ver também Radiodifusão)

(ver também TV Digital)

Canal de Educação

diretrizes para operacionalização do, 291

[Portaria Interministerial $\mathrm{n}^{\circ}$ 2.098, de 14 de maio de 2015]

Cronograma de Implantação da TV Digital

desligamento antecipado do sinal analógico, 290

[Portaria $\mathrm{MC} \mathrm{n}^{\circ} 6.580$, de 2 de dezembro de 2015]

Sistema TELEBRAS

(ver Telecomunicações Brasileiras S.A.)

Situação de Emergência

Regulamento sobre Gestão de Risco das

Redes de Telecomunicações e Uso de

Serviços de Telecomunicações em

Desastres, Situações de Emergência e

Estado de Calamidade Pública aprovação do, 296

[Resolução da ANATEL n 656, de 17

SLE de Agosto de 2015]

(ver Serviço Limitado Especializado)

SLMM

(ver Serviço Limitado Móvel Marítimo)

SLMP 
(ver Serviço Limitado Móvel Privativo)

SLP

(ver Serviço Limitado Privado)

SMA

(ver Serviço Móvel Aeronáutico)

SME

(ver Serviço Móvel Especializado)

SMM

(ver Serviço Móvel Marítimo)

SMP

(ver Serviço Móvel Pessoal)

Solo

Taxa de Licenciamento para Uso ou

Ocupação das Faixas de Domínio das

Rodovias (TFDR)

insconstitucionalidade de disciplina estadual de cobrança de taxa de uso e ocupação de solo e espaço aéreo sobre instalação de equipamentos necessários à prestação de serviço público de telecomunicações, 299 [RE $811620 \mathrm{AgR} / \mathrm{MG}]$

Taxa Municipal de Licença e Fiscalização para Localização, Instalação e Funcionamento

constitucionalidade de disciplina municipal para cobrança de taxa de licença para instalação e de verificação da permanência das condições técnicas iniciais dos equipamentos destinados à energia elétrica e ao fornecimento de serviços de telecomunicações, 299 [RE $456534 \mathrm{ED} / \mathrm{RS}$ ]

Solução de Conflitos, 283

[Lei $\mathrm{n}^{\circ}$ 13.129, de 26 de maio de 2015]

SRA

(ver Serviço de Radiocomunicação Aeronáutica Público-Restrito)

STF, 278

(ver Recurso Extraordinário)

(ver Supremo Tribunal Federal)

STFC

(ver Serviço Telefônico Fixo Comutado)

STJ, 279

(ver Recurso Especial)

(ver Superior Tribunal de Justiça)

Superior Tribunal de Justiça

RESP 1384340 AgRg/DF

inaplicabilidade do Marco Civil da

Internet a fatos pretéritos a sua edição para o caso de ofensa veiculada no ORKUT, 300

[RESP $1384340 \mathrm{AgRg} / \mathrm{DF}]$

Supremo Tribunal Federal

ADI 2615/SC

inconstitucionalidade de disciplina estadual das condições de cobrança do valor da assinatura básica por invasão de competência federativa, 298

[ADI 2.615 - SC]

HC128567/MG

crime de atividade clandestina de telecomunicações do art. 183 da LGT não configura caso de aplicação do princípio da insignificância, 298

[HC 128567/MG]

RE 456534ED/RS

constitucionalidade de disciplina municipal para cobrança de taxa de licença para instalação e de verificação da permanência das condições técnicas iniciais dos equipamentos destinados à energia elétrica e ao fornecimento de serviços de telecomunicações, 299 [RE $456534 \mathrm{ED} / \mathrm{RS}$ ]

RE811620AgR/MG

inconstitucionalidade de disciplina estadual de cobrança de taxa de uso e ocupação de solo e espaço aéreo sobre instalação de equipamentos necessários à prestação de serviço público de telecomunicações, 299 [RE $811620 \mathrm{AgR} / \mathrm{MG}]$

$T$

TAC

(ver Termo de Ajuste de Conduta)

Tarifa Reduzida

Fraude

incentivo à realização de acessos discados à internet em horário de tarifa reduzida sob a promessa de que os usuários de STFC sejam remunerados pelo tempo de conexão ao provedor de acesso à internet, $\mathbf{3 0 3}$ 
[Acórdão do Conselho Diretor da ANATEL, de 5 de novembro de 2015 (Ref. $\left.\left.n^{\circ} 480 / 2015\right)\right]$

Taxa de Fiscalização da Instalação (ver também Fiscalização)

possibilidade de uso de receita excedente em fins diversos dos de custeio, manutenção e aperfeiçoamento da fiscalização dos serviços de telecomunicações caso tenham sido desvinculadas mediante transferência de receita excedente ao Tesouro Nacional, 301

[Acórdão TCU 2320/2015]

Taxa de Fiscalização de Funcionamento (ver Taxa de Fiscalização do Funcionamento)

Taxa de Fiscalização de Instalação

(ver Taxa de Fiscalização da Instalação)

Taxa de Fiscalização do Funcionamento (ver também Fiscalização)

(ver também Fundo de Fiscalização das Telecomunicações)

possibilidade de uso de receita excedente em fins diversos dos de custeio, manutenção e aperfeiçoamento da fiscalização dos serviços de telecomunicações caso tenham sido desvinculadas mediante transferência de receita excedente ao Tesouro Nacional, 301

[Acórdão TCU 2320/2015]

Taxa de Licenciamento para Uso ou Ocupação das Faixas de Domínio das Rodovias (TFDR)

Taxa de Uso e Ocupação de Solo e Espaço Aéreo

insconstitucionalidade de disciplina estadual de cobrança de taxa de uso e ocupação de solo e espaço aéreo sobre instalação de equipamentos necessários à prestação de serviço público de telecomunicações, 299

[RE $811620 \mathrm{AgR} / \mathrm{MG}]$

Taxa de Uso e Ocupação de Solo e Espaço Aéreo

Taxa Municipal de Licença e Fiscalização para Localização, Instalação e Funcionamento constitucionalidade de disciplina municipal para cobrança de taxa de licença para instalação e de verificação da permanência das condições técnicas iniciais dos equipamentos destinados à energia elétrica e ao fornecimento de serviços de telecomunicações, 299 [RE 456534 ED/RS]

\section{TCU}

(ver Tribunal de Contas da União)

\section{Tecnologia}

exclusividade da competência da União sobre a regulamentação e a fiscalização de aspectos técnicos das redes e dos serviços de telecomunicações, inclusive sobre seleção de tecnologia, topologia das redes e qualidade dos serviços prestados, $\mathbf{2 8 2}$

[Lei no 13.116, de 20 de abril de 2015]

\section{Tecnologia Assistiva}

dever do poder público de incentivar a oferta de aparelhos de telefonia fixa e móvel celular com acessibilidade, entre outras tecnologias assistivas, $\mathbf{2 8 3}$

[Lei $\mathrm{n}^{\circ} 13.146$, de 6 de julho de 2015]

\section{TELEBRAS}

(ver Telecomunicações Brasileiras S.A.)

Telecomunicações Brasileiras S.A., 286

[Decreto ${ }^{\circ} 8.632 / 2015$ ]

Backhaul

Telebras como executora de ações de implantação de infraestrutura de conexão entre órgãos e equipamentos públicos locais e à internet, inclusive por meio de construção de, 289

[Portaria MC n ${ }^{\circ} 4.699$, de 14 de outubro de 2015]

\section{TELEFÔNICA BRASIL S/A}

Anuência Prévia

à transferência do controle integral da GVT para a TELEFÔNICA, 301

[Ato do Conselho Diretor da ANATEL $n^{\circ} 448$, de 22 de janeiro de 2015]

GLOBAL VILLAGE TELECOM LTDA anuência prévia à transferência do controle integral da GVT para a TELEFÔNICA, 301

[Ato do Conselho Diretor da ANATEL $\mathrm{n}^{\circ} 448$, de 22 de janeiro de 2015]

inexistência de vinculação entre o interesse público na celebração de TAC e a natureza da matéria tratada em processo sancionador, $\mathbf{3 0 2}$ 
[Acórdão do Conselho Diretor da ANATEL, de 5 de janeiro de 2015 (Ref. $\left.\left.n^{\circ} 6 / 2015\right)\right]$

Televisão Aberta, 264

Televisão Digital

(ver TV Digital)

Terminais, 246

Termo de Ajuste de Conduta, 302

[Acórdão do Conselho Diretor da ANATEL, de 5 de janeiro de 2015 (Ref. $n^{\circ}$ 6/2015)]

inexistência de vinculação entre o interesse público na celebração de TAC e a natureza da matéria tratada em processo sancionador, $\mathbf{3 0 2}$

[Acórdão do Conselho Diretor da ANATEL, de 5 de janeiro de 2015 (Ref. $\left.\left.n^{\circ} 6 / 2015\right)\right]$

\section{TFDR}

(ver Taxa de Licenciamento para Uso ou Ocupação das Faixas de Domínio das Rodovias (TFDR))

\section{TFF}

(ver Taxa de Fiscalização do

TFI

Funcionamento)

(ver Taxa de Fiscalização da Instalação)

Tipificação

(ver Crime)

Tráfego Aéreo

Radar

sua não submissão à disciplina da Lei 13.116, sobre os processo de licenciamento, instalação e compartilhamento de infraestrutura de telecomunicações em área urbana, 282

[Lei ${ }^{\circ} 13.116$, de 20 de abril de 2015]

\section{Tráfego Artificial}

Interconexão

conduta ilítica de uso indevido das rotas de interconexão para cursar tráfego artificialmente gerado, $\mathbf{3 0 3}$ [Acórdão do Conselho Diretor da ANATEL, de 5 de novembro de 2015 (Ref. ${ }^{\circ}$ 480/2015)]

Tribunal de Contas da União, 276

Tribunal de Contas da União

Acórdão TCU 3311/2015

determinações à ANATEL sobre o acompanhamento dos bens reversíveis das concessões de Serviço Telefônico Fixo Comutado, 300

[Acórdão TCU 3311/2015]

\section{Tributação no Setor de \\ Telecomunicações, 249 \\ Tributo Vinculado}

Taxa de Fiscalização da Instalação

possibilidade de uso de receita excedente em fins diversos dos de custeio, manutenção e aperfeiçoamento da fiscalização dos serviços de telecomunicações caso tenham sido desvinculadas mediante transferência de receita excedente ao Tesouro Nacional, 301

[Acórdão TCU 2320/2015]

Taxa de Fiscalização do Funcionamento possibilidade de uso de receita excedente em fins diversos dos de custeio, manutenção e aperfeiçoamento da fiscalização dos serviços de telecomunicações caso tenham sido desvinculadas mediante transferência de receita excedente ao Tesouro Nacional, 301

[Acórdão TCU 2320/2015]

\section{Trunking}

(ver Serviço Móvel Especializado)

\section{TV Analógica}

Cronograma de Implantação da TV Digital

desligamento antecipado do sinal analógico, 290

[Portaria $\mathrm{MC} \mathrm{n}^{\circ} 6.580$, de 2 de dezembro de 2015]

TV Digital, 265

TV Digital

(ver também Digitalização)

(ver também Sistema Brasileiro de Televisão Digital Terrestre)

Canal de Cidadania

sua preferência no uso da faixa de VHF Alto (174 MHz a $216 \mathrm{MHz}$ ), 286

[Portaria MC n ${ }^{\circ} 1.581$, de 9 de abril de 2015]

Canal de Cultura 
sua preferência no uso da faixa de VHF Alto (174 MHz a $216 \mathrm{MHz}$ ), 286

[Portaria $\mathrm{MC}^{\circ}$ 1.581, de 9 de abril de 2015]

Canal de Educação

sua preferência no uso da faixa de VHF Alto (174 MHz a $216 \mathrm{MHz}$ ), 286

[Portaria MC $\mathrm{n}^{\circ} 1.581$, de 9 de abril de 2015]

Canal do Poder Executivo

sua preferência no uso da faixa de VHF Alto (174 MHz a $216 \mathrm{MHz}$ ), 286

[Portaria MC $\mathrm{n}^{\circ} 1.581$, de 9 de abril de 2015]

Cronograma de Implantação da TV

Digital

desligamento antecipado do sinal analógico, 290

[Portaria $\mathrm{MC}^{\circ}$ 6.580, de 2 de dezembro de 2015]

incentivos às indústrias de equipamentos para a, 285

[Lei ${ }^{\circ} 13.159$, de 10 de agosto de 2015]

Retransmissão de Televisão com

Utilização da Tecnologia Digital procedimentos de seleção pública e de autorização para a execução do, 288

[Portaria MC n ${ }^{\circ} 4.287$, de 21 de setembro de 2015]

Retransmissão de Televisão com Utilização da Tecnologia Digital,

Caráter Secundário

procedimentos de seleção pública e de autorização para a execução do Serviço de RTV em, 286

[Portaria $\mathrm{MC} \mathrm{n}^{\circ} 6.738$, de 21 de dezembro de 2015]

VHF Alto

sua utilização para execução de serviço de radiodifusão de sons e imagens em tecnologia digital, 286 [Portaria $\mathrm{MC}^{\circ} 1.581$, de 9 de abril de 2015]

\section{U}

Universalização e Massificação, 257

Urbanização

exclusividade da competência da União sobre a regulamentação e a fiscalização de aspectos técnicos das redes e dos serviços de telecomunicações, inclusive sobre seleção de tecnologia, topologia das redes e qualidade dos serviços prestados, 282

[Lei no 13.116, de 20 de abril de 2015]

\section{Uso de Espaço Aéreo}

Taxa de Licenciamento para Uso ou Ocupação das Faixas de Domínio das Rodovias (TFDR)

insconstitucionalidade de disciplina estadual de cobrança de taxa de uso e ocupação de solo e espaço aéreo sobre instalação de equipamentos necessários à prestação de serviço público de telecomunicações, 299 [RE $811620 \mathrm{AgR} / \mathrm{MG}$ ]

Taxa Municipal de Licença e Fiscalização para Localização, Instalação e Funcionamento

constitucionalidade de disciplina municipal para cobrança de taxa de licença para instalação e de verificação da permanência das condições técnicas iniciais dos equipamentos destinados à energia elétrica e ao fornecimento de serviços de telecomunicações, 299 [RE $456534 \mathrm{ED} / \mathrm{RS}$ ]

\section{Uso de Solo}

Taxa de Licenciamento para Uso ou Ocupação das Faixas de Domínio das Rodovias (TFDR)

insconstitucionalidade de disciplina estadual de cobrança de taxa de uso e ocupação de solo e espaço aéreo sobre instalação de equipamentos necessários à prestação de serviço público de telecomunicações, 299 [RE $811620 \mathrm{AgR} / \mathrm{MG}$ ]

Taxa Municipal de Licença e Fiscalização para Localização, Instalação e Funcionamento

constitucionalidade de disciplina municipal para cobrança de taxa de licença para instalação e de 
verificação da permanência das condições técnicas iniciais dos equipamentos destinados à energia elétrica e ao fornecimento de serviços de telecomunicações, 299 [RE $456534 \mathrm{ED} / \mathrm{RS}$ ]

\section{Usuário}

(ver também Consumidor)

Comitê de Defesa dos Usuários de Serviços de Telecomunicações regimento interno do, $\mathbf{2 9 2}$ [Resolução da ANATEL n ${ }^{\circ}$ 650, de 16 de março de 2015]

Usuário / Consumidor, 280

V

\section{VHF Alto}

sua utilização para execução de serviço de radiodifusão de sons e imagens em tecnologia digital, 286

[Portaria MC n ${ }^{\circ} 1.581$, de 9 de abril de 2015] 
Revista de Direito, Estado e Telecomunicações, v. 8, n. 1, p. 209-332 (2015) 